UNIVERSIDAD NACIONAL DE LA PLATA (UNLP)

Instituto de Derechos Humanos

Facultad de Ciencias Jurídicas y Sociales

Maestría en Derechos Humanos.

\title{
TESIS:
}

"La incorporación de la Educación en Derechos Humanos en el Sistema de Educación Pública, sector de primaria en el Uruguay."

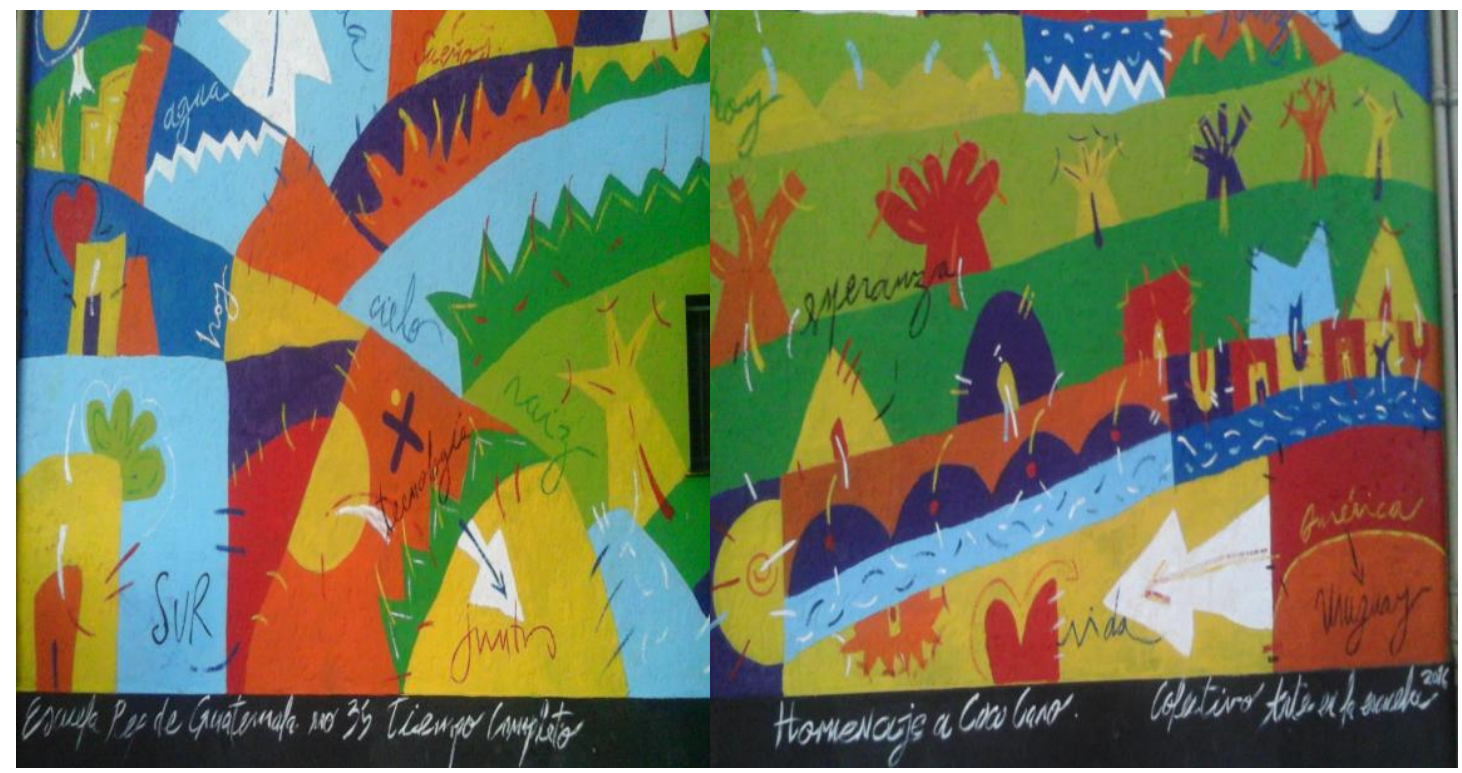

Estudiante:

Ana Laura Piñeyro Jardim

Lic. en Psicología (UdelaR)

Tutora:

Dra. Ana Maria Rodino

Co-tutora:

Dra. Pilar Uriarte

Noviembre 2016 


\section{La incorporación de la Educación en Derechos Humanos en el Sistema de Educación Pública, sector de primaria, en el Uruguay}

INDICE Pag. I

\section{CAPÍTULO I:}

LA INVESTIGACION: PROBLEMA Y ABORDAJE METODOLOGICO........Pag. 1

1. Delimitación del problema y objetivos. ...................................Pag. 3

2. Metodología: un acercamiento al campo. ................................... 7

2.1. Opciones y estrategia-............................................ 7

2.1.1. Fase bibliográfica y análisis documental...................Pag. 7

2.1.2. Entrevistas en profundidad.................................Pag. 8

2.1.3. Trabajo de campo en las escuelas ..........................Pag. 8

2.2. Especificidades del trabajo de campo.............................. 10

\section{CAPÍTULO II: MARCO TEÓRICO}

LA EDUCACIÓN EN DERECHOS HUMANOS: UNA PRÁCTICA SOCIAL

QUE SE BASA EN LA DIGNIDAD .....................................Pag.14

1. Dando una vuelta a los derechos humanos...................................Pag.16

1.1. De qué universalidad estamos hablando.............................Pag. 17

1.2. Prácticas concretas y contextualizadas: nuevas formas de relación.... .Pag. 18

2. Un enfoque basado en los derechos humanos para pensar

las políticas públicas

3. El derecho humano a la educación: un marco general para la integralidad y

Transversalidad de la dignidad humana....................................... 24

3.1. La educación bisagra que permite acceder a los demás derechos......Pag.27

3.2. El derecho a la educación y su protección en el ámbito internacional..Pag.29 3.2.1. La educación, un derecho que relaciona a todos

los derechos. ............................................Pag. 30

3.2.2. Características de las obligaciones del derecho a la

educación........................................................ 1

3.3. La educación en derechos humanos en el ámbito internacional.....Pag.33

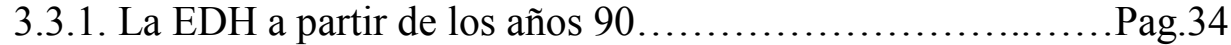

3.3.2. Programa mundial para la educación en derechos

humanos

Pag. 37

3.3.3. La Declaración de las Naciones Unidas sobre educación y

formación en materia de derechos humanos.

Pag. 41 
4. La EDH, un enfoque de transformación socio-cultural

Pag.42

4.1. La EDH, herramienta que construye sentidos Pag. 45

4.2. EDH: paradigma ético que conlleva una disciplina integral y compleja....

4.2.1. Una mención al pensamiento complejo de Edgar Morin:

la "religazón" de los saberes..................................Pag.48

4.2.2. Fines y contenidos de la EDH............................Pag.49

4.2.3. La EDH plantea como central el fenómeno de

relación humana.

Pag.52

\section{CAPITULO III: MARCO CONTEXTUAL}

EVOLUCIÓN HISTÓRICA Y NORMATIVA DE LA EDUCACIÓN PÚBLICA

EN EL URUGUAY ..................................................... 5.56

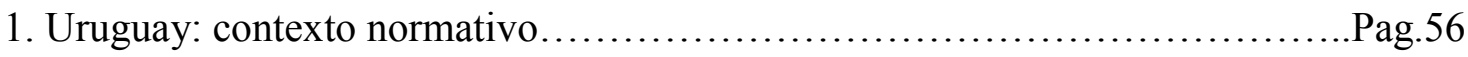

1.1. Principio de autonomía en la educación pública del Uruguay. .........Pag.57

2. Desarrollo del proceso histórico de la educación pública en el Uruguay.........Pag.60

2.1. Primer momento: normalismo, creación de la imagen

del "ser docente" ..................................................Pag.61

2.2. Segundo momento: régimen cívico-militar.....................Pag.62

2.3. Tercer momento: conflictividad en la educación por confluencias

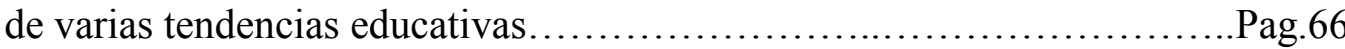

2.3.1. Restitución democrática...............................Pag.66

2.3.2. Inserción de la EDH en el sistema educativo................Pag.68

2.3.3. Una reforma carente.....................................Pag. 70

2.3.4. El gobierno progresista.................................Pag.74

3. Un proceso en construcción en el Uruguay: el Plan Nacional de EDH..........Pag.78

\section{CAPITULO IV}

MARCO NORMATIVO ACTUAL DE LA EDUCACIÓN URUGUAYA

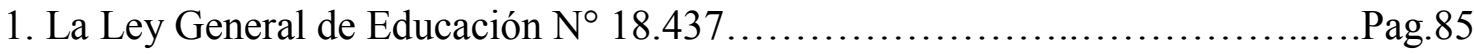

1.1. Antecedentes

1.1.1. Antecedentes en las leyes..............................Pag. 85

1.1.2. Marco institucional de la educación en el Uruguay...........Pag.85

1.2-.Análisis de la nueva Ley General de Educación......................Pag.86 
1.2.1. Sistema Nacional de Educación Pública....................Pag. 88

1.2.2. Comisión nacional de EDH...............................Pag.91

1.2.3. Ejes transversales....................................Pag.92

1.2.4. Principio de participación.............................Pag.94

1.3. Implementación de la nueva ley.................................Pag.96

2.El Programa de educación inicial y primaria...............................Pag.100

2.1. Análisis del programa de educación inicial y primaria................Pag.101

2.1.1.Redes conceptuales y contenidos de las Áreas y

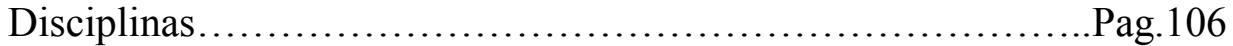

2.1.2. Puesta en práctica del Programa...........................Pag.109

2.2. La introducción de la EDH. Un paso adelante y muchos desafíos.....Pag.111

2.3. Programa único, diferentes miradas sobre edh....................Pag.114

2.3.1. Movimientos del ámbito educativo entre,

un enfoque tradicional y un enfoque integral. ...............Pag. 114

2.3.2. ¿Qué pasa con las prácticas educativas? .....................Pag.117

2.4. Pensando una nueva formación docente..........................Pag.119

2.4.1. Más allá de las instancias formales de formación docente, otras instancias.

Pag. 123

\section{CAPÍTULO V}

TRABAJO DE CAMPO EN TRES ESCUELAS DE MONTEVIDEO............Pag.129

1. Metodología y procedimientos del trabajo de campo.....................Pag.130

1.1.Estrategia de ingreso a las escuelas para llevar adelante la investigación...................................................... 130

1.2. Breve caracterización de las escuelas............................Pag.134

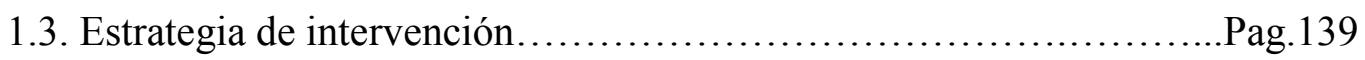

1.4. Estrategia de cierre: Taller de devolución y cierre...................Pag.142

1.5. Caracterización del rol docente y la tarea educativa..................Pag.144

2. Los derechos humanos en la escuela, diferentes visiones desde el campo......Pag.147

2.1. La primera reacción: “¡En la escuela no se violan los ddhh!” Pag. 148

2.2. Cumplir los derechos de los niños Pag. 149

2.3. Enseñar los derechos a los niños Pag.151 
2.4. Algunas miradas integrales. Pag.153

2.5. Efectos de transformación durante el trabajo de campo Pag. 155

3. Otras formas posibles para pensar la EDH. Pag. 157

3.1. El tema de la Participación Pag. 157

3.2. Modalidades de comunicación. Pag. 158

3.3. Trabajo en equipo y nuevas prácticas educativas Pag.161

3.4. Docentes invitados: implementación de talleres Pag. 165

3.5. Para ir cerrando.. Pag. 166

\section{CAPITULO VI}

CONCLUSIONES Y RECOMENDACIONES. .Pag.169

BIBLIOGRAFIA Pag. 179

ANEXOS Pag.186

Anexo I: Mapa de Montevideo, ubicación de las escuelas Pag.187

Anexo II: Permiso del CEIP-ANEP: Resolución n¹8, Expediente n 1225/14...Pag.188

Anexo III: desgravaciones de las seis entrevistas a Autoridades de la Educación y especialistas. Pag. 191

Anexos IV: Información complementaria al capítulo II. Pag.229

Anexos V: Fotos de las Escuelas. Pag. 234

Anexo VI: A afiche de la campaña. Pag.239 



\section{CAPÍTULO I: Introducción}

\section{LA INVESTIGACIÓN:}

\section{PROBLEMA Y ABORDAJE METODOLOGICO.}

En nuestro mundo actual, las vulneraciones y violaciones de los derechos humanos no cesan; se hacen presentes tanto en los contextos macro políticos y sociales, como en las realidades vividas a diario por los individuos y grupos. Esto sucede a pesar de las luchas por la defensa de los derechos de las organizaciones sociales, de los colectivos que las protagonizan, del trabajo en torno a la protección y promoción de los derechos humanos en las instancias intergubernamentales.

Es así que cobra importancia la tarea de educar en derechos humanos, con un desafío de transformación a los tiempos que vivimos, y con un componente profundamente ético (Juanche, 2013). Esto implica un proceso de cuestionamiento por nuestros referentes éticos, cómo los llevamos a la práctica en nuestros comportamientos y en la forma de relacionarnos con los otros (Pérez Aguirre, 1991, 1999), dando un lugar central al fenómeno de relación entre sujetos de derecho: con nosotros mismos, con los otros y con los entornos.

La Educación en Derechos Humanos (en adelante EDH) conlleva, a nuestro entender, no solo una tarea de transformación de los educandos, sino, y sobre todo, una actividad de mutua transformación entre todos los sujetos parte del proceso educativo (Pérez Aguirre, 1999). Como decía el pedagogo brasileño Paulo Freire "Nadie educa a nadie, los seres humanos se educan en comunión". Se comprende el acto educativo, como un proceso dinámico y dialéctico, con la multidimensionalidad y complejidad particular de lo humano. Involucra una afectación mutua entre las personas que intervienen en él, aunque tengan roles diferentes, e implique una asimetría de responsabilidades, (Magenzo, 2008) que caracteriza a la relación educando-educador. A su vez incorpora un componente político, en el que están en juego las relaciones de poder, las formas de relacionarnos entre estos dos roles (Rodino, 1999, 2006). Re-ubica, asimismo, el lugar del saber, del conocimiento, desplegando un movimiento interno de auto-conocimiento (Mujica, 2002), así como la construcción de conocimientos con los otros, y genera el lugar de lo común, lo compartido, lo co-construido (Rebellato, 1997). 
Con la EDH nos introducimos en un camino, en una forma educativa que nos cuestiona: "desde dónde", "para qué" y "cómo actúo" cuando educo en derechos humanos. Es la figura del educador quien representa la intención del proceso de adquisición de los valores y actitudes (Mujica, 2002) que encarnan los derechos humanos.

La EDH, considerada como un derecho en sí mismo -concepto que parte de las esferas internacionales- contó con una amplia difusión en los últimos tiempos. Llega al ámbito nacional con el desafío de poder transmitir los principios fundamentales de los derechos humanos, como ser la igualdad y la no discriminación, así como de profundizar la relación entre todos los derechos, destacando su interdependencia, indivisibilidad y universalidad. Los principios, objetivos de los derechos humanos se deberían encarnar en la experiencia cotidiana de las realidades vividas por las personas (Pérez Aguirre, 1999), desde sus propios contextos socio-culturales, y así fomentar y fortalecer sociedades donde se respete la dignidad humana y sus múltiples manifestaciones (De Sousa Santos, 2002).

Es en la órbita del Derecho Internacional de los Derechos Humanos, que podemos identificar la obligación del Estado uruguayo en adecuar su normativa interna, y llevar adelante políticas públicas donde la EDH esté presente, como estrategia para promover "las actitudes y el comportamiento necesario para que se respeten los derechos humanos de todos los miembros de la sociedad". 1

\footnotetext{
$1 \quad$ Naciones Unidad, Plan de Acción, Programa Mundial para la EDH, primera etapa (Resolución 59/113B -Asamblea General)
} 


\section{Delimitación del problema y objetivos}

Desde 2008 el Uruguay cuenta con una nueva Ley General de Educación ( $\mathrm{N}^{\circ} 18.437$ - 2008) y, a partir del mes de marzo de 2009, con un nuevo programa único de Educación Pública de nivel inicial y primaria, de aplicación en todo el territorio nacional. En estos dos documentos se observa la explícita enunciación, tanto de los principios y objetivos, como de los contenidos de la EDH. En la nueva Ley de Educación, en su artículo 40, se determina la creación de diferentes líneas transversales que deberán implementarse en todas las modalidades del Sistema Nacional de Educación (artículo 20) ${ }^{2}$, entre las que se encuentra (artículo 40.1) la educación en derechos humanos (EDH) ${ }^{3}$. Esta está considerada como un derecho en sí mismo y un componente del derecho a la educación.

“Artículo. 40,1: La educación en derechos humanos tendrá como propósito que los educandos, sirviéndose de conocimientos básicos de los cuerpos normativos, desarrollen las actitudes e incorporen los principios referidos a los derechos humanos fundamentales. Se considerará la educación en derechos humanos como un derecho en sí misma, un componente inseparable del derecho a la educación y una condición necesaria para el ejercicio de todos los derechos humanos". 4

A su vez en la fundamentación del actual programa de educación inicial y primaria, se encuentran los derechos humanos como el marco, tanto en la dimensión del conocimiento como en la práctica social integral.

"Las ideas directrices, que en el contexto del Programa dan sentido a la educación y se orientan hacia la construcción del ciudadano del siglo XXI son:

- Democracia Social que se fundamenta en los Derechos Humanos, la diversidad, la participación, el posicionamiento ético, el trabajo digno y la solidaridad.

2 Ley $\mathrm{n}^{\circ}$ 18.437(dic.2008) Artículo 20. (Concepto).- "El Sistema Nacional de Educación es el conjunto de propuestas educativas integradas y articuladas para todos los habitantes a lo largo de toda la vida". Incluye la educación formal, la no formal y la educación de primera infancia.

La otras líneas transversales que se encuentran en el art. 40 de la Ley $N^{\circ}$ 18.437: b) la educación ambiental para el desarrollo humano sostenible; c) la educación artística; d) la educación científica; e) la educación lingüística; f) la educación a través del trabajo; g) la educación para la salud; h) la educación sexual; i) la educación física, la recreación y el deporte. 
- Integralidad a través de la estética, la educación ambiental, la promoción de la salud y la sexualidad."

Este nuevo marco, de incorporación explícita de la EDH tanto en la Ley General de Educación como en el Programa vigente de Educación Inicial y Primaria, implica cambios en la concepción del ámbito educativo. Sin embargo, la mera enunciación de estos conceptos en los documentos no cambia automáticamente la práctica y concepciones que orientan el quehacer cotidiano de docentes, familias y estudiantes. Se trata de un proceso complejo, que involucra ámbitos sociales, culturales, jurídicos, administrativos, vivencias, experiencias y condiciones materiales que permitan llevar adelante el trabajo. Consciente de la densidad de fenómenos que el hecho educativo encierra, el presente trabajo se propone la tarea de investigar la forma en que estos cambios de paradigma se procesan en el sistema educativo de primaria.

En ese sentido las preguntas guían esta investigación son:

- ¿Cómo se formula la incorporación de la EDH en la Ley General de Educación $\mathrm{N}^{\circ}$ 18.437 y en la nueva actualización del Programa oficial para la educación primaria? Interesa indagar e identificar cuáles han sido los elementos incorporados desde la normativa e implementaciones en la metodología y valorar su importancia para la educación nacional.

- ¿Cómo se realiza la tarea de transversalizar la EDH en los centros educativos de primaria en la cuidad de Montevideo? El trabajo recoge las opiniones de expertos y autoridades, así como de los equipos de dirección y de los maestros y maestras de las escuelas, a quienes se les preguntó: ¿qué concepción de EDH tienen los y las docentes hoy en día?, ¿cómo la entienden?

- ¿Cómo es entendida la EDH en el desarrollo de la práctica educativa, por los equipos docentes? ¿Cómo se lleva adelante la tarea de educar en derechos humanos, en las escuelas? Interesa indagar las opiniones de los equipos docentes de las escuelas, saber cómo lo están desarrollando en la práctica concreta; conocer

\footnotetext{
5 Programa de Educación Inicial y Primaria. Publicado por CODICEN-CEP. Montevideo, Uruguay,
} marzo 2009 (P. 12) 
qué formación o espacios de reflexión tienen para eso, o consideran que tendrían que tener.

Toda innovación conlleva cambios e impulsa nuevos desarrollos. La inclusión en los ámbitos educativos de ejes o temas transversales hace a una necesidad contemporánea de nuestra sociedad de formar personas con capacidades para la convivencia en el respeto de la pluralidad y la democracia. Hoy en día se hace imperativo el tratamiento de ciertas problemáticas y temáticas de relevancia social que habilitan al desarrollo de las sociedades (Jurado Gómez, 2008), permitiendo el proceso de desarrollo integral de las personas en relación de pertenencia y referencia a sus grupos, colectivos y cultura.

Es así que el pensar la educación con ejes transversales, como lo establece la nueva normativa según analizaremos más adelante (ver capítulos III y IV ). Implica designar contenidos de carácter actitudinal. Se trata de conductas que corresponden a valores que hacen al desarrollo integral de las personas, así como al desarrollo de sociedades más respetuosas y conscientes de la dignidad humana, de los derechos humanos (Magendzo, 2008). Estos contenidos que recorren todas las áreas del currículo no corresponden a ninguna en particular y plantean el deber de ser trabajados en forma global, de forma generalizada. Esto permite transitar por un proceso continuo de aprendizajes integrales (Jurado Gómez, 2008), donde están en juego el poder pensar, analizar, comprender desde lo racional, lo sensible, para poder generar nuevas actitudes y conductas, nuevos conocimientos sobre temas y problemáticas, desde un abordaje interdisciplinario.

A nuestro entender, la incorporación de la EDH puede traer modificaciones significativas. Por un lado, se altera la concepción de la relación educando-educador que repercute en la imagen de la función docente y por ende en las prácticas educativas. Por otro lado, al plantear la generación de ejes transversales a las diferentes modalidades del Sistema Nacional de Educación Pública, introduce a los contextos sociales como elemento por desarrollar en la tarea educativa, su comprensión, su análisis y la promoción de habilidades para actuar en ellos.

Así quedan planteados nuestros objetivos de investigación como describir y analizar el proceso de incorporación de la Educación en Derechos Humanos en la actual Ley General de Educación; los cambios establecidos en el nuevo currículo de educación 
primaria y cómo estos se reflejan en las prácticas educativas, en la cuidad de Montevideo, es el marco general que encuadra el presente trabajo.

La investigación analiza:

(1) los aspectos que se incorporan sobre la EDH en los documentos normativos de la educación pública en el Uruguay y su incidencia en las prácticas educativas, para lo cual se compara la actual ley general de educación con las anteriores;

(2) el nuevo currículo para identificar los elementos incorporados y las metodologías sugeridas, $\mathrm{y}$

(3) las prácticas educativas, en particular si estas se llevan adelante desde una perspectiva de EDH y cómo.

Esta investigación aspira a ser un insumo de evaluación de la política pública educativa que se está llevando a cabo actualmente en el Uruguay. Pretende indagar la EDH desde una concepción de disciplina compleja, ${ }^{6}$ e identificar fortalezas o debilidades en su planteo como eje transversal del Sistema Nacional de Educación Pública, en especial en primaria. Se confía en que permitirá comprender las vinculaciones entre la ley, el currículo y las prácticas educativas - los tres elementos que hacen a la incorporación de los derechos humanos en la educación- para poder establecer si se están articulando de manera coherente y eficiente, de manera total o parcial.

\section{Metodología: un acercamiento al campo.}

\section{1-Opciones y estrategia}

Para esta tesis de Maestría en Derechos Humanos, se realizó un trabajo de investigación que tuvo diferentes fases:

\footnotetext{
6 El término "Complejo o Complejidad". Se refiere a una comprensión del mundo como un todo, compuesto por partes que se encuentran entrelazadas y, en esa interacción, generan nuevas características. Uno de sus pensadores más destacados en el ámbito educativo y de las ciencias humanas es Edgar Morin. (MORIN, 1998)
} 


\subsection{1-Fase bibliográfica y de análisis documental.}

En una primera instancia, tuvo lugar la construcción de un marco teórico, junto a una investigación documental centrada en la normativa educativa del Uruguay y su desarrollo histórico en relación a los diferentes períodos socio-políticos.

Se realizó la construcción de un marco de referencia que permite la explicitación de algunos conceptos en torno a los cuales se llevó adelante todo el proceso de investigación. Es así que en el capítulo II, se elaboran una serie de recorridos teóricos, que permiten ir dando contenidos y encuadres de comprensión que acompañan el análisis realizado. Allí se referencia y define qué se entiende por derechos humanos, y una visión en la órbita del Derecho Internacional de los derechos humanos, del derecho a la Educación y a la EDH.

Fue importante generar un marco histórico-contextual para el análisis de documentos oficiales. El capítulo III presenta un recorrido bibliográfico, que permite comprender en complejidad la evolución histórica de la educación pública dentro de la sociedad uruguaya; su origen, su desarrollo, las características de nuestro sistema educativo y sus desafíos hoy.

Se tomó como referente la nueva Ley General de Educación $\mathrm{N}^{\circ} 18.437$ 2008, que se contrastó con sus antecesoras: Ley de Educación General N 14.101, de enero de 1973; Ley de Emergencia $N^{\circ} 15.739$, de marzo de 1985 y Ley $N^{\circ} 16.115$, de julio de 1990 (capítulo III). También se analizó la Ley General de Educación N ${ }^{\circ} 18.437$ (2008) y el nuevo Programa de Educación Inicial y Primaria (2009), para identificar los aportes concretos realizados con respecto a la EDH (Capítulo IV). Se analizaron los documentos normativos específicos, con apoyo en bibliografía de las áreas de Historia, Ciencias de la Educación, Ciencias Jurídicas, Derechos Humanos, y Filosofía.

\subsection{2-Entrevistas en profundidad.}

En el segundo momento de la investigación se realizaron una serie de entrevistas en profundidad a expertos en EDH que trabajan en áreas destacadas del sistema educativo y también a autoridades de la educación pública uruguaya que han sido protagonistas de la redacción de la normativa analizada. El objetivo fue indagar y comprender desde qué concepción y cómo ha sido la incorporación de la EDH en el sistema educativo uruguayo. Se realizaron entrevistas a las siguientes personas: 
- Fernando Willat, Coordinador de EDH, de la Secretaria Nacional de Derechos Humanos de Presidencia de la República e integrante de la Comisión Nacional de EDH (por MEC).

- Martín Prats, Director de la Dirección de Derechos Humanos de la Administración Nacional de Educación Pública (ANEP) e integrante de la Comisión Nacional de EDH (por ANEP).

- Margarita Navarrete, Instituto de Derechos Humanos de la Facultad de Derecho-UdelaR, integrante de la Comisión Nacional de EDH (por UdelaR) e integrante del Observatorio de Políticas Públicas de Derechos Humanos, MERCOSUR.

- Luis Garibaldi, Director de Educación del Ministerio de Educación y Cultura (MEC).

- Fernanda Blanco, Dirección de Educación (MEC) e integrante de la Comisión Nacional de EDH (MEC).

- Irupé Buzzetti, Consejera del Consejo de Educación Inicial y Primaria (CEIP), Administración Nacional de Educación Pública (ANEP). ${ }^{7}$

\subsection{3-Trabajo de campo en las escuelas.}

En una última etapa se busco investigar las prácticas educativas en el terreno. Se tramitó el permiso, en el ámbito correspondiente ${ }^{8}$ y a través de las inspectoras generales del departamento de Montevideo, fueron designadas tres escuelas. ${ }^{9}$ El trabajo de campo consistió en una aproximación a las prácticas educativas con un enfoque etnográfico, a través de observación participante y entrevistas y talleres, con modalidad de Investigación Cualitativa.

La metodología de investigación cualitativa con orientación etnográfica, tiene raíces en la tradición de las ciencias sociales y supone una serie de condicionantes teóricas y metodológicas, donde se cruzan temas y disciplinas, en este caso la investigación en

\footnotetext{
7 Desgravaciones de las entrevistas seis entrevistas, anexo III.

8 Resolución $n^{\circ} 18$, Expediente $n^{\circ} 1225 / 14$. Anexo II.

9 El Consejo de Educación Inicial y Primaria (CEIP) de la Administración Nacional de Educación Pública (ANEP) divide a Montevideo en tres grandes zonas (oeste, centro y este) para ordenar la jurisdicción a la que corresponden las escuelas otorgando una inspección para cada región.
} 
educación y la antropología. Esto lleva a que la metodología aplicada tenga características propias que se manifiestan en la modalidad de construcción del conocimiento: el modo como se llevan adelante las observaciones, la forma de análisis y elaboración de los conceptos y nociones teórico-metodológicas; y los procedimientos para obtener la confiabilidad y la validez. Esto implica que la búsqueda de conocimiento está orientada a la comprensión de ideas, de sentimientos y de significados, presentes en las descripciones obtenidas de las palabras y/o de las conductas y prácticas observadas (Tarrés, 2001).

Se trabajó en tres escuelas de Montevideo, una por cada inspección zonal del departamento, acorde a la división administrativa (Ver anexo I, mapa de ubicación de las escuelas). Después de lograr el permiso y la designación de las escuelas por parte de las autoridades correspondientes, se llevaron adelante varias entrevistas con:

b) Las tres inspectoras departamentales, para recoger sus opiniones sobre la incorporación de la EDH en la normativa y su grado de implementación en la práctica.

c) Las tres inspectoras de las escuelas seleccionadas por las autoridades, con el objetivo de recoger sus opiniones sobre la temática tratada e información sobre la escuela.

d) Equipos de dirección (director/a y secretarias)

e) Maestras y maestros de los centros educativos.

A su vez se realizaron observaciones participantes en espacios de aula, clases especiales, espacios extracurriculares, recreos, horarios de entradas y salidas de los centros, y en las reuniones de Sala Docente.

En un principio se buscó conocer las características generales de cada escuela. Las informaciones recogidas en una primera etapa fueron la composición y distribución de su personal y de su población escolar, su historia, e inserción en la comunidad de pertenencia barrial. A continuación se indagó sobre las preguntas que planteamos para la presente investigación de tesis.

La investigadora asistió a los tres centros educativos durante un período de tres meses aproximadamente, y concurrió un mínimo de 10 jornadas, a un máximo de 16 visitas por cada escuela dependiendo del proceso particular de cada centro. 
Al finalizar el proceso se realizó dentro de cada centro estudiado, un taller de devolución general con participación de todo el equipo docente. Esta actividad tuvo como objetivo hacerles llegar las conclusiones del proceso desarrollado en conjunto, como forma de devolución y retribución de la información brindada, y a su vez, cerrar una instancia que implicó una apertura en los vínculos de comunicación y confianza hacia la figura de la investigadora.

\section{2- Especificidades del trabajo en campo.}

Dado que esta fase de la investigación fue la más desafiante, en la medida que propuso la aplicación de nuevas técnicas y el adaptarse a los tiempos y formas de funcionamiento institucionales, nos detendremos específicamente en ella.

Para el desarrollo de esta fase de investigación fue importante diseñar una estrategia en diferentes etapas (ingreso a los centros, estrategia de intervención y estrategia de cierre). Hubo que organizar, y por momentos reorganizar, los datos de forma que pudieran dar cuenta de un proceso de producción de conocimiento. En varios momentos tuve que replantear las estrategias de acercamiento al objetivo de investigación, re-adecuando las modalidades de acceso.

En un primer momento había planificado como estrategia de intervención en las escuelas solicitar observar una clase por grado para cubrir los seis niveles que abarcan el sector de primaria. Pero luego de la estrategia de ingreso a los centros educativos que implicaba conseguir los permisos formales de las autoridades, así como alcanzar la disposición y acercamiento necesario de las inspectoras, directores y equipos docentes a través de una presentación personal y una presentación del trabajo de tesis a desarrollar, tuve que cambiar la modalidad de intervención por percibir actitudes de resistencia en el contacto espontáneo.

Alcanzar la confianza necesaria para lograr los climas intrasubjetivos apropiados para esta investigación fue fundamental. Ser paciente con los docentes, escucharlos primero, ser una presencia frecuente, conversar y esperar que ellos fueran quienes me invitaran a sus aulas $u$ otras actividades, terminó siendo la estrategia emprendida siempre con el objetivo de establecer vínculos de confianza, de respeto hacia ellos y su labor profesional. 
Fue ya transcurrido un mes, aproximadamente, de mi presencia en las escuelas, con una concurrencia semanal durante la cual me entrevistaba con los directores, secretarias, maestras comunitarias o integradora, interactuaba en los recreos con los maestros y maestras, así como con los niños y niñas, que fui accediendo a ser invitada a las clases o a presenciar algunas de las tareas significativas para los equipos docentes, como ser los talleres, los grupos integrados donde trabajan varios docentes.

La estrategia de cierre llevada a cabo en el trabajo de campo consistió en un taller con el equipo de maestros y maestras de cada una de las escuelas al finalizar el trabajo. Esta instancia consistió en una primera parte, trabajar en grupo con los y las docentes sobre sus opiniones sobre la EDH. También se destinó en esta instancia de cierre, a trabajar en la devolución y algunas conclusiones de la investigación, ya que los maestros y maestras fueron actores de la misma, y por lo tanto es importante realizar un cierre temático y afectivo por la disposición, la información y la confianza brindada.

Durante el desarrollo del trabajo de campo se utilizaron las siguientes técnicas:

- La observación participante es una forma de recolección de información que se vincula predominantemente con el método etnográfico Permite observar las conductas, las conversaciones, la participación, la comunicación de las personas; es decir, implica recoger la información significativa de forma directa, amplia, donde el diseño del instrumento no altera el carácter profundo y complejo de la información recabada; “... permite dar cuenta de los fenómenos sociales, a partir de la observación de contextos y situaciones en que se generan los procesos sociales" (Sánchez Serrano, 2001:99).

- La entrevista es una situación construida, un mecanismo controlado donde interactúan dos o más personas, en dos roles predeterminados: rol del entrevistador y rol del (o los) entrevistado(s); ahí se genera un proceso de intercambio simbólico que retroalimenta el proceso mismo (Vela Peon, 2001). La entrevista, desde un enfoque cualitativo, permite la expresión, la puesta en palabras de ciertos aspectos esenciales que hacen a una reconstrucción de situaciones y de experiencias; permite comprender desde una dimensión individual en interacción con el entorno concreto grupal, institucional, cultural. Es una técnica que se ha transformado en un instrumento básico y privilegiado para la recolección de información. Además permite la exploración o profundización en ciertos temas de la realidad social y 
subjetiva a través de conocer y conferir significado tanto a la dimensión subjetiva como a las relaciones sociales.

- El taller en el ámbito educativo y cultural, es una modalidad de trabajo grupal donde los y las participantes ponen en juego su integralidad. Es una propuesta vivencial que privilegia el "sentir", el "hacer" e implica una posterior reflexión que involucra la construcción de conocimientos, la participación y la creatividad. (González De Cuberes, 1987)

Interesa dejar planteado que para la comprensión de los derechos humanos que propone este trabajo de investigación de tesis, se considera esencial poder indagar en estos tres ámbitos:

1- Llegar a una comprensión global de los procesos socio-históricos y normativos de los contextos donde se desarrolla las prácticas educativas desde el paradigma ético de los derechos humanos;

2- Indagar las concepciones de las autoridades y especialistas que llevaron adelante la incorporación de la EDH en la normativa educativa actual; y

3- Observar que está pasando en las prácticas educativas concretas, desde qué concepción se está desarrollando la incorporación de la EDH en las escuelas.

Solo desde la interacción de estos ámbitos, integrados en la acción de la cotidianeidad de las prácticas, podemos concebir a los derechos humanos como herramientas de transformación social, como paradigma ético, símbolo de un producto cultural universal y de relación entre sujetos de derecho. Las prácticas de derechos humanos y de EDH, en nuestra concepción, hay que entenderlas desde una visión crítica y compleja, enmarcadas en sus contextos reales. Y esto llevó a diferenciar los tres ámbitos diferentes que componen este trabajo. Es así que cobra sentido la investigación y análisis de los derechos humanos, de los procesos de derechos humanos. 


\title{
CAPÍTULO II: MARCO TEÓRICO
}

\section{LA EDUCACIÓN EN DERECHOS HUMANOS: UNA PRÁCTICA SOCIAL QUE SE BASA EN LA DIGNIDAD}

\begin{abstract}
"La meta de la educación en derechos humanos es farjar saciedades dande no se atrapelle la dignidad humana. No basta can denunciar o castigar los abusos después que han acurrido. Hay que evitarlo y para ello, es necesario que las persanas conazcan sus derechos, los defiendan y, a la vez, respeten y defiendan su ejercicio por parte de los demás. La educación en derechas humano es un media para promaver ese conacimienta y respeto y, de esta manera, se convierte en un instrumento cancreta de prevención de violaciones a los derechos humanos. Al mismo tiempo, se propane canstruir una canvivencia pacífica y demacrática, cada día más respetuosa de la vida y las libertades individuales, más igualitaria, justa y solidaria para tadas y cada uno. En breve: más humana. Vista de esta manera es el mator de transfarmaciones individuales y saciales."
\end{abstract}

Ana María RODIND (1999).

Interesa esbozar una referencia sobre la concepción de derechos humanos a los que se apela en este trabajo. Dejar claro el lugar que ocupa el proyecto de los derechos humanos en el planteo, tanto como una construcción histórico- social y como un paradigma ético que permite entender y actuar desde este concepto complejo, como una herramienta de emancipación y de transformación social.

Se presentan en este capítulo algunos elementos que permitirán construir un recorrido por los derechos humanos y la educación en derechos humanos. De acuerdo a lo que se entiende para esta tesis de investigación, son centrales en esta propuesta y pretenden generar un dialogo entre culturas, grupos sociales e individuos. Permiten, de esta manera, el desarrollo y evolución de las sociedades, priorizando un enfoque de dignidad y respeto entre las personas y sus grupos de pertenencia y referencia, con especial atención a la justicia social y a la igualdad y no discriminación.

Para esto se desarrolló un apartado con una problematización de algunos aspectos centrales que hacen a la definición del concepto de derechos humanos y a los principios fundamentales como la universalidad y la igualdad. El sistema de derechos humanos es una noción profundamente ética, social, política, anclada en un orden jurídico que se desarrolla a través de la historia de la humanidad. Generar un espacio para trabajar el encuadre de la universalidad desde la actualidad y asimismo la contextualización de los procesos educativos insertos en el movimiento socio-cultural permitirá centrar la comprensión de la igualdad y la diferencia desde un enfoque de derechos. 
El desarrollo de los derechos humanos en el ámbito internacional permite ampliar la comprensión sobre el tema y destaca la importancia del mismo como herramienta de transformación social y guía para las políticas públicas de los Estados. Da un marco valioso a las dimensiones de integralidad y transversalidad que son fundantes en los principios de la EDH.

Desde la normativa y estándares internacionales sobre derechos humanos se deja muy claro la perspectiva integral que debe asumir la educación como derecho humano. Y también una postura de protección y promoción de respeto hacia todas las personas para desarrollar sus potencialidades, transformar sus realidades de vida y construir una convivencia digna entre todos y todas, en consonancia con los derechos humanos.

La comunidad internacional reconoce en el derecho a la educación enmarcada en los derechos humanos un papel fundamental para el desarrollo de las personas y de las sociedades, con pautas de respeto a la dignidad humana y a las diferentes culturas. Así también, implica la comprensión y posible realización de los demás derechos humanos. En este marco, las Naciones Unidas a través de la Organización de las Naciones Unidas para la Educación, la Ciencia y la Cultura (UNESCO) y el Alto Comisionado para los Derechos Humanos (ACDHUN) han impulsado diferentes iniciativas, como ser: el Decenio para la Educación de los derechos humanos (1995-2005); un "Programa Mundial para la educación en derechos humanos" (que comenzó en 2005, y se encuentra actualmente en su tercera etapa) ${ }^{10}$ y se proclamó recientemente la "Declaración sobre educación y formación en materia de derechos humanos" (2011).

10 NACIONES UNIDAS. PROGRAMA MUNDIAL PARA LA EDUCACIÓN EN DERECHOS HUMANOS

Plan de Acción para la 1ra. etapa (2005-2009) A/59/525/rev 1 Resolución AG- 59/ 113. Centrado en el sistema de enseñanza primaria y secundaria, y formación docente.

Plan de Acción para la 2da. etapa (2010-2014) A/HRC/15/28 Resolución Consejo ddhh 12/4. Centrado en la enseñanza superior y en los programas de formación para docentes y educadores, funcionarios públicos, fuerzas del orden y personal militar.

Plan de Acción para la 3ra. etapa (2015- 2019) A/HRC/27/28. Centrado en reforzar la aplicación de las dos etapas anteriores y promover la formación de profesionales de los medios de comunicación y los periodistas. 


\section{Dando una vuelta a los derechos humanos}

"La opción por los derechos humanos no nace de una tearía ni de una dactrina en particular. La misma Declaración Universal es producta de una larga y compleja madeja de gritas, y "ayes" de millanes de persanas a lo larga del plantea y de la histaria" Luis "PERICD" PÉREZ AEUIRRE (1999).

Los derechos humanos desde una visión crítica y compleja nos permiten, por un lado, un posicionamiento ético frente a realidades que estamos viviendo $\mathrm{y}$, por otro, nos ofrecen un encuadre de acción emancipatoria que nos da la posibilidad de intervenir y de transformar estas realidades sociales que entrañan grandes injusticias y discriminaciones. Estas, entendidas desde el marco de los derechos humanos, implican graves violaciones a los mismos.

Desde una postura crítica de los derechos humanos, se plantea la existencia de algunas tensiones (Herrera Flores, 2005) importantes a tener en cuenta en la concepción de estos derechos. Desde un principio, los podemos visualizar como una manera de regulación social (De Souza, Santos, 2002), o concebirlos desde la promoción de formas de emancipación social. (Rebellato, 1997).

"Los derechos humanos, pues, son el producto cultural que Occidente propone para encaminar las actitudes y aptitudes necesarias para llegar a una vida digna en el marco del contexto social impuesto por el modo de regulación basada en el capital... Pero, asimismo, estas actitudes y aptitudes pueden generar un tipo de práctica de empoderamiento que conduzcan a los militantes y teóricos de los derechos humanos a dialogar transculturalmente con el objetivo de construir alternativas (no al mundo, sino) en el mundo." (Herrera Flores, J. 2005: 25)

Desde este lugar, se comprende a los derechos humanos de forma amplia, donde los conflictos y tensiones son partes fundantes de este planteo, que implican procesos socioculturales, políticos, económicos y normativos de las luchas por la dignidad humana. Para transitar estas tensiones es importante asumir algunas premisas que permitan posicionarnos y así generar una base de comprensión y apoyatura para tratar los temas enmarcados en los derechos humanos, como "procesos de derechos humanos". Y así se puede hablar de dinámicas sociales (de relaciones sociales) que tienden a construir condiciones materiales e inmateriales que a través de estos "proceso de derechos humanos" que instalan prácticas sociales, medios e instrumentos (políticos, económico, socio, 
culturales y jurídicos) que permitan las condiciones de una vida digna (Herrera Flores, 2005)

\subsection{De qué universalidad estamos hablando.}

\section{"Pensar de atra mada es, pues, la reacción cultural más importante que pademos llevar a caba. En esta cansiste esa que podemas llamar el pracesa de humanización de los humanas № en la que se refiere a la impasición universal de algún contenido aceptable por todos, sina en la potenciación de nuestra capacidad cultural de creatividad y de pastulación de alternativas a la existente."}

Joaquín HERRERA FLDRES (2007).

Si hay un tema polémico en los derechos humanos, ese es la universalidad. La intención no es de reducir la polémica, sino proponer y problematizar algunas aristas sobre el tema.

Se quiere partir del planteo de la universalidad de los derechos humanos como forma de fortalecer y enriquecer las diferentes luchas de las personas, de los grupos y de los pueblos por alcanzar una vida digna (Herrera Flores. 2005, 2007). Esto va en oposición a concebir los derechos como un ideal abstracto universal que se basa en una sola forma de entenderlos y de realizarlos, es decir la forma dominante y hegemónica.

“... es imperativo trascender el debate sobre el universalismo y el relativismo cultural. Dicho debate es inherentemente falso, cuyos conceptos polares son conjunta e igualmente perjudiciales para una concepción emancipadora de los derechos humanos. Todas las culturas son relativas, pero el relativismo cultural, como postura filosófica, es erróneo. Todas las culturas aspiran a valores y asuntos últimos, pero el universalismo cultural, como postura filosófica, es erróneo. Contra el universalismo debemos proponer diálogos interculturales sobre preocupaciones isomórficas. Contra el relativismo, debemos desarrollar criterios procedimentales interculturales para distinguir las políticas progresistas de las reaccionarias,..." (De Sousa Santos. 2002: 67)

Dentro de este marco de comprensión de los derechos humanos, cobra importancia el planteo de la construcción del concepto de interculturalidad, basado en que cada cultura tiene diferentes prácticas sociales que reivindican la dignidad humana (Herrera Flores, 2005), pero que todas las culturas tienen procesos de desarrollo y, por lo tanto, van variando algunas de esas prácticas, se van modificando, se van transformando (De Souza, Santos, 2002). Es dentro de este marco que se plantea la necesidad de generar las condiciones de respeto y entendimiento mutuos para que las diferentes culturas, grupos e 
individuos puedan entrar en un dialogo y así ir buscando y reivindicando sus diversas luchas por el acceso a los bienes que les permitan generar las condiciones para una vida digna para todas las personas.

"Éstas son las premisas de un diálogo intercultural sobre la dignidad humana que eventualmente puede conducir a una concepción mestiza de los derechos humanos, una concepción que en lugar de recurrir a falsos universalismos, se organice como una constelación de significados locales mutuamente inteligibles, como redes de referencias normativas de apoderamiento." (De Sousa Santos, B. 2002: 69-70)

Entendido así, lo que hace universales a los derechos humanos, no es solamente su reconocimiento jurídico a nivel internacional, o su adaptación a determinados ideales abstractos reconocidos a priori, sino también reconocer prácticas sociales basadas en el respeto y la dignidad que fortalezca a los individuos, a los grupos y a las organizaciones y, generen condiciones y garantías a todas las personas del planeta para acceder a modos de vida digna.

Al decir de Paulo Freire, es la búsqueda por una "ética universal" del ser humano que hace a un componente indispensable en la convivencia humana, donde las realidades se construyen social e históricamente y nosotros nos construimos como sujetos éticos, sujetos históricos y sujetos de derechos en el desarrollo de esas prácticas sociales. Entonces es indiscutible la naturaleza ética de la práctica educativa, en cuanto práctica específicamente humana (Feire, 1996).

\section{2- Prácticas concretas y contextualizadas: nuevas formas de relación.}

Lo que puede par esencia un emancipado es ser emancipadar: dar, na la llave del saber, sina la conciencia de lo que puede una inteligencia cuando se considera igual a cualquier atra y considera cualquier atra como igual a la suya.

Jacques RANCIÈRE

El planteo de los derechos humanos como procesos o prácticas sociales que reivindican la dignidad humana se da en contextos determinados donde una realidad se ve afectada, en lo particular o en lo general, por una división social, sexual, étnica y territorial, donde un grupo de personas se encuentra en condiciones de desigualdad social. Y estas condiciones desiguales generan las dificultades o la negación de acceso a bienes, materiales o inmateriales, necesarios para lograr una vida digna (Herrera Flores, 2007). 
“... cuando hablamos de derechos humanos lo hacemos de dinámicas sociales que tienden a construir las condiciones materiales e inmateriales necesarias para conseguir determinados objetivos genéricos que están fuera del derecho (y que si tenemos la suficiente correlación de fuerzas parlamentarias veremos garantizadas en normas jurídicas). Es decir, al luchar por acceder a los bienes, los actores y actrices sociales que se comprometen con los derechos humanos lo que hacen es poner en funcionamiento prácticas sociales dirigidas a dotarnos a todas y a todos de medios e instrumentos -sean políticos, sociales, económicos, culturales o jurídicosque nos posibiliten construir las condiciones materiales e inmateriales precisas para poder vivir." (Herrera Flores, 2007: 25)

Por eso la comprensión de los contextos históricos y concretos, que dieron y dan lugar a las luchas por los derechos humanos, permite repensar de una forma crítica e integradora, contextualizando las prácticas sociales emancipadoras. El reconocimiento de la pluralidad y la diversidad de estos movimientos da lugar a nuevas luchas por la dignidad, es decir estas prácticas de derechos humanos nos permite replantearnos, dar nuevos sentidos a la vida y a los mundos en que vivimos.

Es así que las prácticas de los derechos humanos dan lugar a la construcción de espacios, de lugares compartidos, donde la participación en los mismos, desde diferentes propuestas igualmente válidas, genera conciencia sobre formas alternativas e integrales de relación, entre las personas, con nosotros mismos y con el entorno (Herrera Flores, 2005). Estos fenómenos dan como resultado una nueva forma de plantearnos el concepto de la igualdad. Ya no oponiéndolo a la diferencia, sino a la desigualdad.

Las relaciones en un marco estructural de desigualdad generan dominación y explotación y los fenómenos como el racismo y el sexismo aumentan las diferencias. Por eso es importante reconocer que no todas las igualdades son idénticas y no todas las diferencias son desiguales. (De Sousa Santos, 2002).

Asumir entonces la pluralidad en sus diferentes dimensiones implica la transformación de una concepción de homogeneidad y centralidad, que está en la base de la sociedad moderna. Da lugar a un proceso de construcción diferente de las formas de relacionarnos con uno mismo (a nivel individual), con los otros (a nivel colectivo-social) y con el entorno (a nivel medio ambiental-sistémico). Hace un intento de superar una visión fragmentada del individuo en su integración social. Replantea, de esta manera, las relaciones de poder, de subordinación, de dominación, así como las formas de pensar la igualdad. Lo 
importante es que se tenga "el derecho a ser iguales cuando la diferencia haga inferiores, pero también el derecho a ser diferentes cuando la igualdad ponga en peligro la identidad" (De Souza Santos, 2002:82).

Pensar la igualdad y la diferencia en los contextos educativos nos proyecta directamente a la relación educativa. Al vínculo entre docentes y estudiantes, ya no con la función de homogeneizar los procesos evolutivos y la construcción de identidades, sino de reconocer y valorar la diversidad en dialogo, para construir lo común, lo de todos. Así como a la relación entre los componentes pedagógicos de conocimientos, valores y aptitudes que implica la EDH.

Entiendo que los derechos humanos y la EDH deben ser pensados y practicados desde una concepción crítica y compleja, que permita comprender las acciones y los conflictos de interés, donde se encuentran invisibilizados o naturalizados algunas concepciones y funcionamientos ideológicos de la cultura hegemónica y dominante. De ahí la importancia de un análisis de los contextos social, económico, histórico, cultural y jurídico en donde se desarrollan las prácticas de derechos humanos y, en especial, las prácticas de EDH. Pues es la tarea educativa la que va a permitir encontrar modelos de dominación, o en su lugar, modelos de respeto de las personas, los colectivos y los pueblos. Es desde allí, desde una educación en y para los derechos humanos, que pueden partir las luchas por la dignidad humana, y así co-construir sociedades más justas, solidarias, más humanas.

\section{2-Un enfoque basado en los derechos humanos para pensar las políticas públicas.}

Es importante retomar un enfoque general de derechos humanos, que permita pensar críticamente las realidades de nuestro contexto donde se llevan a cabo las políticas públicas. ¿Qué nos permite un enfoque de derechos?; ¿Cómo entender, desde un enfoque de derechos, la inclusión de la educación en derechos humanos en la normativa educativa del Uruguay? 
En el contexto de gran desigualdad social y de pobreza que vive nuestra región, y en el mundo entero, se encuentra el desafío de construir nuevos modelos sociales que permitan la superación de las condiciones que mantienen a las personas en estados de indignidad.

Las situaciones de desigualdad están basadas en una estructura de poder que genera y desarrolla relaciones sociales asimétricas. Esto perpetúa las desigualdades y genera injusticias sociales que son importantes combatir para el paradigma ético de los derechos humanos.

En este proceso de lucha contra la desigualdad es importante mencionar el rol estratégico que han cumplido a nivel internacional los convenios y tratado ratificados por los Estados sobre derechos humanos; también los planes y programas, así como la legislación interna de los países, porque consagran los derechos humanos en cada sociedad. Es de esta forma que aparece el "enfoque de Derechos" de la mano del Derecho Internacional de los Derechos Humanos (Abramovich, 2006) como un marco conceptual que cuenta con amplia aprobación de la comunidad internacional y brinda una importante función de guiar las estrategias de desarrollo (Tomasevki, 2004) y el diseño de las políticas públicas (Pautassi, 2007).

"En tal sentido, uno de los principales aportes de este enfoque es dotar a las estrategias de desarrollo de un marco conceptual explícito, del cual puedan inferirse elementos valiosos para reflexionar sobre los diversos componentes de esa estrategia: los mecanismos de responsabilidad, la igualdad y la no discriminación, la participación y el otorgamiento de poder a los sectores postergados y excluidos. Ese marco conceptual podría contribuir además a definir con mayor precisión las obligaciones de los Estados frente a los principales derechos humanos involucrados en una estrategia de desarrollo, tanto económicos, sociales y culturales como civiles y políticos". (Abramovich, 2006:36)

El reconocer que los derechos proclamados en los tratados y las convenciones internacionales generan obligaciones a los Estados de carácter jurídico, imperativo y exigible (Abramovich, 2006), permitiría cambiar la lógica de los procesos de diseño y elaboración de las políticas públicas (formulación, implementación, evaluación y seguimiento), basadas en la noción de sujetos de derechos y no en personas con necesidades que deben ser asistidos (Pautassi, 2007). En los aportes de los últimos años sobre principios, reglas y estándares que componen el Derecho Internacional de los Derechos Humanos se ha definido más claramente lo que el Estado puede y no puede hacer (obligaciones positivas y negativas) para lograr la realización de todos los derechos, imperando una lógica de prevención de violaciones y promoción de los derechos humanos. 
"En tal sentido, los derechos humanos no son pensados hoy tan solo como un límite a la opresión y al autoritarismo, sino también como un programa que puede guiar $\mathrm{u}$ orientar las políticas públicas de los Estados y contribuir al fortalecimiento de las instituciones democráticas, particularmente en procesos de transición o en democracias deficitarias o débiles.“ (Abramovich, 2006:38)

El enfoque de derechos aporta ciertos elementos que hacen a una reformulación de las estrategias de desarrollo en el diseño e implementación de las políticas públicas de los Estados. La dimensión de la igualdad y la no discriminación, la participación y el otorgamiento de poder a los sectores postergados y excluidos, y los mecanismos de responsabilidad horizontal y vertical, entre otros, van generando un marco conceptual, teórico-operativo, que permite definir parámetros mínimos de dignidad para las personas enmarcados en las obligaciones de los Estados en el cumplimiento de los derechos humanos (Pautassi, 2007). Es así que aparece muy fuerte el cambio de concepción en este ámbito, que abandona una visión de corte asistencialista para asumir a las personas como titulares de derechos, garantizado por la responsabilidad del Estado.

Uno de los obstáculos es la tendencia al uso de políticas focalizadas (tan difundidas en la década del 90, y recomendadas por algunos organismos de cooperación financiera, postConsenso de Washington) que en vez de poner el acento en los derechos de forma integral y universal, van generando un tratamiento parcializado de las situaciones a resolver y una distorsión del concepto de titular de derecho que está lejos de los planteos que propone el enfoque de derechos, donde no solo es importante el contenido y orientación de las políticas públicas sino los parámetros de evaluación y fiscalización de las mismas (Pautassi, 2007).

"En consecuencia, otorgar derechos implica a su vez, reconocer un campo de poder para sus titulares, reconocimiento que limita el margen de acción de los sujetos obligados, entre ellos el Estado, en tanto define en sentido amplio, aquellas acciones que el obligado puede y las que no puede hacer. En rigor, el enfoque de derechos explicita un reconocimiento de la relación directa existente entre el derecho, el empoderamiento de sus titulares, la obligación correlativa y la garantía, todo lo cual conjuga en una potencialidad que puede actuar como una forma de restablecer equilibrios en el marco de situaciones sociales marcadamente desiguales. " (Pautassi, 2007:18)

Esto da cuenta de la intensión concreta que pretende este enfoque, de poder contribuir a un cambio en la esfera del sistema socio-cultural y político donde los derechos humanos cobran una centralidad efectiva que se refleje en la igualdad real de las personas (tanto igualdad formal pero sobre todo igualdad material). Esto implica el reconocimiento de la 
existencia de desigualdades a tener en cuenta a la hora de diseñar una política pública, de reconocer que hay grupos específicos, históricamente en desventaja, que necesitan un trato diferenciado, lo que hoy se conoce como políticas de acción afirmativa. Porque el garantizar un trato igualitario no reconociendo las distintas realidades genera y perpetúa las desigualdades y produce así la discriminación (De Sousa Santos, 2002).

Existe una tendencia internacional a reconocer el rol central de la educación y la EDH en reformas estatales donde se incluyen los principios, objetivos y contenidos de los derechos humanos y el reconocimiento de la EDH como un derecho en sí mismo, como lo hizo el Estado Uruguayo en la Ley General de Educación ( $\mathrm{N}^{\circ}$ 18.437- 2008). La incorporación de elementos de EDH más allá de las reformas educativas implica una herramienta que tiende a un cambio cultural priorizando una forma de relacionarse entre los individuos desde el respeto a la dignidad humana y tendiente a la justicia social, como por ejemplo en el Plan Nacional de Igualdad de Oportunidades y Derechos ${ }^{11}$, que contribuye a generar prácticas tendientes a la inclusión social y a la participación democrática.

"Los instrumentos internacionales...configuran progresivamente, el derechos de todas la personas y la obligación de los Estados a favor del establecimiento de la EDH entendida en un sentido cada vez más profundo, que toca a las libertades civiles, al ejercicio de la democracia y al logro de los derechos económicos, sociales y culturales. Así mismo este desarrollo amplía y especializa progresivamente el derecho a la EDH en favor de sectores sociales que en razón de sus especialidades requieren de acciones afirmativas para promover, recuperar o proteger de modo más directo sus derechos específicos, que son precondiciones del disfrute de los derechos y libertades fundamentales: tales los casos de las mujeres, los niños, los pueblos indígenas, las personas que sufren algún tipo de discapacidad o se encuentran privadas de libertad.” (IIDH, 2002: 40)

Se observa una tendencia creciente a la puesta en marcha de diversos programas, planes y políticas públicas que transmiten componentes de la EDH, que permiten el desarrollo de procesos de enriquecimiento de la ciudadanía en la comprensión, la adquisición de conocimiento sobre derechos humanos que posibilitan ejercitar una convivencia desde el respeto y por la dignidad humana. Así se pretende el fortalecimiento de la participación ciudadana y el desarrollo de la democracia efectiva.

\footnotetext{
11 Primer Plan Nacional de Igualdad de Oportunidades y Derechos. Políticas hacia las Mujeres. 2007 2011 / Uruguay. Aprobado por Decreto del Poder Ejecutivo 184/007 el 15 de mayo de 2007. Ministerio de Desarrollo Social (MIDES), Instituto Nacional de las Mujeres (INMUJERES).
} 


\section{El derecho humano a la educación: un marco general para la integralidad y transversalidad de la dignidad humana.}

Existe pues un gran númera de problemas de derechos humanos que es imposible resalver a menas que se considere que el derecha a la educación es la llave que abre pasa a atros derechos humanos.

\section{Katarina TDMASEVSKI (2003).}

En el Derechos Internacional de los Derechos Humanos, la educación, proclamada desde el inicio en la Declaración Universal de Derechos Humanos-ONU $1948^{12}$ (en adelante DUDH) es un derecho que va más allá de su mero contenido específico, y tiene una enorme implicancia en la realización de los demás derechos (Tomasevski, 2003). El texto del artículo 26 expresa claramente objetivos y finalidades del derecho humano a la educación (Bolívar, 2010), conforme al carácter integral de la persona humana y su desarrollo en sociedad (Claude, 2005).

“Artículo 26. 1. Toda persona tiene derecho a la educación. La educación debe ser gratuita, al menos en lo concerniente a la instrucción elemental y fundamental. La instrucción elemental será obligatoria. La instrucción técnica y profesional habrá de ser generalizada; el acceso a los estudios superiores será igual para todos, en función de los méritos respectivos.

2. La educación tendrá por objeto el pleno desarrollo de la personalidad humana y el fortalecimiento del respeto a los derechos humanos y a las libertades fundamentales; favorecerá la comprensión, la tolerancia y la amistad entre todas las naciones y todos los grupos étnicos o religiosos, y promoverá el desarrollo de las actividades de las Naciones Unidas para el mantenimiento de la paz.

3. Los padres tendrán derecho preferente a escoger el tipo de educación que habrá de darse a sus hijos. "(DUDH ONU 1948)

Desde la elaboración del texto de la DUDH, según Richard Pierre Claude, los integrantes de la Comisión de Derechos Humanos de la Organización de las Naciones Unidas ${ }^{13}$,

\footnotetext{
12 Asamblea General, ONU-Resolución 217, A, 3. Paris, Francia, 10 de diciembre 1948. “Declaración Universal de Derechos Humanos"

La Comisión de Derechos Humanos fue creada en 1946 por el Consejo Económico Social y Cultural de las Naciones Unidas (ECOSOC), como órgano subsidario. Esta comienza a trabajar en 1947 presidida por Eleonor Roosevelt (EEUU), y constituida en la época por: Charles Malik (Libano); Alexander Bogomolov (URSS); Peng-Chun Chan (China); René Cassin (Francia); William Hodgson (Austria); Hernan Santa Cruz (Chile); John P. Humphrey (Canadá)
} 
tuvieron la intención de dejar plasmado en la misma una concepción de la noción de educación relacionada con los valores que definen a los derechos humanos, alejándose de una concepción de neutralidad educativa (Claude, 2005). Es así que, para este autor y otros recogidos, aparece en el artículo 26 el planteamiento de una serie de metas educativas (Bolívar, 2010) dejando en claro que la educación, desde una concepción de los derechos humanos, es una estrategia a largo plazo e implica una concepción integral del individuo (Tomasevski, 2003), así como del establecimiento de las relaciones entre estos y las organizaciones sociales de pertenecía y referencia.

Pero esta forma de entender a la educación no solo quedó plasmada en al artículo 26, sino que está presente en toda la DUDH. Sus autores no solo se limitaron a plantear a la educación como integral y fundante en el desarrollo de los individuos y de las sociedades. También incluyeron desde el texto mismo una concepción transversal de la función educativa (Claude, 2005) al destacarla como estrategia para la realización de este proyecto que son los Derechos Humanos (Rodino, 2003).

Según el Dr. Charles Malik, relator de la Comisión de Derechos humanos de 1948:

"Es necesario elaborar una declaración general de los derechos humanos definiendo en términos sucintos los derechos y las libertades fundamentales de [todos] que, según la Carta, la Organización de las Naciones Unidas debe promover. [...] Este respetable anuncio de los derechos fundamentales ejercerá una poderosa influencia doctrinaria, moral y educativa en las mentes y en el comportamiento de las personas de todo el mundo". ${ }^{14}$

Esta cita de C. Malik, se refleja en el Preámbulo de la misma DUDH, "ideal común por el que todos los pueblos y naciones deben esforzarse, a fin de que tanto los individuos como las instituciones, inspirándose constantemente en ella, promuevan, mediante la enseñanza y la educación, el respeto a estos derechos y libertades ...".

Esta concepción de integralidad y transversalidad que plantea a los derechos humanos como un sistema, como una unidad, un todo en relación, está vinculada con otra idea central de la concepción de los derechos humanos, expresada en el artículo 1 de la DUDH: la igualdad de todas las personas está en relación directa con la concepción de dignidad humana.

Esto está recogido en el primer artículo de la DUDH:

14 Charles Malik, These Rights and Freedoms. Naciones Unidas: Department of Public Information, 1950, pp. 4-5. Citado por CLAUDE: 2005: 41. 
Artículo 1:"Todos los seres humanos nacen libres e iguales en dignidad y derechos y, dotados como están de razón y conciencia, deben comportarse fraternalmente los unos con los otros." (DUDH ONU 1948)

Se daba así un marco privilegiado al "pleno desarrollo de las personas", integrando la dimensión individual y particular de todas y cada una de las personas con la dimensión social-comunitaria. Se entiende a esta última como el conjunto de las conductas y comportamientos de los seres humanos, que constituyen los contextos posibles de favorecer el pleno desarrollo de los individuos, vinculando la concepción de ser humano integral donde lo individual y lo social están directamente relacionados con la noción de dignidad.

Esta idea se observa varias veces plasmada en el articulado de la DUDH.

El Artículo 22 dice que toda persona tiene derechos sociales, económicos y culturales "indispensables [...] al libre desarrollo de su personalidad".

- El Artículo 26 consagra un derecho a la educación y afirma: "La educación tendrá por objeto el pleno desarrollo de la personalidad humana".

- El Artículo 29 reafirma la visión holística de los derechos humanos al establecer: "Toda persona tiene deberes respecto a la comunidad, puesto que solo en ella puede desarrollar libre y plenamente su personalidad". (Claude, 2005: 42)

\section{1-La educación bisagra que permite acceder a los demás derechos}

De acuerdo a la tesis de la indivisibilidad e interdependencia de los derechos humanos, se entiende que en el derecho a la educación se explicitan claramente ciertos objetivos y finalidades que son otorgados conforme al carácter integral de la personalidad humana y su desarrollo en sociedad. El derecho a la educación es parte de un sistema de derechos humanos y como todos los derechos no puede realizarse por separado porque si no perdería el significado como tal y su eficacia (Tomasevski, 2003).

Entendido de esta manera, el derecho a la educación facilita el cumplimiento de todos los demás derechos. Implica una acción transversal, que repercute en el ejercicio y goce de todos los otros derechos humanos (Bolívar, 2010). Es así que el carácter transversal del derecho a la educación con respecto a los demás derechos humanos le imprime una afectación directa al conocimiento y calidad de disfrute o de reclamo, de todo el conjunto de los derechos humanos por parte de todas las personas.

"La lógica de las dos ideas combinadas expresa que, al promover el pleno desarrollo de la personalidad humana, y la dignidad que esto conlleva, la educación también promueve los derechos humanos. Y para este pleno desarrollo la educación 
para la dignidad debe tener presente la lista completa de los derechos humanos, derechos personales como la privacidad; derechos políticos, como la participación, como también la búsqueda y la divulgación de información; derechos civiles, como la igualdad y la ausencia de discriminación; derechos económicos, como un nivel de vida digno; y el derecho a participar de la vida cultural de la comunidad". (Claude: 2005: 43)

La educación es parte importante del desarrollo de la persona: implica la capacidad de disfrutar la vida, de participar de su cultura y de su sociedad, y de desarrollar su autoestima. También, el acceso a la educación permite a los seres humanos adquirir pautas responsables hacia la salud, la alimentación, el medio ambiente, entre otras, así como generar una visión crítica de su realidad, desarrollar las habilidades para relacionarse y comunicarse respetando la dignidad de todas las personas y sus entornos ambientales, y asumir las acciones para transformar la sociedad acorde a pautas y normas de respeto de los derechos humanos.

"Contar con una educación de calidad no solo es un derecho en sí mismo, sino una condición para el pleno ejercicio de todos los demás derechos. El acceso al empleo y a la seguridad social, la participación en el mercado laboral, el disfrute de las garantías del derecho a la información y a una plena participación en la vida política, la posibilidad de exigir servicios de salud o de vivienda están, en la práctica, estrechamente vinculados a las destrezas y conocimientos que ofrece la educación. Más aún el reconocimiento de que la obtención de esos satisfactores constituyen derechos, que estos están garantizados en las normas internacionales y nacionales y que son reclamables por la vías institucionales, son aprendizajes necesarios para el pleno ejercicio de la ciudadanía comprendida como un estatuto de acceso a todos los derechos." (IIDH. 2007:27)

En la misma sintonía sobre el contenido del derecho a la educación se encuentra el Comité de los Derechos Económicos, Sociales y Culturales, que señala en su Observación General $\mathrm{n}^{\circ} 13^{15}$ sobre el derecho a la educación (artículo 13), en el párrafo primero:

"1.La educación es un derecho humano intrínseco y medio indispensable de realizar otros derechos humanos. Como derecho del ámbito de la autonomía de la persona, la educación es el principal medio que permite a adultos y menores, marginados económica y socialmente salir de la pobreza y participar plenamente en sus comunidades. La educación desempeña un papel decisivo en la emancipación de la mujer, la protección de los niños contra la explotación laboral, el trabajo peligroso y la explotación sexual, la promoción de los derechos humanos y la democracia, la protección del medio ambiente y el control del crecimiento demográfico. ... su importancia no es únicamente práctica pues disponer de una mente instruida,

\footnotetext{
15 NACIONES UNIDAS. Comité DESC, Observación General N¹3 “Derecho a la Educación"
} (E/C.12/1999/10) 
inteligente y activa, con libertad y amplitud de pensamiento, es uno de los placeres y recompensas de la existencia humana."

Desde la normativa y estándares internacionales de derechos humanos se deja clara la perspectiva integral que debe asumir la educación como derecho humano. Y también una postura de protección y promoción del respeto de todas las personas para desarrollar sus potencialidades y transformar sus realidades de vida y de convivencia. Pero a su vez, también se plantea una finalidad emocional subjetiva del ejercicio de la educación, denominándola "los placeres y recompensas de la existencia humana”.

Esta visión compleja y holística de los derechos humanos ubica a la educación en un lugar central de este proyecto. Se plantea así tanto el derecho a la Educación con enfoque de derechos humanos, como a la educación en y para los derechos humanos.

\section{2- El derecho a la educación y su protección en el ámbito internacional}

La educación es entances no sula un fin en sí mismo, sina también un medio para el logro de muchos atras abjetivas acordados universalmente. El derecho internacional de los derechos humanos constituye un marco ya listo para evaluar el progresa en la cansecución de estas abjetivas, tada vez que define las metas, las propósitas y los métadas de la educación. para permitir que todas y tadas disfruten tados los derechos humanos.

La comunidad internacional reconoce en el derecho a la educación un papel fundamental para el desarrollo pleno de la persona y en fomentar pautas de respeto a la dignidad humana y de las diferentes culturas. Esto se encuentra consagrado en diferentes tratados internacionales de derechos humanos generales, como la ya citada DUDH, en el Pacto Internacional de Derechos Civiles y Políticos (PICyP $)^{16}$, el Pacto Internacional de Derechos Económicos, Sociales y Culturales (PIDESC) $)^{17}$, así como en numerosos instrumentos específicos, como por ejemplo: la Convención de Derechos del Niño $(\mathrm{CDN})^{18}$, Convención contra la Eliminación de todas las Formas de Discriminación contra la Mujer (CEDAW) ${ }^{19}$, Convención Internacional sobre la Eliminación de todas las Formas

\footnotetext{
16 Pacto Internacional de Derechos Civiles y Políticos. ONU 1966. Art: 18 y 20.

17 Pacto Internacional de Derechos Económicos, Sociales y Culturales. ONU 1966. art: 13 y 14

18 Convención de Derechos del Niño. ONU 1989. art: 28 y 29.

19 Convención contra la Eliminación de todas las Formas de Discriminación contra la Mujer. ONU
} 1979. art: 10 
de Discriminación Racial (CERD) ${ }^{20}$, la Convención Internacional sobre la Protección de los Derechos de todos los Trabajadores Migrantes y sus familias ${ }^{21}$, la Convención sobre los Derechos de las Personas con Discapacidad. ${ }^{22}$

Dentro de la protección regional, es en el Sistema Interamericano (OEA) que encontramos el derecho a la educación proclamado en la propia Declaración Americana de Derechos y Deberes del Hombre ${ }^{23}$ y en el Protocolo de San Salvador, Protocolo adicional a la Convención Americana sobre derechos humanos en materia de derechos económicos, sociales y culturales. ${ }^{24}$

En consecuencia, al consagrar el derecho a la educación los Estados partes de los instrumentos internacionales tienen la obligación de garantizar esta prestación a toda la población, de forma constante e imprescindible. De acuerdo al artículo 2.1 del PIDESC, los Estados deben adoptar medidas para el logro progresivo de la efectividad de los derechos proclamados en este pacto.

\subsection{1- La educación, un derecho que se relaciona a todos los derechos.}

Si bien se ubica el derecho a la educación generalmente dentro de los Derechos Económico Sociales y Culturales, este derecho tiene características (Bolivar, 2010) que hacen que simultáneamente también pueda ser ubicado en otras categorías de derechos (Tomasevski, 2003). Como lo señala el Comité DESC en su observación General №11:

2. El derecho a la educación, reconocido en los artículos 13 y 14 del Pacto, así como en otros tratados internacionales, tales como la Convención sobre los Derechos del Niño y la Convención sobre la eliminación de todas las formas de discriminación contra la mujer, es de vital importancia. Se ha clasificado de distinta

\footnotetext{
20 Convención Internacional sobre la Eliminación de todas las Formas de Discriminación Racial. ONU, 1969. art:6 y 7

21 Convención internacional sobre la protección de los derechos de todos los trabajadores migrantes y sus familias, ONU 1990 art: 12, 30, 33 y 43.

22 Convención sobre los derechos de las personas con discapacidad, ONU, 2006. arts. 4 y 8.

23 “Declaración Americana de Derechos y Deberes del Hombre" OEA 1948. Art: XII

24 Protocolo adicional a la Convención Americana sobre derechos humanos en materia de derechos económicos, sociales y culturales. (OEA, 1989) PROTOCOLO DE SAN SALVADOR. Art: 13.
} 
manera como derecho económico, derecho social y derecho cultural. Es todos esos derechos al mismo tiempo. También, de muchas formas, es un derecho civil y un derecho político, ya que se sitúa en el centro de la realización plena y eficaz de esos derechos. A este respecto, el derecho a la educación es el epítome de la indivisibilidad y la interdependencia de todos los derechos humanos. ${ }^{25}$

Entonces se puede pensar que la educación es un derecho civil cuando se considera, por ejemplo, la libertad a particulares y organizaciones de crear institutos de enseñanzas, y a padres y tutores la posibilidad de elegir para sus hijos escuelas de acuerdo a sus creencias, convicciones y religiones; así también cuando se refiere a la libertad de cátedra del cuerpo docente, con la garantía cumplir con el respeto a las normas mínimas prescritas por el Estado en estas materias, conforme al artículo 13.3 del PIDESC y el 18.4 del PICyP. (Bolivar, 2010).

Se da cuenta así de que la educación es un derecho con un carácter especial y complejo, que permite la interrelación no solo de los diferentes derechos humanos desde una dimensión conceptual sino también desde lo concreto, que hace al ejercicio de los derechos en los proyectos de vida de las personas.

\subsection{2- Características de las obligaciones de derecho a la educación.}

El PIDESC en su artículo 14 exige a los Estados parte que adopten planes de acción para instituir la enseñanza primaria obligatoria y gratuita para todos. El Comité DESC, en su $20^{\circ}$ período de sesiones (1999), ha elaborado una Observación General dedicada a este asunto, la Observación General N ${ }^{\circ} 11$. "Planes de acción para la enseñanza primaria". ${ }^{26} \mathrm{El}$ Comité del PIDESC establece -en su Observación General Nº3 - la obligación de que los Estados parte adopten las medidas para lograr la progresiva efectividad de las mismas con el fin de garantizar el pleno goce de los derechos (OG3). ${ }^{27}$ Esta intervención de los Estados en brindar prestaciones en el área educativa a todas las personas, sin discriminación de

\footnotetext{
25 NACIONES UNIDAS. Comité DESC, Observación General №11 "“Planes de acción para la enseñanza primaria (art: 14)" E/C.12/1999/4 . párrafo 2

26 NACIONES UNIDAS. Comité DESC, Observación General N¹1,“Planes de acción para la enseñanza primaria (art: 14)" E/C.12/1999/4

27 Pacto Internacional de Derechos Económicos, Sociales y Culturales. ONU 1966. art: 2. Y Comité DESC, Observación General N 3 “La índole de las obligaciones de los Estados Partes (párrafo 1 del art 2)". E/1991/23.
} 
ningún tipo, de ser sistemática y de calidad, es sustancial y condición para el pleno ejercicio del derecho a la educación (IIDH, 2006) y por él se accede a todos los demás derechos. (Tomasevski, 2003).

En cuanto al contenido del derecho a la educación, el Comité de DESC, en su Observación General $\mathrm{N}^{\circ} 13$, referida al artículo 13 del respectivo Pacto, fija una serie de características, de estándares internacionales sobre el cumplimiento de las obligaciones de los Estados para el derecho a la educación.

6. Si bien la aplicación precisa y pertinente de los requisitos dependerá de las condiciones que imperen en un determinado Estado Parte, la educación en todas sus formas $\mathrm{y}$ en todos los niveles debe tener las siguientes cuatro características interrelacionadas:

a) Disponibilidad. Debe haber instituciones y programas de enseñanza en cantidad suficiente en el ámbito del Estado Parte. Las condiciones para que funcionen dependen de numerosos factores, entre otros, el contexto de desarrollo en el que actúan; por ejemplo, las instituciones y los programas probablemente necesiten edificios u otra protección contra los elementos, instalaciones sanitarias para ambos sexos, agua potable, docentes calificados con salarios competitivos, materiales de enseñanza, etc.; algunos necesitarán además bibliotecas, servicios de informática, tecnología de la información, etc.

b) Accesibilidad. Las instituciones y los programas de enseñanza han de ser accesibles a todos, sin discriminación, en el ámbito del Estado Parte. La accesibilidad consta de tres dimensiones que coinciden parcialmente:

i) No discriminación. La educación debe ser accesible a todos, especialmente a los grupos no vulnerables de hecho y de derecho, sin discriminación por ninguno de los motivos prohibidos (véanse los párrafos 31 a 37 sobre la no discriminación).

ii) Accesibilidad material. La educación ha de ser asequible materialmente, ya sea por su localización geográfica de acceso razonable (por ejemplo, una escuela vecinal) o por medio de la tecnología moderna (mediante el acceso a programas de educación a distancia).

iii) Accesibilidad económica. La educación ha de estar al alcance de todos. Esta dimensión de la accesibilidad está condicionada por las diferencias de redacción del párrafo 2 del artículo 13 respecto de la enseñanza primaria, secundaria y superior: mientras que la enseñanza primaria ha de ser gratuita para todos, se pide a los Estados Parte(s) que implanten gradualmente la enseñanza secundaria y superior gratuita.

c) Aceptabilidad. La forma y el fondo de la educación, comprendidos los programas de estudio y los métodos pedagógicos, han de ser aceptables (por ejemplo, pertinentes, adecuados culturalmente y de buena calidad) para los estudiantes y, cuando proceda, los padres; este punto está supeditado a los objetivos de la educación mencionados en el párrafo 1 del artículo 13 y a las normas mínimas que el Estado apruebe en materia de enseñanza (véanse los párrafos 3 y 4 del artículo 13).

d) Adaptabilidad. La educación ha de tener la flexibilidad necesaria para adaptarse a las necesidades de sociedades y comunidades en transformación y responder a las necesidades de los alumnos en contextos culturales y sociales variados. 
7. Al considerar la correcta aplicación de estas "características interrelacionadas y fundamentales", se habrán de tener en cuenta ante todo los superiores intereses de los alumnos. ${ }^{28}$

También encontramos en las Observaciones Generales $\mathrm{N}^{\circ} 11$ y 13 del Comité DESC que se hace referencia a dos principios: la no discriminación e igualdad de trato y la libertad de elección de los padres y tutores de escoger la institución educativa de sus hijos, la libertad académica y la autonomía de las instituciones, bajo supervisión de los Estados, los cuales deben estar presentes en la aplicación de las características (Bolívar, 2010).

"39. Los miembros de la comunidad académica son libres, individual o colectivamente, de buscar, desarrollar y transmitir el conocimiento y las ideas mediante la investigación, la docencia, el estudio, el debate, la documentación, la producción, la creación o los escritos. La libertad académica comprende la libertad del individuo para expresar libremente sus opiniones sobre la institución o el sistema en el que trabaja, para desempeñar sus funciones sin discriminación ni miedo a la represión del Estado o cualquier otra institución, de participar en organismos académicos profesionales o representativos y de disfrutar de todos los derechos humanos reconocidos internacionalmente que se apliquen a los demás habitantes del mismo territorio. El disfrute de la libertad académica conlleva obligaciones, como el deber de respetar la libertad académica de los demás, velar por la discusión ecuánime de las opiniones contrarias y tratar a todos sin discriminación por ninguno de los motivos prohibidos. ${ }^{, 29}$

\section{3- La educación en derechos humanos en el ámbito internacional}

La EDH ha tenido un desarrollo progresivo desde que se explicitó en el artículo 26 de la DUDH. Se ha incorporado en diferentes instrumentos de protección y planes de acción internacionales, hasta llegar a nuestros días, con la Declaración de las Naciones Unidas sobre educación y formación en materia de derechos humanos del 2011. ${ }^{30}$ También se ha incorporado en legislaciones internas así como planes y programas nacionales de diversas áreas. Podemos encontrar la EDH no solo en educación formal, sino en muy diversos ámbitos de políticas públicas. Uruguay es parte de estas tendencias actuales.

28 NACIONES UNIDAS Comité DESC: Observación general $\mathbf{N}^{\circ}$ 13. El derecho a la educación. Op.cit. Párrafos 6 y 7.

29 NACIONES UNIDAS Comité DESC: Observación general N¹3. El derecho a la educación. Op.cit. Párrafo 39.

$30 \quad$ NACIONES UNIDAS, Asamblea General:“Declaración de las Naciones Unidas sobre educación y

formación en materia de derechos humanos". 2 de noviembre de 2011. A/C.3/66/L.65 
La conferencia mundial de derechos humanos de Viena en 1993 es un momento destacado, pues representa un nuevo estímulo en las estrategias emprendidas para la promoción y prevención de los derechos humanos. En su Declaración y Programa de Acción se proclama:

"Todos los derechos humanos son universales, indivisibles e interdependiente, y están relacionados entre sí. La comunidad internacional debe tratar los derechos humanos en forma global y de manera justa y equitativa, en pie de igualdad y dándose a todos el mismo peso. Debe tenerse en cuenta la importancia de las particularidades nacionales y regionales, así como de los diversos patrimonios históricos, culturales y religiosos, pero los Estados tienen el deber, sean cuales fueren sus sistemas políticos, económicos y culturales, de promover y proteger todos los derechos humanos y las libertades fundamentales." ${ }^{31}$

Es así que se da un nuevo empuje a la tesis de la indivisibilidad e interdependencia de los derechos humanos desde un enfoque universal, indivisible y de interrelación. Pero también genera una nueva mirada a la EDH, re-ubicándola en un lugar central de estrategias para favorecer la realización de sociedades que promuevan la dignidad de las personas y permitan el ejercicio de una convivencia respetuosa de las diferentes culturas que coexisten en el mundo.

\subsection{1-La EDH a partir de los años 90.}

El ámbito educativo formal, como lo conocemos hoy, es resultado del proyecto de la Modernidad; siempre se afirmó que este espacio debe transmitir la base para la ciudadanía democrática. Pero la amplia promoción de los derechos humanos y la democracia a través de la educación como un estándar internacional es bastante reciente. (Claude, 2005). Es después del fin de la guerra fría que las Naciones Unidas lanzan el Decenio para la Educación en la esfera de los Derechos Humanos (1995-2004) (Salvioli, 1997).

Tras la realización de la Conferencia Mundial de los Derechos Humanos en Viena (1993), la Asamblea General de la Organización de las Naciones Unidas aprueba mediante las resoluciones 48/127, 49/184 y 50/177 El Decenio para la educación en la esfera de los derechos humanos. Allí se plantea la introducción de la educación en y para los derechos

31 Declaración y Programa de Acción de Viena (parte I, párr. 5), aprobada por la Conferencia Mundial de Derechos Humanos, Viena, 25 de junio de 1993 [A/CONF.157/24 (Part I), cap. III]. 
humanos en todos los niveles de la educación formal (sistema escolar oficial) y de la educación informal.

Se reconoce entonces la importancia de la dimensión educativa en los diferentes momentos de la vida de las personas (primera infancia, infancia, adolescencia, educación para el trabajo, educación superior, entre otros). Así también se destacan y estimulan las acciones complementarias en esta área, que se desarrolla entre los sistemas educativos oficiales y las tareas de las organizaciones no gubernamentales. La propuesta del Decenio también se refiere a cuestiones metodológicas, valorizando métodos de enseñanza interactivos, participativos y culturalmente relevantes (Claude, 2005).

Se plantea así el requisito de la incorporación de contenidos, principios y objetivos, relativos a los derechos humanos en los programas, currículos y en el diseño de políticas educativas en particular y políticas públicas en general. Lo mismo en los materiales y métodos usados por los docentes y agentes sociales (Juanche, 2013).

Es importante destacar que dentro de las recomendaciones del Decenio para la EDH (19952004) aparece la importancia de que los países puedan elaborar, ejecutar y evaluar Planes Nacionales de EDH. Por eso en 1998 se proponen las "Directrices de las Naciones Unidas para elaborar planes de acción en materia de EDH" (A/52/469/Add.1) que plantean:

Los planes nacionales contribuyen a establecer o fortalecer las organizaciones e instituciones que promuevan los derechos humanos. Es una acción tendiente a evitar las violaciones de los mismos y sus consecuencias ruinosas desde el punto de vista humano, social, cultural, ambiental y económico. Permite identificar a los miembros de la sociedad que se ven privados del goce pleno de sus derechos humanos y velar por que se adopten medidas eficaces para remediar su situación. A su vez genera un entorno propicio para dar respuestas rápidas con un enfoque de derechos a cambios sociales y económicos; promoviendo la diversidad de fuentes, de enfoques, de metodologías y de instituciones respecto a la educación en la esfera de los derechos humanos. Se amplía la cooperación en las actividades de EDH entre la esfera gubernamental, la no gubernamental, los grupos de profesionales, así como con la sociedad civil. Se subrayar la importancia de los derechos humanos en el proceso de desarrollo nacional; Se pretende asistir a los gobiernos para que cumplan los compromisos y recomendaciones que han contraído anteriormente respecto de la educación en la esfera de los derechos humanos con arreglo a instrumentos y programas 
internacionales, como la Declaración y Programa de Acción de Viena (1993) y el Decenio de las Naciones Unidas para la educación en la esfera de los derechos humanos (19952004). (A/52/469/Add.1)

Tras el Decenio para la EDH, también se van a incluir explícitamente las referencias de garantías de protección generales de derechos humanos, así como de grupos específicos, por ejemplo personas con discapacidad, mujeres, niños y grupos étnicos. Esto se va a ver reflejado en las Declaraciones y Planes de acciones surgidos en las diferentes Conferencias Internaciones (Salvioli, 1997) que se han realizado durante la década de los 90 y principios del siglo XXI.

Es importante mencionar algunos ejemplos como la Conferencia Internacional de Educación de 1994, que adoptó en su declaración varios objetivos sobre la Educación para la Paz, los Derechos Humanos y la Democracia. También destacar la Plataforma de Acción de la Cuarta Conferencia Mundial sobre la Mujer (Beijing, 1995), que identifica a prácticas educativas como elemento fundamental a modificar para combatir la discriminación. En cuanto al tema de lucha contra la discriminación, podemos destacar que en la Declaración y el Programa de Acción de la Conferencia Mundial contra el Racismo, la Discriminación Racial, la Xenofobia y las Formas Conexas de Intolerancia (Durban, Sudáfrica, 2001), la EDH tiene un rol fundamental que aparece en sus diferentes componente, desde la incorporación explicita en los planes de estudios hasta la acción docentes y materiales de apoyo.

Otra importante acción de promoción y protección de los derechos humanos en la órbita de la educación fue el mandato de la Resolución 1998/33 de la Comisión de Derechos Humanos. En ella se creó el cargo de Relator Especial sobre el derecho a la educación y se nombró a Katarina Tomaševski ${ }^{32}$ para ocuparlo. El mandato del relator sería informar sobre el grado de cumplimiento progresivo del derecho a la educación en todo el mundo y sobre las dificultades y avances en la consecución de ese objetivo, con especial atención a

\footnotetext{
32 Actual Relator especial sobre el derecho a la educación de la ONU, Dr. Kishore Singh (india) desde agosto de 2010 .
} 
la desigualdad de género y también ayudar a los gobiernos a asegurar una aplicación progresiva de esta área de derechos humanos.

\subsection{2- Programa mundial para la educación en derechos humanos.}

Este Programa fue preparado por la Oficina del Alto Comisionado de las Naciones Unidas para los Derechos Humanos (ACNUDH) y la agencia de la Organización de la Naciones Unidas para la Educación, la Ciencia y la Cultura (UNESCO) $)^{33}$. Se viene desarrollando desde 2005 con el objetivo general de promover la aplicación de programas de EDH en todos los sectores educativos y relevantes de las sociedades. (Resolución AG 59/113). Consta de tres etapas, cada unas con su respectivo objetivo y muy detallado Plan de Acción, sobre los cuales volveremos más adelante.

Con el antecedente del Decenio de la educación en la esfera de los derechos humanos (1995-2004), la EDH empieza a visualizarse como una estrategia a largo plazo, que genera resultados de gran alcance en el respeto de la dignidad humana, la igualdad entre las personas, así como la participación en la adopción democrática de decisiones, previniendo situaciones de vulneración y violación de derechos y de conflictos violentos.

De acuerdo al "Plan de Acción de la primera etapa del Programa Mundial para la Educación de los derechos humanos" se entiende a la EDH, como una educación integral que "no solo proporciona conocimientos sobre los derechos humanos y los mecanismos para protegerlos, sino que,...transmite las aptitudes necesarias para promover, defender $y$ aplicar los derechos humanos en la vida cotidiana ... a todos los miembros de la sociedad" (Resolución 59/113B: 1, de la Asamblea General julio 2005). De modo que la EDH se presenta como un derecho en sí misma.

\footnotetext{
33 Existen antecedentes interesantes dentro de la UNESCO, de los que se puede destacar: 1974, "Recomendaciones sobre la Educación para la comprensión, la Cooperación y la Paz Internacionales, y la Educación relativa a los Derechos Humanos y las Libertades Fundamentales"; 1986-89, "Manifiesto de Sevilla" aporte interdisciplinarios sobre la violencia y la guerra, a favor de una cultura de Paz; 1993, "Plan de Acción de Montreal para la Educación en derechos humanos y la Democracia"

Convención relativa a la lucha contra la discriminación en la esfera de la enseñanza, (UNESCO) artículos 2, 3, 4 y 5.
} 
Para contribuir a que el disfrute de los derechos humanos sea realidad en todas las comunidades, el Programa Mundial tiene por objetivo promover el entendimiento común de los principios y metodologías básicas de la $\mathrm{EDH}$, proporcionando un marco concreto para la adopción de medidas y reforzar las oportunidades de cooperación y asociación, desde el nivel internacional hasta los niveles nacionales y locales.

El Programa Mundial ha tenido hasta la fecha tres etapas, cada una de las cuales desarrolló un Plan de Acción especifico:

- Plan de Acción para la 1ra. etapa (2005-2009) (A/59/525/rev 1 Resolución AG- 59/ 113) se centra en el sistema de enseñanza primaria y secundaria, y formación docente.

- Plan de Acción para la 2da. etapa (2010-2014) (A/HRC/15/28 Resolución Consejo ddhh 12/4) se centra en la enseñanza superior y en los programas de formación para docentes y educadores, funcionarios públicos, fuerzas del orden y personal militar.

- Plan de Acción para la 3ra. etapa (2015-2019) (A/HRC/27/28) se centra en reforzar la aplicación de las dos etapas anteriores y promover la formación de profesionales de los medios de comunicación y los periodistas.

Aquí se hará referencia solamente a la primera y segunda etapas del Plan Mundial porque son las que más se vinculan a la incorporación de la EDH en la educación primaria y secundaria. En particular la primera etapa es la que más nos interesa describir pues es la que desarrolla en más detalle esa incorporación. Está basada en la articulación de tres pilares que permitirían una acción estratégica y coherente para su desarrollo y concreción de los objetivos propuestos.

- Un enfoque de la educación "con base en los derechos humanos" es parte del derecho a la educación, permite percibir una educación de calidad así como fortalecer la capacidad de disfrutar de todos los derechos y fomentar una cultura donde prevalezcan los valores de los derechos humanos.

- Adopta un enfoque holístico/integral, donde todos los componentes y procesos de aprendizaje (cognitivo, afectivo y actitudinal) impliquen la EDH en todo el contexto educativo. Es decir, plasma la concepción filosófica, ética en la "realización de los derechos humanos en la educación", incluido planes de estudio, material didáctico, métodos pedagógicos, capacitación docente. Y para hacer valer el respeto de los derechos humanos de todos los miembros de la comunidad escolar, afectando las prácticas educativas.

- Los derechos humanos en la educación aportan contenido para el desarrollo de la sociedad y para profundizar la democracia. 
Se ha señalado cinco componentes a tener en cuenta para la real integración de la EDH en la educación formal:

1. Políticas educativas

2. Aplicación de las políticas

3. Entorno de Aprendizajes

4. Enseñanza y aprendizaje

5. Formación y perfeccionamiento profesional del personal docente.

La EDH multiplica los frutos del aprendizaje al promover una enseñanza y un aprendizaje basado en el niño, previendo la inclusión y participación de estos en la sociedad. Fomenta, de esta manera el acceso al proceso de escolarización y la participación en los niños y niñas, promueve entornos de aprendizaje incluyentes que propicien la igualdad de oportunidades, la diversidad y la no discriminación. Contribuye a la cohesión y a la prevención de los conflictos apoyando el desarrollo emocional y social de los niños y niñas $\mathrm{y}$, fomentando valores democráticos.

El Plan de Acción implica la adopción de una serie de medidas simultáneas en diversas esferas. Se prevén cuatro etapas en el proceso Nacional:

Etapa 1: estudio diagnóstico.

Etapa 2: planificación, establecer prioridades, elaborar estrategias tendientes a desarrollar: planes y programas Nacionales.

Etapa 3: aplicación y supervisión de los planes y programas nacionales.

Etapa 4: evaluación

En la segunda etapa del Programa Mundial (2010-2014), se enfatizan las acciones que profundizan la formación y capacitación docente. En la resolución 12/4 del Consejo de Derechos Humanos (octubre 2009), se centra la atención en "la EDH en la enseñanza superior y en los programas de capacitación sobre derechos humanos para maestros y educadores, funcionarios públicos, fuerzas del orden y personal militar a todos los niveles" sin descuidar que "los Estados miembros deben seguir impartiendo educación en materia de derechos humanos en la enseñanza primaria y secundaria". En consecuencia, es importante mantener y ampliar los programas de formación docente. Esto ya estaba delineado en la primera etapa del Programa para el personal docente de primaria y 
secundaria, mientras que en esta segunda etapa se introduce la formación de los docentes de enseñanza superior.

Se hace un señalamiento de trabajar con los "educadores" en el sentido amplio del término, haciendo referencia a las "personas que elaboran, desarrollan, aplican y evalúan actividades y programas de educación en derechos humanos en sectores formales, informales y no formales de la enseñanza."(A/HRC/15/28: 14)

La formación del personal docente debe ser integral, que no solo tenga en cuenta los contenidos temáticos de los planes de estudio, sino los procesos de enseñanza con método pedagógicos acordes a la EDH que incluye "los derechos humanos por conducto de la educación" y "los derechos humanos en la educación". Esto incluye la adopción de medidas en las cinco esferas:

a) Políticas y medidas de aplicación conexas

b) Procesos e instrumentos de enseñanza y aprendizaje

c) Investigación

d) El entorno del aprendizaje

e) Educación y perfeccionamiento profesional del personal docente de la enseñanza superior, lo cual abarca seis procesos:

1) Elaborar planes de los estudios;

2) Elaborar y utilizar metodologías de formación apropiadas;

3) Elaborar y difundir recursos y materiales de formación apropiados;

4) Establecer redes de contacto y cooperación entre los proveedores de educación y formación;

5) Promover intercambios;

6) Evaluar las actividades de formación en la materia. (A/HRC/15/28)

\subsection{3- La Declaración de las Naciones Unidas sobre educación y formación en materia de derechos humanos.}

La Asamblea General de la Naciones Unidas aprueba por unanimidad el 19 de diciembre de 2011, la Declaración de las Naciones Unidas sobre educación y formación en materia de derechos humanos (Resolución 66/137). 
Este documento ${ }^{34}$, si bien no es vinculante, consolida la EDH como un derecho en sí mismo y ratifica que esta debe ser accesible a todas las personas (artículo 1) reafirmando los principios de universalidad, indivisibilidad, interdependencia de los derechos humanos.

En su artículo 2 plantea la finalidad fundamental de esta tarea como "contribuir a la creación y promoción de una cultura universal de derecho humanos". En su numeral 2 establece los ejes fundamentales que le conciernen:

Artículo 2.2: la educación y la formación en materia de derechos humanos engloba: a) La educación sobre los derechos humanos, que incluye facilitar el conocimiento y la comprensión de las normas y principios de derechos humanos, los valores que los sostienen y los mecanismos que los protegen;

b) La educación por medio de los derechos humanos, que incluye aprender y enseñar respetando los derechos de los educadores y los educandos;

c) La educación para los derechos humanos, que incluye facultar a las personas para que disfruten de sus derechos y los ejerzan, y respeten y defiendan los de los demás. Del planteo de estos tres ejes se desprende que la educación en derechos humanos alude a contenidos, a metodologías y prácticas tanto de aula como institucionales.-

Plantea la EDH como un proceso a lo largo de toda la vida y que afecta a todas las edades, y las etapas del sistema educativo (artículo 3) (inicial, primaria, hasta superior). Asimismo considera la educación formal, informal y no formal de los sectores públicos y privados. Incluye también la formación de profesionales, de funcionarios públicos y, especialmente formación de formadores (personal docentes y educadores en general). Destaca la característica de adaptabilidad de la EDH en sus métodos de enseñanza (Artículo: 3,3)

Esta Declaración reafirma los principios de los derechos humanos como las características que tiene que tener la EDH, recogidas del derecho a la educación definidas en la Observación General $\mathrm{N}^{\circ} 13$ del Comité DESC (disponibilidad, accesibilidad, aceptabilidad, adaptabilidad). Destaca los principios de igualdad y no discriminación en el acceso a la EDH, así como el fomentar el empoderamiento de las personas y grupos en situación de vulnerabilidad como forma de combatir las exclusiones sociales (artículo 5).

\footnotetext{
34 Declaración de la Naciones Unidad sobre educación y formación en materia de derechos humanos. Resolución 66/137 del 19 de diciembre de 2011. A/RES/66/137.
} 
Los Estados son responsables de promover y garantizar la EDH con criterios de participación, inclusión y responsabilidad (artículo 7) a todos los sectores de la sociedad. Se pone especial importancia en la formación a los funcionarios públicos, los diferentes agentes de justicia y de seguridad, tanto militar como policial, así como "promover la formación adecuada en derechos humanos de maestros, instructores y otros educadores y personal privado que desempeñen funciones a cuenta del Estado.” (artículo: 7,4)

Dentro de las acciones recomendadas está la de ajustar y formular estrategias políticas, y programáticas para integrar adecuadamente la EDH, recordando los compromisos del Plan Mundial para la EDH en la elaboración de programas y planes nacionales (artículo 8).

\section{4- La EDH, un enfoque de transformación socio-cultural.}

..."la cultura está estructurada en tarno a relaciones saciales y redes camunicacionales. Supane la canjunción de distintas elementas que confarman una visión del munda, del entarno, de la naturaleza y de los demás. Una determinada manera de interpretar la producción de conacimienta. El recanacimienta a la negación de las propias patencialidades. La construcción de una identidad, ligada a valores, tradiciones y a una historia compartida. En este sentida, la cultura es una matriz generadara

de compartamientas, actitudes, valores, códigos de lenguaje, hábitas y relaciones saciales. En ella se reproducen las relaciones de daminación-dependencia vigentes en la saciedad en que vivimas. Pero es en ella donde puede camenzar a gestarse nuevas alternativas." Jasé Luis REBELLATO (1996).

En el Derecho Internacional de los Derechos Humanos, en la órbita del Sistema Universal $(\mathrm{ONU})$ como en el ámbito Interamericano (OEA), existe una coincidencia de criterios con respecto al derecho a la educación y a la educación en derechos humanos (Claude, 2005). Así como en el artículo 26.2 de la Declaración Universal de Derechos Humanos, en el "Protocolo Adicional a la Convención Americana sobre derechos humanos en materia de derechos económicos, sociales y culturales", el "Protocolo de San Salvador"35, en su artículo 13.2, se explicita la finalidad que debe tener la educación.

“... la educación deberá orientarse hacia el pleno desarrollo de la personalidad humana y del sentido de su dignidad y deberá fortalecer el respeto por los derechos humanos, el pluralismo ideológico, las libertades fundamentales, la justicia y la paz. ... la educación debe capacitar a todas las personas para participar efectivamente en

35 Protocolo adicional a la Convención Americana sobre derechos humanos en materia de derechos económicos, sociales y culturales. (OEA, 1989) PROTOCOLO DE SAN SALVADOR. 
una sociedad democrática y pluralista, lograr una subsistencia digna, favorecer la comprensión, la tolerancia y la amistad entre todas las naciones y todos los grupo raciales, étnicos o religiosos y promover las actividades a favor del mantenimiento de la paz."

Entendida así, el recibir una educación sistemática, de calidad, que permita a todas y cada una de las personas comprender los derechos humanos desde la dimensión de respeto mutuo para una convivencia responsable con la dignidad propia y la de las otras personas, grupos y pueblos implica asumir a la EDH como un derecho humano en sí mismo.

Esta concepción ubica al sistema de educación formal y en especial a la etapa de educación primaria, en un lugar de importancia para la promoción, prevención y realización de los derechos humanos. Ya que la obligación del Estado es generar una política pública educativa con acceso universal a todos los niños y niñas en edad escolar ${ }^{36}$, se hace relevante esta prestación de enseñanza con un enfoque de EDH.

Se puede entonces definir por todo lo antedicho que... "La educación en derechos humanos es en sí misma un derecho, que hace parte del contenido del derecho a la educación y es condición necesaria para el ejercicio activo de todos los derechos humanos" (IIDH, 2006:12).

La incorporación de la EDH con sus objetivos, principios y contenidos a la educación formal es una medida fundamental que aporta, profundiza y consolida una cultura de respeto a la dignidad humana, apostando a sociedades democráticas, con justicia social, respeto por la diversidad, promoción de la igualdad y tolerancia en el ejercicio de la ciudadanía.

La EDH es considerada como "un proceso de adquisición de determinados conocimientos, valores, actitudes y comportamientos necesarios para conocer, comprender, afirmar y reivindicar los propios derechos sobre la base de las normas dispuestas en los distintos instrumentos internacionales en conexión con la normativa interna."(IIDH. 2007: 28 y 29). Los procesos educativos enmarcados desde este enfoque deben ser comprendidos como integrales u holísticos (Magendzo, 2008, 2009), involucrando el área cognitiva, afectiva y actitudinal (Rodino, 1999, 2003, 2010).

36 Articulo 13 y 14 del Pacto Internacional de Derechos Económicos, Sociales y Culturales, ONU, 1966. 
Es así que la EDH cobra fuerza como un derecho en sí misma con un doble sentido, conteniendo una concepción del ser humano y de una forma de relacionarse entre las personas, y como prácticas concretas de convivencia respetuosa (Pérez Aguirrez, 1999). Esto quiere decir que la EDH implica una acción que incluye o contiene la finalidad de que se educa en y para los derechos humanos (Magendzo, 2008, 2009). Es decir educar en la filosofía de los derechos humanos y también para generar prácticas sociales y educativas donde se respete la dignidad de todas las personas involucradas (Rodino, 1999, 2003, 2010).

Ubica a la EDH en una propuesta de construcción y promoción de una nueva cultura ética, política, la cultura de los derechos humanos. Su fundamento se encuentra en el pensamiento crítico y una praxis comprometida (Juanche, 2013).

\subsection{La EDH, herramienta que construye sentidos}

"Las derechas humanas san un fenámena complejo y dinámica -en su cancepción y en su realización- que está en el centro del problema tanta ética cama política, y jurídica, y que reclama transfarmaciones profundas a las saciedades."

IIDH (2006)

La educación es un área de construcción de sentidos sociales y culturales, así como de prácticas sociales legitimadas. A su vez, la EDH contextualiza a los derechos humanos (IIDH, 2006) como una herramienta de emancipación. Esto permite que los derechos humanos se alejen de ideas abstractas y ajenas a las realidades vividas (Herrera Flores, 2005) por las personas. Entonces la EDH permite una acción como agente de cambio social a favor de la dignidad humana.

La EDH involucra los conocimientos, los valores y actitudes y habilidades o capacidades para la acción (IIDH, 2006, 2007, 2008, 2009, 2010) que se deberían desarrollar en los sujetos y las sociedades, para favorecer una convivencia en permanente dialogo entre individuos, grupos y pueblos.

Pero también hay que reconocer que en la sociedad existen otras concepciones y formas de entender la educación (Mosca-Pérez Aguirre, 1985), como ser la transmisión de información, la reproducción de la hegemonía dominante y el control social, entre otras. 
Estos conflictos y tensiones que representan las contradicciones entre visiones diferentes sobre la realidad son parte de todo proceso de desarrollo y evolución de las sociedades. Por lo tanto es importante no negarlas sino asumirlas, ponerlas a dialogar, como una característica humana. Estas contradicciones están presentes en las prácticas educativas de los y las docentes (Magendzo, 2008, 2009) de forma consciente o inconsciente. Se transmiten a través de los valores y actitudes de las personas, más allá de los contenidos explícitos desarrollados en los programas, currículos o leyes, (IIDH, 2006, 2007, 2008, 2009) que rigen la educación pública establecida por el Estado.

Los modelos y las pautas de conductas representan los valores e ideas que transmitimos en nuestra forma de relacionarnos con los demás y con las cosas. Por eso es importante la formación de los y las docentes en materia de análisis crítico de las realidades y de sus actitudes y acciones (Freire, 1990, 1996) acordes con los principios y valores de los derechos humanos.

Al reconocer la complejidad y contradicciones de la vida social se entiende entonces que existen otros actores importantes en la EDH que no son parte del sistema educativo formal. Estos tienen un gran valor en transmitir modelos y actitudes acordes a los principios de los derechos humanos o no. Entre ellos están, por ejemplo, la familia, los medios de comunicación y otros agentes sociales y políticos. (IIDH, 2006)

Todo se expresa y manifiesta en el desarrollo de las sociedades. Es parte del movimiento social, de su devenir en las comunidades, los lugares que ocupamos, los roles, cómo se van procesando las tensiones y los conflictos, lo que va marcando el progreso y evolución social. Pero el poder identificar las incoherencias, los elementos que representan dificultades a través de análisis crítico, de la reflexión y autoreflexión es lo que va a permitir asumir el problema, identificar las posibilidades de diálogo y delinear estrategias de resolución (Freire, 1990, 1996).

Se aprecia cómo las diferentes dimensiones de la EDH trascienden el espacio-tiempo de la escuela, para darle sentido a otros procesos de desarrollo personal y social de los individuos.

“... Así pues, los valores que se inculcan en el proceso educativo no deben socavar, sino consolidar, los esfuerzos destinados a promover el disfrute de otros derechos. En esto se incluyen no sólo los elementos integrantes del plan de estudios, sino también los procesos de enseñanza, los métodos pedagógicos y el marco en el que se imparte la educación, ya sea en el hogar, en la escuela u otros ámbitos. Los niños 
no pierden sus derechos humanos al salir de la escuela." (CRC/GC/2001/1, párrafo 8) 37

Desde la EDH se plantea el poder que tiene la escuela, espacio de acceso universal de todos las niñas y niños, como lugar de formación de sujetos de derecho, que puedan aprender desde modelos y actitudes basados en los valores y principios de los derechos humanos. Así se trabajará por desarrollar sociedades donde la dignidad humana sea un valor fundamental en las relaciones entre las personas y sus contextos. El desarrollar capacidades críticas, comunicativas, cooperativas y solidarias permitirá pensar y analizar los contextos y realidades sociales en que la niñez vive para actuar sobre ellos. Los procesos de auto-reflexión y de autoevaluación permitirán la toma de decisiones responsables enmarcadas en la democracia y la ética de los derechos humanos.

Esto requiere metodologías de enseñanzas coherentes con los valores, objetivos y principios de los derechos humanos, que atraviesen todo el ámbito educativo, desde lo que se enseña como contenido, las relaciones, los vínculos y los climas que se desarrollan en los espacios institucionales hasta la concepción y gestión propia de todos los espacios educativos.

\section{2- La EDH: paradigma ético que conlleva una disciplina integral y compleja.}

...estamas mucha más allá del tema de la mera infarmación y la 'instrucción' sabre las derechus humanas. Quizás sea más accesible, aunque nunca fácil, trasmitir infarmación sobre ellos, su histaria, el contenida de la Declaración Universal, las

Convenciones... Pero educar es atra cosa. Educar es modificar las actitudes y las conductas. Es afectar las corazones, los estilas de vida, las convicciones. Y es evidente que esta no puede hacerse sino en el sentida de las actitudes del propio educadar. No podemas cancebir el praceso educativo más que camo una especie de empatía, de mímesis de actitudes entre ambas sujetos del praceso educativo. Y esta me lleva a saspechar que

educación siempre será una tarea de carácter ético o no será.

Luis "PERICD" PÉREZ AEUIRRE

El Instituto Interamericano de Derechos $\operatorname{Humanos}^{38}$ (IIDH) en su amplia trayectoria e investigación sobre el tema, plantea pensar la EDH hoy en el cruce de varias dimensiones:

\footnotetext{
37 NACIONES UNIDAS, Comité de los Derechos del Niño, Observación general $\mathbf{N}^{\circ} \mathbf{1}, \mathbf{2 0 0 1}$,
} CRC/GC/2001/1, párrafo 8 
- dimensión filosófica: en un sentido estricto se refiere a los principios y fundamentos éticos de los derechos humanos $\mathrm{y}$, en un sentido amplio, a las representaciones culturales que permiten la práctica social, la concepción sobre los seres humanos y sus formas de relacionarse, y el valor de la dignidad humana;

- dimensión socio-política: la organización social, económica y de la distribución del poder en los grupos, que genera y permite las condiciones para la efectividad de los derechos humanos;

- dimensión jurídica: la normativa para la defensa, legitimación de los derechos en el ámbito público, las adecuadas legislaciones que permitan una tarea educativa acorde;

- dimensión de los procesos históricos: esta dimensión atraviesa las otras tres y permite comprender los derechos humanos "como una conquista de los seres humanos a lo largo de la historia de la humanidad y un proceso de construcción social" (IIDH, 2006:18-19).

Es en la conjunción de estas diferentes dimensiones que podemos generar los procesos de comprensión de los contextos sociales para un cabal entendimiento de las luchas por la defensa, la promoción y la protección de los derechos humanos. Y a su vez, nos permite ubicar los elementos necesarios para pensar y desarrollar una acción transformadora de las realidades sociales en que vivimos para generar las condiciones necesarias donde la EDH sea una herramienta eficaz de desarrollo de sociedades más justas y democráticas.

\subsection{1-Una mención al pensamiento complejo de Edgar Morin: la "religazón" de los saberes.}

La propuesta de Edgar Morin sobre la articulación de los saberes nos permite problematizar cómo la tradición de enseñanza en la escuela, de contenidos y de disciplinas aisladas entre sí, refuerza el mecanismo de separación de saberes, de parcelamiento del conocimiento y constituye una forma de pensar y de actuar que no favorece la integración. Para este autor la importancia de aprender a contextualizar, a situar al conocimiento dentro de un conjunto organizado, permite entender las interacciones que unen al conocimiento con su contexto. Buscar las relaciones que unen los opuestos, las contradicciones, para encontrar en la diferencia, en la unidad. (Morin, 1998).

$38 \quad$ Creado en 1980 por un convenio entre la Corte Interamericana de Derechos Humanos y la República de Costa Rica, el IIDH es una entidad internacional autónoma, académica, dedicada a la enseñanza, investigación y promoción de los derechos humanos. http://www.iidh.ed.cr/ 
“...Es la coherencia del pensamiento complejo la que contiene a la diversidad y permite comprenderla... Pienso que esta misión aprenderá a religar, a problematizar, es un retorno a una misión fundamental...Agrego que esta es una tarea vital, en ella va la posibilidad de regenerar la cultura por la religazón de dos

culturas separadas, la de las ciencias y la de las humanidades.” (Morin, 1998:66)

Es en la propuesta de un pensamiento complejo, que tenga en cuenta la multidimencionalidad y la organización de las relaciones reciprocas entre el todo y las partes, donde se pueden considerar entonces los contextos, las condiciones reales, del fenómeno a estudiar. El paradigma de la complejidad que propone Edgar Morin está fundado en la distinción, la conjunción y la implicancia mutua, pero reconoce su carácter incompleto, por lo cual es necesario generar una acción dialógica para negociar con la incertidumbre y producir el cambio (Morin, 1998).

Este planteo, al unirse con la EDH, intenta dar cabida al acto educativo como fenómeno humano (Freire, 1990, 1996) para pensar a las personas como individuos productos y productores de las sociedades. La propuesta del pensamiento complejo pone al alcance los elementos para comprendernos y comprender el mundo, no de forma cerrada, acabada, sino abierta, incierta, incompleta, con la capacidad de transformación.

La EDH propone una mirada compleja e integral del ser humano, a diferencia de la concepción educativa tradicional que viene de la racionalidad instrumental, y de una visión fragmentada del individuo. (Juanche, 2013). La persona humana entendida en sus múltiples dimensiones, se va transformando de forma dialéctica en un permanente cambio con los otros y con los contextos. Un movimiento constante que se crea, se recrea en los sujetos, en las relaciones de estos y se desarrolla, se transforma en los procesos históricos (Freire, 1990, 1996).

\subsection{2- Fines y contenidos de la EDH.}

La EDH viene realizando un recorrido como disciplina compleja, intentando dar respuestas teóricas y metodológicas a los desafíos que implica la promoción y el respeto de los derechos humanos en general en los ámbitos de convivencia y en particular en los ámbitos educativos, tanto formales como no formales.

Fines de la educación en derechos humanos 


\begin{tabular}{|l|l|}
\hline Éticos & $\begin{array}{l}\text { Formar en los valores de naturaleza universal que sustentan la } \\
\text { dignidad y derechos de la persona. }\end{array}$ \\
\hline Críticos & $\begin{array}{l}\text { Formar en la capacidad de análisis y evaluación de la realidad } \\
\text { con los parámetros valóricos y normativos de los derechos } \\
\text { humanos. Es decir, formar a los sujetos para el juicio crítico de } \\
\text { sí mismos y de sus contextos de acción - desde los más } \\
\text { cercanos e inmediatos hasta los más distantes y mediatos -. }\end{array}$ \\
\hline Políticos & $\begin{array}{l}\text { Formar en el compromiso activo por modificar los aspectos de la } \\
\text { realidad -de orden individual o social- que impiden la } \\
\text { realización efectiva de los derechos humanos. } \\
\text { Es decir, formar para concebir los cambios sociales necesarios y } \\
\text { para hacerlos realidad. }\end{array}$ \\
\hline
\end{tabular}

Material extraído de: "Propuesta curricular y metodológica para la incorporación de la educación en derechos humanos en la educación formal de niños y niñas entre 10 y 14 años de edad". Publicado por Instituto Interamericano de Derechos Humanos (2006) San José de Costa Rica.pág.22

Desde este lugar entendemos que los sistemas de educación formal que organizan y llevan adelante los Estados son una herramienta privilegiada para dar cumplimiento al derecho a la Educación y al derecho a la EDH, sin que esto signifique negar el rol que también puede cumplir la educación no formal en esta materia. A su vez los programas y currículos son documentos explícitos donde podemos encontrar plasmadas las iniciativas políticas de los Estados para los diferentes niveles educativos.

Sin embargo, para una cabal puesta en práctica de las finalidades del derecho a la EDH, se tiene que tener en cuenta complementariamente la metodología aplicada por el cuerpo docente. En la dimensión metodológica se pone en juego la coherencia entre los elementos teóricos y las prácticas concretas, haciendo foco en las relaciones de poder entre los diferentes roles de los actores del sistema educativo. Se involucran, simultáneamente, los fenómenos de relación entre las personas y los saberes, núcleo central del proceso de enseñanza-aprendizaje. Para la EDH la metodología debe implicar tres niveles simultáneos y complementarios: los conocimientos específicos sobre los derechos humanos; los valores y actitudes coherentes con los derechos humanos y las competencias o habilidades para la acción en defensa y promoción de esos derechos (Rodino, 2003; IIDH, 2006).

\section{Macro-contenidos de la educación en derechos humanos}

\begin{tabular}{|l|l|l|}
\hline $\begin{array}{l}\text { Información } \\
\text { y conocimientos }\end{array}$ & $\begin{array}{l}\text { Valores } \\
\text { y actitudes }\end{array}$ & $\begin{array}{l}\text { Destrezas o capacidades } \\
\text { para la acción }\end{array}$ \\
\hline $\begin{array}{l}\text { Enseñanza del manejo } \\
\text { comprensivo de: }\end{array}$ & $\begin{array}{l}\text { Formación en la apreciación y } \\
\text { disposición a actuar conforme }\end{array}$ & $\begin{array}{l}\text { Desarrollo de competencias } \\
\text { necesarias para el ejercicio }\end{array}$ \\
\hline
\end{tabular}




\begin{tabular}{|c|c|c|}
\hline $\begin{array}{l}\text { Conceptos: categorías de } \\
\text { análisis, principios, estándares, } \\
\text { lógica de la argumentación, } \\
\text { debate de posiciones } \\
\text { ideológicas, etc. } \\
\text { Historia: origen, evolución y } \\
\text { sucesos significativos para el } \\
\text { reconocimiento y la vigencia -o } \\
\text { la violación- de los derechos } \\
\text { humanos, la democracia y el } \\
\text { Estado de Derecho en el mundo, } \\
\text { la región y el país: contexto, } \\
\text { antecedentes, influencias, } \\
\text { protagonistas, resultados, } \\
\text { efectos, trascendencia, etc. } \\
\text { Normas: instrumentos de } \\
\text { derechos humanos, documentos } \\
\text { internacionales } \\
\text { y regionales de distinta } \\
\text { naturaleza y efecto jurídico, } \\
\text { legislación nacional, etc. } \\
\text { Instituciones : instancias de } \\
\text { protección de derechos - } \\
\text { nacionales, regionales y } \\
\text { universales -, estructura, función, } \\
\text { procedimientos, etc. }\end{array}$ & $\begin{array}{l}\text { los principios universales que } \\
\text { sustentan la dignidad y derechos } \\
\text { de las personas. } \\
\text { El núcleo central de valores se } \\
\text { expresa en los instrumentos de } \\
\text { derechos } \\
\text { humanos acordados por la } \\
\text { comunidad internacional: } \\
\text { - Vida e integridad personal } \\
\text { - Dignidad humana } \\
\text { - Identidad } \\
\text { - Libertad y responsabilidad } \\
\text { - Igualdad y no discriminación } \\
\text { - Justicia y equidad } \\
\text { - Solidaridad y cooperación } \\
\text { - Participación } \\
\text { - Pluralismo } \\
\text { - Desarrollo humano } \\
\text { - Paz } \\
\text { - Seguridad }\end{array}$ & $\begin{array}{l}\text { pleno de los derechos } \\
\text { humanos y la práctica de la } \\
\text { democracia: } \\
\text { - Para el pensamiento crítico } \\
\text { - Para la comunicación y la } \\
\text { argumentación eficaz } \\
\text { - Para la participación y el } \\
\text { trabajo cooperativo }\end{array}$ \\
\hline
\end{tabular}

Material extraído de: "Propuesta curricular y metodológica para la incorporación de la educación en derechos humanos en la educación formal de niños y niñas entre 10 y 14 años de edad". Publicado por Instituto Interamericano de Derechos Humanos (2006) San José de Costa Rica. Pág. 25.

Los derechos humanos como objetivo y como contenido de respeto a la dignidad de las personas son un marco valórico para la convivencia, es decir un referente indispensable en la organización de la cultura escolar, de la vida de los centros educativo. Esto hace a las manifestaciones del currículo oculto o implícito que se pone en juego en la cotidianeidad del centro educativo de forma consciente o inconsciente, dando mensajes y ejemplos que hacen al respeto o a la vulneración de los derechos humanos. Pero también los derechos humanos tienen que aparecer en el currículo explícito o manifiesto, es decir en el programa donde aparecen las diferentes disciplinas y sus contenidos de estudio (IIDH, 2006).

\subsection{3- La EDH plantea como central el fenómeno de relación humana.}

Es así que la EDH está vinculada por sus contenidos, temas y objetivos en la totalidad del ámbito educativo (Magendzo, 2008), siendo sensible tanto al currículo manifiesto en las 
diferentes asignaturas y al currículo oculto que es referente de la cultura escolar (IIDH, 2006, 2008). Es en la interrelación de estas dimensiones donde se concretiza la coherencia y genera la fuerza de la EDH como elemento de transformación social en la promoción y efectivización del respeto de los derechos humanos. Es una fuerza que da jerarquía al fenómeno humano de la comunicación y pone en el centro de la cuestión la relación educando-educador (Freire, 1990, 1996).

Así el acto educativo ya no es solo información a ser transmitida o actitudes a ser imitadas, sino implica la actividad humana del encuentro con un otro, que nos afecta, que nos conmueve y nos interpela en nuestro accionar (Pérez Aguirre, 1991). Redefine los diferentes roles de la educación y problematiza los aprendizajes en juego donde los derechos humanos nos instan cada vez a actuar con más coherencia, a ser más humanos.

Los centros educativos representan desde su función social espacios donde se transmiten los valores que una sociedad seleccionó o excluyó de forma particular. Se expresan en la forma de conocimientos que se priorizan, en los usos del lenguaje que se desarrollan y en la relaciones sociales que en ellos se practican.

Las escuelas introducen y legitiman formas particulares de la vida social (Giroux, 2001). Y ahí aparecen reveladas las diferentes tendencias políticas y de relaciones de poder, plasmadas en " ...formas de autoridad, tipos de conocimientos, regulación moral e interpretaciones del pasado y del futuro deberían ser legitimadas y transmitidas a los estudiantes" (Giroux, 2001:65).

Entonces interesa plantear la importancia de no concebir a las escuelas como espacios neutrales, así como tampoco las posturas de los y las docentes. Porque ellos representan determinados significados de la ideología y de la ética social, así como de las relaciones de poder que se dan en la sociedad.

Al decir de Rosa María Mujica:

"Para ser educadores en derechos humanos y en democracia no basta que tengamos ideas claras o conocimientos teóricos sobre estos temas: es fundamental que, afectivamente, nos sintamos convencidos de su utilidad para la construcción de una sociedad más humana, y nos comprometamos afectivamente con ella. Podemos afirmar que la propuesta de educar en derechos humanos y en democracia será real, cuando los educadores interioricemos y asumamos -intelectual y emocionalmentesu necesidad e importancia”. (Mujica. 2002) 
La integralidad se representa no solamente en el ámbito educativo, sino también involucra a la figura y personalidad de los y las docentes, dando un lugar privilegiado a cómo se encara la práctica educativa. En cuanto práctica social y humana está cargada de intencionalidad, de sentido y, por lo tanto, de transformación social (Freire. 1990; 1996).

Es importante pensar el espacio de lo educativo como un espacio que garantice la justicia, la igualdad en derechos y accesos a los mismos, que nos interpele constantemente sobre cómo estamos llevando adelante la participación. Donde la comunicación efectiva sea un dispositivo que permita construir nuevas formas de relaciones. La relación educativa conlleva una asimetría de roles y de responsabilidades, pero no debe confundirse por esto con el control y la sumisión. Porque como en toda relación, el diálogo tiene que estar basado en la igualdad, en la dignidad de sus interlocutores y en la acción de entendimiento mutuo y de respeto por las diferencias.

Es en la inserción profesional dentro del ámbito educativo que se pueden buscar las articulaciones que dan sentido a esa acción, dentro de la dialéctica entre lo que es y lo que debería ser.

“Articular es, también, encontrar puntos de fusión, tejer redes y animarlas sin ahogarlas. La articulación produce estructuras a partir de las redes y no restringe las redes desde estructuras ya preconcebidas. Articular es respetar la diversidad y compartir las experiencias que suponen construcción de nuevas relaciones y de nuevos valores éticos" (Rebellato, 1997: 13)

Es en esta dialéctica, entre lo viejo y lo que está por construirse, sin negar la tensión que esto conlleva, que se construye la vida dentro de la comunidad, dentro de la comunidad educativa. Una vida que plantea una apuesta, que implica asumir riesgos, riesgos personales y riesgos colectivos. El riesgo de transformarnos constantemente, de dejarnos afectar por los otros, y en ese devenir convertirnos en lo inesperado.

Así los procesos de derechos humanos planteados desde una concepción compleja, crítica y holística, son visualizados como universales e inalienables, en una interrelación de interdependencia e indivisibles. Las tensiones de igualdad y desigualdad entre los derechos cobran estas características mencionadas, que se ven reflejadas y resignificadas en los proceso históricos de las diferentes luchas sociales por la dignidad humana de forma dialéctica y conflictiva. 
Es fundamental poder generar un análisis y tratamiento de los mismos para transformar estas situaciones conflictivas en nuevas formas de relacionamiento de sus diferentes componentes y dinámicas. Hay que promover la creación de nuevas formas de estar en el mundo, más justas y dignas, en acuerdo al enfoque de los derechos humanos. Esto implica tratar seria y complejamente la dimensión del poder, que atraviesa todo relacionamiento humano, formando las subjetividades (contextualizadas en un espacio- tiempo) y producir nuevos sentidos y significados en las situaciones asimétricas que se dan en las relaciones de poder.

El tener una mirada crítica a la dimensión subjetiva de las relaciones de poder desde un enfoque de EDH requiere no solo ser sujeto de derecho sino sentirse y sentir al otro como sujeto de derecho. Esto debería replantear el quehacer educativo, ¿Cómo concebimos el proceso de aprendizaje? ¿Qué entendemos por disciplina? ¿Qué evaluamos y cómo? Se nos replantea el lugar del conflicto en el ámbito educativo.

Trabajar los derechos humanos en la escuela implica una tarea de problematizar el ámbito educativo desde lo conceptual y también desde lo metodológico. Trabajar el conflicto es una tarea ineludible que nos lleva a visualizar las tensiones en diferentes dimensiones, desde el orden de los valores y desde las experiencias en la realidad. Esto permite identificar un componente importante de la EDH, el componente vivencial.

El conocimiento y enseñanza de los valores no es discursivo, sino que implica el enunciado y su concreción en la práctica de parte de quien los expresa. De ahí la importancia del modelo que significa el docente. “...de allí que su aprendizaje y su enseñanza constituya un verdadero desafio intelectual y emocional (en fin, vital) para todos los participantes del proceso educativo. Y un desafio cotidiano" (Rodino, 1999: 8)

Es desde este lugar, del desafío de sostener en la cotidianeidad la relación entre ética discursiva y la experiencia vivida, que planteamos la coherencia de la práctica educativa. ¿Qué tan coherentes somos en nuestras actitudes y conductas, con nosotros mismos y con los otros de acuerdo a los principios de derechos humanos?

Porque desde una comprensión coherente y multidimensional de los derechos humanos, es importante tener en cuenta las referencias de lo universal, sin perder de vista lo local. Comprender los procesos colectivos así como los individuales y no concebir el mundo público separado de lo privado. (Rodino, 1999) 
"La repugnancia moral que nos provocan violaciones flagrantes conocidas internacionalmente (practicas de esclavitud, tortura, desapariciones de personas, genocidio étnico, o represión política) no debe impedirnos ver también aquellas otras, menos espectaculares o divulgadas, que ocurren en nuestro entorno cercanos (prácticas de manipulación, corrupción, adoctrinamiento, exclusión, prejuicios, discriminación, irrespeto a la identidad y necesidades de otros). Tampoco la crítica necesaria a las injusticias sociales pueden distraernos del examen de nuestra propia conducta en los espacios del hogar, la comunidad, el lugar de trabajo, la escuela..." (Rodino, 1999: 8)

Es así que aparece como un elemento necesario y central desde el enfoque de la EDH, tener en cuenta la coherencia interna del docente, del educador para que desde un proceso de formación constante e integral se vayan desarrollando aptitudes, habilidades y cualidades, que van desde el orden de lo ético, lo sensible, lo comunicacional, lo pro-activo y cooperativo dando forma a lo humano.

\section{CAPITULO III: MARCO CONTEXTUAL}

\section{EVOLUCIÓN HISTÓRICA Y NORMATIVA DE LA EDUCACIÓN PÚBLICA EN EL URUGUAY.}

Este capítulo desarrolla y contextualiza históricamente algunos aspectos que hacen a cómo se plantea el Derecho a la Educación en el Uruguay, a fin de entender cómo ha sido concebido el sistema educativo en nuestro país, desde su fundación a fines del siglo XIX, hasta llegar a nuestros días. Esto significa la puesta en acción de las diversas maneras de concebir al sistema educativo desde las ideologías dominantes en los diferentes momentos históricos, tal como quedaron plasmados en los documentos normativos de cada época.

El intento de contextualizar los procesos histórico-sociales en torno a los momentos políticos y la normativa correspondiente hacen a la comprensión de la función social del ámbito educativo y a la función del rol docente en cada uno de estos momentos. Es ahí donde podemos analizar más concretamente las diferentes relaciones que existen entre la órbita educativa formal específica, el desempeño del rol docente y su imaginario simbólico en relación con la sociedad en general. 
El primer objetivo del Capítulo es mostrar en qué contexto se introduce la EDH en Uruguay, para poder explicar su aplicación en la actualidad. Desde donde se la entiende, se la defiende y reivindica, o se la resiste.

\section{1-URUGUAY: Contexto normativo.}

"La idea de educar al puebla, hacienda que la educación alcance a tadas las miembras de la comunidad, sin distinción de clases ni posiciones, de nombres ni de fortuna, es una idea esencialmente demacrática, ya que presupane la igualdad ariginaria del hambre, y que, si na explííita, implícitamente revela la tendencia de recanacerle las mismas derechas"

El derecho a la educación está regido en la Republica Oriental del Uruguay por la Constitución de la República de 1967, vigente hasta nuestros días, y está basado en el respeto de los derechos humanos reconocidos por nuestro derecho interno. O sea, desde un inicio está regido por el principio de constitucionalidad.

La Constitución Nacional consagra a la educación como un derecho fundamental. Este está reglamentado por la intervención del Estado, el cual garantiza la libertad de enseñanza, y el derecho de elección de los padres sobre la educación de sus hijos (artículo 68) y defiende la importancia de que la educación no sea monopolio del Estado (artículo 69), garantizando a particulares la libertad de establecer centros educativos.

Sus características de bien común universal, están reguladas por los principios de obligatoriedad, de responsabilidad de parte de las autoridades públicas (artículo 70), por la gratuidad (artículo 71) y la laicidad (artículo 5).

Así queda enunciada una de las grandes finalidades de formación moral y cívica de la educación pública:

Artículo 71: "Declárase de utilidad social la gratuidad de la enseñanza oficial primaria, media, superior, industrial y artística y de la educación física; la creación de becas de perfeccionamiento y especialización cultural, científica y obrera, y el establecimiento de bibliotecas populares. En todas las instituciones docentes se atenderá especialmente la formación del carácter moral y cívico de los alumnos" 
Es de destacar que el Uruguay es un Estado laico (artículo 5). El principio de laicidad fue $\mathrm{y}$ es un valor reivindicado por la sociedad uruguaya para la educación pública, vinculándose con la libertad de expresión del pensamiento (art. 29). Esto se relaciona con la pluralidad, el respeto y la tolerancia de ideas diferentes en el desarrollo de la sociedad y la democracia.

\section{1-Principio de autonomía en la educación pública del Uruguay.}

En el Uruguay, ya desde la Constitución de 1918, en el artículo 100, se reconocen diferentes organismos autónomos, denominados "Entes Autónomo" que se encargan de administrar los servicios del Estado de dominio industrial, comercial y también la enseñanza pública (primaria, secundaria, superior, industrial y artística). De modo que la administración de la educación pública en sus diferentes niveles queda desligada del entonces Ministerio de Justicia e Instrucción Pública, y desconcentrada en diferentes órganos de conducción para sus respectivos dominios: el Consejo de Educación PrimariaCEP; el Consejo de Educación Secundaria-CES; la Universidad del Trabajo del UruguayUTU y la Universidad de la Republica UdelaR-Educación Superior. Es en este periodo que se da la separación de la Iglesia del Estado y se concreta el ideal del pensamiento Vareliano $^{39}$ de laicidad en la escuela.

En la Constitución de 1952 se ratifica la autonomía de los Entes de enseñanza. En octubre de 1958 se promulga la Ley Orgánica $N^{o}$ 12.549, de la Universidad de la Republica (UdelaR) que concreta la total autonomía técnica, financiera y administrativa de esta institución universitaria (Badaracco, 2008).

El principio de autonomía de la educación pública en el Uruguay, otorgado por la constitución, es un rasgo distintivo que caracteriza nuestro sistema educativo. Se le quiso imprimir desde un principio un grado de neutralidad a las políticas de los gobiernos de turno, enmarcándolo en una política de Estado (Badaracco, 2008).

\footnotetext{
39 José Pedro Varela, (1845-1879) considerado fundador de la Escuela pública uruguaya, lleva a cabo la primera gran reforma de la educación (1876, gobierno de facto de Gral. Latorre) bajo las ideas liberales de progreso, orden civilizador, laicidad y democracia.
} 
En la Constitución vigente de 1967, en su Capítulo II, artículo 202 y siguientes, se encuentran las disposiciones de funcionamiento de la educación pública:

Artículo 202.- La Enseñanza Pública Superior, Secundaria, Primaria, Normal, Industrial y Artística, serán regidas por uno o más Consejos Directivos Autónomos.

Los demás servicios docentes del Estado, también estarán a cargo de Consejos Directivos Autónomos, cuando la ley lo determine por dos tercios de votos del total de componentes de cada Cámara.

Los Entes de Enseñanza Pública serán oídos, con fines de asesoramiento, en la elaboración de las leyes relativas a sus servicios, por las Comisiones Parlamentarias. Cada Cámara podrá fijar plazos para que aquéllos se expidan. La ley dispondrá la coordinación de la enseñanza.

Artículo 203.- Los Consejos Directivos de los servicios docentes serán designados o electos en la forma que establezca la ley sancionada por la mayoría absoluta de votos del total de componentes de cada Cámara.

El Consejo Directivo de la Universidad de la República será designado por los órganos que la integran, y los Consejos de sus órganos serán electos por docentes, estudiantes y egresados, conforme a lo que establezca la ley sancionada por la mayoría determinada en el inciso anterior.

Para el maestro Miguel Soler Roca ${ }^{40}$, el equilibrio que debe alcanzar la educación pública con el principio de autonomía deviene de la responsabilidad y buenos criterios del ejercicio de poder asignado a los Consejos Autónomos, cuyos miembros provienen tanto del Poder Ejecutivo como del Legislativo, y del interés y preocupaciones de la comunidad educativa y de toda la sociedad en general, representado por el Estado en la vigencia y cumplimientos de la ley de educación.

"Principio de autonomía. Respaldado por una larga tradición de luchas, éxitos y violaciones, este principio está claramente enunciado en el Art. $202^{\circ}$ de la Constitución actual. De hecho, conforme a lo que éste prescribe, toda la educación pública oficial, de todos los niveles y modalidades, ha de estar "regida por uno o más Consejos Directivos Autónomos", cometiéndose a la Ley -a esta Ley que ahora estamos comenzando a elaborar [ $\left.\mathrm{N}^{\mathrm{o}} 18.437\right]$-, según los Arts. $203^{\circ}$ y $204^{\circ}$, todo lo relativo a la designación o elección de los miembros integrantes de los respectivos Entes

$40 \quad$ El maestro Miguel Soler Roca es un referente en la historia del magisterio uruguayo que se destaca en áreas de escuela rural y educación para adultos. Tiene una vasta trayectoria de trabajar en el país como fuera de él en organismos e instituciones de carácter internacional, por ejemplo en México, Chile, Paris y Barcelona. 
rectores. No cabe duda alguna de la voluntad del constituyente de salvaguardar toda la educación pública de los posibles efectos de la acción de los partidos políticos en el área de la educación. Esto no supone, naturalmente, que el Estado en su conjunto pueda desentenderse de sus responsabilidades en materia educativa ni que aquellos Consejos puedan actuar, cada uno por su cuenta, al margen de las líneas de política general que ha de marcar la Ley, ..." (Soler, 2006:7)

Pero esta autonomía del sistema educativo no impidió que él mismo fuera alcanzado por las circunstancias políticas que atravesó el Uruguay (Soler, 2006). Su pretendida neutralidad no quedó al margen de las realidades sociales y momentos histórico que vivió el país. (Romano, 2010).

\section{Desarrollo del proceso histórico de la Educación Pública en el Uruguay.}

En el Uruguay existe una amplia tradición educativa que desde la época de la reforma de José Pedro Varela, a fines del siglo XIX, viene sosteniendo un discurso pedagógico basado en autonomía, laicidad, gratuidad, y neutralidad ideológica como los pilares de la educación pública (Badaracco, 2010). Estos conceptos/valores tienen un gran arraigo en el conjunto de la población y la cultura uruguaya (Romano, 2010) y están reflejados en el orden normativo de la Constitución de la Republica.

"El sistema educativo uruguayo se ha constituido en el segundo tercio del siglo XIX y ha coadyuvado a la consolidación del Estado-Nación, al punto de que varios historiadores mencionan el hecho de que no es posible separar el destino de la Republica del destino del sistema educativo, particularmente, el de la Escuela pública. La educación se constituyó en un terreno "neutral" en torno al cual los constructores de la naciente República acordaron que debían abandonar las pertenencias políticas-partidarias que desgarraban al país a través de las guerras civiles. Por esta razón, tempranamente, el Estado necesitó sujetos especializados para su funcionamiento; es decir formar una nueva burocracia técnica que pudiera situarse por encima de las disputas de poder coyuntural." (Romano y Bordoli, 2010:3)

Es así que se institucionaliza el sistema educativo, se establece su funcionamiento y se genera un imaginario de sujeto que permite el cumplimiento de sus funciones a través del rol del "ser docente". 
Pero de acuerdo a algunos estudios e investigaciones recientes se puede dar cuenta de que el discurso pedagógico en el Uruguay tuvo varios momentos, lo que da lugar a lo que algunos autores denominan la "gramática escolar". El concepto hace referencia a las diferentes formas en la cuales se refleja la dinámica entre las tradiciones y los cambios en el ámbito educativo. (Tyack y Cuban, 2001, citados en Romano y Bordoli, 2010). Para los investigadores Antonio Romano y Eloísa Bordoli4 ${ }^{41}$, se pueden diferenciar tres etapas en el proceso del sistema educativo en nuestro país:

a) La génesis de la formación docente- formación y consolidación del "normalisimo" como marca identitaria del "ser maestro".

b) El quiebre y reconfiguración del normalismo en el período de la última dictadura cívico-militar, con el afianzamiento del "tecnicismo-burocrático" y el control.

c) El período actual en el que convergen, conflictivamente, las tradiciones centrales de los períodos anteriores con nuevas tendencias pedagógicas." (Romano y Bordoli, 2010:1)

Siguiendo a estos investigadores a continuación se desarrollan las tres etapas mencionadas para dar un marco de comprensión al contexto histórico, educativo y normativo del Uruguay.

\section{1.-Primer momento: el normalismo, creación de la imagen del "ser docente".}

El discurso educativo de la modernidad funda una red simbólica que impregna de sentido a la institución escolar y a su vez genera una imagen identitaria del "ser docente". Esto denota que la instancia de construcción del rol y función docente no es exclusivamente un proceso individual de formación y voluntad personal, sino que implica una inscripción, una identificación a un imaginario simbólico del "ser docente".

Los hechos, las acciones, todo lo que se presenta en el mundo social-histórico se ve impregnado de lo simbólico, más allá de lo empírico concreto, que da sentido a la organización de las instituciones en una sociedad. Es así que el sentido de las acciones, de

\footnotetext{
$41 \quad$ Antonio Romano y Eloísa Bordoli, docentes e investigadores del Departamento de Ciencias de la Educación, de la Facultad de Humanidades y Ciencias de la Educación de la Universidad de la República (UdelaR), Uruguay.
} 
los acontecimientos, aparecen en las representaciones que los sujetos tienen de esos hechos o acciones, tanto en la producción de quien los realiza como por el reconocimiento que se les atribuye por parte de otros sujetos.

La red simbólica, que se constituye en la articulación de los significados sociales y culturales en su proceso histórico, implica una identificación del maestro, como forma de apropiación de las representaciones, que habilita el desarrollo del "hacer docente". Esto ocurre en condiciones institucionales determinadas, con la configuración de relaciones vinculares que permiten el rol y las inscripciones en una legalidad que legitima la función. Así aparecen los currículos, la carrera docente y el sistema educativo. (Romano y Bordoli, 2010)

La promulgación de la primera Ley de Instrucción Pública, denominada Legislación escolar, y sus programas magisteriales a fines del siglo XIX (los cuales son concebidos en el primer golpe militar de la historia democrática del Uruguay, el del Gral. Lorenzo Latorre) se ven promovidos por la reforma educativa más importante del país a cargo de José Pedro Varela.

El marco normativo institucional y la formación de los maestros se centraban en la norma moral y el disciplinamiento de los sujetos. Se constituyó en una tradición pedagógica y una identidad de los maestros que se define como "normalismo". El proyecto educativo liberal de la Modernidad en América Latina crea las Escuelas Normales para formar a sus docentes, centradas en la formación del ciudadano, con un objetivo de orden civilizatorio y de homogenización ideológica basado en la construcción de la Nación.

"La imagen del maestro normalista se articuló discursivamente con los significantes difusor de la cultura $\mathrm{y}$, a su vez, la cultura se asoció a la transmisión de pautas de comportamiento (moral) y de conocimiento mínimos y útiles para la nuevas generaciones, para que estas se integraran "civilizadamente" a la naciente república y sistema económico capitalista". (Romano y Bordoli, 2010: 5)

Es así que el o la maestra normalista, egresada de la Escuela Normal, trasmitía una imagen de docente con tendencias vocacionales, condiciones morales intachables, tendientes a hábitos de orden y prolijidad, considerándolos referentes de buenas actitudes y posiciones sociales destacadas. 


\section{2- Segundo momento: régimen cívico-militar.}

A mediados de los años 60 aparecen nuevas formas de entender el ámbito educativo. La tradición del discurso pedagógico de la educación Normalista, vinculado con lo civilizatorio, los buenos hábitos y el disciplinamiento del cuerpo, pierde fuerza al introducirse elementos de modernización. Aparecen nuevas tendencias con miradas de conocimientos técnicos y académicos y de gestión educativa, vinculadas a las disciplinas de sociología y de economía.

El proyecto de esta nueva modernización hace referencia a una construcción de ciudadanía sobre la base de la racionalidad instrumental. La razón instrumental es un concepto que tiene la pretensión de llegar al conocimiento científico de forma objetiva, neutral, universal tendiente a lo definitivo y, se convierte en una herramienta de la sociedad, donde se pretende que la razón o la racionalidad sea el mejor camino para lograr el conocimiento, del cual se generan técnicas para el dominio de la naturaleza y de la organización social.

Los cambios dan lugar a la introducción de técnicas de investigación y estudio de la realidad proveniente de las ciencias sociales, con pretensión de neutralidad política. Se constituye el ámbito de la educación como campo de intervención y de conocimiento. Este proceso fue acompañado de varios cambios de normativa, estructura organizativa de la Educación Púbica, programas curriculares y directrices de funcionamiento.

"se estructurará el régimen educativo a fin de adecuarlo a las exigencias del momento histórico dentro del tradicional estilo de vida oriental" (Acto Institucional $\left.\mathrm{N}^{\mathrm{o}} 7\right)^{42}$

Se crea así un nuevo dispositivo pedagógico en el que se imprime el binomio "innovacióntradicional“. Se relaciona la idea de"identidad nacional" a una tradición que se debe mantener y defender, vinculada a la dimensión del control social. Esto es plasmado en el ámbito educativo tanto en la formación docente como en modificaciones de normas institucionales y de programas de las asignaturas (Romano y Bordoli, 2010). Se introduce, por otro lado, como innovación de la tecnología educativa, en la cual aparece estructurada la propuesta científica.

Simultáneamente se empiezan a generar, por parte del sistema administrativo y político de Estado, sospechas de subversión del ámbito educativo, en especial asociadas a la figura del

$42 \quad$ Citado por ROMANOY BORDOLI.2010 
docente. Se da una persecución explícita y la implementación de acciones represivas, que fueron desde la destitución o encarcelamiento hasta la intervención de los órganos de dirección en los diferentes niveles de la Educación pública ${ }^{43}$.

De acuerdo a los estudios de Antonio Romano, tras la década del 60 -en la que se hallaba consolidada una perspectiva educativa en consonancia con el proyecto de la modernidad-, comienza a partir del 68 y se prolonga durante la dictadura cívico-militar de 1973 a 1985 un "lento pero inexorable declive" del discurso pedagógico. Este se vuelve netamente autoritario y rompe con una tradición educativa fundante del Estado Uruguayo y el imaginario del "ser docente".

"Dicho episodio [la dictadura cívico-militar] no solo modifica "el espejo" en el que la sociedad uruguaya pretendió mirarse durante el siglo XX (desconociendo que ya era el tercer golpe de Estado que ocurría), sino que también puso en cuestión el lugar de la educación en la edificación del proyecto moderno... El nuevo discurso autoritario logra quebrar varias representaciones imaginarias muy caras a los uruguayos, empezando por ubicar al sistema educativo como parte del caos que vivía la sociedad. La educación se había convertido en una de las principales causas de los males que afligían a la nación.

Para el nuevo régimen, la educación se constituyó desde temprano en un "campo de guerra"....

Es, entonces, en el terreno educativo donde se produjo, tiempo antes del golpe de Estado, la primera "intervención", que va a significar una violación flagrante de la Constitución. En este sentido, podemos decir, que en el Uruguay el golpe a la educación es anterior al golpe de Estado" (Romano, 2010: 1 y 2).

Se va a encontrar en este periodo una pérdida de especificidad del discurso pedagógico, pero a su vez una subordinación del mismo al proyecto político del proceso dictatorial (Romano, 2010). Este autor plantea que "el golpe a la educación se preparó con mucho tiempo de anticipación al golpe de estado, y se produjo en tres etapas: 1) la primera

\footnotetext{
$43 \quad$ Un ejemplo es la intervención en la Universidad de la Republica-UdelaR (1973-1985). Durante 1974 hubo una disminución significativa de la actividad y se definieron nueva condiciones de funcionamiento. Casi el $40 \%$ de los docentes fueron destituidos, renunciaron o no se les renovaban los contratos, cubriéndose las vacantes por designaciones directas. El movimiento estudiantil fue desarticulado y un régimen policíaco se instaló en los locales de estudio mientras se iban rehabilitando los cursos. Se cerraron varias carreras universitarias y sus respectivos servicios. Se desmanteló la estructura académica y se sustituyeron planes y programas. En 1975 comienzan a aplicarse mecanismos restrictivos a la admisión de estudiantes y se establece el examen de ingreso, comenzando con las carreras de Medicina y Odontología; se generaliza en 1980. En 1982 se impone un sistema de cupos prefijados.
} 
intervención de Secundaria en 1970; 2) la promulgación de la Ley 14.101 en 1973; y 3) la segunda intervención en 1975." (Romano, 2010:4)

La promulgación el 4 de enero 1973 de la Ley de Educación General $\mathrm{N}^{\circ} 14.101$, a cargo del Ministro de Educación de la época, Dr. Julio María Sanguinetti, será la plataforma sobre la cual se va a reorganizar la enseñanza, con características más centralizadoras y habilitando tendencias autoritarias.

Esta Ley de Educación $\mathrm{N}^{\circ} 14.101$ de enero de $1973^{44}$ estableció un cambio en la estructura organizacional de la educación pública. Centraliza y unifica por un lado, con la creación del Consejo Nacional de Educación (CONAE), compuesto por cinco miembros (artículo 15), junta a de esta manera a los Entes autónomos de la educación primaria, la secundaria y la técnica-UTU, así como la formación docente; y por otro lado, queda a la Universidad (UdelaR). Esta nueva organización va a significar una pérdida de autonomía de los Entes educativos, tan característica del Uruguay.

El momento social previo a la dictadura cívico-militar en el Uruguay (junio1973-1985) se ve reflejado en esta ley que entiende al ámbito educativo como preventivo y adoctrinante de una conducta acorde a la tradición y la defensa de la soberanía. En su artículo 1 podemos encontrar:

Artículo 1: "Su meta esencial será asegurar, coordinar y armonizar la adecuada educación permanente de todo el pueblo oriental, la continuidad del proceso educativo personal, la constante superación de todos los miembros de la comunidad, la defensa de la soberanía nacional, el orden y la seguridad integral del Estado y el desarrollo del país."

Siguiendo con esta línea de observaciones encontramos en su "Capítulo VII, de las funciones tuitivas", un especial énfasis en la conservación del orden y la seguridad, así como del control en el ámbito educativo.

Artículo 20: Los directores de establecimientos de educación deberán emplear la diligencia propia de un buen padre de familia en el cumplimiento de sus

\footnotetext{
$44 \quad$ Esta Ley lleva el nombre de: la ley sobre enseñanza pública primaria, normal, secundaria $e$ industrial, denominándola del Consejo Nacional de Educación. Dejando claro que unifica bajo el Consejo Nacional de Educación (CONAE) todos las diferentes modalidades de educación desconcentrados que existían hasta esa fecha, con excepción de la Universitaria.
} 
obligaciones funcionales, así como para vigilar, prevenir daños y hacer desistir a los educandos de cualquier actitud o comportamiento incorrecto, reputado ilícito o prohibido, no permitiendo que los educandos experimenten presiones o compulsiones individuales o colectivas.

Artículo 21: Los directores de establecimientos de educación deberán dar cuenta de inmediato a sus superiores de la existencia de ambientes perniciosos, inconvenientes, peligrosos o de corrupción, situados en el área de influencia del establecimiento.

Si bien esta ley no va a ser modificada en la dictadura (Badaracco, 2010), sí se desarrolló más con varios decretos con tendencias centralizadoras y de control social. (Romano, 2010).

"La educación ya no es apolítica ni neutral: es un "instrumento" de defensa de la democracia, es un instrumento de cambio político. Ahora quienes están en la oposición se convierten en enemigos de la democracia. Entonces, se puede pasar por encima del orden jurídico porque lo que está en juego es "la continuidad institucional”. "(Romano, 2010:6)

A partir de la segunda intervención en la educación, el 12 de febrero de 1975, se observa una radicalización, en la cual las preocupaciones del Consejo del órgano directivo de enseñanza (CONAE) son de orden básicamente doctrinarias.

"El régimen autoritario, a medida que se afirma, desconfía cada vez más del sistema educativo tradicional. La educación se convierte no en una posible solución, sino en un "problema". Y el principal problema de la educación es la infiltración ideológica. Esto explica la centralidad que va a adquirir la dimensión doctrinaria."(Romano, 2010:9)

Es en este marco que la figura del "ser docente" se va a ver muy debilitada en su valoración social, con sospechas de subversión, de desestabilizador del orden social, y en consecuencia de peligrosidad. Su figura va a ser perseguida con acciones concretas de control en su formación y en el desarrollo de su rol profesional.

2.3 -Tercer momento: conflictividad en la educación por confluencias de varias tendencias educativas.

\subsection{1- Restitución democrática}

Después de la restitución de la democracia en el año 1985 se promulgó en marzo de ese año la denominada "Ley de emergencia" $\mathrm{N}^{\circ}$ 15.739. Esta ley permitió el tránsito de la dictadura a la democracia y que generaran acuerdos de todos los sectores políticos sobre 
algunos principios generales de la educación, "reivindicando una formación del carácter moral y cívico de los educandos, defendiendo los valores morales y los principios de libertad, justicia, bienestar social, los derechos de la persona humana y la forma democrática de gobierno." (Badaracco, 2010).

Se reintegró a miles de personas que habían sido destituidas en la época de la dictadura; se generalizó la experiencia, para todos los sectores de la educación, de Asambleas Técnico Docentes (ATD) y se reglamentaron las elecciones universitarias ${ }^{45}$, como algunas medidas. Esto significó un avance respecto a la ley de $1973 \mathrm{~N}^{\circ} 14.101$ en cuanto a principios democráticos en la enseñanza, aunque se mantiene la estructura organizacional y centralizada de la educación.

Es así que la "Ley de emergencia" N 15.739 del 28 de marzo de 1985, promulgada tras la restitución democrática, tiene referencias claras del momento social que estaba viviendo el país, restituyendo un orden de funcionamiento y de actuación en consonancia.

Artículo 1: La enseñanza-aprendizaje se realizará sin imposiciones ni restricciones que atenten contra la libertad de acceso a todas las fuentes de la cultura. Cada docente ejercerá sus funciones dentro de la orientación general fijada en los planes de estudio y cumpliendo con el programa respectivo, sin perjuicio de la libertad de cátedra en los niveles correspondientes.

Se reintegra a las personas y a la función docente la conciencia moral y las libertades de pensamiento (artículos 2, 3 y 4). Se declaran nulas las destituciones, cesantías y privaciones de trabajos de docentes, funcionarios y estudiantes por cualquier tipo de motivo político e ideológico, "violatorio de reglas de derecho o viciadas por desviación de poder". Así como se anulan y derogan decretos anteriores en este sentido que marcaba la ley anterior (artículos: 44, 45 y 46).

Esta ley mantiene la estructura centralizada de la Educación. Crea en su artículo 5 la Administración Nacional de Educación Pública (ANEP) ${ }^{46}$, como hoy conocemos a la educación inicial, primaria, secundaria, técnica y formación docente, compuesta por un

45 Durante la dictadura cívico-militar, la UdelaR estuvo intervenida; las autoridades de la misma eran designadas por el Régimen. Las elecciones universitarias fueron signo y significante de la restitución democrática y del funcionamiento de sus órdenes (estudiantes, docentes y egresados).

46 Ley № 15.739, artículo 5.- Créase la Administración Nacional de Educación Pública, Ente Autónomo con personería jurídica que funcionará de acuerdo con las normas pertinentes de la Constitución y de esta ley." 
Consejo Directivo Central (CODICEN) que sustituyó al Consejo Nacional de Educación (CONAE), creado por la ley $\mathrm{N}^{\circ}$ 14.101de 1973; y los Consejos de Primaria, Secundaria y UTU. La ANEP es un ente autónomo con personería jurídica, que funciona de conformidad a los artículos 202 y siguientes de la Constitución de la República y de la Ley General de Educación.

En julio del 1990 se promulga la Ley $\mathrm{N}^{\circ} 16.115$, compuesta de un artículo único que sustituye los artículos 8, 9, 10 y 11 de la ley 15.739 de 28 de marzo de 1985 y se establece la forma de designación de las autoridades de la ANEP, ya que la ley de emergencia de 1985 lo permitía por una sola vez. Se restablece, entonces, la forma de organización de las autoridades de la ANEP, la integración del Consejo directivo central (CODICEN) y la de los Consejos de los diferentes subsistemas (Primaria, Secundaria y UTU) y así como la forma de designación de sus miembros.

Si bien en un principio la Ley $\mathrm{N}^{\circ} 15.739$ pretendió ser una salida rápida de la dictadura, esperando que se pudiera seguir profundizando los esfuerzos del sistema político de la época hacia la educación, fue la normativa vigente hasta 2008 cuando se promulgó la nueva ley (Garibaldi, 2006).

\subsection{2- Inserción de la EDH en el sistema educativo.}

En el Uruguay, como en la mayoría de los países de América Latina, se vinculan fuertemente los derechos humanos a situaciones que se asocian históricamente a formas de violencia social y política que se dieron masivamente en el pasado reciente. En nuestro país, en relación con las décadas de 1970 y 1980 (dictadura cívico-militar), se logró la denuncia de algunos de estos hechos ante los sistemas de protección internacional e interamericano de derechos humanos.

En los procesos de la restitución democrática se hace imperativo romper con la cultura autoritaria, ya que persisten en los contextos sociales las consecuencias de la violencia sistemática sufrida, que reproduce las desigualdades y la violencia institucional. Es así que 
en el año 1985, fecha de la restitución democrática del Uruguay ${ }^{47}$, el tema de la EDH entra en las escuelas. La Administración Nacional de Educación Pública (ANEP) firma un convenio con el Instituto Interamericano de Derechos Humanos (IIDH) para desarrollar experiencias piloto de EDH en algunas escuelas del interior del país. Margarita Navarrete, Integrante del Instituto de Derechos Humanos de la Facultad de Derecho-UdelaR, representante del mismo en Comisión Nacional de $\mathrm{EDH}^{48} \mathrm{y}$ también integrante de la organización civil: "Observatorio de Políticas Públicas de derechos humanos en el MERCOSUR", cuenta en la entrevista que nos concedió:

“...el IIDH hizo un convenio con varias escuelas de primaria en el Uruguay, una experiencia piloto que hubo donde seleccionaron algunas escuelas. Quien estaba a cargo del convenio era Leticia Olguin, por el IIDH. ... Fue en el periodo de Ministra de Adela Reta. Fue todo un tema, por un lado, los derechos humanos eran tabú, por aquello de la Dictadura y el gobierno militar, y por otro lado al mismo tiempo, eran tiempos muy fermentales, Uruguay estaba comprometido a la EDH, a la aprobación de los nuevos textos a nivel internacional."

A su vez ya existían organizaciones sociales que venían trabajando fuertemente en el tema. Es Luis Pérez Aguirre "Perico", que desde 1981 con el Servicio de Paz y Justicia (SERPAJ) venía hablando de Educar en Derechos Humanos.

"Ya se hablaba mucho de educación popular. Joselo Mosca y Luis Pérez Aguirre ya habian hecho el libro "Derechos Humanos. Pautas para una educación Liberadora", y estaban haciendo talleres por distintos lados. Pero [en el 85] ahí, toman la opción para trabajar en formación de docentes. Surge el Programa de Educación formal en SERPAJ."(Entrevista a Margarita Navarrete)

La EDH aparece con el objetivo de fortalecer la democracia recientemente restaurada y la promoción, protección y defensa de los derechos humanos (IIDH, 2002; 2006), así como de reparar la violación de los mismos y cumplir la promesa de "nunca más", asociada a los procesos de búsqueda de verdad, memoria y justicia que siguieron a los periodos de dictaduras en los países de América Latina.

Durante la década de los años 90 se generaron en el sistema educativo uruguayo diferentes emprendimiento por parte de los gobiernos de turno, reformas, cambios de currículos

$47 \quad$ El 1ro de marzo de 1985 asume como presidente electo por el pueblo, el Dr. Julio María Sanguinetti después de una dictadura cívico-militar que, como ya se dijo, formalmente fue desde 1973 a 1984.

48 La Comisión Nacional de EDH, fue creada a partir de la Ley General de Educación N 18.437-2008, art: 110; como instancia asesora al Sistema Nacional de Educación Pública, también creado por dicha ley. 
escolares y cambios en los programas de formación docente. También por esos tiempos se empezó a hablar de "Educación en Valores", y se generó una invisibilización de la EDH.

La reforma más destacada y controversial, fue la que llevó adelante el Prof. Germán Rama (1995- 2000), durante el segundo gobierno del Dr. Julio María Sanguinetti, enmarcada en la política neoliberal, de programas focalizados y asistencialistas para la población carenciada.

Se implementó un Plan de estudios 96' que implicaba cambios en el sistema educativo. Los planteos de nuevas formas de gestión de los centros educativos, la extensión del tiempo pedagógico (para algunas escuelas de primaria y centros del ciclo básico de Educación Media), la diferenciación en la formación y trato con los docentes que ocuparían cargos en los centros de la Reforma, generaron en los colectivos docentes y en el ámbito educativo en general, situaciones de conflictos, malestares, y resistencias. Además, despertaron visiones opuestas en cuanto a los objetivos y concepciones de la educación y la política pública.

\subsection{3- Una reforma carente.}

Tras las dictaduras ocurridas en el cono sur, de las que el Uruguay no estuvo ajeno, se impulsó el proyecto político y económico neoliberal. Este implicó un programa de ajuste económico y de estabilización promovido por los organismos financieros internacionales, en especial el Banco Mundial y el Fondo Monetario Internacional, conocido como “Consenso de Washington”. Fue implementado por los gobiernos latinoamericanos en las décadas de 1980 y 1990. Incluyó varios tipos de reformas: disciplina fiscal; redefinición del gasto público; reforma tributaria; liberalización del sector financiero; mantenimiento de tasas de cambio competitivas; liberalización comercial; atracción de inversiones de capital extranjero; privatización de empresas estatales; desregulación de la economía; protección de derecho de autor, y, por supuesto, una reforma educativa (Gentili, 1998).

Este programa de ajuste estuvo acompañado en el área de lo social por una fuerte tendencia a generar políticas públicas focalizadas hacia determinadas poblaciones (Gentili, 1998). Se incorpora un modelo de desarrollo social y económico basado en la noción de equidad ${ }^{49}$

$49 \quad$ Esto se observa en documentos de la CEPAL, como por ejemplo: "Transformación productiva en equidad” (1989); “Educación y conocimiento, eje de la transformación productiva con equidad” (1992). 
que pretendía equiparar los niveles mínimos de satisfacción de necesidades, y de esta manera igualar los puntos de partida de los sujetos para que pudieran desarrollar sus potencialidades. Desde esta concepción se le asigna a la educación un lugar de articulación del conjunto de las políticas sociales (Martinis, 2006), es decir que a través de la escuela se cubrirían algunas necesidades que no son estrictamente educativas, como ser alimentación y salud.

"La tarea que la "reforma educativa" identifica como prioritaria en los años 90 podría leerse como la de recrear ese carácter completo de lo educativo, estableciendo las formas a través de las cuales la educación transforma la sociedad y aborda el problema de la pobreza desde la perspectiva de la equidad." (Martinis.2006: 21)

Esta postura en torno de la noción de equidad, como un elemento central del desarrollo social y particularmente del educativo ${ }^{50}$, naturalizó la desigualdad estructural del ámbito socio-económico, como los puntos de partida, la cual pasa a denominarse "diferencia" (Martinis, 2006). Vincula esas desigualdades socio-económicas, profundamente injustas de la estructura capitalista con diferencias personales. La educación, de acuerdo a autores críticos a esta postura neoliberal, ya no tendría la capacidad de igualarnos sino que nos diferencia en el punto de partida en la "carrera" de las oportunidades (Gentili 2011), que mediante discursos y dinámicas de inclusión recrean mecanismos de exclusión.

Estas "diferencias" producen en el ámbito educativo un discurso sobre sujetos vinculados a la noción de ineducabilidad y peligrosidad. Clasifica así a las personas que viven en situación de pobreza, en función de tener como características diferenciales desfavorables (adquiridas o innatas: la influencia del entorno social y/o la herencia familiar). Se tiende de esta manera a invisibilizar y a naturalizar las posiciones desiguales que ocupan en la estructura social, y ahora también en el sistema educativo, los sujetos caracterizados como pobres.

50 "En su momento también la CEPAL entro en esta euforia reduccionista cuando en el año 1992 publicó el informe Educación y conocimiento: eje de la transformación productiva con equidad. Después retomó la tradición que históricamente tuvo y hoy es sin duda una de las agencias que junto con la UNESCO tienen un papel central en la resistencia a los enfoques tecnocráticos y reduccionistas". Fragmento de la entrevista a Pablo Gentili En DIALOGOS DEL SITEAL (2014) 
"Los pobres, sujetos difícilmente educables, tienden naturalmente a conductas socialmente reprobadas linderas con la violencia y el delito. Desde este lugar es lógico que se avance en la construcción de una cadena de equivalencias que articula: niño pobre $=$ niño carente $=$ fracaso escolar $=$ sujeto en riesgo $=$ sujeto peligroso $=$ delincuente. ... [este discurso] instala como un dato de la realidad la preocupación por la seguridad, siempre producida por el otro, por el inadaptado.” (Martinis, 2006: 3)

Se instala un discurso de riesgo social, en torno a la pobreza, donde la noción de equidad, más allá de ayudar a combatir el tema de la desigualdad, lo instala, lo construye como un dato a priori (Martinis, 2006). Así se instituye el problema de la seguridad, como riesgo en el cual tiene que intervenir fuertemente el Estado, con políticas públicas para ocuparse de los individuos pobres. Políticas públicas que generan una fragmentación social dividiendo a la población en dos grupos: los que tienen derechos y los que atentan contra estos. Se da lugar a la construcción del concepto de peligrosidad.

Para Robert Castel, es importante no generar una suma de riesgos. Diferenciar entre estos va permitir encontrar una respuesta adecuada para cada uno. “...hay que desconstruirlos, y evitar que sea una amalgama que asocie elementos completamente heterogéneos, y cuyos efectos principales consistan en mantener el miedo y conducir a la impotencia en cuanto a la posibilidad de encausarlos por lo menos...”(Castel, R. 2008: 2)

El tema de la asociación de los pobres con la violencia y la delincuencia se podría interpretar como una amalgama de lo que es un riesgo social y un riesgo civil (Castel. 2008). Esta conjunción de riesgos tiene consecuencias en el funcionamiento de una sociedad. Para este autor, la seguridad total es un mito, no se puede suprimir todos los riesgos, siempre habrá situaciones de inestabilidad que requieran que una sociedad implemente acciones, pero es importante que estas acciones pasen por un control democrático (Castel. 2008).

La reforma educativa, según Pablo Martinis ${ }^{51}$, se construyó en base a un discurso sobre riesgos que renuncia a la posibilidad de educación desde el momento que anula al sujeto de la educación y lo sustituye por el "niño carente". Se instala un "borramiento" de uno de los actores de la relación educativa, lo que conlleva a la disolución de la misma, pues ya no se

51 Pablo Martinis, docente e investigador del Departamento de Ciencias de la Educación, de la Facultad de Humanidades y Ciencias de la Educación de la Universidad de la República (UdelaR), Uruguay. 
necesita de un docente que enseñe, sino de una figura que dé sostén, que atienda, que contenga, que rescate. Esto se carga de un significado específico, donde la reforma enuncia una emergencia educativa, dando como solución la renuncia de la Escuela a enseñar para pasar a una escuela que asiste, contiene y rescata. El autor plantea que esta emergencia educativa significa la ruptura "ya no del lazo social sino de la posibilidad de establecerlo”. (Martinis, 2006)

En el discurso de la reforma educativa se expresa claramente que existe en nuestra sociedad una situación de "emergencia educativa", donde se explicitan como amenazas y dificultades los contextos de pobreza para la escuela. Este discurso se instala en base a una triple construcción discursiva:

“i) nombrar al sujeto de la educación como niño carente;

ii) postular la necesidad de un nuevo modelo de atención escolar para atender a estos niños;

iii) concebir a los maestros como técnicos a los que habrá que capacitar para trabajar con esos niños." (Martinis, 2006: 13)

En el marco del desarrollo de las prácticas educativas es importante entender que de acuerdo a cómo concebimos a los actores de la misma (educando-educador) se van a definir las posibilidades y funcionalidades que el acto educativo tiene para la sociedad.

"Un sujeto de la educación es alguien en proceso de humanización, colocado en posición de recibir un legado, de acceder a la transmisión de aquello que la humanidad ha sido capaz de construir históricamente y que le ha valido devenir precisamente en eso: humanidad. Es una cría humana, que necesita de la educación, de la transmisión, para acceder al estatus de sujeto humano." (Martinis, 2006: 14)

Entonces, al concebir a la persona humana más allá de su etapa etarea, de su contexto socio-cultural, su posición económica y su género como un ser humano capaz de desarrollar sus potenciales, su creatividad, de formarse con sujetos histórico, sujeto de derechos (Freire, 1996), se da la posibilidad de su conformación y su pleno desarrollo como persona en una comunidad de iguales.

"La justicia supone, a su vez, la exigencia de la igualdad. No es posible el florecimiento de la diversidad de formas y de planes de vida, si no se garantiza una estructura que asegure igualdad. Igualdad no equivale a uniformidad, sino a condiciones que fomenten el desarrollo de las diversidades" (Rebellato, 1997: 5).

En esto reside la acción educativa que da sentido a la producción de sujetos singulares, considerados como dignos, a los que se les ofrece una cultura, "objetos comunes, un lugar 
habitable para que se encuentren con ellos" (Rebellato, 1997). Desde este lugar la educación es un acto de profunda justicia (Martinis, 2006).

Desde este planteo se nos presenta una exigencia ética, ya que nadie se puede desarrollar desde la opresión, la dominación y la carencia que representan las desigualdades en la estructura social (Freire, 1996). Son condiciones que influyen en las expectativas y los deseos y en los proyectos de vidas de las personas.

Continuando con el análisis del autor Pablo Martinis, no es por causa de la pobreza que irrumpe en la institución escuela que se produce la emergencia educativa, sino por la renuncia de una sociedad a su responsabilidad de educar a los sujetos, a todos los sujetos que en ella se desarrollan. Porque es en la relación educativa, en el vínculo que se establece entre las personas, donde se generan las condiciones de transmisión de un legado sociocultural, de conocimientos (Freire, 1996) y de la posibilidad de reproducción, de creación y transformación. Lugar donde los destinos no están fijados de antemano (Martinis, 2006). Es decir, es desde el acto educativo, concebido desde la igualdad y la justicia, que se da posibilidad a la construcción de lo humano (Rebellato, 1997).

\subsection{4- El gobierno progresista.}

Bajo la presidencia del Dr. Tabaré Vázquez (2005-2009), primer gobierno progresista, parte de una tendencia regional que implicó a otros cuantos países del continente, se generaron varias expectativas. Dentro del ámbito educativo comenzó un proceso de reformas, acompañado por un proceso de debate social sobre la educación que culminó con la promulgación de una nueva ley de educación, tan esperada por varios sectores sociales.

Es así que se promulgó la nueva Ley General de Educación №18.437 (12 de diciembre 2008) y se realizaron varios cambios y modificaciones en los programas educativos. Entre ellos el Programa de educación inicial y de primaria, que empezó a aplicarse en marzo 2009 en todo el país.

Estos cambios fueron precedidos de una instancia de consulta y debate en todo el territorio nacional, que se denominó "Debate educativo". Se trató de un proceso consultivo que se llevó adelante mediante la realización de varias asambleas y grupos de trabajo sobre diferentes temas y fue abierto a la participación sin restricción de toda la población 
(docentes, funcionarios no-docentes, técnicos- profesionales, padres y madres, y estudiantes). Este proceso, que culminó con la formulación y promulgación de la ya citada ley, no estuvo exento de conflictos.

Se llegó a declarar por parte de los sindicatos de la educación y varias figuras significativas del ámbito, que el resultado de la ley y varias de las conclusiones no representaban el proceso realizado porque habían modificado y falseado los resultados y contenidos. Se cuestionó, por parte de algunos sectores, que durante el proceso de promulgación de la ley no se generó la discusión parlamentaria y social necesaria que requiere una normativa de este tipo. Uno de los puntos más polémicos fue el tema de la autonomía de la educación, como también el co-gobierno. Por parte de los sindicatos de la educación se pretendía que esta nueva ley re-implantara la descentralización de la educación anterior a la Ley $\mathrm{N}^{\circ}$ 14.101 de 1973, cosa que no sucedió.

A pesar de los cuestionamientos y tensiones, para varios de nuestros entrevistados es en el gobierno de Tabaré Vázquez (2005-2009) que aparece un fuerte impulso al enfoque de derechos en las políticas públicas. En el ámbito de la educación se da la incorporación de la EDH en la nueva Ley General de la Educación $\left(\mathrm{N}^{\circ}\right.$ 18.437, 2008). Se consolida así jurídicamente un lineamiento estratégico de política educativa propuesto por el Consejo Directivo Central (CODICEN) de la ANEP que se venía desarrollando desde 2006.

Martin Prats, director de la Dirección de derechos humanos de CODICEN-ANEP, cuenta al respecto:

"En el gobierno de Vázquez, en la administración de la ANEP, encabezada por Yarzábal [2005-09], se empezó a delinear como líneas de acción estratégica, y una de ellas fue la EDH.... La Ley de Educación lo que hizo fue reconocer esta línea y ya expresarla con mandato legal. (...) desde antes de la Ley de Educación, ya la EDH estaba establecida como una linea estratégica transversal para la Educación. Eso llevó a que, en el Programa de Educación Inicial y Primaria, en la parte introductoria estén establecidos la línea de los derechos humanos y de la EDH. “

Por su parte, Luis Garibaldi, ex-Director de Educación del Ministerio de Educación y Cultura (MEC), redactor de la Ley General de Educación $\left(\mathrm{N}^{\circ} 18.437,2008\right)$ planteaba que "las prácticas educativas no se cambian solo con la normativa”. Él reconoce los avances del Uruguay en cuanto a los debates políticos y públicos sobre los temas de derechos humanos. Se crean diferentes instancias de la educación para trabajar derechos humanos: 
se instala una Dirección de derechos humanos en ANEP-CODICEN (2006) ${ }^{52}$ para asistir al sistema educativo oficial en sus diferentes sub sistemas y también al interior del propio MEC se crea la Dirección de Derechos Humanos ${ }^{53}$.

La nueva Ley General de Educación representa un avance. Pero a su vez señala como una limitación a la comprensión global de la EDH los periodos históricos que implicaron las denuncias y reivindicaciones de los derechos humanos por determinaros sectores sociales. Dice: "Todavía derechos humanos es sinónimo de violación de derechos en la historia reciente, más que de educar, educación, promoción en derechos humanos para el ejercicio de derechos humanos."'(Entrevista a Luis Garibaldi)

Los entrevistados dan cuenta de que una mirada global desde la óptica de los derechos humanos todavía está muy impregnada de la lucha por la defensa de los derechos durante la dictadura reciente de nuestro país. Y que una nueva mirada, entendiéndolos desde la promoción, educación y prevención, no está aún consolidada en el ámbito social en general y tampoco en el colectivo docente.

Luis Garibaldi contaba de la siguiente manera otra manifestación de este hecho que reduce o parcializa el concepto de la EDH. Comentaba la tensión que se generó al momento de la discusión de la Ley General de Educación №18.437 (2008) entre los conceptos de EDH y de Educación en Valores:

"Cuando se discutió [la ley] hubo gente que dijo: que no aparecen los valores. Y sobre todo algunas observaciones que desde la derecha se hicieron, fue sobre este tema [Educación en valores]. Y en realidad el enfoque de la ley no es negar los valores, sino más bien considerar esos valores universales integrados desde la óptica de los derechos humanos."

"EDH contiene los valores de los derechos humanos. Los valores universales más consensuados están allí. ... Es que en realidad están los valores de los derechos

52 Creación en 2006 de la Dirección de Derechos Humanos por parte del Consejo Directivo Central, de la ANEP (CODICEN). Director actual Dr. Martin Prats.

53 Creación de la Dirección de Derechos Humanos del Ministerio de Educación y Cultura (MEC), diciembre de 2005, Ley $N^{\circ} 17.930$ art. 229. Primera directora Dra. María Elena Martínez, le siguió como director Dr. Javier Miranda.

La Dirección de Derechos Humanos del Ministerio de Educación y Cultura, pasó en enero de 2014 a la órbita institucional de Presidencia de la República, convirtiéndose en la Secretaria de Derechos Humanos. Este cambio fue realizado a través de la Ley $\mathrm{N}^{\circ} 19.149$ (Rendición de cuentas y Balance de ejecución presupuestal 2012) en sus artículos 67,68 y 69. 
humanos, es una forma distinta de verlos. Una forma más que de los valores individuales, de los valores colectivos. ..."(Entrevista a Luis Garibaldi)

Aparecen en el discurso de nuestros entrevistados referencias que marcan la importancia histórica de la introducción de EDH en nuestro medio, precedida de una etapa de denuncias de violaciones a los derechos humanos en nuestra historia reciente. Pero a su vez esta vinculación histórica genera fuertes contradicciones a la hora de conceptualizar los derechos humanos en la educación desde una concepción diferente a la denuncia o a la posición partidaria del periodo histórico mencionado.

Esta forma de entender los derechos humanos también aparecerá en el trabajo de campo en las escuelas que se hizo como parte de la presente investigación. En tal sentido, la fuerza de las denuncias de las violaciones a los derechos humanos, estos hechos tan atroces, impide acercarse a la construcción colectiva y a una mirada desde la promoción y educación en derechos humanos.

Es en este periodo que se da la iniciativa de crear un Plan Nacional de Educación en Derechos Humanos, sugerencia de la ONU durante el Decenio para la EDH (1995-2004) ${ }^{54}$. Esta propuesta en Uruguay partió en 2006 desde el Ministerio de Educación y Cultura (MEC). Actualmente está coordinada por la Comisión Nacional de EDH, creada por la Ley General de Educación $N^{\circ} 18.437$ (artículo 110) y cuenta con un proceso en curso que da lugar a varios momentos significativos. Por su importancia para la investigación se va desarrollar ampliamente en el siguiente apartado.

\section{Un proceso en construcción en el Uruguay: EI Plan Nacional de EDH}

La propuesta de la elaboración de un Plan Nacional de EDH cuenta en Uruguay con varias incitativas, pero es un proyecto que aún hoy no ha logrado un grado de visibilidad importante. Este tema lo indagamos en las entrevistas con nuestros informantes calificados, pertenecientes a la Comisión de EDH, y también preguntamos sobre el grado de conocimiento y participación de los docentes durante el trabajo de campo en las escuelas.

\footnotetext{
$54 \quad$ NACIONES UNIDAS. "Directrices de las Naciones Unidas para elaborar planes de acción en materia de EDH de 1998" (A/52/469/Add.1)
} 
Esto último representó una sorpresa ya que encontramos un total desconocimiento de la propuesta que se estaba llevando a cabo, dentro de las escuelas y por parte de sus colectivos docentes, así como de las inspectoras entrevistadas.

En el Uruguay se creó en el año 2006, a instancias del MEC- Dirección de derechos humanos, una comisión para desarrollar un Plan Nacional de EDH (en adelante PNEDH). En esta participaban el MEC, la ANEP, la UdelaR, la Universidad Católica, como representantes de centros de educación católicos, de educación privada, de educación pública no formal y de educación policial, entre otros. "Esta Comisión es el ámbito interinstitucional que articula, genera instancias de intercambio y consulta con actores claves del sistema educativo con la finalidad de llevar adelante la elaboración, implementación y monitoreo del PNEDH" (documento: "Informe, Plan Nacional de Educación en derechos humanos. 2007”, pág.15).

Se tomaron como base las Directrices de las Naciones Unidas para elaborar planes de acción en materia de EDH de 1998 (A/52/469/Add.1) y las del Plan Mundial proclamado por la Asamblea General (Resolución 59/113). Una breve reseña de estas directivas fue planteada en el capítulo II, sección 3.3.1)

Como parte de las actividades orientadas a la elaboración del PNEDH se realizaron acciones en torno a difundir información sobre la EDH, se desarrollaron actividades de formación y difusión (mesas redondas, talleres y debates) y se produjeron varias publicaciones especializadas, así como la re-edición del libro "Derechos humanos, pautas para una Educación liberadora", texto emblemático de Luis Pérez Aguirre y Juan José Mosca. Asimismo, se llevó a cabo una encuesta sobre EDH a los centros educativos públicos y privados de enseñanza primaria, secundaria y de educación no formal. Se presentó un Documento "Informe, Plan Nacional de Educación en Derechos Humanos2007”, en el cual se plantearon las líneas estratégicas para desarrollar el Primer PNEDH. Pero el trabajo de esta Comisión se detuvo aquí, si llegar a prosperar las iniciativas planteadas. 
Poco después, tras la promulgación, en 2008, de la Ley General de Educación $\mathrm{N}^{\circ} 18.437$ y la conformación de la Comisión Nacional sobre EDH ${ }^{55}$ (artículo 110), esta se plantea la tarea de continuar con la elaboración del PNEDH.

En el año 2011 la Comisión presenta la propuesta de un "Proceso hacia la construcción de un Plan Nacional de Educación en Derechos Humanos" que es aprobada por la Comisión Coordinadora del Sistema Nacional de Educación Pública.

Esto implicó la construcción en un proceso participativo de debate sobre la EDH donde se desarrollaron dos estrategias:

- Un sitio web y una página en Facebook donde se encuentran documentos y también se reciben aportes, tanto de organizaciones como individuales. http://pnedh.snep.edu.uy/

- Cuatro instancias presenciales regionales de debate con participación de docentes, funcionarios no docentes y estudiantes. (Documento: "Bases hacia un plan nacional en EDH”, 2015: pág. 32)

Se realizaron cuatro encuentros regionales de debate organizados por la Comisión Nacional de EDH y las Comisiones Departamentales de Educación. Los encuentros se llevaron adelante entre el segundo semestre del año 2013 y el primero del 2014 y contaron con la participación de actores representativos de la educación formal y no formal, tanto docentes como no docentes y estudiantes, activistas de derechos humanos y funcionarios públicos.

1) Encuentro región Norte, participaron personas de los departamentos de Salto, Artigas, Rivera, Cerro Largo, Paysandú y Tacuarembó.

2) Encuentro regional en Montevideo con participación de Montevideo y Canelones.

3) Encuentro región Este, participantes de los departamentos de Lavalleja, Maldonado, Rocha y Treinta y Tres.

4) Encuentro región Oeste, participaron desde Colonia, Durazno, Flores, Florida, Rio Negro, San José y Soriano.

Se recogieron por estas diferentes vías aportes de organizaciones sociales, federaciones de profesores, organizaciones no gubernamentales y personas particulares, entre otras, así como se sistematizaron los debates de los cuatros encuentros regionales y los aportes recibidos. Se desarrolló un documento "Bases hacia un plan nacional en EDH", que se

55 Se constituye el 11 de junio de 2009, por representantes del MEC, ANEP y UdelaR. Se integra recientemente la UTEC, de creación en el 2012. 
presentó públicamente en febrero del 2015. En él se encuentran la descripción del proceso desarrollado a nivel nacional, así como aportes conceptuales sobre EDH y su desarrollo a nivel internacional. Se destaca en él que "A pesar de los avances en materia legal y de los cambios que se han constatado en algunas áreas, existe coincidencia en que persisten tanto el desconocimiento de los derechos como la violación de los mismos." (Documento: "Bases hacia un plan nacional en EDH”, 2015: pág. 38)

En el documento "Bases hacia un plan nacional en EDH" se reseñan cuatro objetivos estratégico, desglosados en objetivos específicos y una lista de posible acciones a desarrollar dentro de los mismos.

Objetivo estratégico 1. Construir una cultura de derechos humanos comprometida con la dignidad de todas las personas y con el respeto por los derechos humanos propios y de las demás personas.

Objetivo específico 1.1. Contribuir a la universalización del conocimiento sobre Derechos Humanos mediante una formación básica dirigida a todas las personas en una estrategia de corto plazo.

Objetivo específico 1.2. Avanzar en la incorporación de la educación en derechos humanos en los objetivos, directrices y programas de todos los ámbitos y niveles de la educación.

Objetivo específico 1.3. Contribuir al reconocimiento de las diferencias y el respeto de la diversidad favoreciendo la comprensión, la tolerancia y la convivencia pacífica entre todas las personas y los colectivos humanos.

Objetivo específico 1.4. Educar en la memoria de las violaciones a los derechos humanos, procurando que el conocimiento de las mismas y la formación en ciudadanía y en valores, sean garantes para evitar que se repitan.

Objetivo estratégico 2. Garantizar entornos de convivencia y aprendizaje en las comunidades educativas en clave de derechos humanos.

Objetivo específico 2.1. Adecuar las prácticas de las instituciones educativas para que operen con una racionalidad acorde a un enfoque de derechos humanos.

Objetivo específico 2.2. Pensar y rediseñar los centros educativos para que habiliten, incluyan y protejan a los diversos grupos que padecen situaciones de discriminación, exclusión o vulneración de su dignidad.

Objetivo específico 2.3. Implementar la participación como instrumento para ejercer y defender derechos y para construir los ámbitos y proyectos educativos.

Objetivo estratégico 3. Sensibilizar, capacitar y comprometer para el desarrollo de procesos de educación en derechos humanos a actores que resultan estratégicos por su capacidad de multiplicación o por el carácter particularmente pertinente de su especificidad. 
Objetivo específico 3.1. Sensibilizar y capacitar a los educadores de los diferentes ámbitos y niveles de la educación.

Objetivo específico 3.2. Educar en derechos humanos a los funcionarios públicos del Poder Judicial y de la Administración Pública, con énfasis en los funcionarios de las áreas de seguridad.

Objetivo específico 3.3. Educar en derechos humanos y apoyar a voluntarios promotores de derechos humanos.

Objetivo específico 3.4. Comprometer a los medios de comunicación como agentes en la estrategia nacional de educación en derechos humanos.

\section{Objetivo estratégico 4. Crear y fortalecer la institucionalidad de la Educación en Derechos Humanos. \\ Objetivo específico 4.1. Crear los órganos institucionales responsables de la política pública de educación en derechos humanos, definiendo sus cometidos y competencias.}

Objetivo específico 4.2. Institucionalizar los mecanismos de construcción, ejecución y seguimiento del Plan Nacional de Educación en Derechos Humanos.

Objetivo específico 4.3. Institucionalizar los espacios para la participación de la sociedad civil en el marco del proceso del Plan Nacional de Educación en Derechos Humanos. (Documento: "Bases hacia un plan nacional en EDH”,2015: pág. 64 a la 81)

El entrevistado Dr. Martin Prats habló de la tarea del plan como un esfuerzo de articulación de diferentes instituciones que ya venían trabajando sobre el tema y la importancia de identificar objetivos y elementos comunes. Pero sobre todo, él identificó la importancia de poder generar en conjunto de mecanismos de evaluación de las prácticas educativas:

"Uruguay no tiene un Plan, en cuanto a que TODA la educación Nacional formal y no formal, dirigidas por la ANEP, u otras instituciones públicas, y también como participa la sociedad civil en EDH, no han formulado un plan con objetivos únicos para el mismo. Pero los distintos niveles de la educación o el tema de EDH están planteados. No podemos decir que un Plan va a empezar con el tema, no hay un vacio... Está incorporado en planes y programas. Está incorporado en estrategias de corto y mediano plazo. Pero falta un poco el desarrollar un Plan que coordine acciones y precisamente que apunte a poder establecer mecanismos de evaluación de resultados. Y a mí lo que más me preocupa es la evaluación, no de cómo los contenidos de derechos humanos están en los programas, porque están, y en eso el Uruguay está bien! sino los resultados en las prácticas !! "(Entrevista a Martin Prats)

Queda clara la finalidad del trabajo en EDH para este entrevistado. Preocupación que va planteada por las prácticas: “¿Estamos logrando que los centros educativos sean lugares donde se respeten y promueven los derechos humanos?, y otra cosa más grande aún, ¿estamos logrando que la gente que salga de la educación pública tenga incorporada la 
dimensión de derechos? ¿Para qué queremos EDH? Para que la sociedad cambie y sea más respetuosa de los derechos. Y eso es más difícil de evaluar! Y ver cómo se evalúa también. (Entrevista a Martin Prats).

Los entrevistados identifican que el trabajo articulado es importante pero se preguntan por las coherencias internas de la acción dentro de cada institución. En consonancia, Margarita Navarrete plantea: "El Plan son una serie de lineamientos. Pero cada institución es autónoma”... "el PNEDH van a ser líneas transversales. Habría que ver cómo a la interna se aplica." Esta entrevistada se pregunta por lo que está pasando en las prácticas educativas dentro de los centros, por la coherencia de estas con los postulados y objetivos de la EDH, y reflexiona sobre cómo evaluar estas prácticas. Las dificultades y complejidades están en poder concretar prácticas en EDH sostenidas, que hagan líneas de trabajos planificadas, ejecutadas y evaluadas, por parte de las instituciones referentes (existiendo diferentes niveles de realización de la EDH en estas instituciones educativas). Se plantea el desafío de no quedarse en experiencias aisladas de EDH, sino que se pueda llegar, a través del PNEDH, con un planteo más central y claro a los colectivos

Fernando Willat, coordinador de EDH de la Secretaria de DDHH de Presidencia e integrante de la Comisión Nacional de EDH, contó sobre el trabajo en torno al PNEDH como ámbito de articulación de diferentes instancias:

"Esa es la razón de ser del plan, dar una mirada estratégica común que pueda hacer que en los distintos ámbitos de la educación haya una referencia hacia dónde vamos, después ajustada en cada lugar, pero un sentido común compartido, de orientación estratégica. Estamos tratando de involucrar a los distintos actores, de los distintos ámbitos. Hemos tenido una vinculación importante con el interior, a través de las Comisiones departamentales de Educación. Se nota el notable avance de tener un Sistema Nacional de Educación Pública que como todas las cosas, como tantas otras cosas de institucionalidad nueva, todavía es muy precaria."

Pero este entrevistado dejó clara su opinión sobre la dificultad de este trabajo de articulación, cuyo resultado es que se demoran los procesos, porque desde los ámbitos políticos existen diferentes prioridades y hay diferencia en los tiempos de las diversas instituciones:

“La EDH todavía está lejos de ser un tema de agenda pública importante,... ninguna encuesta de opinión publica lo va a señalar como un tema prioritario. $Y$ 
tampoco está apareciendo como un tema prioritario en la agenda política de los gobiernos. No quiere decir que no le den ninguna bolilla, pero hay otros temas que se comen la energía, y se comen también los recursos. Terminan siendo esos espacios que empujan y alguna gente que está muy convencida y que es parte de la racionalidad que se va imprimiendo en las instituciones, pero no tiene todavía una centralidad muy fuerte."... "Nosotros con el proceso del PNEDH estamos queriendo hacer un empuje nuevo. Pero fijate que empezamos a plantear el proceso del Plan en principios de 2011, y tenemos recién la habilitación para empezar el proceso en del 2013”. (Entrevista a Fernando Willat)

Es así que se encuentran diferentes elementos que hacen que aun no se haya podido concretar un PNEDH en el Uruguay. Ello a pesar de que existe una continuidad en las iniciativas; un trabajo sistemático que cuenta con un grado importante de institucionalización, ya que la constitución de la Comisión asesora de EDH está plasmada en la ley $\mathrm{N}^{\circ} 18.437$ (artículo 110), y un trabajo coordinado con representantes de las diferentes instituciones de educación pública nacional de los diferentes niveles. 


\section{CAPITULO IV}

\section{MARCO NORMATIVO ACTUAL DE LA EDUCACIÓN URUGUAYA}

\section{La Ley General de Educación $N^{\circ} \mathbf{1 8 . 4 3 7}$}

\subsection{Antecedentes.}

\subsection{1-Antecedentes en las leyes.}

En esta sección se presenta una breve reseña sobre las leyes de educación que existieron en el Uruguay antes de la actual Ley General de Educación $\mathrm{N}^{\circ} 18.437$, como ya se mencionó promulgada el 12 de diciembre de 2008.

Entre los antecedentes cercanos de la actual ley se encuentra la Ley de Educación $\mathrm{N}^{\circ}$ 14.101 del 4 de enero de 1973, sancionada previo a la dictadura cívico-militar que afrontará el país a partir de junio de 1973 hasta marzo de 1985. Esta ley estableció un cambio en la estructura del sistema educativo que significó una organización más centralizada, con pérdida de autonomía para los diferentes niveles educativo (primaria, secundaria y técnica UTU).

En la restitución democrática se promulga el 28 de marzo de 1985 la "Ley de emergencia" $\mathrm{N}^{\circ}$ 15.739. En ella podemos encontrar referencias claras al momento social e histórico que estaba viviendo el país y se restaura un orden de funcionamiento y de actuación en consonancia con la democracia recientemente alcanzada.

En julio del 1990 se promulga la Ley $\mathrm{N}^{\circ}$ 16.115, que está compuesta de un artículo único, el cual establece la forma de organización de las autoridades de la Administración Nacional de Educación Pública (ANEP), la integración del Consejo Directivo Central (CODICEN) y la de los Consejos de los diferentes subsistemas (Primaria, Secundaria y UTU), así como la forma de designación de sus miembros. 


\subsubsection{Marco institucional de la educación en el Uruguay.}

El sistema educativo uruguayo, como antes se dijo, funciona distinto a los de otros países de la región. Tiene dos organismos estatales a los que les compete el funcionamiento de la educación pública en la etapa que nos interesa indagar para esta investigación. Estas entidades son el Ministerio de Educación y Cultura (MEC) ${ }^{56}$ y la Administración Nacional de Educación Pública, (ANEP).

Al Ministerio (MEC), el cual tiene esta denominación y constitución desde 1970, le compete el desarrollo de los principios generales de la educación, la articulación entre las políticas educativas nacionales y las políticas de desarrollo humano, cultural, social, tecnológico y económico, así como también relevar, confeccionar y difundir las estadísticas del sector en el marco del Sistema Estadístico Nacional (Artículo 51 inciso A, B, C, F y G, del de la Ley General de Educación No 18.437).

La Administración Nacional de Educación Pública (ANEP) es un ente autónomo creado por la ley $\mathrm{N}^{\mathrm{o}} 15.739$ de marzo de 1985 (artículo 5), cuyos cometidos son elaborar, instrumentar y desarrollar políticas educativas; garantizar la educación a todos los habitantes del país, asegurando su ingreso, permanencia y egreso; asegurar el cumplimiento de los principios y orientaciones generales de la educación, y promover la participación de toda la sociedad en la formulación, implementación y desarrollo de la educación (Artículo 53, incisos A, B, C y D, de la Ley General de Educación No 18.437). Es la entidad que define los currículos de educación inicial, primaria, secundaria y técnica UTU y supervisa el funcionamiento de los centros educativos correspondientes a cada subsistema.

\subsection{Análisis de la nueva LEY GENERAL DE EDUCACIÓN}

\footnotetext{
56 A nivel ministerial la Educación conforma el Ministerio de Educación y Cultura (MEC) a partir de 1970. Anteriormente se encontraba en el Ministerio de Instrucción Pública y Prevención social (1936), casi sin incidencia por la autonomía de los sectores educativos que se encontraban descentralizados en sus respectivos Consejos Directivos de primaria, de secundaria y Universidad del trabajo UTU.
} 
La Ley $\mathrm{N}^{\circ} 18.437$ o Ley General de Educación regula toda la educación en el país incluyendo la primera infancia, los niveles de educación inicial, primario, secundario y terciario, educación policial, militar y educación no formal. Vino a sustituir la Ley 15.379 de 1985.

Desde su inicio ubica al tema de la educación como derecho humano fundamental y hace referencia a la obligación del Estado de garantizar dicho derecho para todos los habitantes a lo largo de la vida.

“artículo 1: Declárese de interés general la promoción del goce y el efectivo ejercicio del derecho a la educación, como un derecho humano fundamental. El Estado garantizará y promoverá una educación de calidad para todos los habitantes, a lo largo de toda la vida, facilitando la continuidad educativa."

En el artículo 2 reconoce a la educación como bien público y social, con un alcance formativo de desarrollo integral de la persona humana, incorporando explícitamente el principio de no discriminación. La orientación que le da esta Ley a la educación (artículo 3) responde a un concepto integral de la vida humana bio-psico-socio-ambiental, incluyendo "el ejercicio responsable de la ciudadanía, como factor esencial del desarrollo sostenible, la tolerancia, la plena vigencia de los derechos humanos, la paz y la comprensión entre los pueblos y las naciones."

El artículo 4 complementa al artículo 1, dando el marco de los derechos humanos para el ejercicio del derecho a la educación enmarcado en la Declaración Universal de Derechos Humanos, así como otros instrumentos internacionales ratificados por el país y la Constitución Nacional.

“artículo 4: La educación tendrá a los derechos humanos consagrados en la Declaración Universal de los Derechos Humanos, en la Constitución de la República y en el conjunto de los instrumentos internacionales ratificados por nuestro país, como elementos esenciales incorporados en todo momento y oportunidad a las propuestas programáticas y acciones educativas, constituyéndose en un marco de referencia fundamental para la educación en general y en particular para los educadores en cualquiera de las modalidades de su actuación profesional."

El artículo 5 identifica a las y los educandos como sujetos del derecho a la educación.

El capítulo II de la ley enmarca los principios de la educación desde la universalidad y la obligatoriedad (artículos 6 y 7). También son principios de la educación la participación, la libertad de enseñanza y la libertad de cátedra (artículos 9, 10 y 11). Adicionalmente, el artículo 8 destaca los principios de diversidad e inclusión educativa: 
“artículo 8: El Estado asegurará los derechos de aquellos colectivos minoritarios o en especial situación de vulnerabilidad, con el fin de asegurar la igualdad de oportunidades en el pleno ejercicio del derecho a la educación y su efectiva inclusión social. Para el efectivo cumplimiento del derechos a la educación, las propuestas educativas respetarán las capacidades diferentes y las características individuales de los educandos, de forma de alcanzar el pleno desarrollo de sus potencialidades."

El capítulo III de la ley (artículos 12 al 14) propone como objetivo político de la educación nacional articular con políticas que impulsen el desarrollo humano en general y, en lo particular, que se desarrollen en torno de la promoción de la justicia, la solidaridad, la libertad, la democracia, la inclusión social, la integración regional e internacional y la convivencia pacífica. O sea, se acentúa la formación en la vida en democracia, el progreso social, el respeto a la diversidad, la resolución de conflictos, la cultura de paz y la integración y cooperación internacional.

Es así que observamos elementos alentadores de incorporación de los principios, objetivos y contenidos de la EDH en la nueva Ley General de Educación. La profesora Fernanda Blanco, que estuvo encargada de EDH de la Dirección de Educación del Ministerio de Educación y Cultura (MEC) y ex-integrante de la Comisión de EDH, destaca la intención política de plasmar la EDH en la normativa, hecho que entiende como habilitante para promover la problematización de las realidades que vivimos desde una forma más institucionalizada:

"...la EDH sin duda ha sido afectada por un avance importante. Partimos de una voluntad expresa en una Ley de Educación. Pasando la Constitución incluso, avanzando más. Eso sin duda es una voluntad de quienes tienen a cargo la organización de un Estado, que es de gran ayuda." (Entrevista a Fernanda Blanco)

Esta Ley crea una nueva articulación de la Educación Pública, así como nuevas instancias de asesoría y coordinaciones entre sus diferentes estructuras y niveles.

\subsubsection{Sistema Nacional de Educación Pública}

El Sistema Nacional de Educación Pública (SNEP) es creado por la Ley n ${ }^{\circ} 18.437$ en su artículo 20. La ley lo define como:

“artículo 20: (Concepto) El Sistema Nacional de Educación es el conjunto de propuestas educativas integradas y articuladas para todos los habitantes a lo largo de toda la vida." 
Incluye la educación formal, la no formal y la educación de primera infancia. Así, la Educación Pública en el Uruguay tiene como particularidad institucional que está conformado por diferentes organismos, todos de alcance nacional (artículo 49). Ellos son:

- El Ministerio de Educación y Cultura (MEC),

- La Administración Nacional de Educación Pública (ANEP), un Ente autónomo para la administración y conducción de la educación pública no universitaria.

- La Universidad de la República (UdelaR), un Ente autónomo para la administración y conducción de la educación pública universitaria en todo el territorio nacional,

- La Universidad Tecnológica (UTEC), una persona jurídica pública que funcionará como Ente autónomo de educación terciaria de reciente creación en el 2012 (Ley $\mathrm{N}^{\mathrm{o}}$ 19.043), por lo que no va ser desarrollada en este trabajo. ${ }^{57}$

Al Ministerio de Educación y Cultura (MEC) le compete el desarrollo de los principios generales de la educación, facilitar la articulación y promoción entre las políticas educativas nacionales y las políticas de desarrollo humano, cultural, social, tecnológico, de investigación y económico. Y le compete también relevar, confeccionar y difundir las estadísticas del sector en el marco del Sistema Estadístico Nacional y realizar propuestas a los diferentes órganos competentes. (Artículo 51 inciso A, B, C, F y G, de la Ley General de Educación $\mathrm{N}^{\mathrm{o}} 18.437$ )

Dentro del MEC, la Dirección de Educación juega un importante papel. Tiene como "lineamiento estratégico facilitar la coordinación de las políticas educativas nacionales con el propósito de que todos los habitantes logren aprendizajes de calidad, a lo largo de la vida y en todo el territorio nacional... ${ }^{58, . ~ E n ~ s u ~ o ́ r b i t a ~ f u n c i o n a ~ l a ~ s u p e r v i s i o ́ n ~ d e ~ l o s ~}$ Centros de Educación Infantil Privados para la primera infancia (Centros Privados MEC o CEIP-MEC); El Consejo Nacional de Educación No Formal (CONENFOR) creado por la ley (Capítulo XV, artículos 92 al 95) y el Consejo Consultivo de Enseñanza Terciaria (que da autorización a las instituciones y reconoce el nivel académico de sus carreras).

$57 \quad$ La UTEC es la nueva Universidad Tecnológica, una propuesta de educación terciaria universitaria pública de perfil tecnológico, orientada a la investigación y la innovación. Fue creada por la Ley № 19.043 de diciembre del 2012, en el gobierno del Presidente José Mujica (2010-2014). Está ubicada en el interior del país. Es la más reciente incorporación al Sistema Nacional de Educación Pública.

58

http://www.educacion.mec.gub.uy 
La Administración Nacional de Educación Pública $(A N E P)^{59}$ es un Ente autónomo con personería jurídica, creado en marzo de 1985. Está compuesto por el Consejo Directivo Central (CODICEN) y por los Consejos de Educación Inicial y Primaria (CEIP) de 3 a 12 años; el Consejo de Educación Secundaria (CES) Educación Media básica y superior; el Consejo de Educación Técnico Profesional (antes conocido como Universidad del Trabajo o UTU) y el Consejo de Formación en Educación (CFE), creado a partir la Ley de Educación de $2008^{60}$.

Sus cometidos, en referencia a los niveles educativos de su competencia, son: elaborar, instrumentar y desarrollar políticas educativas; garantizar la educación a todos los habitantes del país, asegurando su ingreso, permanencia y egreso; asegurar el cumplimiento de los principios y orientaciones generales de la educación, y promover la participación de toda la sociedad en la formulación, implementación y desarrollo de la educación. (Artículo 53, incisos A, B, C y D, de la Ley General de Educación No 18.437)

La Universidad de la República (UdelaR) es un ente autónomo con personería jurídica que tiene a su cargo la enseñanza pública superior universitaria. Le compete acrecentar, difundir y defender la cultura; impulsar y proteger la investigación científica y las actividades artísticas; contribuir al estudio de los problemas de interés general y propender a su comprensión pública y defender los valores morales y los principios de justicia, libertad, bienestar social, los derechos de la persona humana y la forma democráticorepublicana de gobierno. (Artículo 2 de la Ley Orgánica No 12.549, del 29 de octubre de $1958)^{61}$ Se encuentra gobernada por un Consejo Directivo Central. Las diferentes instancias de co-gobierno se integran mediante designación de representantes de los tres órdenes (docentes, estudiantes y egresados) en cada uno de los órganos que componen la Universidad. (Artículos 202 y 203 de la Constitución de la República).

\footnotetext{
59 http://www.anep.edu.uy/ ANEP, creada por la Ley Nº15. 739, de marzo de 1985, Art. 5

60 La Ley General de Educación N 18.437 propone la creación del Instituto de Universitario de Educación, aunque no ha sido concretado a la fecha. Por eso se creó el Consejo de Formación en Educación (CFE), por El Acta Extraordinaria $\mathrm{N}^{\circ} 5$, Resolución $\mathrm{N}^{\circ} 1$ del 24 de junio de 2010. "Los cometidos de este Consejo son los que la ley $\mathrm{N}^{\circ} 18.437$ establece para los restante Consejos y su ámbito de competencia será la formación de profesionales de la educación. Incluirá la formación de educadores sociales. Este Consejo estará integrado por cinco miembros designados por el CODICEN de la ANEP..."
} 
El Sistema Nacional de Educación Pública (SNEP) está coordinado por una Comisión Coordinadora (artículos 106 y siguientes). A su vez se conforma de varias Comisiones asesoras, una de ella sobre el tema de Educación en Derechos Humanos.

\subsubsection{La Comisión Nacional de EDH}

El artículo 110 de la Ley de Educación creó una Comisión asesora en EDH para el SNEP

"artículo 110: La comisión Coordinadora del Sistema Nacional de Educación Pública conformará una Comisión Nacional para la Educación en Derechos Humanos que tendrá como cometido proponer líneas generales en la materia".

La comisión comenzó a reunirse en el segundo semestre del $2009^{62}$ compuesta por la Administración Nacional de Educación Pública-Dirección de derechos humanos (ANEP), la Universidad de la República-Instituto de derechos humanos, perteneciente a la Facultad de Derecho (UdelaR) y el Ministerio de Educación y Cultura- Dirección de Educación y Dirección de derechos humanos $(\mathrm{MEC})^{63}$. Se espera una próxima incorporación de un representante de la UTEC.

Dicha comisión viene trabajando en un proceso de construcción del Plan Nacional de Educación en Derechos Humanos (PNEDH). Como se señaló en el Capítulo III, esta idea viene de la órbita internacional como sugerencia del Decenio para la EDH y es retomada en el Programa Mundial para la EDH de la ONU. Una versión del documento "Bases hacia un plan nacional de EDH" fue presentada en febrero de 2015. El proceso cuenta con la aprobación en una primera instancia de la Comisión Coordinadora del Sistema Nacional de Educación Pública y con una estrategia de trabajo de cuatro jornadas en diferentes zonas del país (ver apartado 3 del capítulo III).

\subsubsection{Ejes transversales}

\footnotetext{
62 Tuvo un cambio de integración en los delegados del MEC en el 2010, por el cambio de gobierno.

63 La Dirección de Derechos Humanos del Ministerio de Educación y Cultura pasó en enero de 2014 a la órbita institucional de Presidencia de la República, convirtiéndose en la Secretaria de Derechos Humanos. Este cambio fue realizado a través de la Ley $\mathrm{N}^{\circ} 19.149$ (Rendición de cuentas y Balance de ejecución presupuestal 2012) en sus artículos 67, 68 y 69.
} 
La nueva ley, en su artículo 40, determina la creación de líneas transversales que deberán implementarse en las diferentes modalidades del Sistema Nacional de Educación Pública (artículo 20). Entre ellas se encuentra la educación en derechos humanos, a la que se considera como un derecho en sí mismo y un componente del derecho a la educación (artículo 40.1). Se formula de esta manera:

“artículo 40.1: La educación en derechos humanos tendrá como propósito que los educandos, sirviéndose de conocimientos básicos de los cuerpos normativos, desarrollen las actitudes e incorporen los principios referidos a los derechos humanos fundamentales. Se considerará la educación en derechos humanos como un derecho en sí mismo, un componente inseparable del derecho a la educación y una condición necesaria para el ejercicio de todos los derechos humanos."

La iniciativa de plantear la política educativa a través de líneas transversales hace referencia a una concepción integral de la educación, donde la formación de los individuos involucra tanto los aspectos intelectuales y de conocimiento como los ético-morales, que implican el proceso de construcción de ciudadanía. Apunta a la formación en los aspectos cognitivos, afectivos, actitudinales y procedimentales, con el objetivo de desarrollar capacidades críticas a los desafíos históricos, científicos, sociales y culturales de nuestra sociedad.

"La transversalidad de los derechos humanos introduce en el desarrollo del currículum y la práctica docente la propuesta de reivindicar la función moral y social de la escuela y resolver la cuestión entre enseñar conocimientos y educar para la vida. En este sentido la transversalidad debilita los límites entre el discurso institucional y el discurso regulativo (moral); establece puentes entre el saber sistemático-universal y el saber cotidiano-particular; promueve equilibrios entre la formación intelectualcognitiva, la formación afectiva y la valorica-actitudinal." (Magendzo, 2008:91)

Que el sistema educativo uruguayo considere a la educación como un derecho humano, implica replantearse los "por qué", "para qué", "para quién” y "como" de la educación (Sales, 2010). La propuesta de transversalidad da cuenta de una comprensión compleja del ámbito educativo, entendido como práctica social situada y vinculada a otras políticas públicas en el intento de abordar los problemas claves de hoy y con una mirada hacia el futuro, siempre que no se lo tome en forma compartimentada y/o descontextualizada (Gatti. 2010). Así se pretende una visión integral y sistémica del campo de la educación que no solo tenga en cuenta los contenidos a ser enseñados, sino que implique una práctica cotidiana que permita 
"avanzar en un progreso por el cual las personas pueden optimizar sus capacidades, adquirir conocimientos, crear hábitos, desarrollar su memoria, su inteligencia, socializase y obtener un desarrollo personal pleno. De esta forma, partiendo de los principios de gratuidad y obligatoriedad, la educación desde un enfoque de derechos humanos debe permitir a cada uno dar respuesta a sus necesidades de acuerdo a las exigencias de su entorno, dignificando a la persona y habilitándola para ejercer todos los otros derechos en condiciones de igualdad y no discriminación, concibiendo a la educación como el derecho a aprender a lo largo de toda la vida." (Prats, 2010:160)

A criterio de esa investigadora, la incorporación transversal de la EDH apunta hacia una acción que permita que las personas puedan aprender mutuamente en el encuentro con la información, con el otro y/o consigo mismas, generando procesos de toma de decisiones autónomos, conscientes y responsables, con una interpretación critica de la realidad; desarrollando las capacidades que impliquen transformar y transformarse de acuerdo a los desafíos que se van planteando en la realidad actual.

Prosiguiendo con un análisis de la Ley $\mathrm{N}^{\circ}$ 18.437, dentro de sus líneas transversales, además de la EDH ya mencionada, se encuentran las que se mencionan a continuación.

Educación ambiental para el desarrollo humano sostenible: pretende brindar conocimientos y desarrollar habilidades para mejorar las relaciones entre los seres humanos y sus entornos. (Artículo 40.2);

Educación artística: promueve a través de los diferentes lenguajes artísticos una educación integral, para el desarrollo de la creatividad, la sensibilidad y la precepción, impulsando la creación de universos singulares que den sentido a lo que es significativo para cada persona. (Artículo 40.3);

Educación científica: apoyándose en todas las áreas -social, natural y exactas - tiende a promover diversas vías para la comprensión y apropiación social del conocimiento científico y tecnológico para su democratización. Implica también la difusión de procedimientos y métodos para su generación y uso sistemáticos. (Artículo 40.4);

Educación lingüística: incluye las diferentes lenguas maternas del país (español de Uruguay, portugués de Uruguay y lengua de señas) y la formación plurilingüe a través de segundas lenguas y lenguas extranjeras. (Artículo 40.5);

Educación a través del trabajo: se orienta hacia la incorporación del concepto de trabajo como actividad humana y de integración social. (Artículo 40.6); 
Educación para la salud: pretende desarrollar una cultura de prevención y hábitos saludables. (Artículo 40.7);

Educación sexual: tendrá como el propósito proveer instrumentos adecuados que acerquen y promuevan, en educadores y educandos, una reflexión crítica ante las relaciones de género y la sexualidad en general para el disfrute responsable de la misma. (Artículo 40.8);

Educación física, en recreación y deporte: tendiente a desarrollar el cuerpo, el movimiento, la interacción y la actividad humana para contribuir al mejorar la calidad de vida, el desarrollo personal y social, así como la adquisición de valores necesarios para la cohesión social y el diálogo intercultural. (Artículo 40.9);

\subsubsection{Principio de participación.}

La Ley General de Educación en su artículo 48 plantea como un principio la participación de los diferentes actores de la comunidad educativa y de la sociedad en su conjunto:

“artículo 48:La participación de los educandos o participantes, docentes, madres, padres o responsables de la sociedad en general, en la Educación Pública constituirá uno de los principios básicos. Se promoverá el cogobierno en los ámbitos que corresponda, atendiendo los diferentes ámbitos y niveles educativos“"

Como ámbito del ejercicio de la participación de sus diferentes referentes, la ley crea los Consejos de Participación en cada uno de los centros educativos de todo el país (artículos 76, 77 y 78). Estos deben estar integrados por estudiantes, educadores, madres o padres y representantes de la comunidad. Cada Consejo de Participación reglamentará la forma de elección de sus miembros, así como su funcionamiento. Se destaca que para los centros de educación Media Básica y Media Superior como los de educación Técnico Profesional, los Consejos de Participación deberán tener al menos un tercio de representantes estudiantiles.

Tales Consejos pueden realizar propuestas a las direcciones de su centro de pertenencia sobre el proyecto educativo correspondiente; hacer acuerdos con otras instituciones; planificar la realización de obras acordadas dentro del centro y generar y gestionar recursos extra presupuestales y actividades socio-culturales del centro.

“artículo 77: A los Consejos de participación les compete realizar propuestas a la Dirección del centro educativo en relación: A) al proyecto educativo que en ejercicio de su responsabilidad profesional elabore la Dirección y el cuerpo docente del centro educativo; B) a la suscripción de 
acuerdos y convenios con otras instituciones según lo establecido; C) a la realización de obras en el centro educativo; D) a la obtención de otros recursos extra presupuestales; E) al destino de los recursos obtenidos y asignados; F) al funcionamiento del centro educativo; G) a la realización de actividades sociales y culturales en el centro educativo; $\mathrm{H}$ ) sobre todo aquello que lo consulte la Dirección del centro educativo".

A su vez, los Consejos de Participación podrán pedir informes y realizar propuestas a los Consejos de Educación respectivos por ser elementos partícipes de los procesos de autoevaluación de los centros educativos correspondientes.

Los Consejos de Participación vienen a sustituir a las Comisiones de Fomento ${ }^{64}$ que eran integradas por padres y vecinos de la comunidad barrial del centro educativo. Se destaca el lugar que se le asigna a los estudiantes para ser verdaderos protagonistas de la vida de sus centros de estudio.

Artículo 76: [en cada]"centro educativo público de Educación Inicial, Primaria, Media Básica y Media Superior y Educación Técnico-Profesional, funcionará un Consejo de Participación integrado por: estudiantes o participantes, educadores o docentes, madres, padres o responsables y representantes de la comunidad."

Es así que la Ley crea un ámbito concreto de participación de los diferentes actores de la comunidad educativa, dando contenido y función a este principio.

\section{3. Implementación de la nueva ley}

En síntesis, en la Ley General de Educación analizada aparecen varios elementos de innovación educativa y avances en materia de derechos humanos y de EDH. Esto representa el intento de articulación en el ámbito educativo de las concepciones ideológicas que están en juego en la sociedad. Repasemos sus principales aportes en tal sentido.

\footnotetext{
64 El concepto de Comisión Fomento en la Escuela Pública uruguaya fue creado por la Ley 8.012 de 1926, donde se señala que toda escuela pública tendrá una. De acuerdo al último reglamento del Consejo de Educación de 2004..."tendrán como única finalidad la colaboración armónica con las Autoridades Escolares, en beneficio de la Enseñanza Primaria, quedándoles expresamente prohibido intervenir en las actividades docentes..." (artículo 22). Colaboran en tareas y actividades acordadas con las direcciones respectivas de cada escuela, como ser: limpieza y mantenimiento de los locales escolares, compra de materiales, pago a algún profesor especial, paseos y salidas didácticas, etc.
} 
La ley está formulada desde un enfoque transversal de EDH, se inicia con un planteo enmarcado en los derechos humanos y ubica a la educación como un derecho humano. Se procura una comprensión de la vida humana de forma integral con un concepto "bio-psicosocio-ambiental", en concordancia con los planteos de EDH como disciplina pedagógica.

En cuanto a la obligatoriedad de la escolarización, esta ley amplía el rango de cobertura al incluir la educación inicial desde los 4 años (artículo 7). También promueve la inclusión y la diversidad, al declarar el apoyo específico a personal, colectivos y sectores en situación de vulneración (artículo 8) como una forma de inclusión social y para alcanzar la igualdad real de oportunidades y aboga por una transformación de los estereotipos de discriminación (artículo 18). Asimismo plantea el principio de participación como básico, apelando a la participación de múltiples actores de la comunidad educativa y creando una instancia para ello como son los Consejos de Participación.

Cuando la ley plantea sus ejes transversales destaca en primer lugar a la EDH, definiéndola como un derecho en sí mismo y como un componente del derecho a la educación. En la organización del Sistema Nacional de Educación Pública (SNEP) crea una comisión sobre la temática de EDH con el mandato de asesorar y proponer líneas de acción en la materia.

Luis Garibaldi, ex Director de Educación del Ministerio de Educación y Cultura (MEC) ${ }^{65}$, redactor de la Ley General de Educación ( $\mathrm{N}^{\circ} 18.437$ - 2008), comenta:

“La ley... lo que plantea, es la aparición de la EDH en más de un lugar.

Primero aparecen los derechos humanos como un eje, como fundamento de la propia Ley. En primer lugar los derechos humanos en general y en segundo lugar en la educación como un derecho.

Después aparece la EDH, como un derecho en sí mismo, como una línea transversal. En algunos aspectos hay quienes plantearon, cuando se discutió esto, que engloba todas las otras lineas y todos los otros derechos. ${ }^{66}$

65 Luis Garibaldi ya no ocupa el cargo de Director de Educación del MEC, desde marzo de 2015, cuando se realizó el cambio de Gobierno. Hoy desempeña funciones como integrante del Consejo de Formación en Educación (CFE-ANEP).

66 En coincidencia con Abraham Magendzo, quien también plantea a la EDH como la línea transversal por excelencia, que incluye a las demás. 
$Y$ después aparece especificamente, como una forma de aterrizarlo, la creación de la comisión [de EDH].

Desde ese punto de vista diríamos que la ley es muy coherente y muy completa en ese sentido. El enfoque es el mismo en toda la ley, sobre derechos humanos. Y después establece contenidos específicos y después crea una comisión para aplicar. $Y$ además aparece luego en distintos ámbitos la idea de los derechos de los educandos, de los docentes, de las familias." (entrevista a Luis Garibaldi)

En suma, esta ley presenta importantes méritos en cuanto a los avances en su concepción desde un enfoque de EDH (principios, objetivos y contenidos). Sin embargo, aunque existe una coherencia interna en la explicitación durante su desarrollo, su implementación plantea varias dudas. En el transcurso de las entrevistas que se realizaron durante la presente investigación surgieron importantes preocupaciones.

Una de estas preocupaciones es la diferencia entre los planteos teóricos de EDH, las definiciones formales, la normativa, y la aplicación de la EDH en las prácticas en las escuelas. En relación a este desfasaje, el ex Director de Educación del MEC comenta:

"Bueno, ahi es donde tenemos mayores dificultades, en la práctica educativa. Porque en ocasiones, o se trabajar sin tener conciencia que se trabaja, o cuando se trabaja con conciencia, en varios casos, se hacen actividades más reducidas. Se reduce el concepto de derechos humanos a algún derecho en particular. $O$ a algún tipo de actividades en particular y no se lo transversaliza a las demás áreas..." (Entrevista a Luis Garibaldi)

Así aparecen las inquietudes sobre la conceptualización del trabajo educativo con ejes transversales y como este se ve reflejado en la práctica escolar.

Luis Garibaldi plantea como un problema el concebir la EDH como línea transversal. “... No tiene [la EDH] todavía una adscripción estricta en la gramática escolar especifica... puede quedar en la nada". Para este entrevistado la EDH corre el riesgo de quedar vacía de contenido si no aparece explicitada en algún lugar en particular. Pero también plantea la contradicción que puede existir cuando se describen contenidos específicos en los programas: aquí se puede correr el riesgo de reducir el enfoque de derechos, de limitar su abordaje a lo descriptivo o en un tratamiento aislado.

“...cuando aparece explícitamente ayuda, pero la puede reducir a determinados contenidos, a determinadas actividades, o por ejemplo en el caso de secundaria y sobre todo en formación docente, en la responsabilidad de alguna asignatura o docente en particular y pierde ese carácter transversal. No es sencillo en todas 
aquellas áreas que son más bien transversales, cuando no se planifica y no se trabaja de manera interdisciplinaria, que es parte de [un abordaje] transversal." (...)

[Hay contenidos que] “... son transversales porque tienen que desarrollarse a lo largo de todo el sistema educativo, en todos los niveles..."... son efectivamente transversales, porque son efectivamente inter y trans- disciplinarios."(entrevista a Luis Garibaldi)

La dificultad para comprender los ejes transversales también hace a una característica de las prácticas educativas que fragmentan el objeto de conocimientos y reducen el proceso de aprendizaje de forma focalizada a los contenidos a trabajar. Se suele omitir un enfoque de comprensión de los conocimientos de forma más global, dando valor a los contextos y las realidades, así como a las interacciones entre estas.

"Pero también te diría que es una dificultad [de la comprensión de líneas transversales,] es producto del enfoque de las prácticas educativas. Estas están más enfocadas sobre los contenidos y no sobre una mirada global y partiendo de la realidad." (entrevista a Luis Garibaldi)

Los conceptos de abordajes desde la interdisciplina, la transdisciplina y una mirada global, integral, sobre las situaciones sociales en general y educativas en particular son el resultado que aparece como habilidades y actitudes necesarias a desarrollar para nuestra sociedad actual, y que acompañan un enfoque diferente en el ámbito educativo. Es su diferencia con el abordaje surgido de la modernización educativa (concepción liberal y neoliberal), que planteaba la fragmentación y especialización del proceso de aprendizaje. Es desde este enfoque integral/holístico que se plantea la incorporación de ejes transversales en la educación, aunque encuentra, actualmente, algunas dificultades en la puesta en práctica.

La entrevistada Margarita Navarrete enfatiza la cercanía de la EDH con los ámbitos y estrategias metodológicas de la educación no formal. Este elemento no es menor a la hora de pensar y plasmar la EDH en prácticas de educación formal, ya que estas dos dimensiones de la educación son diferentes en sus orígenes y objetivos. Aparece también esta vinculación desde la dimensión histórica porque en nuestro continente la EDH recoge muy significativamente los aportes teóricos y prácticas sociales de emancipación que hacen al pensamiento crítico, la educación popular, la teoría de la liberación (Juanche, 2013), los movimientos de participación social-comunitaria y la psicología social, entre otras corrientes. 
Otra área de trabajo importante en la EDH que destaca la ley y que es visualizada con preocupación por algunos de nuestros entrevistados es la experiencia de los Consejos de Participación. Esta práctica es muy escasa ya que no se está llevando a cabo en un gran número de centros educativos. Existen en cada centro realidades diferentes que hacen cuestionarse si las prácticas de la participación no necesitan que se creen algunas condiciones previas para que estas se desarrollen desde un enfoque de derechos. Parece que no alcanza con el mandato en la normativa. Para que los diferentes protagonistas puedan aprender a participar desde un rol de "formar parte" de un grupo y "tomar parte" en las decisiones de ese grupo, donde se respeten los diferentes roles y se pueda construir en común, hay que trabajar para generar las condiciones necesarias para que se dé una participación con enfoque de EDH. Martín Prats sobre este tema nos decía:

"La ley mandata la implementación de los Consejos de Participación, pero también en todos estos años de la ley para acá no basta con la obligación legal de que haya Concejos de Participación, sino que hay que aprender a participar, hay que crear las condiciones para desarrollar una participación genuina. Y ahí vemos que la realidad de los centros puede ser muy distinta. Pero también existe la preocupación de cómo trabajamos este tema, y cómo ir a la participación con una dimensión de derechos. ¡Eso es un paso adelante!... Yo creo que en muchos centros educativos la convivencia en clave de derechos, con el tema de la participación en clave de derechos está instalada. Habría que evaluar si es después de la conciencia o se han desarrollado prácticas en los centros educativos, más amigables, donde se respeta de mejor manera los derechos de todos."(Martin Prats)

Recapitulando, entonces, si bien la ley decreta la creación de los Consejos de Participación en cada centro educativo del país, esto no es una realidad todavía.

Estas dificultades sobre la implementación de la ley muestran al ámbito educativo como un campo de contradicciones, donde se desarrollan conflictos y que presenta varias formas de concebir la práctica educativa y cómo se la lleva adelante.

\section{El Programa de educación inicial y primaria.}


Desde el año 2006 se comenzó en el Uruguay con la revisión y actualización de varios programas del sistema educativo, tanto en el nivel primario como en secundario. El resultado fue un nuevo Programa de educación inicial y primaria, que tiene avances importantes en materia de EDH. El documento fue aprobado por el Consejo Directivo Central (CODICEN) de la Administración Nacional de Educación Pública (ANEP) por Resolución $\mathrm{N}^{\circ} 2$, acta ext. $\mathrm{N}^{\circ} 21$ del 12 de diciembre de 2008 y comenzó a ser utilizado en marzo del 2009 en todo el territorio nacional. Abarca las edades de tres años a doce años, es decir, desde el comienzo de la educación inicial al $6^{\circ}$ grado de primaria.

En este apartado se analiza el nuevo Programa de educación inicial y primaria con énfasis en los elementos que se relacionan con la EDH. El documento programático contiene una fuerte impronta de derechos humanos; se observa que tiene incorporados los principios, objetivos y contenidos de EDH tanto en su fundamentación conceptual como didáctica. El nuevo Programa implica una renovación y actualización en nuestro país en materia educativa curricular, que acompaña y complementa la nueva Ley General de Educación en la que, como ya se mencionó, la EDH constituye una línea transversal.

También, a través de las opiniones de los entrevistados, se reflexiona sobre algunas dimensiones que hacen a las prácticas educativas desde la implementación del Programa con foco en la EDH. Es un elemento sustancial a la hora de analizar integralmente la implementación de una política pública de EDH, ya que esta, desde su conceptualización teórica y metodológica está vinculada directamente con la experiencia, con la dimensión vivencial.

\subsection{Análisis del Programa de educación inicial y primaria.}

Desde su proceso de elaboración, en el Programa de educación inicial y primaria se destacan innovaciones en aspectos de acción curricular. Por ejemplo, desde un principio el texto mismo del programa enfatiza la participación de los docentes de múltiples formas: integración de grupos de trabajo, jornadas de reflexión y análisis, Asambleas Técnico Docentes de todos los centros educativos del país, y asambleas nacionales, entre otras. Se destaca un trabajo continuado de la mesa permanente de las Asambleas Técnico Docentes como órgano consultivo y asesor. 
Es indispensable hacer una mención sobre las Asambleas Técnico Docentes (ATD). Estas constituyen órganos públicos deliberantes con facultades de iniciativa y funciones consultivas en asuntos técnico-pedagógicos del sub-sistema de enseñanza a la que pertenecen (primaria, secundaria o técnica), así como en temas de educación general. Fueron generalizadas por la Ley de Educación $\mathrm{N}^{0} 15.739$ de 1985, si bien existieron algunas experiencias anteriores en el sector de secundaria, y en ellas participan todos los y las docentes del sistema de ANEP. Funcionan por establecimiento educativo (escuelas, liceos, centros, institutos, etc.), así como en Asambleas Nacionales correspondientes a cada Consejo Desconcentrado (Primaria, Secundaria y Educación Técnico Profesional) y en la Dirección de Formación y Perfeccionamiento Docente. Están reguladas por la circular 1950, del CODICEN de la ANEP. Los miembros de la Asamblea Nacional de ATDMagisterio, al igual que de los otros sub-sistemas, son elegidos cada tres años por el sistema de representación proporcional integral mediante elecciones organizadas y verificadas por la Corte Electoral. La Asamblea citada está compuesta por 190 delegados, de los cuales 95 se eligen en circunscripción nacional y los 95 restantes a razón de 5 por departamento. Para el mantenimiento y la continuidad del trabajo de la Asamblea Nacional se elige entre los delegados una Mesa Permanente de la ATD de cinco miembros.

Retomando el análisis de Programa, en su introducción también se señala que participaron en la elaboración, en carácter de invitados, profesores de enseñanza secundaria y docentes universitarios. Estos docentes aportaron, cada uno desde sus propios campos disciplinarios, en la organización de las áreas de conocimiento y en los contenidos a ser enseñados.

En la nueva propuesta programática los derechos humanos tuvieron un lugar central; Ya en 2007 el Congreso de Inspectores ${ }^{67}$ había recomendado al grupo de trabajo ${ }^{68}$ designado para realizar la propuesta incluir tres lineamientos generales: 1) políticas educativas universales, 2) programa único y 3) programa centrado en los derechos humanos.

\footnotetext{
$67 \quad$ Son encuentros de lo/as inspectores de un sector, de todo el país, para este caso fue citado por el Consejo de Educación Primaria -CEP (actual CEIP, Consejo de educación inicial y primaria) para elevar propuesta para el nuevo programa de ed. inicial y primaria.

${ }^{68}$ El grupo de trabajo estuvo conformado por representantes del Consejo de Educación Primaria, la Asamblea Técnico Docente Nacional y la Federación Uruguaya del Magisterio.
} 
El Programa señala que el contexto que da sentido a la función educativa y orienta la construcción de ciudadanía en el siglo XXI son las ideas directrices de Democracia Social e Integralidad, y las define de esta manera:

- La Democracia Social se fundamenta en los Derechos Humanos, la diversidad, la participación, el posicionamiento ético, el trabajo digno y la solidaridad.

- La Integralidad se expresa a través de la estética, la educación ambiental, la promoción de la salud y la sexualidad". ${ }^{69}$ (Programa. 2009: 12)

Es de destacar que dentro de los cambios se incorporan como innovación dos Áreas de Conocimiento: el Área de Conocimiento Artístico, que incluye Artes visuales, Música, Expresión corporal, Teatro y Literatura; y el Área de Conocimiento Social que crea un nuevo campo de conocimiento, la Construcción de Ciudadanía, elaborado a partir de dos disciplinas: la Ética y el Derecho. En esta última basaremos el análisis.

En la fundamentación del campo de Construcción de Ciudadanía encontramos un modelo de educación en el marco de los derechos humanos, tanto en el orden del conocimiento como en la práctica social comprometida con los contextos de pertenencia y referencia.

Se justifica la práctica educativa como "praxis liberadora", que da marco a la Teoría de Crítica Social como posibilidad de superar etapas en el proceso histórico social, desde la postulación de compromisos éticos, solidarios y de responsabilidad social comunitaria, “...orientado hacia la construcción de una sociedad más justa donde el sujeto adquiere poder para desocultar las formas de dominación y está en condiciones de diseñar un modelo de educación en el marco de los Derechos Humanos. (Programa 2009:18). Se destaca una concepción de ser humano integral, en profunda vinculación con los contextos sociales donde habita, se relaciona y es protagonista con la capacidad de transformarlos. Por esto se plantea que toda práctica educativa debe estar enmarcada en la EDH.

"La centralidad del hombre exige que los derechos humanos impregnen el proceso educativo. Para ello debe conocerlos, lo que implica descubrirlos en la práctica social para comprender que no son neutros, que suponen opción, que significa no

\footnotetext{
69 Administración Nacional de Educación Pública, Consejo de Educación Primaria, PROGRAMA DE
} EDUCACIÓN INICIAL Y PRIMARIA, año 2008, pág. 12. 
aceptar cualquier comportamiento social, político o cultural, que exige valorar situaciones, posiciones, prácticas y relaciones.” (Programa 2009:18)

Para este Programa, educar para los derechos humanos implica pensar, comprender, practicar y argumentar desde estos derechos, que son concebidos como conquistas, como construcción colectiva a lo largo de la historia de la humanidad, y por tanto son considerados universales y obligatorios para todas las personas en cualquier situación.

“Los Derechos Humanos son una cuestión pública. Lo público ha estado y continúa estando vinculado con lo universal, lo referido a todos, a la sociedad en general, al pueblo. Por ello constituye un compromiso y responsabilidad del Estado garantizar el derecho de todos a la educación, la cultura, la salud y la vida." (Programa 2009: 19)

Dentro de la obligación del Estado de garantizar el derecho a la educación como un derecho humano fundamental se encuentran la obligatoriedad y gratuidad como principios fundantes. También se plantea la autonomía financiera y técnico-profesional del sistema educativo; el principio de laicidad como garantía para una cultura democrática plural, así como la igualdad, integralidad y libertad, conceptos centrales para la formación integral del ser humano y de la ciudadanía.

Se concibe a la educación implícita en la cultura y, por lo tanto, la apropiación y producción de diferentes conocimientos que intervienen en ella son los procesos y situaciones que nos permiten definir qué es enseñar y qué es aprender.

Al definir al sujeto de la educación primaria como al niño, poseedor de una identidad cultural propia, de una historia personal, unido a un contexto social concreto que comprende y conforma su vida, reconoce al niño como sujeto de derecho. Se plantea la importancia de la formación de los sujetos de la educación, de los sujetos de derechos, en un proceso donde la interdisciplinariedad hace a la comprensión de los marcos de referencia para asumir el desarrollo de las personas, de estos niños y niñas, como formación integral acorde a los tiempos que corren.

"La educación de nuestro tiempo requiere este enfoque antropológico, político y ético. Conjuntamente con este encuadre humanista y socio-crítico referido al desarrollo de la persona humana, es necesario plantear una formación para la democracia, la ciudadanía y los derechos humanos. (Programa. 2009: 26)

Como los fines de la educación Inicial y Primaria, el Programa plantea: 
- Educar para ser ciudadanos activos, capaces de ser protagonistas en la construcción de sociedades democráticas, y una enseñanza que permita valorar y participar de las manifestaciones, de los conocimientos y saberes de las artes, las ciencias, y la cultura de la humanidad;

- Educar para desarrollar un pensamiento crítico sobre el conocimiento y la información brindada, y

- Formar sujetos éticos, corresponsables capaces de tomar sus propias decisiones. (Programa.2009:37 y 38)

En la fundamentación dentro del Campo de construcción de ciudadanía se destaca a los derechos humanos como valores universales, incorporando una multiplicidad de saberes para la definición del concepto y su abordaje didáctico. Son los ejes centrales Democracia, Ciudadanía y Derechos Humanos.

En el último aparece un desarrollo histórico en la teoría de las generaciones, destacando a la Convención de los Derechos del Niño y la concepción del "niño como sujeto de derecho". Como temas de problematización del mundo actual para una reflexión crítica de los derechos propone género; consumo y ciudadanía; sexualidad; trabajo; tecnología y medios de comunicación; Cultura de Paz y discriminación;

Los objetivos generales del Área de conocimiento social son:

- Contribuir a la formación de ciudadanos críticos, responsables, autónomos desde un marco de derechos;

- Enseñar acciones y conductas desde criterios críticos donde el análisis de los hechos, las acciones y las opiniones, permitan desarrollar el respeto y la solidaridad por todas las personas y las diferentes minorías, el juicio crítico $\mathrm{y}$, valorar otras culturas;

- Construir las normas de la convivencia desde, el respeto por las diferencias, la cooperación, la solidaridad y la participación en la vida democrática, y

- Estimular la formación de "sujetos situados" con identidad nacional y latinoamericana (Programa.2009:107.) 
Se puede destacar en el Programa un tratamiento transversal de los temas de identidad de género, tratado desde la valoración de uno mismo y del otro, como construcción social, estereotipos sociales, etc. y las condiciones de convivencia en el hogar y en la escuela, y el trato con los pares. Estos son puntos que están desde los 3 años de edad hasta el final. El valor de la palabra, el diálogo y el posicionamiento frente a conflictos aparece desde los 5 años hasta el final. Esta concepción de recursividad, donde un cierto tema aparece varias veces, es una noción fuerte que está planteada en las fundamentaciones de las Áreas y Disciplinas a lo largo de todo el programa.

En el planteamiento de las áreas aparecen varios esquemas de Redes Conceptuales tanto por áreas como por disciplinas. En los esquemas del Área de Conocimientos Social se encuentran expuestos los esquemas por disciplinas de forma separada. En los que corresponden a la Construcción de ciudadanía se encuentran dos esquemas: el de Ética y el de Derecho.

\subsubsection{Redes conceptuales y contenidos de las Áreas y Disciplinas.}

Construcción de Ciudadanía-Ética/Construcción de Ciudadanía-Derecho.

Cuadro extraído del Programa de Educación Inicial y Primaria. Pág. 136 y 137 

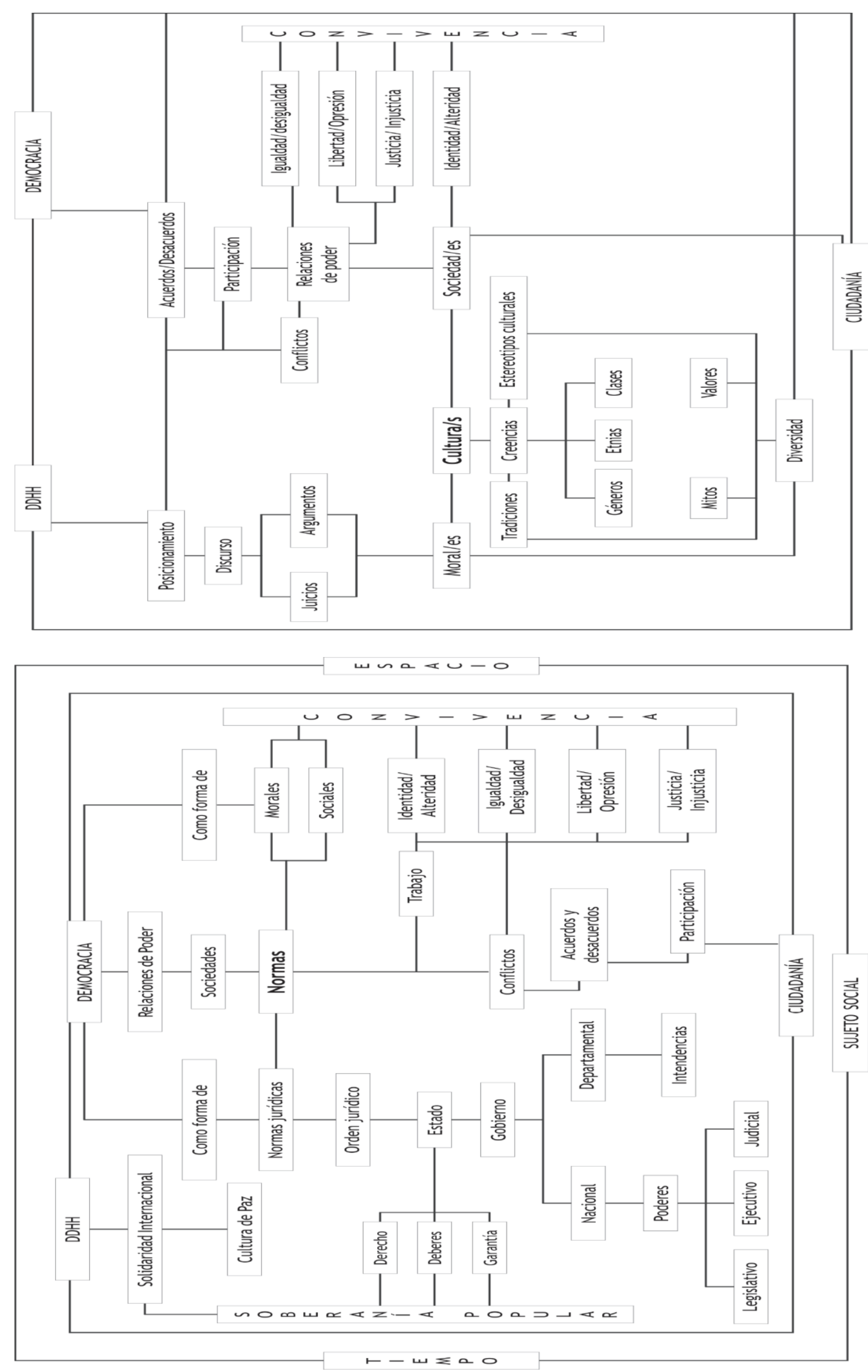
En el apartado de contenidos aparecen en forma de esquemas, unos listados por grados y por áreas y disciplina, donde se enumeran contenidos.

En cuanto a los Derechos que se mencionan explícitamente para ser enseñados, en el Programa encontramos:

- Derecho a tener un nombre (en el nivel correspondiente a los 3 años de edad);

- Derecho a tener una familia (en el nivel correspondiente a los 4 años);

- Derecho a tener una opinión (en el nivel correspondiente a los 5 años);

- El niño como sujeto de derecho (en $1^{\circ}$ grado);

- Derecho a elegir y los límites de la vida en comunidad. Derecho a la integridad física y moral. Derecho a la intimidad (en $2^{\circ}$ grado).

- Derecho a la educación. Derecho a la libertad de culto. Derecho de los consumidores. Derecho a la protección social (marco legal para la seguridad y denuncias...) Gobiernos departamentales. (en $3^{\circ}$ grado).

- Las relaciones de poder: las mayorías y las minorías. El trabajo y la dignidad. Derechos de los trabajadores. Participación política y sistema democrático (en $4^{\circ}$ grado).

- Libertad de expresión y de opinión, garantías constitucionales. Derecho a la opción sexual. Democracia como forma de gobierno. Derecho a la igualdad laboral y ámbitos de negociación salarial. Derecho a la seguridad social (en $5^{\circ}$ grado).

- Derechos Humanos, conquistas, generaciones, vida como valor, Declaración Universal de Derechos Humanos, organismos humanitarios La cruz Roja. Soberanías nacionales en el contexto internacional. Construcción de una cultura de paz como alternativa a diferentes formas de autoritarismo. La violencia que genera la exclusión social. La construcción de la sexualidad en el marco del proyecto de vida (en $6^{\circ}$ grado).

Además, se encontraron algunos contenidos que también involucran a la EDH en el desarrollo temático de los programas dentro de otras áreas. Por ejemplo, en el Área de Conocimiento Social, en las materias de Historia (creación de la ONU y rupturas institucionales en $6^{\circ}$ grado) y Geografía (diversidad étnica y cultural de la poblaciones americana, y movimientos migratorios en $5^{\circ}$ grado). También existen elementos en el Área de Conocimiento de la Naturaleza en la materia Biología (el ambiente y la salud, y la alimentación en $4^{\circ}$ grado); en el Área de Conocimiento de Lenguas (el debate a través de la exposición de opiniones y argumentos y contra argumentos en $4^{\circ}$ grado), así como en el Área de Conocimiento Artístico (la comunicación interpersonal, juegos teatrales y construcción intragrupal en $3^{\circ}$ grado). 
Con estos ejemplos se quiere señalar que existen varias modalidades de incorporación de los elementos de EDH en el programa estudiado, que no se limitan exclusivamente a la creación del Área de Construcción de la Ciudadanía.

\subsubsection{Puesta en práctica del Programa}

En la actualización del presente Programa se observa que existe un progreso del Estado uruguayo en cuanto al tratamiento que se le da a la inserción y desarrollo de los derechos humanos dentro los programas curriculares de educación formal. Esto se ve tanto en su concepción más integral así como en el planteo de las áreas de conocimientos. En la justificación general del Programa se pueden comprender y aprehender con mayor cabalidad y complejidad los principios teórico-conceptuales de universalidad, integralidad y multidimensionalidad de los derechos humanos. A su vez se observa una mayor explicitación y tratamiento directo de temas de derechos humanos como contenido dentro del currículo escolar.

En el Programa se propone un tratamiento más destacado de temas y problemáticas vinculados con los derechos económicos, sociales y culturales, así como sobre la igualdad y no discriminación en diferentes esferas: de género, racial, social, laboral, económica y generacional. También se pretende generar reflexión y pensamiento crítico frente a situaciones de conflictividad social. Existe un trato importante y destacado de la educación para la ciudadanía y la democracia.

Asimismo está explicitada la búsqueda a través de los planteos didácticos de un sujeto de la educación más activo en su proceso de enseñanza aprendizaje, más protagonista. El posicionamiento y la reflexión frente a diferentes situaciones sociales son una metodología destacada desde el planteo teórico que realiza el programa. Esta búsqueda implica el desarrollo de una didáctica y una metodología que apunten a favorecer e impulsar habilidades y capacidades en los y las estudiantes que les permitan asumir una actitud de sujetos de derecho activos en la sociedad y tomar decisiones responsables y coherentes con los principios éticos de los derechos humanos. 
En contraposición a los avances planteados en este nuevo Programa, se observa con preocupación un reducido tratamiento de conocimientos sobre los sistemas y los instrumentos internacionales de protección de derechos humanos (tanto universal como regional), así como la falta de información sobre las diferentes instancias de los mecanismos de protección y sus seguimientos. Se percibe además que no existe un señalamiento sobre los instrumentos de Derecho Internacional de los Derechos Humanos (DIDH) ratificados por el Estado uruguayo, excepto la Declaración Universal de Derechos Humanos y la Convención de los Derechos del Niño.

También podemos ver en el programa un tratamiento desparejo de elementos conceptuales sobre la concepción del sujeto integral y de educación integral. Si bien existe una tendencia hacia la integralidad, sobre todo discursiva, esto no se refleja en la formulación y tratamiento que se da al interior de cada área de conocimiento. Se encuentran contenidos esquematizados, listado de contenidos e información a ser trabajada, lo que da un resultado algo atomizado. Esto no facilita el tratamiento de estos contenidos en la práctica de forma integral e interrelacionada.

La forma en que los contenidos y temáticas son presentados no estimulan la integración y transversalización propuesta en los objetivos del programa. Se plantean algunas dudas respecto a su implementación. Por ejemplo ¿está todo el cuerpo docente capacitado para llevar adelante este Programa con una concepción acorde con la $\mathrm{EDH}$ ? ¿O en la práctica queda librado a la comprensión y sistematización que cada docente realice para llevarlo adelante, según una visión de EDH y educación participativa, o como una mera reproducción de los contenidos?

Hay que señalar que el Programa no está escrito en lenguaje género sensitivo y que utiliza en muchas oportunidades el término "hombre" como genérico de ser humano. El incluir un lenguaje de género sensitivo en el texto oficial del programa de educación inicial y primaria hubiera sido un avance importante para profundizar la coordinación y coherencia 
en la política pública educativa, ya que dicho objetivo está señalado en la Ley General de Educación (artículo 12) y en el primer Plan Nacional de Igualdad de Oportunidades y Derechos (2007-2011).

Frente a este Programa existe un reclamo que realizan las ATD y los sindicatos de la enseñanza. Estas organizaciones hacen una crítica a las autoridades por no haber tenido en cuenta las sugerencias planteadas en las etapas de consultas y por no haberse capacitado suficientemente a los colectivos docentes para una adecuada implementación del nuevo Programa. Son críticas con los procedimientos de validación y la implementación tanto del Programa como de la Ley.

\subsection{La introducción de la EDH. Un paso adelante y muchos desafíos.}

La incorporación de la EDH en la educación formal no tiene una justificativa única, sino que debe ser comprendida en los contextos sociales en que se procesa, a nivel internacional y local. Al introducir a nivel formal la EDH en la normativa educativa, Uruguay cumple con algunos objetivos y estándares de nivel internacional: el derecho a la educación y el derecho a la EDH, así como el Programa Mundial para la EDH (Resolución 50/113b de la ONU). Pero su incorporación a la normativa nacional y su puesta en práctica son también el resultado del trabajo y lucha de colectivos y personas comprometidos con los derechos humanos y la justicia social en nuestro país.

La EDH implica la complejidad que hace al cruce de varias dimensiones y que no puede estar ajena a las realidades donde se desarrolla. De ahí su potencial de creatividad y transformación. Es así que su explicitación en la normativa educativa, tanto en la Ley como en el Programa y a partir de ahí su tratamiento en los centros educativos, son elementos que impulsan y renuevan la escena educativa.

De acuerdo con varios entrevistados, la inclusión de los derechos humanos y la EDH dentro de la normativa educativa es un avance importante, pero esto no quiere decir que 
signifique una incorporación total y global. Fernando Willat, encargado de EDH de la Secretaria de DDHH de Presidencia e integrante de la Comisión de $\mathrm{EDH}^{70}$, sostiene:

"Por un lado hay un nivel de incorporación de la temática de derechos humanos en el programa de primaria; se empieza a incorporar en los discursos; en los textos empiezan a aparecer referencias. Uno lo empieza a encontrar en forma más o menos repetida. Eso es una señal de algo. ¡Algo está pasando!...

...El hecho de que uno consiga que a nivel normativo estén reconocido los derechos humanos es una primera conquista, pero no los vuelve efectivos. Luego hay que empezar a dar una pelea adicional."

El entrevistado daba su explicación sobre la importancia de la incorporación de la EDH en la normativa, como el resultado de los procesos de lucha que hacen a las conquistas de los derechos humanos. Visualizaba este hecho como el resultado militante de un colectivo comprometido con este tema y causa: "Creo que lo que está pasando es que hay alguna gente que ha sido militante de la EDH, que ha peleado para que eso se incorpore, y va logrando que en algún lugar de la institucionalidad haya un anclaje."(Entrevista a Fernando Willat)

No desconoce que la tarea de la EDH en la sociedad de hoy genera y conlleva una profunda brecha entre discurso y práctica. Deja clara la existencia de dos dimensiones distintas que hacen al quehacer educativo: el orden del discurso y la vivencia concreta.

"Otra cosa es que después la vida concreta de las instituciones lo vuelva carne cotidianamente, seguramente hay una distancia. ...otra cosa todavia es que haya coherencia entre el funcionamiento de las instituciones y el discurso. Porque de pronto se incorpora porque hay que hacerlo y se incorpora en un discurso que puede tener una práctica contradictoria. Pero, bueno, los avances de derechos humanos funcionan un poco así. Sí suele haber una avanzada que pelea y conquista un espacio. En lo institucional la cultura masiva suele estar rezagada en relación a eso. Entonces aparecen prácticas contradictorias. La propia institucionalidad está encarnada en personas, que por lo tanto hacen que el propio funcionamiento institucional no sea consecuente plenamente con esa intención que estaba formulada en los objetivos. Pero de alguna manera en la medida que eso está, empieza a habilitar otras posibilidades para seguir dando la pelea..." (Entrevista a Fernando Willat)

\footnotetext{
70 La Secretaria de Derechos Humanos de Presidencia, fue en un inicio la Dirección de Derechos Humanos del Ministerio de Educación y Cultura, organismo que integra la Comisión de EDH, de la cual salió un representante a la misma. Al efectivizarse este cambio de pertenencia institucional en enero del 2014, dicho representante se mantuvo vinculada a la Comisión de EDH.
} 
El Director de Derechos Humanos del CODICEN, Dr. Martin Prats, plantea también esa vertiente de la complejidad de la EDH. La temática está instalada en el sistema, pero la práctica concreta aparece como el campo de dificultad.

"Un poco por lo que dijo Pérez Aguirre, u otros que han pensado la EDH. Que la EDH no es solamente posición de contenidos sino que son fundamentalmente prácticas. Entonces, en cuanto a esas prácticas y cómo llevar adelante realmente una EDH que apunte a la convivencia de todos los actores educativos, que las relaciones interpersonales se lleven desde los derechos humanos, bueno, i; ahi falta mucho!!.. Porque para enseñar los derechos humanos hay que sentirlos!! Entonces es una transformación cultural que tratas que llegue a los docentes y que los docentes sientan los derechos humano cuando traten de enseñarlos. ... En eso falta, porque es una tarea permanente. Entonces uno puede establecer determinados planes, programas, algún objetivo a lograr, pero ese cambio de cultura, es un cambio a mediano, a largo plazo. Donde se va de a poco."

Es así que aparece claramente la dimensión de la vivencia como ámbito importante para la EDH. Lo que se siente da sentido a la reflexión, a la enunciación y a la argumentación, para pasar a la acción entendida como educación integral. Porque los tiempos de los aprendizaje integrales no son los mismos que los de los aprendizajes racionales. En el enfoque integral del aprendizaje es importante tener en cuenta que todas las personas tienen diferentes motivaciones y que estas diferencias deben tenerse en cuenta para los procesos educativos pues son las que van a permitir un aprendizaje significativo para cada uno. Esto involucra el éxito de una propuesta de EDH bien planteada desde el educador.

Surge aquí la pregunta de si la letra normativa, el contenido programático, alcanza para motivar a los y las docentes a trabajar profundamente en EDH.

\subsection{Programa único, diferentes miradas sobre edh.}

La llegada al gobierno en 2005 de un nuevo partido político con orientación progresista implicó un cambio significativo en las tendencias del país. Comenzó un período de revisión y replanteos de las políticas públicas, durante el cual la educación inició una etapa de reflexiones y nuevas iniciativas.

Al igual que Martín Prats, Margarita Navarrete identifica el período anterior a la promulgación de la nueva Ley de Educación, es decir entre 2006 y 2008, como el período 
más interesante de incorporación de la EDH. En esa época también se desarrolla el diseño del nuevo Programa de educación inicial y primaria.

..."el programa llevó más tiempo discutirlo y lo que sí implicó es ver como un esfuerzo, de cada edad, de cada nivel, para poder incorporar la visión de derechos humanos. Donde ahí si implicaba desterrar la idea de que a partir de una edad habia que empezar a educar en derechos humanos. Ya sea que se le llame derechos humanos o no, pero sí desde la educación inicial se puede trabajar con los niños y con las niñas en estos temas. Y con los docentes."(Entrevista a Margarita Navarrete)

Se da cuenta que en el ámbito educativo se encontraba en marcha algunos procesos de cambios, de reformulación de estrategias y enfoques.

\subsubsection{Movimientos del ámbito educativo entre un enfoque tradicional y un enfoque integral.}

Se puede reconocer que existen diferentes visiones sobre la educación. Encontramos claramente diferencias sobre modelos más tradicionales que apuntan a comprender a tarea educativa con un énfasis en la enseñanza de contenidos, en la capacitación para determinadas actuaciones, o modelos donde lo que prima es la formación en los sujetos críticos, reflexivos, estimulados en procesos de transformación (Mosca-Pérez Aguirre, $1985) .^{71}$

Se observó la existencia de estos modelos educativos en los discursos de los entrevistados, que están relacionados con las concepciones que tienen sobre la práctica educativa y sobre las características que hacen al sujeto de la educación así como al rol docente. Se percibe un movimiento de ir y venir entre el paradigma más tradicional y una concepción más integral de la educación. Por momentos se genera un doble discurso o ciertas contradicciones que dan cuenta de las dificultades a la hora de trabajar o encarar la EDH en la práctica educativa formal; se deja entrever la coexistencia de estas diferentes visiones. También se identifica la presencia de elementos de coexistencia de los diferentes enfoques de la educación en el Programa cuando se analiza su forma y contenido.

\footnotetext{
71 De acuerdo a Juan José MOSCA y Luis PÉREZ AGUIRRE (1985) podemos identificas tres modelos: la Instrucción con énfasis en la transmisión de contenidos; la Capacitación con énfasis en alcanzar ciertos resultados; y la Formación con énfasis en los procesos y transformaciones. Este último enfoque es más acorde a los objetivos y contenido de la EDH.
} 
La Consejera de educación inicial y primaria, Irupé Buzzetti, parte de la Comisión que escribió el Programa de educación inicial y primaria, decía:

“...queríamos un programa que estuviera bajo el paraguas de los derechos humanos. Ahí lo que se trató fue de pensar a la educación como una opción ética y política-política, digamos, de la educación.

$Y$ en este marco todas las disciplinas que se trabajaran, las áreas de conocimiento, tenían que tener un enfoque sobre este sujeto a educar en los derechos de primera, segunda, tercera y cuarta generación."

Se destaca así el rol central en el Programa de primaria: un "sujeto a educar", en este caso en derechos humanos. Se reconocen en su discurso elementos que hacen a la transmisión de información, de contenidos a ser enseñados por el o la docente, sin generar la reflexión que el contenido de derechos humanos implica otro tipo de proceso de aprendizaje.

En el presente Programa los derechos humanos están incorporados en un lugar central, con características integrales, de respeto a la diversidad y procesos particulares de los desarrollo de los sujetos, integrados y protagonistas partícipes de la sociedad. Es un lugar bien diferente al de la concepción de formación de ciudadano que le otorgaba la modernidad, donde el sujeto a educar era un sujeto a disciplinar, un sujeto individual, blanco, masculino y burgués. En la actualidad la EDH plantea la acción educativa "como" y “a través de" un fenómeno de relación, (Pérez Aguirre, 1989; 1999) que desde la promoción de la comunicación efectiva desarrolla procesos de conocimiento, autoconocimiento (Magenzdo, 2008), reflexión, participación, creación y transformación (Freire, 1996).

El alumno, en una noción de educación tradicional, aparece ubicado en un lugar central y único, el de adquirir conocimientos y pautas actitudinales que le permitirán desarrollar, individualmente, su potencial para vivir en la sociedad de pertenencia. El maestro, que pasó por un proceso de formación docente desde esa misma concepción, es el encargado de transmitir, enseñar y posibilitar este aprendizaje, con los recursos de conocimientos y actitudes aprendidas respectivamente.

Mientras tanto, en EDH, la importancia del proceso educativo está dada por el movimiento conjunto, por el intercambio que se da entre educando y educador. Si bien se reconoce una asimetría de roles y responsabilidades, en los dos está prevista la capacidad de aprender, de comprender desde diferentes circunstancias y de actuar sobre la realidad y los vínculos en 
juego en esta actividad humana (Rodino, 2003) de educar-educarse en relación (a sí mismo, a otro/s y a un entorno).

La Consejera Buzzetti recordó cómo fue el trabajo para la construcción del Programa en esta temática, donde se incorporan la ética y el derecho como disciplinas para fortalecer la formación ciudadana, dando cuenta de un procedimiento poco integral:

"De hecho el programa tiene un fuerte encare a lo que hace a la construcción ética, a la construcción de ciudadanía. No es un área de conocimiento, sino que es un campo disciplinar de las Ciencias Sociales. Porque eso fue lo que dio más trabajo en el programa 2008... Nosotros queríamos armarlo en dos partes. ...

Aquí trabajó con nosotros, orientándonos, Cullen, el [filósofo] argentino. Porque nosotros queríamos una parte que fuera la ética, la moral del niño y las morales, digamos, de la sociedad donde vive el niño. Y otra parte que (si vos ves, el programa está hecho así) fuera el derecho. ...

Entonces digo, ¿por qué eso costó mucho trabajo? Porque tuvimos que trabajar. En la parte de la ética hubo que trabajar con profesores de Filosofia y en la parte de derecho, con profesores de Derecho". (Entrevista a Irupé Buzzetti)

La misma entrevistada se permite reflexionar sobre la dificultad de definir los contenidos que hacen a la EDH. Deja entrever que los resultados no se lograron cabalmente y que la comprensión de los mismos no está siendo del todo positiva en el ámbito educativo.

"A los profesores de Filosofía les costaba poner contenidos. ¿Qué contenidos le pondrías vos a un tema como el trabajo? Entonces de esa manera se fueron poniendo contenidos! ¿Qué contenidos le pondrías a la violencia? Que era un tema ético! " ... Entonces era muy difícil para los profesores de Filosofía, transformar en contenidos lo que pasa por un discurso. Eso nos llevó mucho trabajo,... Yo a veces digo, no lo ven en la real dimensión que tuvo este Programa en ese campo disciplinar. Porque ese campo disciplinar apunta exactamente a todos los derechos”. (Entrevista a Irupé Buzzetti)

Se marca la dificultad de trabajar integralmente algunos elementos del orden del discurso, de la reflexión ética y de su puesta en práctica en el ámbito educativo. Las construcciones y clasificaciones académicas, teóricas, no siempre dan respuesta a la complejidad de los contextos en la realidad. Por eso es importante dedicarle más atención a esta característica de la integralidad en la educación, así como a los procedimientos de la formación de sujetos integrales.

\subsection{2. ¿Qué pasa con las prácticas educativas?}


Varios de los entrevistados opinan sobre la aplicación y ejecución del programa, caracterizándolo como un proceso que no es parejo ni homogéneo. Plantean que hay un nivel de implicancia particular de cada persona o de los diferentes equipos docentes que es fundamental en este proceso. Según estos expertos, más allá de lo que pueda aportar explícitamente el texto, es necesario considerar cómo se están desarrollando las prácticas educativas con enfoque de EDH.

Martín Prats plantea la incorporación de la EDH de forma transversal. En primaria se daría de forma natural, a diferencia de secundaria donde el sistema está más organizado por materias.

"La educación en primaria es necesariamente transversal, no está tan establecida, encasillada en disciplinas y asignaturas como se da en la educación secundaria. Bueno, y la EDH, la Educación en la diversidad, ésta cruza prácticamente todos los temas. ...Claro que, a nivel de primaria, una cosa es lo que se ponga en los planes y programas específicos y otra cosa es lo que los docentes puedan hacer en el aula. Fundamentalmente habiendo una carencia de formación en la EDH que recibieron cuando se formaron como maestros”. (Entrevista a Martín Prats)

Como hemos visto, las dimensiones de la integralidad y de la transversalidad están interrelacionadas para el enfoque de EDH. Desde su planteamiento en la esfera del Derecho Internacional de los Derechos Humanos lo podemos encontrar de esta manera. Así también en la bibliografía especializada se jerarquiza estas dos modalidades como las más apropiadas. Pero recordamos el señalamiento que nos hacia Luis Garibaldi, que si la EDH no estaba inscripta en la gramática escolar corría el riego de no verse traducida a la tarea educativa concreta.

En la entrevista con Fernanda Blanco, ex encargada de EDH de la Dirección de Educación del Ministerio de Educación y Cultura (MEC) e integrante de la Comisión de EDH, ella plantea una visión compleja de la EDH, pudiendo visualizar un tratamiento integral de la misma según la cual no alcanza con transmitir los derechos sino que hay que tenerlos en cuenta en las conductas que asumimos en nuestra cotidianeidad. Da cuenta de una metodología que reflexiona sobre la relación educativa y sus componentes.

"Sin duda es importante que en lo áulico se trabaje especificamente lo que nosotros tradicionalmente decimos o entendemos por derechos humanos. Pero también es importante que nosotros trabajemos otros aspectos, otros conceptos. El tema del poder, del ejercicio del poder. Del poder entre el que sabe y el que no sabe, el que enseña y el que aprende. Hoy, en lo personal, estoy convencida, que 
aprendemos de los alumnos, también ellos de nosotros. Pero distintas cosas. En esta interacción es donde se da una verdadera EDH”. (Entrevista a Fernanda Blanco)

Es necesario dar cuenta de la dimensión de la EDH desde un pensamiento crítico, integrador, que problematice diferentes dimensiones de la realidad, para después poder trabajar con ella desde una perspectiva de derechos:

...”¿Qué es en sí mismo la EDH?” Desde la accesibilidad, desde la mejor calidad en la educación, desde procurar un ciudadano con un espíritu y mente crítica, capaz de reconocer la otredad. Capaz de no solamente aquello de "no hago lo que no me gusta que me hagan." No. Sino sentir que somos parte de un colectivo, donde todos tenemos derechos (...).Está muy vinculado los derechos humanos y la EDH con el trabajar en valores. ¿Pero cómo? Fundamentalmente a través de la experiencia misma. A través del ejemplo!" (Entrevista a Fernanda Blanco)

La consejera Buzetti, introduciendo el elemento de las prácticas educativas y dando cuenta de que este programa tiene una mirada que pretende generar algunos cambios en las prácticas y en las tareas docentes, oportunamente se cuestiona sobre una formación docente que tenga la posibilidad de introducir otros elementos, que provengan directamente de la experiencia: ..." y hoy, nosotros, para ese Programa, para ese texto curricular, lo que tenemos es que lograr una formación en servicio para los maestros que en realidad están acostumbrados a hablar. Pero no están acostumbrados a trabajar desde la Filosofía." (Entrevista a Irupé Buzetti)

Así aparece otro importante pilar de la EDH: la metodología. Y aparece de la mano de la formación docente. Surge la pregunta por los recursos que tienen los maestros y maestras, así como por las tradiciones educativas que son fundamentalmente discursivas. Porque la EDH y la educación integral plantean la incorporación de otros recursos igualmente válidos, importantes para complementar y ajustar la tarea educativa a los contextos reales y actuales.

\subsection{Pensando una nueva formación docente.}

Para la introducción de la EDH en el sistema educativo es necesario que las escuelas se conviertan a un modelo de aprendizaje y práctica de derechos humanos. El rol que desempeña todo el personal vinculado a estos centros educativo es importante, desde 
docentes, administrativos, personal de servicio e inspectores. Pero es imprescindible y clave que la función docente esté impregnada de un enfoque de EDH.

La entrevistada Irupé Buzzetti deja planteada la dicotomía entre enseñar derechos humanos y vivir en clave de esos derechos. Se pregunta: “estamos todos en condiciones de abordarlos?". De esta manera pone sobre la mesa el tema de la formación de las maestras y maestros, y se pregunta: ¿qué tipo de formación? Ya no alcanza con una formación académica, basada en desarrollos de contenidos. "Entonces falta esa otra parte, la formación en servicio."

..."la estamos institucionalizando, esa formación permanente del maestro, tiene que pasar también por esto. Hay que enseñar Filosofía!! Hay muchos programas de filosofía para niños. Esa filosofía hay que bajarla al maestro. Porque en realidad, yo creo que esto se necesita. Es un trabajo más profundo en cuanto que el maestro no tome esto como un tema más que hay que dar, sino que lo tome como está realmente en el programa. Los derechos humanos no son para enseñar, son para vivirlos." (Entrevista a Irupé Buzeztti)

La entrevistada plantea una formación que enseña, y enseña contenidos, procedimientos, sin problematizar que esta "forma", separa, ordena, jerarquiza, privilegia, juzga, desde un lugar individualizante con pretensiones de neutralidad. Por un lado, se reduce la EDH a la filosofía, y por otro, se plantea la dimensión de la vivencia como punto fuerte. Se deja entrever la coexistencia de los diferentes enfoques educativos y la dicotomía entre enseñar derechos humanos y vivir en clave de derechos humanos.

Aparece jerarquizado el tema de la convivencia, como un lugar de encuentro no solo espontáneo sino como un espacio educativo importante a ser aprovechado para la EDH.

"Yo creo que, obligatoriamente, tanto en la escuela de primaria como en una institución de educación media y bachillerato debería haber un espacio de convivencia. A la gente le falta hablar, a la gente le falta poder discutir y hacerse entender por otro. ...es un mundo, una sociedad que está mucho con la imagen, con lo virtual, con poca conversación. Entonces esos espacios de convivencia son espacios reales. (Entrevista a Irupé Buzeztti) 
La consejera introduce el espacio de convivencia como espacio educativo. Relata como en el Proyecto de Escuela de Tiempo Completo ${ }^{72}$ se trabaja este espacio y el de juego como propuestas para promover valores y la formación integral de los niños.

Hay dos espacios que vos no los podes obviar: uno el espacio de convivencia, espacio para poder usarlo para persuadir y para argumentar, específicamente. $Y$ otro espacio es la recreación. ... Cuando dos personas están jugando, vos tenés que estar viendo a tu contrincante. Esa situación tiene que ver con la formación de la moral. Esto no es nada nuevo! Piaget decía ¿Cómo se le forma la moral a un niño? Y se le forma jugando!! Y jugando a perder y a ganar!! No solo se es ganador en la vida! Sos ganador y sos perdedor y de cada una de esas cosas vas sacando enseñanzas." (Entrevista a Irupé Buzeztti)

Sin dejar de reconocer la importancia que esta entrevistada le asigna a los espacios de convivencia y a los espacios lúdicos y recreativos, pensamos que la forma de habitar esos espacios - no el espacio por sí mismo - es lo que va a permitir o no hacer real el vivir los derechos humanos. La EDH plantea la necesidad de coherencia entre el discurso y la acción, una acción integral que involucre lo cognitivo, afectivo y lo actitudinal, donde el estar juntos implique el respeto mutuo. Y entonces hay que ir definiendo las cualidades del juego, de los espacios de convivencia, donde el compartir, el cooperar y el dialogar sean habilidades construidas desde el respeto y el aprecio por las diferencias y no desde una competencia descalificadora, como es la resignación de ajustar la conducta a estereotipos prefijados socialmente.

El desarrollar la sensibilidad y la comunicación deben ser tarea central del acto educativo. Luis Pérez Aguirre, gran pensador uruguayo sobre la EDH planteaba: "En pedagogía, la teoría es el método. Aun cuando se cuente con valiosos contenidos, si no se los pone en juego dentro de un método rico en expresión y comunicación, no se llega muy lejos”. Deja claro que lo importante es la coherencia y la interrelación entre los elementos declarativos y la correlación de estos con la experiencia vivida. Experiencia coherente, que refuerce y permita aprehender integralmente, desde una síntesis cognitiva, afectiva y actitudinal. O, a la inversa, una experiencia que genere una vivencia contradictoria y por ende, una disociación entre lo que se explicita y lo que se vive afectivamente.

72 Proyecto de "Escuelas de Tiempo Completo", pertenece al CEIP. En estos centros los niños y niñas asisten con una extensión horaria de siete horas y medias (de 8:30 a 16hs). Cuentan con una mayor oferta de experiencias educativas, dentro de las cuales se destacan diferentes talleres de expresión y artísticos, lúdico-recreativo (si bien existe una organización central del CEIP, estos dependen de la gestión de cada dirección). También cuentan con un espacio remunerado para reunión del equipo docente, denominado Sala Docente. 
Así, hay que pensar en una formación docente que impregne los procesos de aprendizaje con la dimensión de la comunicación efectiva entre las personas, que destaque la sensibilidad para promover y favorecer las relaciones respetuosas y crear climas adecuados para el pleno desarrollo de las personas y el trabajo en grupos. Esto generará en la experiencia de aprendizaje un carácter significativo que permitirá la construcción de conocimiento, que involucrará la esfera de lo individual así como la dimensión colectiva (González De Cuberes, 1987).

Fernando Willat se refiere a la formación docente, manifestando que está aún lejos de lo que plantea la EDH. El desarrollo de contenidos no alcanza para pensar en preparar a los y las docentes para educar en derechos humanos. La EDH tiene que pasar por darle un sentido significativo a la práctica educativa, tanto para el docente como para el educando.

“...hemos sido formados más allá de los contenidos con una racionalidad que es contradictoria con la de los derechos humanos. Entonces educar es transformarnos a nivel afectivo, a nivel integral; el sentido de nuestras vidas está puesto ahí. Y en el proceso educativo tiene que estar puesto en juego el sentido de nuestras vidas... [hay] que mirar hacia cierta preparación en la formación docente para que puedan [trabajar desde la EDH]"

Se reconocen avances en la implementación de los "Seminarios de derechos humanos", en $3^{\mathrm{o}}$ año de formación docente de todos los institutos pertenecientes a $\mathrm{ANEP}^{73}$, que apuntan a una transversalidad del tema. Existen otras iniciativas públicas como un curso a distancia sobre derechos humanos de la Dirección de Educación del MEC. Pero según este entrevistado "son insuficientes". Fernando Willat rescata el interés de los docentes en formarse en estos temas, una preocupación en aumento donde se buscan diferentes estrategias y ofertas dentro de otras instancias no oficiales, organizaciones civiles, entre otras. Señala el aumento de la cultura de los derechos humanos así como la importancia e interés por la EDH que está presente en algunos docentes.

Martín Prats, que trabaja con los diferentes subsistemas de la ANEP, reseñó los diferentes esfuerzos realizados en la formación y actualización del sistema educativo sobre EDH:

"Entonces lo que hoy tenemos, como sintesis (...)es:

\footnotetext{
73 En el Uruguay la formación docente, tanto para Magisterio como para los diferentes profesorados, está en la órbita de Consejo de Formación en Educación (CFE- ANEP).
} 
- a nivel de planes y programas, la perspectiva de Derechos está incorporada. Primaria hizo una reforma del programa, incorporando el tema; en secundaria en alguna materias está el tema de derechos humanos, incluso en algunas materias, a algunos temas específicos, se les dio mayor espacio;...

- a nivel de formación docente, hacia el futuro, la temática de derechos humanos, también está incorporada. Se están dando los seminarios en 3ros o 4tos años [se vienen dictando desde 2008 con una carga horaria de 30hs.] O sea que los futuros docentes tienen al menos una visión pequeña de lo que es la malla curricular, de lo que es formación en $\mathrm{EDH} ;$...

- a nivel de formación permanente, se busca con esta estrategia y los pocos recursos con que se cuenta, hacer una tarea de difusión (...) a través de cursos, seminarios, talleres, preparándolos no solo en temas especificos sino para que puedan ser ellos referentes en la temática de derechos humanos en los centros donde les toque actuar.”. (Entrevista a Martín Prats)

El entrevistado explica la existencia de un curso de perfeccionamiento para los docentes ya recibidos y que están en actividad en los tres subsistemas de ANEP (Primaria, Secundaria y técnica). Consta de ocho módulos de 15 horas cada uno (total 120 horas), de duración anual, que se puede realizar completo o por módulos separados.

También la Dirección de Derechos Humanos de CODICEN trabaja en otras estrategias que incorporan a la EDH y que pretenden dar herramientas y profundizar el enfoque de EDH en los centros educativos de los diferentes subsistemas. Por ejemplo, la elaboración y actual implementación del Protocolo de Violencia Doméstica y el apoyo a diferentes programas que trabajan en los centros educativos de la ANEP.

“...el proceso de implementación del Protocolo de Violencia Doméstica. Si bien es un proyecto de implementación sobre un documento especifico, se busca que a partir de ese instrumento los docentes que participan de este proceso también puedan abarcar más ampliamente la dimensión de derechos y puedan trabajar desde esta perspectiva otros problemas que se den en los centros educativos.... Y también [se busca] poder apoyar desde la Dirección de Derechos Humanos a todos los cursos o programas donde se trabajan estos tipos de temas. De ahi que se trabaje con "Aulas Comunitarias", "Maestros Comunitarios", "Escuelas Disfrutables", así como con el Proyecto de la Comisión de Participación de Secundaria, etc." (Entrevista a Martin Prat)

En las palabras del entrevistado se reconoce la existencia de diferentes estrategias para difundir y apoyar la incorporación de los derechos humanos y la EDH dentro de la ANEP, tanto en la formación docente como en el apoyo a programas de intervención educativa en los centros. 


\subsubsection{Más allá de las instancias formales de formación docente, otras instancias.}

El director de Educación del MEC, Luis Garibaldi, desde una reflexión crítica, reconoce una dificultad en la formación docente para trabajar en EDH. Considera que ésta tiene un enfoque pensado desde algunas áreas disciplinares en particular, pero carece de una mirada integradora. Destaca, al igual que varios directores y maestras durante nuestro trabajo de campo, que hay que hacer más conciencia de que "Los docentes se terminan de formar en la práctica".

Con el mismo razonamiento, un director de escuela entrevistado planteaba la posibilidad de que durante los primeros años después de la titulación de magisterio, los nuevos docentes trabajen en otros espacios dentro de la escuela mientras van incorporando y comprendiendo la complejidad de la práctica educativa de hoy. El director nos decía: " $E l$ título no te da el rol de maestro, acá te haces en la práctica. ... la formación, la experiencia profesional está relacionada con las experiencias personales. Es un aprendizaje constante. Yo sigo aprendiendo...”. Señaló como elementos importantes para desarrollar la tarea educativa: la comunicación con el otro; la capacidad de construcción colectiva; los valores de vida que hacen y permiten el crecimiento personal. De esta manera se comprende la formación integral de la persona del docente, desde aspectos profesionales hasta aquéllos asociados a su calidad afectiva y actitudinal dentro de los grupos, que hace al proyecto de vida de las personas que se dedican a la docencia.

Varios entrevistados plantearon la necesidad de incorporar y destacar estos temas también como formación permanente de los y las docentes, pues ello implica una reflexión constante de la práctica educativa y de los contextos actuales en que se realiza. Asimismo, la necesidad de pensar una formación que priorice un enfoque grupal desde lo colectivo y no tanto desde un enfoque individual.

Garibaldi reflexionaba sobre la dimensión de lo que aprenden los y las docentes y cómo asumir la introducción de un nuevo enfoque educativo para poder después trasladarlo a su función de aula, en la cual son fundamentales la capacidad de reflexión, análisis, autoevaluación.

“... en realidad, un docente cuando se enfrenta a situaciones nuevas o desconocidas normalmente lo que aplica es su experiencia como educando. Por lo tanto vas y 
transferís lo que aprendiste, cuando lo aprendiste. Porque es lo que tenés a mano. Lo otro implica un proceso de deconstrucción de lo ya existente y aquí [radica] la necesidad de lo colectivo y la necesidad de la reflexión.

Deconstruir prácticas añejas, inconscientes, se hace a través de un proceso de reflexión y de visualización de cuáles son las dificultades..." (Entrevista a Luis Garibaldi)

Estas preocupaciones nos recuerdan los planteos de Paulo Feire sobre su concepción de enseñanza, que cuestiona la sola transmisión de conocimientos neutros, abstractos, =para enfatizar la posibilidad de crear las condiciones para producir, construir ese conocimiento históricamente contextualizado en una realidad dada. La práctica del educador implica una revisión permanente, una reflexión consciente, una acción emancipadora; es decir, una reflexión crítica.

"La reflexión crítica sobre la práctica se torna una exigencia de la relación teoríapráctica sin la cual la teoría puede convertirse en palabrería y la práctica en activismo."

\section{$(\ldots)$}

..."Cuanto mejor realice esta operación mayor entendimiento gana [el educador] de la práctica que se analiza y mayor comunicabilidad ejerce en torno de la superación de la ingenuidad por el rigor... así, más capaz me vuelvo de cambiar, de promover, en este caso, del estado de curiosidad ingenua al de curiosidad epistemológica." (Freire. 2006:24 y 40)

El entrevistado Luis Garibaldi menciona varias iniciativas que van en la línea de aprendizajes colectivos, de vivencias de reflexiones sobre las prácticas y las realidades que se empiezan a desarrollar en el Sistema educativo, como una tendencia a construir espacios colectivos. Son ejemplos la construcción de los proyectos de centro en cada escuela y las Asambleas Técnico Docentes (ATD) que se realizan en cada centro.

“...hay otras líneas de acción que se vienen desarrollando por este otro lado. Algunas formaciones en servicios pensadas colectivamente. La creación de espacios de debate de los docentes pensado en este tipo de cosas. La de promover políticas de que cada centro tenga su proyecto educativo. Que lo discutan colectivamente. Todas esas cosas ayudan. De que en los Consejos de Participación tengan que conocer los proyectos de los centros educativos. Esas son las líneas que contribuyen." (Entrevista a Luis Garibaldi)

Destaca dos tipos de acción que para él ayudan a concretar una experiencia transversal de $\mathrm{EDH}$, superando la dicotomía planteada anteriormente sobre enseñar y vivir los derechos humanos: 
- tareas que surjan desde contextos reales, donde el elemento de análisis y producción de conocimiento sea los derechos humanos, y

- actividades donde se reconozcan y se pongan en ejercicio los derechos humanos.

Da como ejemplo los Consejos de Participación, creados por la Ley: “...experiencias significativas en participación democrática y de ejercicios de derechos. El derecho a opinar, el derecho a participar, el derecho a recibir educación de calidad, el derecho a tener un ámbito de intercambio entre los diferentes estamentos. Y me parece que esto no se ha logrado suficientemente.” (... ) todavía no [se lo ve] como un aspecto central o sustancial de la política educativa, sino más bien como una politica lateral. Como antes se armaba la Comisión de Fomento, ahora se convoca al Consejo de Participación."(Entrevista a Luis Garibaldi)

Las propuestas están, los mecanismos están, pero no se ha logrado aun hacer de esto un trabajo consistente y central en los centros educativos. Se plantea que falta mucho trabajo sobre este tema y que hay dificultades en la concreción de este enfoque de EDH en las instituciones y por partes de los colectivos docentes.

"Yo soy muy defensor de esta idea de la EDH no como una idea de enseñar sobre el dictado de clases. Sino más bien de enfoque y por lo tanto de ejercicio y de vivencia de ejercicio de los derechos. Eso educa más que cualquier clase de derechos humanos. Una escuela que sea democrática, participativa, que respete los derechos de los niños, que [acepte que] los niños tienen derecho a tener la palabra y los adultos también. Hay mecanismos, hay normas y reglamentos que regulan,.. esos reglamentos te respetan y te cuidan. (Entrevista a Luis Garibaldi)

El entrevistado plantea que existen experiencias de escuelas abiertas, preocupadas por mantener el dialogo con su comunidad, donde hay un enfoque de derechos. Pero esto no se da en todos los centros educativos. Reconoce, como todos los entrevistados, que la dimensión de la práctica educativa es la más difícil de cambiar, es en la que se están revelando las dificultades y el conflicto.

Se plantea que la principal dificultad está en la base de la cultura escolar actual, que ya esta instituida y es difícil de cambiar. Por más que se forme a las nuevas generaciones de docentes, hay que trabajar sobre las prácticas ya instituidas.

"La formación docente importa, está muy bien, pero si vos tenés centros educativos cuyas prácticas van por un lado diferente, los docentes terminan absorbidos... los estudiantes, los nuevos docentes, terminan absorbidos por prácticas ya instituidas. (...)

A nivel de las autoridades y a nivel de las politicas, esto ha ido avanzando mucho. En las definiciones y acciones particulares. Después es más difícil traducirlas a la 
realidad, porque a veces hay algunas situaciones de funcionamiento o logísticas que no se lo permiten. Cosas que no te ayudan. Colectivos docentes incompletos, rotación, cambios de direcciones... todo este tipo de cosas no contribuyen a este tipo de actividades. A veces formaciones que no están pensadas tanto para los colectivos sino para los individuos. Ese tipo de cosas no contribuyen." (Entrevista a Luis Garibaldi)

Las dificultades que hacen a la logística de la vida de las escuelas, en tanto rotación de maestros, equipos que no se mantienes, nombramientos fuera de tiempos y urgencias de la gestión, entre otras cosas, son señalados por las tres direcciones que se entrevistaron como elementos que entorpecen el clima de los centros educativos.

Esto da cuenta, a través del discurso de las y los entrevistados, de que existen dificultades en la práctica educativa con $\mathrm{EDH}$, donde se observa una tensión real entre lo que se explicita en la normativa y las prácticas concretas. Los espacios supuestos de reflexión docentes, de construcción colectiva, son derivados a atender elementos de gestión de los centros, de casos particulares de algunos niños y de urgencias de algunos acontecimientos, donde no siempre son percibidos como espacios reales para desarrollar los procesos de construcción y de formación de los equipos.

Margarita Navarrete plantea su experiencia cuando trabajó en formación docente en magisterios y en el IPA (Instituto de Profesores Artigas, institución que forma a los profesores de secundaria dependientes de ANEP). Reflexiona sobre la dicotomía que encierra el concepto de educación entre formación integral y desarrollo de contenidos académicos, en el abordaje de la formación docente sobre EDH

“... me frustraba un poco, esto de que los estudiantes lo que querían era la receta y el contenido específico para la parte de Ciencias Sociales. Yo les decía cómo trabajar por ejemplo, efemérides, y hacer una cartelera, lo mismo dentro del Instituto Normal. Lo hacían para quedar bien conmigo. Lo viví como muy instrumental, todo muy pragmático en primaria y la verdad que sentí que no podía con eso. Más allá que como docente una tiene que ayudar a dar herramientas, y demás..." (Entrevista a Margarita Navarrete)

Insiste en la necesidad de partir desde otro enfoque, donde se conciba la educación no tan parcializada y dividida en diferentes asignaturas o áreas, ya que los derechos humanos están en todas ellas y se relacionan con todas ellas (desde Matemática hasta Literatura e Historia). Y no solamente "tiene que encajar en Ciencias Sociales". Porque es desde este lugar, el de la integralidad y la interrelación, que para esta entrevistada tiene sentido y es más interesante la EDH. 
Así se reconoce la complejidad que conlleva el abordaje de la Educación desde la concepción de EDH (integral, transversal). Esto implica una dificultad a la hora de desarrollarla en la formación docente, ya que está instalada hace mucho tiempo en otra concepción de la educación más tradicional, como ser una visión instrumental y fragmentada por áreas de conocimiento a desarrollar académicamente dentro de todo el sistema educativo. También aparecen cuestionamientos desde donde está planteada la formación en EDH dentro el plan de formación docente, por su lugar diferente y por su reciente incorporación.

"Lo que pasa es que de alguna manera un docente de derechos humanos en formación docente es marginal totalmente. Porque no forma parte del colectivo de los docentes... no forma parte del staf, al menos que tenga otra materia"(...)

Tiene otra contra, que la verdad es como muy voluntarista. En algún momento Ema Zaffaroni $^{74}$ me dijo: "es lo que se pudo!!! Hubiéramos querido una materia", porque lo mismo que pasa en el Normal, pasa en todos los institutos de formación docente, en el IPA, etc. ... (Entrevista a Margarita Navarrete)

Los docentes de los seminarios de derechos humanos de formación docente trabajan con una propuesta para el curso de 30 horas que ellos mismo organizan, no es una propuesta común. Estos seminarios se encuentran en el tercer año de la formación y se dan con grupos integrados por estudiantes de diferentes asignaturas, según la entrevistada "Los Seminarios tienen un poco esas características, de ser instancias integradoras, que está bueno!" pero no siempre están dadas la condiciones para eso, siendo su resultado muy variable según esta entrevistada.

Aparecen las dificultades, los conflictos y las tensiones desde la implementación de la $\mathrm{EDH}$, tanto en la formación docente como en las prácticas educativas en la escuela. Queda claro que la incorporación de este enfoque en sus principios, objetivos y contenidos en la normativa, tanto la Ley como el Programa, no es sencilla ni inocua, y que su real implementación en las prácticas educativas va a implicar procesos de acomodación. Lo que nos lleva a pensar que es necesario redefinir algunos componentes del ámbito educativo con una mirada que integre la interdisciplinariedad, así como que reconozca y explicite los abordajes transversales, dando mayor visibilidad al enfoque de la EDH y permita algunas

\footnotetext{
${ }^{74}$ Ema Zaffaroni fue Consejera de Secundaria (CES-ANEP 2012-2014), Profesora de Historia, y militante de ddhh. Cuenta con varias publicaciones sobre historia reciente y ddhh.
} 
metodologías acordes, que desplieguen elementos de procesos individuales pero también destaquen aprendizajes grupales y producción de conocimientos colectivos.

\section{CAPÍTULO V}

\section{TRABAJO DE CAMPO EN TRES ESCUELAS DE MONTEVIDEO}

"Sucede que fuimos y muchos somas tadavía, "analfabetas" en derechas humanas. mal educados para las derechas humanas. Superar esta incultura supane inmediato, de los más íntimo, de los más cotidiana y daméstico,

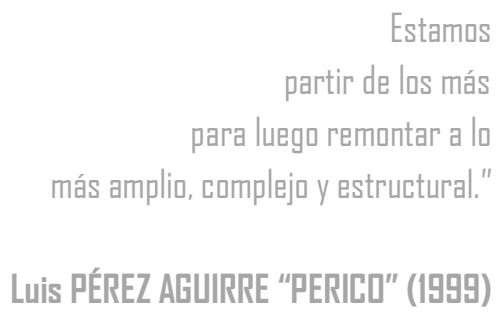

En este capítulo se presenta el trabajo de campo realizado por la investigadora en las tres escuelas de Montevideo con el objetivo de indagar sobre las prácticas educativas con enfoque de EDH. A tal fin se entrevistó a las y los docentes y los equipos de dirección de cada escuela, observando diferentes instancias de trabajo.

Como principal observación de conjunto, a grandes rasgos podemos decir que al profundizar sobre las concepciones de las y los docentes sobre la EDH aparecieron elementos de incertidumbre en relación a lo que se propone y se busca en el trabajo educativo en derechos humanos. En algunos casos aparecieron dificultades de comprensión y conceptualización en torno a los contenidos y formas de trabajo de esta temática.

Como contrapartida, existe en la gran mayoría del cuerpo docente la preocupación por trabajar en áreas que requieren competencias y habilidades en la convivencia, en valores y en actitudes de respeto y valoración de las diferencias entre las personas y las culturas. Anteriormente hemos visto que estas áreas de interés están comprendidas dentro de las proposiciones teóricas y metodológicas de EDH; sin embargo, en la tarea cotidiana de los docentes, no necesariamente son pensadas como tal o asociadas a la EDH al llevar adelante actividades en éstas áreas.

Las y los educadores reconocen que trabajar en estas áreas éticas y de habilidades cooperativas y construcción de las identidades es de importancia para el presente y futuro de las niñas y niños, tanto para sus aprendizajes académicos como para sus procesos de socialización. No obstante, el magisterio argumenta que las realidades con que se 
encuentran a diario en las escuelas no son las mismas para las que fueron formados. Expresan dificultades para abordar las situaciones a las que se enfrentan y reclaman por las carencias en su formación que les dificultan abordar con autonomía la tarea educativa en estos contextos.

Si bien aparecen en los primeros momentos las quejas, las expresiones de malestar y la confusión sobre temas de EDH, también se demuestran actitudes de búsqueda de soluciones para trabajar sobre temáticas nuevas, elementos valóricos y habilidades de la convivencia para poder cumplir con su tarea.

\section{Metodología y procedimientos del trabajo de campo.}

\subsection{Estrategia de ingreso a las escuelas para llevar adelante la investigación}

Después de realizar las entrevistas a las autoridades del sistema de educación público y especialistas $^{75}$ de la EDH en Uruguay, se realizó una solicitud formal al Consejo de Educación Inicial y Primaria (CEIP-ANEP) para obtener la habilitación para realizar el trabajo de campo en las escuelas. Este trámite llevó un tiempo importante en su proceso burocrático y fue necesario contar con la intervención del Director del CEIP para agilitar la resolución y permitir el trabajo en un tiempo acorde al calendario escolar.

Después de obtener los permisos, hubo una comunicación rápida y entrevistas con las tres inspectoras departamentales de Montevideo, las cuales me asignaron tres escuelas para realizar la investigación de campo y facilitaron el contacto con las inspectoras y los equipos de dirección de cada institución. Se realizaron entrevistas con las Inspectoras Departamentales de los tres distritos: zona Este; zona Centro y zona Oeste, así como con las tres inspectoras a cargo de cada una de las escuelas.

Estas escuelas fueron las siguientes: ${ }^{76}$

\footnotetext{
$75 \quad$ Desgravaciones en anexo III

76 Se advierte que algunos datos de las escuelas y los nombres de las inspectoras, los directores y otros docentes que fueron actores de esta investigación han sido omitidos, para preservar la privacidad de estas personas.
} 
- Zona Este, Escuela A, Tiempo Completo, Barrio del Buceo,

- Zona Centro, Escuela B, Tiempo Completo, Barrio Maroñas,

- Zona Oeste, Escuela C, Común, Barrio Belvedere.

En la búsqueda del ingreso a los ámbitos escolares esta investigación se encontró con una estructura con características burocráticas y jerárquicas importantes. Para transitar por esos espacios sin pertenecer a ellos fue necesario obtener habilitaciones de las máximas autoridades del sistema, pasando por todas las instancias intermedias hasta llegar a las escuelas $^{77}$. Fue un trámite algo engorroso y extendido en el tiempo, pero garantizó formalmente la aceptación de la investigadora en los centros educativos, que una vez autorizada por los jerarcas no podría ser rechazada por los equipos de inspección y dirección.

Todas las inspectoras y directores señalaron que era correcto y apropiado el procedimiento para la inserción en los centros. En cada presentación se informaba cual había sido el procedimiento de autorización y se entregaba un juego de copias con todos los permisos y credenciales -esto es, la pertenencia a la Maestría de la Facultad de Derecho y Ciencias Sociales de la UNLP y la resolución del CEIP $^{78}$ para realizar el trabajo de campo necesario para esta investigación de tesis dentro de las escuelas.

Este procedimiento fue un encuadre de acercamiento y de respeto a las reglas del sistema educativo y una forma de proteger a la investigadora y también de cuidar a las personas pertenecientes a las escuelas y al proceso de trabajo conjunto, donde la comunicación y el entendimiento juegan un rol importante para el buen desarrollo de toda actividad de aprendizaje. Se dejó planteado desde el comienzo la realización de una instancia de devolución y cierre por parte de esta investigadora a los equipos docentes, con cada una de las escuelas e inspectoras respectivas, a fin de transmitir una síntesis de lo trabajado

\footnotetext{
$77 \quad$ Fue necesario elevar un pedido por escrito al CEIP, aunque ya contábamos con su aprobación después de la realización de una entrevista con la Consejera Irupé Buzzetti y, una conversación informal con el Director del Consejo Héctor Fliorit. La Inspección técnica de dicho organismo elaboró un expediente cumpliendo con todos los pasos del recorrido burocrático. Se presentó ante las tres Inspectoras Departamentales y posteriomente ante las tres Inspectoras de las Escuelas designadas en el momento del ingreso a las tres escuelas, a efectos de cumplir con el trabajo de campo.

78

Resolución n¹8, Expediente $n^{\circ} 1225 / 14$. Anexo II.
} 
durante la estadía en las escuelas y algunas de las conclusiones de la investigación, así como poder recoger sus opiniones y reflexiones en un ámbito grupal de lo que fue el proceso de investigación.

Sin embargo, más allá de las autorizaciones formales, fue necesario negociar en cada uno de los ámbitos donde se realizaría el trabajo de campo con los actores directamente a cargo de la tarea educativa. El tema de la investigación motivó reacciones diversas: desconfianza e inquietudes en muchos casos, pero también afinidades. Dos de las escuelas que se trabajó son parte del programa de "Escuela Tiempo completo" a las que las y los alumnos concurren 7 horas y media. Esas escuelas cuentan con un espacio semanal llamado "sala docente", en que se reúne todo el equipo de maestras y maestros de aula, profesores especiales, maestras integradoras y comunitarias, así como director/a y secretaria. La propuesta de investigación fue presentada en este ámbito.

En la otra escuela que pertenencia a la categoría de "escuela común" (asistencia de 4 horas), que no cuenta con la instancia de las salas docentes semanales, se me señaló que comenzara trabajando junto al equipo de dirección y que este me iría mostrando cómo realizar el acercamiento a las otras docentes. Estos procedimientos de presentación influenciaron los procesos posteriores de entablar vínculos de confianza y diálogo abierto con las maestras.

En las escuelas de tiempo completo se dio más fácilmente la comunicación con los y las maestras. Tuve acercamientos con la gran mayoría del equipo docente, mientras que en la "escuela común" esa comunicación fue más difícil, impidiendo un contacto fluido con casi la mitad de los docentes de esa escuela.

La inquietud en torno al tema de la investigación no fue exclusiva de las y los docentes, sino que atravesó a todos los actores de los diferentes rangos jerárquicos. Al presentarse la temática de la investigación a las inspectoras se demostró interés por el tema, pero también se cuestionó el indagar sobre los derechos humanos dentro de las escuelas. Al igual que con los equipos docentes, las inspectoras demostraron preocupación y sensibilidad por situaciones conflictivas que se estarían viviendo en las escuelas, lo que no necesariamente fue vinculado a las problemáticas que aborda la EDH. Solicitaron conocer los objetivos y 
metodología de investigación, explicitando su voluntad de "ayudar de la mejor manera posible", incluso en el caso en el que fue cuestionado el tema de trabajo por una inspectora.

Uno de los elementos en los que el cuerpo de inspección hizo énfasis fue en el especial cuidado y comprensión que esta investigadora debía tener con los colectivos docentes, que estaban siendo "muy castigados". Efectivamente, esto puedo ser constatado tanto a través del relevamiento de opiniones y juicios transmitidos por los medios de comunicación como en situaciones concretas de agresiones físicas que se produjeron durante el año 2014 a docentes en centros escolares del país. Tales hechos merecieron ser enviados a instancias judiciales que llevaron al procesamiento sin prisión de los agresores, en todos los eventos. De hecho, dos de las escuelas que me fueron asignadas para llevar adelante el trabajo de campo estaban comprendidas dentro del grupo de centros educativos que habían atravesado por estas situaciones.

A tales situaciones, que ocurrieron reiteradas veces durante ese año y continuaron durante 2015 y 2016, se suman episodios de vandalismo y robo en los centros educativos, que son vividos por muchos docentes y por parte de la opinión pública como un ataque a la educación pública ${ }^{79}$.

En respuesta a estas agresiones, el sindicato de docente de enseñanza primaria lanzó una campaña buscando poner sobre la mesa estos acontecimientos, revalorizando el lugar de la escuela en la sociedad y promoviendo el diálogo y la unidad entre las familias y los educadores. ${ }^{80} \mathrm{~A}$ partir de ese año se incorporó la medida de que se decretaría paro nacional del sistema educativo público por 24 horas en el caso de que sucediera una agresión física a un docente.

Este contexto, vivido en gran medida como un ataque a la escuela pública y al rol que los docentes ocupan en el proceso educativo y de socialización de los niños y niñas, atravesó todo el proceso del trabajo de campo, enmarcando las formas en que los derechos, la tarea educativa y el conflicto presente en ella fueran vivenciados y narrados al indagar en torno a la EDH.

79 En el capítulo III abordamos la importancia que la educación pública tiene para la construcción de la identidad nacional y como elemento de cohesión social.

80 Ver en Anexo IV, afiche de la campaña. Con la consigna, "TUS HIJOS LEVANTAN LA MANO EN LA ESCUELA. NO LEVANTES LA MANO CONTRA LA ESCUELA. Una mejor educación es lo que aspiramos. Maestros y Padres tenemos un mismo objetivo. Por el RESPETO y la TOLERANCIA". 


\section{2- Breve caracterización de las escuelas}

Dos de las escuelas asignadas son centros pertenecientes al proyecto "Escuelas de Tiempo Completo", donde los niños y niñas asisten con una extensión horaria de siete horas y medias (de 8:30 a 16hs), realizando actividades educativas extracurriculares, entre las que destacan talleres de expresión, artísticos lúdico-recreativos y deportivos. El tipo y cantidad de actividades que se realizan en cada centro educativo varía en función del proyecto y del equipo de dirección. Si bien existe una organización central del CEIP, los talleres dependen de la gestión de cada dirección. Nótese que en las escuelas trabajadas existe una gran variabilidad en los contenidos y tiempos asignados a las actividades extracurriculares.

En las escuelas "Tiempo Completo" también existe un espacio semanal de "Sala docente" que reúne todo el equipo (maestras y maestros de aula, profesores especiales, maestras integradoras y comunitarias, director/a y secretaria).

Escuela A: Comprendida en la Zona Este de la división del CEIP, perteneciente al programa de "Escuelas de Tiempo Completo". Se encuentra en el barrio del Buceo, zona costera, dispuesta sobre una avenida destacada. Cuenta con una población de 280 niños y niñas, desde educación inicial hasta $6^{\circ}$ grado escolar (comprende las edades de 4 a 12 años). Es un edificio de construcción antigua que tiene un patio importante y dos anexos: un salón comedor en el mismo predio, de construcción reciente (cinco años) y una casita, cruzando la calle, donde funciona un equipo de estimulación temprana de CEIP-ANEP ${ }^{81}$, que incluye actividades de expresión corporal y danza y, a sus fondos se ubica la huerta de la escuela donde trabajan todas las clases.

Esta escuela recibe mucha población de otras zonas de la ciudad de Montevideo, ya que está ubicada en la cercanía a una zona comercial y empresarial importante, lo que hace que muchos trabajadores de esta zona (empleados comerciales y de servicios) envíen a esta escuela a sus hijos o nietos. Encontramos muy cerca una serie de complejos habitacionales

\footnotetext{
81 Equipo de estimulación temprana, integrado por cinco técnicas: una médico, psicóloga, psicomotricista, fonoaudióloga, maestra especializada que trabajan con la primera infancia; durante ese año realizaban diagnósticos a niños y niñas de la escuela de cuatro y cinco años, así como de los grados 1 ro. y 2 do. año escolar.
} 
y cooperativas de vivienda, mucha de cuya población infantil concurre a este centro de estudio.

Según la definición de su equipo docente, si bien la escuela es de un barrio de "clase media", la población que concurre es "heterogénea", pues abarca todo tipo de situaciones, desde familias muy comprometidas hasta otras muy ausentes ante la educación de sus hijos, con situación de mucha vulnerabilidad económica y social. Existe un número importante de niños y niñas diagnosticado con diversas dificultades de aprendizaje y con tratamientos medicinales, por lo cual la escuela tramitó los permisos para poder suministrarles la medicación correspondiente dentro de la institución.

El director de esta escuela es muy activo en gestionar diferentes actividades para su alumnado. Tienen en su cronograma de planificación talleres de arte visuales, teatro, danza, expresión corporal, educación física, flauta, piscina, tenis, Inglés, talleres de filosofía para niños y talleres de educación sexual, así como intervenciones de prácticas de estudiantes de Facultad de Psicología (UdelaR). Esta escuela es parte del Programa internacional de "Red Global de Aprendizajes" 82 . Se percibe una preocupación de la escuela por incluirse en la comunidad barrial manteniendo lazos con otras instituciones educativas cercanas (Liceo N³0, Escuela Superior de Informática (ESI-UTU), Escuela Tecnológica del Buceo UTU, Centro de educación inicial de la Intendencia y biblioteca barrial), así como con otras instituciones que están en la zona, como la policlínica, iglesias y comercios, entre otros. Según su director, "se intenta que la escuela esté integrada al barrio, que sea una escuela abierta”.

82 La Red Global es una iniciativa de colaboración internacional que integrará nuevas pedagogías de aprendizaje en 1.000 instituciones educativas de diferentes partes del mundo, desarrollando una capacidad colectiva de construcción, a través de un marco común de acciones e investigación. Tiene como objetivo articular e investigar cómo el verdadero potencial de aprendizaje puede ser alcanzado a través de nuevas pedagogías, en una sociedad rica en tecnología. La iniciativa tiene el propósito de generar una comunidad de conocimiento y una base sostenible de prácticas relacionadas con nuevos modos de aprender que surgen de la interacción de la pedagogía y la tecnología (aprendizajes en profundidad). Aprendizajes profundos son aquellos aprendizajes considerados relevantes para esta era; incluyen aquellas habilidades que preparan a los estudiantes para ser solucionadores de problemas, creativos, conectados y colaborativos y a ser personas que contribuyan al bien común en un mundo actual globalizado e interdependiente. Participan de esta Red 10 países (países integrantes: Australia, Dinamarca, Canadá, EE.UU, Finlandia, Francia, Holanda, Inglaterra, Japón y Uruguay), que procurarán que sus centros educativos aprendan de sus propias experiencias, así como de las experiencias de otras instituciones, generando un intercambio nacional e internacional colaborativo entre ellas. http://www.ceibal.edu.uy/art\%C3\%ADculo/noticias/institucionales/red-global-de-aprendizajes 
Escuela B: perteneciente a la zona Centro de la división del CEIP para Montevideo. Es parte del programa de "Escuelas de Tiempo Completo". Está ubicada en el barrio de Maroñas o Ituzaingo (Hipódromo). Cuenta con una población infantil de unos 300 alumnos aproximadamente, distribuidos de $1^{\circ}$ año escolar a $6^{\circ}$ (edades de 6 a 12 años). Tiene grupos no mayores de 25 alumnos por clase. Su edificio fue construido en 2011, en el marco del "Proyecto de Apoyo a la Escuela Pública Uruguaya", que intenta armonizar la arquitectura escolar con la propuesta pedagógica, tal como surge del siguiente fragmento extraído de las líneas guías del plan.

"La problemática sociocultural de las escuelas ubicadas en contextos desfavorables muestra la necesidad de trabajar los aspectos de participación en la vida social de forma sistemática. Las ETC [Escuela de Tiempo Completo] pueden constituirse en un ambiente capaz de mitigar algunas de las vivencias negativas del entorno social y territorial de los niños en situación de pobreza, aproximándose a mejorar las condiciones de equidad. El ambiente escolar proporciona pautas de comportamiento aceptable, el marco de valores para la socialización, los patrones de conducta personal e interpersonal, la disciplina asumida, haciendo explícitas y consensuadas cada una de las normas" 83 (ver fotos en anexos)

Esta escuela cuenta con un edificio nuevo, de espacio bien distribuido, luminoso, tiene en su interior el comedor, un espacio polivalente y un patio importante. Está ubicada en un barrio urbano, de población trabajadora, donde según datos obtenidos del equipo docente y de nuestras observaciones, se destacan algunas vulnerabilidades en las situaciones habitacionales de su población, tales como viviendas precarias y ocupación de terrenos municipales que no cuentan con servicios de saneamiento adecuados, entre otras. El barrio tiene una policlínica municipal que apoya a la escuela con algunos talleres, en general de educación sexual. Existen otras escuelas en sus alrededores pero los centros de educación secundaria están bastante alejados.

La escuela cuenta con maestra comunitaria de forma permanente en el centro, actividades de educación física, danza, educación artística, Inglés, apoyo al plan Ceibal de programa

83 ESCUELAS DE TIEMPO COMPLETO EN URUGUAY: proyecto de apoyo a la escuela pública uruguaya ANEP - BIRF, Uruguay, 2011.

//www.mecaep.edu.uy/imgnovedades/Libro_arquitectura/LIBROEscuelas_de_tiempo_completo_en_Urugu ay.pdf 
de robótica y está integrada al programa de Escuelas Disfrutables ${ }^{84}$. Cuenta con la presencia semanal de una psicóloga integrante del equipo interdisciplinario.

Escuela C: perteneciente a la zona Oeste de la división del CEIP. Es parte de la categoría de "Escuela Común". Comparte el local con la escuela Nº 96 de turno matutino, así como el comedor, donde concurren varios niños y niñas seleccionados por las dos escuelas. Está ubicada en el barrio Belvedere, cercana a una zona comercial e identificada con una barriada obrera. Existen en su perímetro algunos asentamientos precarios cuya población infantil concurre a la escuela, lo que hace que se categorice a este centro como de "contexto sociocultural crítico". Concurren a ella unos 314 niñas y niños, de $1^{\circ}$ a $6^{\circ}$ grado de primaria (edades de 6 a 12 años). Su local era una antigua fábrica que fue reacondicionada con criterios de accesibilidad (rampas) y tiene un patio grande lateral donde se encuentra el comedor, de construcción reciente. En su predio contiguo se encuentra un jardín de educación inicial, perteneciente a CEIP-ANEP.

Dos veces por semana cuenta con una maestra suplente (por encontrase un grupo sin docente referente ${ }^{85}$ ) así como con una maestra de apoyo e integradora. Tiene profesor de educación física, inglés (en los años superiores el programa en modalidad video conferencia) y maestra MAC (Maestra de apoyo al plan Ceibal). Esta escuela es parte del Proyecto Mandela ${ }^{86}$ y del programa IIDI con apoyo de UNICEF. Ambos proyectos

$84 \quad$ Escuelas Disfrutables es un Programa del Consejo de Educación Inicial y Primaria (CEIP) que comenzó a funcionar en el año 2008. Actualmente el mismo realiza intervenciones interdisciplinarias en las escuelas de todo el país sobre aquellos factores que generan malestar institucional, abordando de forma integral dichas situaciones. Se orienta desde una perspectiva de derechos y prácticas acordes al momento socio-histórico que vive la escuela pública. http://www.cep.edu.uy/programas

85 La docente de ese grupo fue agredida en abril de ese año por una madre. Ella deja la escuela frente a la negativa del CEIP-ANEP de trasladar a la niña a otra institución.

86 El Programa de Educación Inclusiva "Mandela", es impulsado por el Instituto Interamericano sobre Discapacidad y desarrollo Inclusivo (IIDI), UNICEF y ANEP. Busca detectar, apoyar y evitar la exclusión y discriminación de niños y niñas que presenten alguna discapacidad. http://www.cep.edu.uy/prensa/393red-mandela-una-forma-de-sistematizar-experiencias-de-escuelas-inclusivas

En su marco conceptual podemos destacar: "La inclusión es una de las líneas de políticas educativas del CEIP, como proceso que busca atender a las necesidades de los alumnos respondiendo a su diversidad y eliminando cualquier práctica de exclusión. Su implementación, ha dado origen a programas y proyectos que se enmarcan, en el reconocimiento de los derechos consagrados en la jurisprudencia nacional e internacional, en el valor educativo, humano y social que la educación desde esta perspectiva conlleva, así como en el fuerte arraigo en la ciudadanía y el magisterio uruguayo del pensamiento vareliano, para quien, 
trabajan el desarrollo inclusivo de niños y niñas con discapacidad motriz. Por este motivo la escuela cuenta con coordinaciones y apoyo de la Escuela Especial $N^{\circ} 203$, la cual facilita la visita de maestras para trabajar en forma de taller con los grupos de inclusión desde un abordaje de "filosofía para niños". El Proyecto Mandela crea espacios de reunión mensual del equipo docente para reflexionar y trabajar el tema.

Esta escuela intenta sostener una inclusión en el barrio a través de actividades con un colegio privado de la zona de orientación católica Franciscana, con el jardín de educación inicial vecino y con la policlínica. También mantiene relación con otros centros educativos del país, en especial los vinculados al Proyecto Mandela a través del sistema de video conferencia.

Si bien las tres escuelas donde se desarrolló el trabajo de campo tienen características diferentes, en todas ellas pudimos encontrar problemáticas similares. Como elementos comunes podemos observar:

- las dificultades en la comunicación y el manejo de pautas de entendimientos con familias;

- algunas dificultades de conducta severas de niños y niñas en el ámbito educativo;

- poco tiempo dedicado a la reflexión crítica y actualización de los equipos docentes $\mathrm{y}$

- niveles de saturación afectiva ${ }^{87}$ de los y las docentes.

aquellos que "se han encontrado juntos en los bancos de una escuela, se acostumbrarán fácilmente a considerarse iguales."

https://duraznodigital.wordpress.com/2014/05/08/escuela-10-y-jardin-87-son-parte-delprograma-de-educacion-inclusiva-mandela/

87 La "saturación afectiva", concepto utilizado por autores de la Escuela de Frankfurt (Theodoro Adorno), demuestra en las opiniones de los sujetos una compensación a una herida narcisista, que sustituye una debilidad mediante una identificación con una causa colectiva o creencia, que ofrece un sentimiento de pertenencia y restituye algo de la autoestima dañada en procesos de socialización o adaptación. 
Pero también se pudo observar en las tres instituciones un aspecto común muy positivo: su disposición para la búsqueda de nuevas alternativas en las modalidades educativas y para trabajo en equipo con el objetivo de desarrollar una tarea educativa integral y participativa, que tenga en cuenta las necesidades y desafíos de aprendizaje de la infancia de la actualidad.

\subsection{Estrategia de intervención}

En el trabajo dentro de las escuelas se realizaron entrevistas a los directores, las secretarias, docentes de aula, profesores especiales, maestras integradoras, de apoyo y maestras comunitarias. También se hicieron observaciones participantes en actividades de aula: clases comunes donde los docentes invitaron a participar a esta investigadora y clases especiales (tales como educación física, inglés, talleres de filosofía para niños, talleres de integración lúdico-creativos, pintada de mural de un $6^{\circ}$ año, talleres de lengua, de razonamiento matemático y talleres de valores y de derechos). Se observaron los recreos, las entradas y salidas de los centros y las instancias de comedor. Se participó de ensayos de actos y de un acto de cierre de cursos, así como de un día de elección de abanderados en los $5^{\circ}$ años. La duración de las actividades en las escuelas fue de tres meses aproximadamente, con una asistencia de una vez por semana a cada escuela, cumpliéndose un mínimo de 10 visitas y un máximo de 16.

Para el desarrollo de las actividades fue importante construir la confianza con los y las maestras. En un comienzo se propuso a los equipos docentes la visita a una clase por grado en cada escuela. Esto no fue posible dado que muchos de los y las docentes a cargo de clase eludían las instancias en las que estas visitas pudieran concretarse. Parte de la estrategia de acercamiento y profundización de la comunicación que permitió desarrollar el trabajo fue la presencia semanal en cada centro; generar encuentros informales, como por ejemplo ir a saludar a los maestros en los recreos, y facilitar conversaciones en ronda, intercambios de opiniones y relatos de anécdotas. Rápidamente se percibió que era necesario contar con la confianza y respeto de los y las docentes para acceder a elementos significativos para la investigación. Esto implicó un cambio en la planificación inicial, que consistió en esperar a ser invitada a las aulas u otras actividades y aceptar la dinámica que los propios docentes iban marcando. 
En algunos momentos se percibió una actitud reticente por parte de algunos docentes, con preguntas como "¿Alguna vez estuviste en una escuela?, porque no vas a entender lo que pasa acá". Se constataron situaciones de resistencia ${ }^{88}$ ante la temática de EDH y algunas actitudes esquivas hacia encuentros conmigo como investigadora. Estas situaciones se fueron revirtiendo paulatinamente y no se dieron de parte de todos los docentes. Hubo otros que se mostraron muy entusiasmados por hablar, contar y mostrar lo que hacían y pensaban, algunos hasta expresaron que me estaban esperando para hablar conmigo y deseaban que visitara sus clases. Destaco una situación que ocurrió el último día en una escuela, al despedirme de un maestro con el que casi no había tenido contacto. El docente valoró lo que describió como perseverancia y dedicación de mi parte, expresando "que no tenía mucho interés en conversar conmigo porque no estaba de acuerdo con eso de los derechos de los niños". Sin embargo dijo que había demostrado ser "muy humana" y pidió disculpas por su actitud. En ese momento comenzó a relatar una situación de agresión vivida con un niño en otra escuela. En esa situación se ubicó como el agredido "la víctima era yo" y contó que no se sintió nada respaldado ni sostenido por sus autoridades, que le dijeron "...es que los niños ahora tiene derechos". El relato deja entrever una situación conflictiva, incluso una contradicción entre lo que él entendía por el enfoque de los derechos del niño y de la EDH en el sistema educativo, incluyendo la relación educando-educador.

Al ingresar a campo buscando indagar las prácticas y representaciones en torno a la EDH, mi presencia como investigadora encarnaba esas contradicciones y conflictos que las y los docentes atraviesan cotidianamente. Las resistencias iniciales fueron siendo superadas en la medida en que el trato personal y el establecimiento de lazos de confianza lograron situarme en un espacio de diálogo y permitieron abrir caminos para pensar y buscar soluciones a esos conflictos.

La intervención realizada desde la observación participante implicó diferentes formas de estar en las escuelas. En varios momentos mi presencia consistió en una actitud atenta, de observación al desarrollo de las actividades en las que se me invitaba a participar. En otras instancias mi presencia en las clases fue central. En estos casos se estableció un dialogo

88 Se considera, en este caso, que en las situaciones de resistencia psicológica intervienen elementos de oposición que obstaculizan los procedimientos y los procesos necesarios para el buen desarrollo del trabajo. 
con los niños y las niñas del cual pude participar. En otros momentos el desarrollo de las actividades planteadas por las docentes implicaba mi colaboración, desde un lugar de apoyo en el que era aprovechada como un recurso más para la tarea, tanto para supervisar el clima de aula como para atender a los niños y niñas en su trabajo.

Es significativo destacar otra situación que hace al orden de la intervención donde se encuentra la observación de la EDH. En una ocasión durante un recreo vinieron unas niñas a hablar con una maestra sobre un conflicto entre ellas. La maestra actuó de mediadora, pidió información a las diferentes partes, puso en palabras la situación conflictiva y las diferentes visiones de las partes y así las niñas rápidamente entre ellas lograron encontrar una solución que conformara a ambas. Yo me acerqué a la maestra y explicité su proceder como mediación en un conflicto y en su resolución, promoviendo la actitud de escucha, de entendimiento entre las niñas. Se percibió que las maestras presentes se sintieron valoradas en esta actitud de su compañera y otra maestra dijo: "Yo no sabía que eso era trabajar derechos humanos, pero esto lo hacemos siempre...".

Es así que se observo que hay diferentes niveles de trabajo en EDH presentes en el ámbito educativo y diferentes formas de abordarlo. No siempre se identifica el proceder docente con la EDH, aunque en varias ocasiones observadas desempeña un lugar importante la formación en valores y la acción para la convivencia, aunque no sea concebida ni conceptualizada como EDH. El tomar conciencia de la temática de EDH y su identificación en las más variadas situaciones dentro de las escuelas fue aumentando en la medida en que continuaba mi presencia como investigadora participante.

\section{4- Estrategia de cierre: Taller de devolución y cierre.}

"Me refiero al taller coma tiempa-espacia para la vivencia, la reflexión y la conceptualización; como síntesis del pensar, el sentir y el hacer. Cama el lugar para la participación y el aprendizaje".

María Teresa GDNZALEZ CUBERES (1987)

Hacer una devolución y cierre del proceso con las personas que se implicaron en la investigación es fundamental para la coherencia en el planteo en la $\mathrm{EDH}$, en términos tanto 
éticos como metodológicos. Marca el lugar que se les da a los sujetos de la investigación y la posibilidad dialógica de un intercambio sobre los datos surgidos del mismo proceso.

Por esa razón, la intervención en las escuelas se cerró con una instancia en la que participó cada uno de los equipos docentes, en la que se presentó una devolución del trabajo realizado enmarcado en los referentes teóricos, jurídicos y pedagógicos que dan cuerpo a esta investigación. Se realizó con una metodología de taller, lo cual permitió una puesta vivencial integral, que en su despliegue metodológico abarcó las dimensiones teórica, política y ética que interesan destacar de la EDH. Se plantearon dinámicas que permitieron visualizar la propuesta de EDH e intercambiar ideas, impresiones y reflexiones sobre lo expuesto y lo vivido. Se entregó a las escuelas el archivo de la presentación realizado por esta investigadora en ocasión de taller de devolución y cierre, así como varios materiales sobre EDH en versión digital, los que me fueron solicitados durante el desarrollo de la investigación. Finalmente, fue muy reconfortante para esta investigadora escuchar que en las tres escuelas se manifestó la voluntad de trabajar el proyecto de centro para el año próximo en el marco de los derechos humanos.

Se observó, en general, gran sintonía con el aporte teórico de la EDH. Una maestra comentó "Es lo que intentamos hacer en cada momento." Pero también hubo otras intervenciones sobre las dificultades que presenta tratar de mantener una coherencia pedagógica a la hora de la práctica misma. La expresión de una de las maestras participantes puede ilustrar esta percepción: “Cuando estudiamos aprendemos todo esto, leemos varios autores... Pero cuando empezamos a trabajar, la práctica en las escuelas se transforma en otra cosa... y parece que nos olvidamos...;Cuanto necesitamos estos momentos de reflexión las maestras!".

En las tres escuelas surgió el comentario, compartido casi por todos, de lo necesario que resulta tener espacios de reflexión y formación en estas temáticas. Se reconoció que existe poca formación en EDH y en derechos humanos durante la carrera de magisterio y tampoco se cuenta con espacios de formación permanente. Si bien algunos maestros sabían que existen ofertas de formación en esta área dentro de Consejo de Formación perteneciente al sistema (ANEP), se reconocieron las dificultades reales de asistir a este tipo de formación: cargas horarias elevadas y sistemas de evaluación importantes que requieren un gran esfuerzo para poder compatibilizarse con las exigencias de la tarea 
profesional diaria. También se señaló que, una vez que los cursos son realizados, no son tomados suficientemente en cuenta en la calificación y evaluación docente por el sistema.

Se explicitó en los tres encuentros de cierre que se apreciaba esta actitud de tener en cuenta a los y las maestras en la devolución, y se reconocieron los sentimientos y actitudes de resistencia iniciales. Se dijo, por ejemplo, "Acá todos vienen, se sienten con el derechos de opinar, sin saber qué es lo que realmente pasa en la escuela"; "vos venías por la inspección y no sabíamos lo que ibas a hacer ni qué teníamos que hacer nosotros." Se concluyó que era valioso el espacio de reflexión, de devolución y cierre que se generó, porque sentían que "alguien de afuera” les devolvía algo.

Estas expresiones dan cuenta de la imagen que los y las docentes se forman respecto a lo que "otros" piensan sobre ellos, porque al excluírselos como interlocutores sienten que se está desvalorizando su rol y la tarea docente.

Algunos docentes reconocieron que trabajaban desde una concepción de EDH sin saber claramente que lo estaban haciendo, por desconocimiento del planteo teórico-metodológico que implica la EDH. Plantearon que era bueno que yo "les dijera todo esto" a las autoridades. En dos de las escuelas, en el taller de cierre algunas docentes comentaron que "recién ahora" estaban prontas para empezar a trabajar en EDH, mostrando que existen diferentes ritmos temporales entre los procesos de investigación y los de la tarea educativa, ya que establecer una vinculación adecuada y significativa entre ambos implicaría un proceso de tiempo más largo.

Al finalizar el trabajo en las escuelas, esta investigadora retomó contacto con las inspectoras manifestando su interés en tener también con ellos una instancia de devolución y cierre de la actividad de campo. En dos casos esta instancia se redujo al envío de de los materiales y presentación vía correo electrónico. En el tercer caso se realizó una reunión con el grupo de inspección para dialogar sobre el trabajo realizado, en la cual se hizo la entrega del archivo de la presentación y otros materiales.

\subsection{Caracterización del rol docente y la tarea educativa}


Algunos docentes manifestaron que no están listos para trabajar algunos temas de derechos humanos porque que no tienen formación. Y en algunos casos plantearon dudas éticas, por ejemplo “cómo trabajar algunos temas de dificil encare para los maestros?”

En el discurso de los y las docentes se hace explícita una dificultad para trabajar con situaciones complejas porque el conflicto los paraliza. Gran parte de ellos ven a los niños y niñas como víctimas de situaciones injustas y se problematizan ¿Cómo trabajar la enseñanza de los derechos humanos con niños que viven y van a vivir siempre la violación o vulneración de sus derechos?

Explicitan las situaciones de pobreza y marginación social y señalan otras situaciones de vulnerabilidad hacia los derechos de los niños, como ser la falta de cuidados de los padres, la violencia doméstica y el maltrato infantil.

Se escucharon algunas opiniones que explicitaron sentir un malestar o una cierta incomodidad frente al concepto de derechos humanos. Dicen estos docentes que les es difícil plantearse enseñar derechos humanos en la contraposición de situaciones reales frente a situaciones ideales, que serán muy difíciles de transformar. Ellos sienten que les produce mucha rabia e indignación y que no les resulta ni fácil ni justo, más bien demagógico, planteárselo así a los niños y niñas.

“Cómo voy a hablarles del derecho a una vivienda digna, si más de la mitad no tienen ni una cama propia?, ... hacen sus necesidades en un balde...”. (Maestra)

"Cuando trabajamos género, un varón, en actitud desafiante y provocadora, contó cómo su papa le pegaba a su mama!... yo me sentí muy mal, ...no lo quería rezongar, pero lo tuve que parar... Y al final empezó a gritar, a molestar, lo mandé a la dirección y terminé con el tema... No fue una buena experiencia" . (Otra maestra)

Dejan así planteada la situación de dificultad de trabajar en el ámbito educativo con situaciones conflictivas que involucran los derechos humanos y varios aspectos de las personas y sus relaciones.

Por otro lado, plantean que los niños y niñas de hoy no son fáciles de motivar para el trabajo en el aula porque la escuela compite con otros canales de comunicación e información, como la televisión y la computadora, que pueden manejar elementos motivadores como el color, la música, las imágenes y diferentes ritmos, entre otros. 
Expresan que la dispersión y el aburrimiento son actitudes muy frecuentes en los niños y niñas en las clases.

Aparece una pregunta reiterada en los y las docentes: ¿dónde nos paramos, nos ubicamos, para educar hoy en las escuelas?, ¿para qué modelo de sociedad estamos educando?

Esta pregunta implica una reflexión por parte del educador, quien se ve inserto en un mundo y en una realidad concreta. Aparece también el cuestionamiento sobre la formación recibida. Varias maestras plantean que no fueron formadas para trabajar con los niños actuales: las problemáticas más nombradas son alteraciones en la conducta, dificultades severas de aprendizaje, el déficit atencional y la hiperactividad, el síndrome de Asperger ${ }^{89}$ y fundamentalmente el difícil relacionamiento con las familias.

Esta investigación identificó opiniones de maestros y maestras con quejas sobre las exigencias que reclaman las autoridades (inspectoras y Consejeros) en relación con el trabajo administrativo y la prioridad en tareas vinculadas a competencias como matemática y lengua. Estas quejas son aún mayores que por las concepciones, tareas y habilidades que hacen al clima de clases y de convivencia. "Acá solo les importa lo que haces en matemática y lengua... Nadie te pregunta como haces para trabajar las cosas del grupo, los conflictos...no te preguntan cómo te llevas con los chiquilines.” (Maestra)

Escuché numerosas veces que "se perdieron los valores en esta sociedad" y cuestionamientos por quién y cómo se enseñan esos valores. En los colectivos docentes se reconoce que existe una dificultad en tarea de educar en valores que genera una rivalidad con el entorno familiar (opiniones y actitudes en desacuerdo). Reconocen que esta tarea implica una acción conjunta de los dos ámbitos, familiar y educativo, pero que esto está en conflicto actualmente. "En las familias no se enseñan los valores y exigen que se los enseñemos en la escuela... pero ¿qué vamos a poder hacer, nosotras acá, en pocas horas?"(Maestra)

A pesar de las numerosas quejas, también se observa que existen docentes que buscan estrategias educativas para enfrentar los problemas que encuentran. Cuenta un maestro en una ronda entre sus colegas "Sí, es verdad que no nos formaron para esto... pero hay que buscar, en internet encontrás de todo!" y comenta varios materiales que usó para trabajar

89 El síndrome de Asperger es un conjunto de características mentales y conductuales que forma parte de los trastornos del espectro autista. 
en sus clases, desde propuestas pedagógicas hasta elementos para usar de disparador, como por ejemplo cuentos.

Todas estas observaciones sugieren que se está ante la presencia de diferentes visiones sobre la educación, que van desde maneras de concebir el rol docente más instrumental, reproductor de un modelo de enseñanza y de una realidad, hasta visiones del rol docente como motivador del proceso educativo con características de transformación de las realidades de los educandos. Se identificó una multiplicidad de sentimientos, sentimientos encontrados, mucho malestar, inseguridad, reclamos hacia las autoridades y la sociedad en general, así como cierta confusión sobre lo que se espera socialmente del docente. Pero también se encontraron muchas acciones esperanzadas y constructivas: movimientos de búsqueda, de transformación e intentos de trabajos en conjunto, de construir significados y nuevas formas de estar en la escuela.

Cuando se indagó sobre formación académica o sistemática en derechos humanos y en particular en $\mathrm{EDH}$, solo una docente planteó que había realizado un curso a distancia sobre derechos humanos y otra maestra comentó que había participado en instancias de formación y trabajo con el grupo de Educadores para la Paz. Estas escasa experiencien confirman que existe un vacío en la materia.

\section{Los derechos humanos en la escuela, diferentes visiones desde el campo.}

Hemos avanzado en la tearía de las derechos humanos y en la aceptación intelectual de los mismos y queda mucho por hacer para lograr que estas mismas avances se traduzcan y consaliden en el terrena de las actitudes y de las relaciones, escenario en el que transcurгe nuestra vida de martales y en la que manifestamo, desde la práctica, nuestra compramisa can las derechas humanas coma estila de vida.

La investigación de campo permitió comprobar que existen diferentes miradas sobre la EDH, cómo se la entiende y como se la lleva a cabo. Pudimos observar que estas diferentes visiones co-existen, a veces de forma complementaria y en otros momentos de manera 
contradictoria. A continuación se presentan y discuten algunas de las concepciones docentes más notorias que aparecieron durante las visitas de campo a las escuelas.

\section{1.- La primera reacción: “¡En la escuela no se violan los ddhh!”}

La primera de las percepciones identificadas en campo es la que asimila los derechos humanos a su vulneración. De esta forma, trabajar en derechos humanos dentro de la escuela significaría identificar aquellas situaciones en las cuales los niños y niñas no tuvieran todos sus derechos respetados por parte de los y las maestras.

Al llegar a las escuelas a hablar de derechos humanos y EDH se observó que algunos docentes reaccionaban como si estuvieran siendo interpelados con la acusación de ¡Acá se violan los ddhh!. Se recibió por parte de una inspectora y una directora una aclaración explícita: “En la escuela no se violan los derechos de los niños, al contrario, acá se respetan!!! Venir a la escuela ya es un derecho... acá damos de comer a todos los niños derecho a la alimentación-, pedimos el carné de salud, la cédula de identidad-derecho a la identidad-...". (Directora)

Algunas maestras preguntaron como inocentemente: “QQué es lo que estás queriendo ver?, ¿cómo tratamos a los chicos?; “...no entiendo bien qué es tu trabajo acá...” Durante todo el período de investigación en las escuelas fue necesario reiterar que el objetivo no era juzgar ni calificar su trabajo. Estas reacciones se dieron con más frecuencia en la primera etapa de la investigación y pueden interpretarse desde una visión de los derechos humanos vinculada a la identificación y denuncia de violaciones. Como tal entendían los y las docentes mi trabajo en la escuela.

En el mismo sentido, una inspectora entrevistada después de que le realizara una breve descripción del proyecto de tesis, me cuestionó: “Desde que se creó la Escuela Pública en este país, con Varela, ella transmite los valores democrático. La escuela forma ciudadanos. Así que no entiendo lo que querés investigar”.

Durante la entrevista la inspectora fue distante y me increpó varias veces, cuestionando el trabajo de investigación en derechos humanos en el ámbito escolar, desplazando el eje de 
lo que entendía como mis preocupaciones hacia otras instancias del sistema educativo. Cuestionó la elección de las escuelas comunes, proponiendo que sería mejor trabajar en educación inicial o especial ya que "es alli donde se violan los derechos humanos". De esta manera reforzaba la concepción que asocia los derechos humanos y la denuncia de sus violaciones. En los capítulos anteriores vimos como esta óptica de identificación y denuncia tuvo una importancia fundamental en el período post-dictadura.

Varios docentes en un primer acercamiento dijeron que no trabajan nada sobre derechos humanos, que no se "metían en ese tema". En general, quienes contestan con una negativa a trabajar la temática fueron quienes identificaban el tema con el período dictatorial, contenido que se encuentra en el área de Conocimiento Social en la disciplina de Historia de $6^{\circ}$ grado. Uno de los directores comentó que cuando el tema se incorporó en el programa 2009, la escuela mandó comprar la colección de libros que publicó la Facultad de Humanidades y Ciencias de la Educación (UdelaR) sobre el pasado reciente en convenio con Presidencia, pero que nunca ningún maestro los había pedido.

Cuando se profundiza en la pregunta sobre cómo se trabaja en EDH, encontramos que el magisterio sí trabaja desde algunos contenidos temáticos que están en el programa, pero no los identifica como derechos humanos. Por ejemplo, el fin de la segunda guerra mundial, la creación de la ONU y los tribunales internacionales y los derechos sexuales y reproductivos (contenidos todos del programa para $6^{\circ}$ grado en el área de conocimiento social en historia y en construcción de ciudadanía-derecho).

Un día, al indagar el trabajo en estas temática, frente a la cerrada negativa de una maestra, le re-pregunté buscando algún ejemplo si ella no trataba con los niños y niñas la igualdad entre hombre y mujeres. Se sorprendió y me dijo: "sí, eso es lo que trabajamos el 8 de marzo, es género... ¿Eso es derechos humanos?"

\section{2- Cumplir los derechos de los niños}

"Niñ̃as san, en su mayaría, las pabres; y pabres san, en su mayaría, las niñ̃as. Y entre tadas las rehenes del sistema, ellas san los que peor la pasan. La sociedad los exprime, los vigila, los castiga, a veces los mata: casi nunca los escucha, jamás los comprende." 
Otra de las concepciones que aparece frecuentemente es la que asocia la EDH al cumplimiento de los derechos de los niños y niñas que asisten a la escuela. Surgieron cotidianamente una variedad muy importante de anécdotas relatadas con sentimientos de dolor, de injusticia e impotencia. Estas narraban situaciones de niños y niñas en condiciones de vulnerabilidad, ya sea por situaciones de pobreza, malos tratos y violencia doméstica, negligencia de los adultos responsables, situaciones de abandono, y todo tipo de contextos familiares difíciles de sobrellevar. Se trata de una gama muy importante de realidades que viven los niños y niñas en sus hogares que impacta en la mirada y el discurso de los adultos. Esas situaciones, fueron expresadas con un sentimiento de dolor que me impactó, más allá de las situaciones de los niños (similares a las que ya conocía de otras experiencias previas), por el grado de saturación afectiva que mostraban en los y las docentes. Manifestaron "no comprender" los accionares de las familias, siendo éstas realidades ajenas a las de los propios docentes y que son resueltas de forma que ellos no comparten. Estas situaciones dan cuenta de una distancia socio-cultural importante.

Así que aparece la concepción de abordar los derechos humanos desde la propia enseñanza asociada al cumplimiento de derechos. Aparecen en varias oportunidades, relatos de cómo se asiste a los niños y niñas (salud, alimentación, acceso a documentación) y se aconseja a las familias acudir a consultas con especialistas de la policlínica barrial, siendo la salud el tema de preocupación más recurrente en el discurso de los y las docentes.

El tema de tratamientos o instancias con especialistas que traten las dificultades específicas del aprendizaje es prioridad para los y las docentes. El pase a "escuela especial" para niños y niñas con estas dificultades es otro tema de mucha incidencia en el cuerpo docente, que es vivido como el cumplimiento de derechos de los niños para el desarrollo de sus personalidades. Existen diferentes quejas sobre cómo los niños y niñas no son llevados a los especialistas o de la interrupción en sus tratamientos por parte de los adultos responsables.

También frente a estas quejas aparece el reclamos de que, si hay niños que no pueden seguir el régimen de "escuela común" por algunas dificultades (de conductas o de rendimiento específico), no es justo que se mantengan en las clases distorsionando y 
dificultando los climas de aprendizajes de los otros niños y niñas. Es recurrente escuchar comentarios como el de esta maestra: "los otros también tienen derecho a aprender y que no los maltraten o vivir ciertas situaciones de violencia en clase”.

Reclaman que las autoridades no siempre entienden esto y exigen mantener a los niños y niñas en las escuelas porque tienen derecho a la educación. Cuestionan que el cumplir con el derecho a la educación de los niños y niñas no es solo asistir al centro educativo, y problematizan sobre qué tipo de procesos educativos se les está brindando a estos niños y niñas con algunas dificultades, así como a los otros.

\section{3- Enseñar los derechos a los niños}

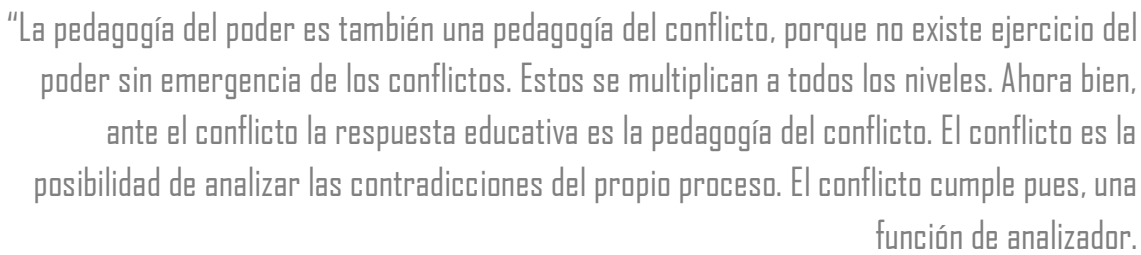
José Luis REBELLATD

En otros participantes de la investigación se pudo observar que entienden a la EDH, como el enseñar los derechos a los niños como contenidos. Desarrollar una actividad centrada en alguna temática especifica que involucre los derechos humanos $\mathrm{y}$, en los casos más interesantes, relacionarla con la vida concreta de los niños o con situaciones vividas o conocidas por estos. A continuación se exponen algunos momentos del trabajo de campo vivido en las escuelas, que hacen referencia al trabajo en EDH dando cuenta de la problematización y re-significación de experiencias en base a un enfoque de EDH.

En una visita a un $4^{\circ}$ año, la maestra les dice a sus estudiantes: "Cuéntenle a Ana Laura qué hicimos para el día del niño”. Los niños y niñas cuentan que hicieron una actividad donde analizaban algunas publicidades de televisión donde se representaba lo que "hacía feliz a los niños", en general tener algo material, un objeto. Y hablaban que si bien tener algo les gustaba, se dieron cuenta que lo que les hace ser felices de verdad son los sentimientos. "También trabajamos con los derechos del niño" y explican que analizaron las realidades de los niños en otros tiempos históricos y las diferencias que existen ahora, con la vigencia de la Convención de Derechos del niño de la ONU. 
Otro grupo de niños me contó cómo trabajaron las elecciones nacionales (que se desarrollaban en ese año 2014) y el sistema democrático. Entonces compararon y analizaron diferentes periodos históricos y diferentes sistemas de gobierno (por ejemplo, democracia/ monarquía).

Una maestra con su grupo recitaron para mí un poema de Mario Benedetti y otro de Federico García Lorca, comentándome que así habían hablado de las dictaduras, regímenes donde no se respetaban los derechos humanos, entre ellos la libertad de expresión. Me contaban que habían escuchado murgas ${ }^{90}$ de la época de la dictadura cuando había censura a las letras de las canciones. Había "palabras y temas que no se podían hablar” y por eso, con creatividad, en las letras de los espectáculos se hacían referencia en forma indirecta. Un niño dijo " ¿y cómo los milicos no se daban cuenta?”

Pero se observó en varias oportunidades que la visión de que los niños y niñas conozcan sus derechos está acompañada por un sentir muy fuerte de parte de los adultos-docentes de ceder autoridad. Se sienten ante la tensión de "niños empoderados" que frente a cualquier problema dicen "Es mi derecho" y "yo tengo derechos...", dejando al adulto con una sensación de quedar sin respuesta y con un sentimiento de pérdida de autoridad.

Así encontramos en algunos casos una sensación, por parte de varios docentes, de sentirse víctimas de estas situaciones, lo cual genera en ocasiones aprendizajes contradictorios o parciales. Asociado a esta opinión, hay docentes que sostienen: "tienen que aprender primero los deberes para ejercer los derechos". Incluso esta investigadora escuchó a una docente reivindicar la disciplina autoritaria: "los niños de hoy, si los dejas hacen lo que quieren..., en la clase tengo que demostrar que mando yo”. (Otra maestra)

$\mathrm{O}$ en el extremo contrario, hay docentes que generan instancias afectivas muy complacientes con los niños y niñas para no encontrarse en situaciones conflictivas que les implique ponerse en contra (tipo chantaje afectivo) “... los niños dicen "no sea mala Mae!"... a veces te sentís que tenés que ser o parecer la maestra buena que les deja hacer lo que quieren, no contradecirles, ...porque en ocasiones, si no [lo hago], siento que no puedo con ellos. "(Otra maestra).

90 La" Murga" es una agrupación de carnaval, del orden de lo coral-teatral-musical, que presenta un espectáculo con sátira social sobre los acontecimientos del año. 
En estas opiniones y actitudes se percibe que lo que está en juego es el modelo de relación entre los educandos y los educadores y la relación entre derechos y poder, porque se relaciona automáticamente que quien tiene derechos tiene poder y el poder se ejerce de forma autoritaria. Esto da lugar a un conflicto en la relación de los roles involucrados en el vínculo educativo. Una maestra decía “ Está bueno que los niños tengan derechos y los conozcan, eso de la Convención de los derechos del niño... a mí me parece bien!... pero también tienen que aprender a respetar... A veces parece que no respetan nada" (Maestra)

Esto nos permite reflexionar sobre el vínculo educativo entre docentes y estudiante, donde aparece un elemento que hace a la puesta en práctica de aspectos comunicacionales, de poder y de relación que ponen en tensión el modelo educativo tradicional y el enfoque de $\mathrm{EDH}$.

\section{4-Algunas miradas integradoras}

No obstante, existen algunos docentes con una visión integradora del trabajo educativo que sí consideran y explicitan sentirse motivados con el tema de EDH. Estos docentes reconocen claramente las dificultades de articulación de contenidos y actitudes que conlleva la tarea. Manifiestan que hay un avance en el Programa con respecto al tema y dicen sentirse respaldados por dicho documento en su accionar profesional. Aunque también reconocen que el sistema educativo no está dando respuestas eficaces a las realidades educativas de hoy, lo cual permitiría ampliar el abordaje desde la EDH.

"No todos los maestros están prontos para entender y menos para trabajar desde este lugar [Enfoque de EDH]... las realidades con que nos encontramos son dificiles y en general nos sentimos muy solos para resolver los problemas... por eso es importante el trabajo en equipo" (Director)

“Acá te la tenés que arreglar como pueda, ... el sistema no te entiende, te exigen por todos lados..." (Maestra)

"los espacios de pensar, discutir, reflexionar entre nosotras y con ...[otros técnicos] son pocos, por más que se intenta dar una mirada diferente ... terminas haciendo lo que podés ... y atendiendo lo urgente"(Directora). 
Se evidencia la necesidad de acompañar y sostener más a los equipos docentes para profundizar las líneas de nuevos abordajes desde la incorporación de la EDH como eje transversal dentro del ámbito educativo, que si bien existes iniciativas estas no alcanzan o tienen escasa cobertura y continuidad dentro de las instituciones.

Así observamos las diferentes formas de entender a la EDH que aparecen en las escuelas. También encontramos en docentes que plantean que el trabajo en EDH debe hacerse de forma integral, vinculado a los climas de respeto y entendimiento que se estimulan en el interior de las escuelas. Aparece así la EDH asociada al tema de la convivencia en el espacio escolar y como modelo para el relacionamiento social desde el respeto y aprecio de las personas.

Son estos actores de nuestra investigación quienes entienden la incorporación de la EDH como una plataforma de acción integral de la educación y una posibilidad de transformación social. Estas personas plantean una comprensión más transversal y a la vez, central de la enseñanza de los derechos humanos en el proyecto escolar en toda la comunidad educativa. Es así que aparecen algunos planteos sobre la importancia de encarar el trabajo educativo desde un equipo. Un equipo que se conozca, que se problematice su realidad y sus tareas y, que actúe en conjunto.

"Esto se hace entre todos. Si no se logra comprometer al otro, a los otros, (los docentes, los padres, los vecinos, los niños, etc.) el proyecto se cae. ... si yo me voy de la escuela, las bases de un trabajo asi tienen que seguir, no depender de mí... llamémoslo proyecto de huerta, desarrollo integral de los niños, o lo que sea, siempre están los derechos humanos..." (Director)

"Acá siempre tenés que trabajar en derechos, apuntando a que los niños aprendan a vivirlos, que se sientan respetados,... no es solo decir los derechos de la Declaración del niño, sino que los respeten en todos lados". (Directora)

En estas personas aparece una preocupación por lo grupal, por una visión global. Como es esperable, las direcciones son las más preocupadas en pensar cómo el equipo docente puede sostener siempre los climas adecuados de convivencia, teniendo en cuenta las características de las personas y los diferentes momentos de los procesos grupales.

“...tengo que tener en cuenta las características de las personas, no todas las maestras pueden trabajar con niños con discapacidad o con algunas 
particularidades. Y no por eso voy a pensar que esa maestra es mala...Es una forma de cuidarla y cuidar la escuela, el proyecto". (Directora)

“...es difícil que todos los docentes te entiendan el trabajo en equipo. Por suerte hay siempre algunos que se prenden y te toman la posta. Asi se va construyendo. Es lento, tiene sus momento buenos y otros de tensión... es que no nos formamos para trabajar en equipos,... Los maestros tenemos una formación muy individualista”. (Director)

En general, estos docentes reconocen haber hecho una elección muy determinada de trabajar en contextos de formación de niños y niñas que viven en situaciones de vulnerabilidad social. Estos contextos son, para ellos, un desafío de crecimiento en lo personal y en lo profesional. Muchas de estas personas, aunque no todas, están en un rol diferenciado en sus escuelas o son portadores de una mirada diferente en sus colectivos.

\section{5- Efectos de transformación durante el trabajo de campo.}

A partir de la experiencia de investigación podemos reconocer que la temática de los derechos humanos y la EDH resulta un tema complejo en el que confluyen varios puntos de vista y aproximaciones. Durante el período en que se desarrolló el trabajo de campo se pudo observar una transformación en los puntos de vista y valoraciones que las y los docentes realizaban en torno a estos temas, modificando alguna de las concepciones previas a la realización de esta investigación. Tales cambios de mirada implicaron el reconocimiento y destaque de la temática en el trabajo educativo. Algunos docentes mencionaron que fue un estímulo para profundizar en su trabajo.

Hay que destacar que varias docentes comentaron modificaciones en su comprensión y abordaje de la EDH. En un principio no tenían una noción clara de lo que era trabajar con derechos humanos y con la EDH. Hubo expresiones como "que no sabían cómo se planificaban estas actividades" o "que eran objetivos permanentes, por eso no los registraban”. Se mencionó que se daba algún tema o contenido sin identificarlo claramente como derechos humanos, por ejemplo la segunda guerra mundial y la ONU, o el tema de género. Estas opiniones pusieron en evidencia la poca cercanía teórica de los y las docentes con la temática de los derechos humanos y la EDH. Sin embargo, al finalizar el proceso de investigación participativa, ellos mismos pudieron identificar los lazos 
existentes entre contenidos académicos, climas de trabajo y metodologías tendientes a un enfoque de EDH.

En varias ocasiones durante los recreos se generaban círculos de maestras hablando sobre estas cosas, intercambiando entre ellas sus visiones y cómo llevarlas adelante. Muy posiblemente mi presencia estimuló este tipo de conversaciones. Un día me dijeron "nos acordamos de ti porque el lunes estuvimos hablado sobre una actividad que hizo[una maestra]...que era con los derechos”. En otra escuela una maestra me recordó: “¿Viste que está en el hall el Muro de la igualdad de oportunidades y de los derechos?". Sin duda esta investigación originó que el tema de los derechos humanos y la EDH pasaran a ser un motivo de conversación y de inquietud de los y las docentes en las escuelas visitadas.

El penúltimo día de mi estadía en su escuela, una directora sacó el proyecto de centro que se denomina "Hacia una convivencia sana y feliz" y, me dijo: "Lo relei todo pensando en vos! No tengo duda de que está pensado desde una propuesta de respeto de los derechos humanos. Pero no dice ni una sola vez derechos humanos...Para el año próximo voy a proponer que lo re-escribamos desde la óptica de la EDH”.

Durante el período de trabajo en las escuelas comenzó un proceso de transformación en los y las participantes de la investigación en relación al tema. Observé que varios de ellos fueron identificando sus propios desempeños e incorporando la EDH a sus actividades.

\section{3-Otras formas posibles para pensar la EDH}

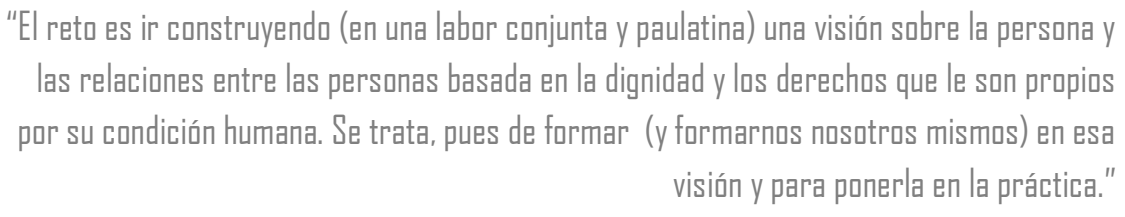

Ana María RDDIND

En el apartado anterior mencionamos las formas en que los derechos humanos y la EDH estaban siendo conceptualizados por los y las docentes en el momento de ingreso a campo. 
El propósito de este apartado es analizar otras concepciones y prácticas educativas que observé y que se vinculan con la EDH en función de sus metodologías y valores, a pesar de que no siempre se las piensa como parte de la EDH por no contener explícitamente contenidos teórico o referencias históricas del tema.

\subsection{EI tema de la participación}

He observado durante el trabajo de campo en las escuelas que el tema de la participación infantil está presente desde un lugar muy contradictorio. Si bien se escuchan lindos discursos sobre cómo los niños y niñas tienen que participar, ser parte de la vida del centro, desarrollar actividades y opinar, en muy pocas ocasiones hemos visto que esto esté realmente presente para las iniciativas de los niños y niñas.

El tema de la participación aparece explícitamente en la Ley General de Educación, como ya se mencionó en el capítulo IV. Se da un desarrollo destacado del principio de participación, con creación de instancias como los Consejos de Participación en cada uno de los centros educativos del país. Pero ésta no es una realidad en todas las escuelas. Solo en una escuela parte de nuestra investigación se me transmitió que tenían conformada esta instancia, aunque nunca pude asistir a ella. Al explicitar mi interés en ver su funcionamiento y entrevistarme con algunos de sus asistentes, me dieron horarios de reunión y fui especialmente en los horarios que me fue señalados, pero nunca pude verla funcionar ni hablar con nadie de la misma.

Cuando esta investigadora indagó explícitamente el tema, las respuestas fueron contundentes: "No, no lo convocamos, ...es una pérdida de tiempo"; "Para qué? Es una complicación. Tenemos Comisión de Fomento,...que por lo menos aporta algo a la escuela". Esas fueron las respuestas de las directoras de las escuelas donde desarrollamos el trabajo de campo.

Al preguntar por las asambleas de la escuela o asambleas de clase previstas en la normativa, las respuestas fueron parecidas. De lo antes dicho se deduce que se realizan actividades de toda la escuela, pero que no son deliberativas sino informativas, a fin de compartir o comunicar algo a las niñas y niños. En los grados superiores depende del docente si organiza asambleas de clase. Allí se pudo encontrar algunas experiencias valiosas, pero pocas. Mientras que en los grados menores tampoco se realizan por entender 
que es una pérdida de tiempo, que las pocas experiencias no son buenas porque se "les van de las manos a los docentes".

Nos han señalado en las escuelas como una experiencia exitosa de participación de los niños y niñas la elección de las y los abanderados ${ }^{91}$. Esta actividad es una réplica de los procedimientos de Elecciones Nacionales, actividad muy interesante para aprender sobre los procedimientos de la vida democrática del país y el derecho de votar y de ser elegido. Pero en sí misma esta actividad no sustituye la experiencia general de la participación como un derecho humano, donde se pongan en práctica el debate y el diálogo en asuntos de interés e incidencia de una comunidad, en este caso comunidad educativa. Precisamente esas experiencias son parte fundante del derecho a la participación, así como una finalidad y contenido de la EDH.

\subsection{Modalidades de comunicación}

"Un pedagaga can experiencia dirá que el lenguaje que articula tadas las lenguas y tadas los discursas, sean estas religiosas, filasóficas, cientifícas, técnica, artísticas a simplemente prácticas, es la ternura, por la cual el afecto y compromisa unen a las persanas y crean el hecho educativa, en la camunicación más plena que puede estar al alcance de un ser

En el tiempo que duró mi trabajo de campo observé que la forma de circular de los niños y niñas en los diferentes espacios escolares era muy libre. Existe una forma de dirigirse a los y las docentes muy amigable, de confianza. En varias oportunidades observé cómo los niños y niñas entran a los escritorios de las direcciones a saludar a directores y secretarias. Les cuentan hechos de sus vidas privadas por el solo hecho de comunicar, compartir con

91 La elección de los abanderados es una actividad ritual de la Escuela Pública Uruguay que se realiza, en el mes noviembre, en las clases de 5 o grado. En ella se eligen 3 abanderados y 6 escoltas (bandera uruguaya Nacional, bandera de Artigas y bandera de los 33 Orientales) que acompañarán durante el próximo año en todos los actos y acontecimientos escolares que la escuela disponga. Esta elección se realiza por un reglamento (circular $N^{\circ} 481$ del año 1989), por el cual se deben calcular los mejores puntajes de todas las generaciones durante su escolaridad. Serán elegibles los alumnos que estén en los promedios de calificación "sobresalientes" y "muy bueno". Se conforma una lista por la secretaría de la escuela y se realiza una elección entre todos los niños y niñas de los 50 años de esa escuela. La realización de la elección es con las lógicas y reglas de las elecciones nacionales. 
ellos. Les traen dibujos y objetos de regalo. Una vez una niña convidó a la directora y secretaria con un pedazo de torta que había traído de merienda, que había sido hecha por su abuela. De esta manera, se comprueba una forma amigable y horizontal de comunicación y de establecer los vínculos.

El tema de la comunicación en los centros educativos es un tema importante porque se enmarca en el fenómeno de la relación humana, en cómo se estructuran los vínculos entre las personas, y si se da en forma autoritaria o de respeto mutuo. La comunicación humana es en sí misma una función integral que involucra las áreas cognitivas, afectivas y conductuales, así como pone de manifiesto la relación del individuo con sí mismo, con "el otro" y con el grupo, que contribuye a construir su realidad psíquica.

Como se dijo en el capítulo II al plantear el marco teórico de esta investigación de tesis, el proceso de EDH se inserta en el proceso educativo como un fenómeno de relación, de profunda comunicación, de comunión entre los dos sujetos de la relación educativa, educando y educador. Tal relación aspira a concebir a las personas como sujetos de derechos, rompiendo con el tipo de relación autoritaria, inscripta en un orden vertical y jerárquico que desconoce al otro en su individualidad subjetiva y grupal, es decir en su dignidad. Esto significa un cambio de mirada y de acción sobre la concepción de poder, que está en la base que conformamos al vincularnos con el otro, con los otros, así también con nosotros mismos, en la cual entran en juego elementos de autoestima y de relación social.

La experiencia de la vida en las escuelas está impregnada de niveles comunicativos y afectivos importantes, donde lo que les pasa a los diferentes integrantes fuera de la escuela es comunicado, resulta parte del proceso de interacción, así como de conocimiento de las diferentes personas puestas en relación. Los docentes también cuentan sus experiencias personales y son interrogados por los niños y niñas sobre sus vidas, generándose así un proceso genuino de intercambio, de comunicación, de relación.

La secretaria de una de las escuelas cuenta:

"Ellos vienen a contarme las cosas que les pasan, porque saben que los escuchamos acá. Que nos preocupamos por ellos... En la escuela hicimos todos los trámites para poder darles las medicaciones [a los niños que toman] ... ellos 
vienen solos para que se las dé, no tengo que ir a buscarlos... Ellos saben que yo quiero lo mejor para ellos..."

Esta actitud comunicativa, interactiva de los niños y niñas fue incluyendo de a poco a esta investigadora. Muchos al verme en la escuela venían a saludarme con un beso y a preguntarme si volvía a sus clases. Un día una niña me paró en un corredor, "Ana, vos que sos psicóloga, ¿los psicólogos dicen la verdad?... después quiero hablar contigo... en el recreo te busco". (Niña)

Pero también con el fenómeno comunicativo asoman los problemas porque los conflictos de las vidas privadas de los niños y niñas aparecen en la escuela. Situaciones duras, difíciles, que impactan a los y las docentes. En muchas ocasiones, estos los verbalizan de manera compulsiva o demuestran en sus actitudes un nivel de saturación y de sufrimiento con respecto a las historias y conflictos que provienen de sus estudiantes y que son traídos a la escuela.

"Nosotras somos maestras, nos formamos para enseñar, no somos psicólogas, asistentes sociales... No sabemos qué hacer con estas situaciones, ... llamanos a las madres, a los abuelos..." (Maestra)

“...a veces es mejor no llamar a la familia, porque es peor... “(Otra maestra)

"Es dificil!!! Hay veces que sentís que no hacés nada por el niño ... Es que no sabemos a veces qué hacer... "(Otra maestra)

Actualmente en las escuelas aparecen nuevos desafíos que trascienden el aprendizaje académico e impregnan la convivencia de niños, niñas y adultos en espacios con una subjetividad marcada por una emocionalidad intensa y conflictividad importante que exigen una comprensión y un abordaje complejo e interdisciplinario. En estos casos la visión tradicional del espacio educativo no logra dar una respuesta cabal.

\subsection{Trabajo en equipo y nuevas prácticas educativas}

"Enseñar no existe sin aprender y viceversa, y fue aprendiendo sacialmente como, a lo largo de la histaria, mujeres y hambres descubrieran que era posible enseñar. Fue así, aprendiendo 
en forma sacial, que con el transcurso de los tiempos mujeres y hombres percibieran que era posible -después, preciso- trabajar maneras, caminas,

métadas de

enseñar. Aprender precedió a enseñar ם, en otras palabras, enseñar se diluía en la experiencia realmente fundadora de aprender."

Paulo FREIRE (1996).

Se encontró que los equipos de docentes en las diferentes escuelas han planificado algunas estrategias o dispositivos diferentes a lo que se entiende como la clase de aula tradicional. Modifican así las formas de enseñar. Aparecen estrategias de talleres, espacios rotativos de actividades, organizados por varias maestras, donde existen coordinaciones, articulaciones dentro del centro educativo.

Estas formas de trabajo aparecieron con anterioridad al cambio de programa. Empezaron con un plan piloto en algunas "escuelas de prácticas",92, donde se desarrollaba una modalidad entre las maestras paralelas ${ }^{93}$ de $6^{\circ}$ grado, planificando y realizando las actividades de diferentes áreas de forma articulada ${ }^{94}$. No son formas de trabajo impuestas sino que están amparadas en la libertad de cátedra. Cuenta una maestra:

“acá tenemos eso de la libertad de cátedra, que vos podes planificar como pensás que es mejor para tus clases...Siempre cuando empezás a hacer cosas nuevas y diferentes tenes que justificar a la inspección y a la directora,...no podes hacer cualquier cosa ... Acá la directora está de acuerdo con plantear cosas nuevas, nos apoya”.

Más adelante, la misma maestra explica que si algún docente no está de acuerdo con esta modalidad puede no involucrarse. Durante la investigación se observó que estas modalidades de trabajo varían para cada escuela y que no necesariamente son adoptadas por todos los y las docentes.

92 Las "Escuelas de Practicas" son escuelas comunes donde tienen lugar algunas actividades de formación a futuros maestros y maestras. Estos centros son en general calificados como de buen rendimiento de sus docentes que se desempeñan allí. En ocasiones en estas escuelas se inician algunas propuesta pedagógicas, en calidad de pilotos, que después se generalizan al conjunto.

93 El término "maestra paralela" es usado en las escuelas para identificar a las y los docentes que dentro del mismo centro tienen a cargo el mismo grado con diferente grupo de niños.

$94 \quad$ En los inicios el plan piloto implicaba el trabajo por un lado en ciencias sociales y por otro en ciencias naturales de forma articulada de los o las maestras de 6 to grado. 
En cada escuela se observó una forma distinta de llevar adelante el trabajo, pero con algunas características similares. Por ejemplo, es común que se tienda a un enfoque integral de los procesos de aprendizaje, priorizando una mirada de lo grupal, sin descuidar los procesos individuales. Las metodologías utilizadas son más participativas, de trabajo en equipos y empleando técnicas expresivas; se realiza una planificación articulada y coordinada entre varios docentes, lo que da como resultado la idea de trabajo en equipo. Es importante el lugar que juegan en estas propuestas las maestras comunitarias ${ }^{95}$ y las maestras integradoras o de apoyo ${ }^{96}$. Estos son cargos pertenecientes a la escuela y esas maestras son parte de los equipos docentes. Sin embargo, el cumplir con una función diferente a la de los modelos tradiciones de un docente por aula les permite re-organizar la intervención educativa de una manera distinta.

Estas formas alternativas que se realizan en las escuelas están muy relacionadas con la metodología de la EDH desarrollada en el capítulo II, aunque los y las maestras no las identifiquen como tales.

Según las y los docentes indagados en esta investigación, estas modalidades de trabajo cumplen varios objetivos:

A nivel académico les permiten profundizar en algunas áreas disciplinares al poder compartir el trabajo con la docente paralela, o con otros docentes del equipo.

"Yo planifico en Ciencias Naturales, mientras la otra maestra de $2^{\circ}$ en Ciencias Sociales. Y así vamos cubriendo el programa que es muy extenso, de otro modo es imposible abarcarlo". (Maestra)

Las y los docentes trabajan en equipo, lo que les permite producir un nuevo conocimiento colectivo y climas afectivos estimulantes. Es decir, logran un mayor nivel de sostén en la tarea profesional que les posibilita observar y evaluar mejor a los niños y las niñas. Crean redes afectivas entre maestras y maestros, a modo de sostén en el trabajo. Así pueden

\footnotetext{
95 El Programa "Maestros Comunitarios" es una de las Políticas Educativas que comenzó en 2005, con el gobierno de Dr. Tabaré Vázquez. Uno de sus principales objetivos es mejorar los vínculos de la escuela con las familias y encontrar diferentes caminos pedagógicos y didácticos para que los niños y las niñas tengan el deseo de aprender perdido por muchas causas.

96 Las Maestras integradora apoyan al equipo docente, así como a niños y niñas en situaciones de inclusión frente a algunas dificultades. Se encontró que estas docentes tienen formas de funcionar diferente de acuerdo a cada centro educativo.
} 
experimentar en primera persona las dificultades y posibilidades de trabajar en equipo y ser, al mismo tiempo, un ejemplo para los niños y niñas.

“...no te sentís tan sola, somos varias que conocemos y vemos trabajar a los chiquilines. Podemos intercambiar..."(Maestra)

"cuando me quedo a participar en los talleres de [la maestra integradora], los veo en otro tipo diferente de actividades,...me ayuda a conocerlos mejor...". (Otra maestra)

Respeta los diferentes tiempos de aprendizaje, así como las diferentes modalidades de las niñas y los niños. En algunos casos estas re-organizaciones momentáneas logran bajar el número de niños por grupo (que en ocasiones llega y pasa los 30). De esta manera los y las docentes pueden apoyar a niños de forma más individualizada, si estos los requieren y enriquecer los niveles de integración grupal e internivel. Las maestras destacan que han observado que cuando comienzan a trabajar en estas modalidades se genera un mejor relacionamiento y convivencia en los recreos.

"al trabajar los $1^{\circ}$ y $2^{\circ}$ integrados, los separamos en 3 niveles (eso los niños no lo saben), les permitimos más tiempo a algunos que necesitan... mientras que los más rápidos no se aburren, están en el grupo de los avanzados... Hacemos evaluaciones intermedias todas juntas, cada tres meses. Los niños van pasando de subgrupo cuando lo consideramos importante... Nos hemos llevado sorpresas muy positivas por el rendimiento de algunos chiquilines!!!”. (Maestra)

Además, el trabajar dos o más adultos juntos permite que los niños y niñas logren vinculaciones diferentes con los docentes, permitiendo una rotación en los roles en cuanto a mantener climas adecuados en las clases y haciendo más amena la tarea.

"Hay niños que se llevan mejor con una que con otra, (nosotras también tenemos nuestras preferencias, es ineludible, somos humanos) y así al ser más maestros que trabajan con el grupo, permite diferentes maneras... te da aire en las relaciones cuando son difíciles... no es siempre la misma que rezonga o que los marca..." (Maestra)

Las maestras cuentan que al principio hubo resistencias, no todas y todos estaban de acuerdo con trabajar de esta manera, pero al empezar a ver los resultados en el funcionamiento, tanto en los rendimientos personales como en una mejor convivencia 
grupal, se fueron convenciendo de que estas modalidades aportan a la tarea educativa en la actualidad. El trabajo con un enfoque integral y desarrollado en equipo les permitió distribuir tareas y roles, reorganizar la didáctica en co-coordinaciones y generar alianzas entre colegas, de manera de potenciar el desarrollo de los niños y las niñas en sus procesos de aprendizaje, como en la socialización.

“No es fácil, cuesta trabajar en equipo... las coordinaciones...”; (Maestra)

“... a veces se te hace pesado, sentís que no avanzás, que estamos discutiendo sobre lo mismo... pero después se ven los resultados... ";(Otra maestra)

"Sí, es mejor, a mí me gusta, aprendo de las compañeras...por los chicos, a ellos les encanta, son diferentes los dias que hay talleres". (Otra maestra)

Observamos cómo cada equipo configura una forma particular de modalidad de enseñanza que hace a una diferencia en cada centro educativo, como respuesta creativa y profesional de los equipos docentes. Estas actividades son denominadas talleres de valores y derechos, talleres de lengua, talleres de razonamiento matemático, grupo de reflexión, actividades multitareas y trabajo en áreas integradas.

Esta metodología integradora que se está aplicando dentro de los centros escolares implica relacionar los objetivos educativos del programa de diferentes disciplinas y contextualizarlos en las realidades de una educación pública en contextos sociales determinados de acuerdo con las necesidades y capacidades de la población infantil de hoy.

\subsection{Docentes invitados: implementación de talleres}

Se encontró que por parte de las y los docentes se le da gran valor a trabajar con metodologías que apuntan a problematizar información, comparar datos y desarrollar argumentaciones.

A continuación se traen como ejemplos del trabajo en las escuelas durante esta investigación las experiencias de diferentes instancias que desarrollan las habilidades en la perspectiva señalada. En dos de las escuelas se encuentra que los años superiores, $5^{\circ}$ y $6^{\circ}$, tienen talleres donde realizan actividades con la disciplina filosofía para niños, que tiene 
como objetivo trabajar el análisis de situaciones y generar preguntas a partir de diferentes disparadores. Una maestra integradora nos señalaba la importancia de estas actividades con que los niños y niñas van experimentando "el poder preguntarse". También trabajan la argumentación. En ambos casos observados los talleres son realizados por equipos de docentes, con invitados y otra maestra de la institución (maestras integradoras y maestra secretaria), que coordinan entre ellos y con las docentes de aula. Todos los y las docentes reconocen la importancia de estas actividades que permiten niveles de reflexión, de evaluación y de auto-evaluación en las niñas y niños.

En una de las escuelas, una maestra de $6^{\circ}$ año destacó el resultado de este trabajo y mostró cómo sus estudiantes valoraban en una producción de auto-evaluación que estaba acoplada en el carnet de los niños las experiencias de este aprendizaje, concretamente en relación a los vínculos afectivos. Compartió las reflexiones de un niño que valoraba cómo las maestras y sus compañeros lo habían ayudado a darse cuenta de alteraciones en su conducta y en su humor. Su nota de auto-evaluación decía: “...me ayudaron a darme cuenta que no me tenía que enojar tanto...yo me enojaba pero ahora entendí... Gracias a los amigos y a las maestras!!! Nunca los voy a olvidar!!!”. La maestra decía ... ”esto es lo que realmente vale!... estas buenas experiencias es lo que los marca como personas ". Enfatizó la importancia de instancias como los talleres de filosofía para niños, que les permiten reflexionar, sacar conclusiones y aplicarlas a sus vivencias.

Es en estas actividades alternativas que se encontraron en las escuelas donde se observa la existencia de una búsqueda de los colectivos docentes, de un compromiso con su tarea profesional y de la conciencia sobre la necesidad de adecuación, todo lo cual da cuenta de creatividad y de transformaciones. Pero a su vez se dejan entrever algunas contradicciones. Se observaron en varias oportunidades dificultades en transmitir estas modalidades diferentes de trabajar en la tarea educativa, de valorarlas, hasta cierta timidez al comunicarlas. Después de haber participado en estas instancias, recién algunas maestras me hablaban de estas formas de trabajar. En ocasiones ellas me preguntaban mi parecer o, cuando yo les señalaba algo sobre lo observado, recién ahí, frente a mi aprobación, me contaban sus observaciones y análisis positivo de esta forma de trabajo. Hubo quienes señalaban a sus compañeras: “... mirá que participó de los talleres y le gustó!”... “¿Viste los que dijo Ana Laura? Trabajo en el grupo integrado..., sí, tiene razón, no lo había pensado así..." 
Si bien la investigación registró dificultades y resistencias en cuanto a reconocer y apreciar estos movimientos de cambio en las actividades educativas, es muy alentador observar que como resultado del proceso de análisis y propuestas de estos colectivos de profesionales aparecen indicios sólidos de transformaciones que indican cambios muy positivos en la vida dentro de las escuelas.

\subsection{Para ir cerrando...}

"Cueda el no renegar del canflicta. Lo que nas falta es ver que el conflicta na es un mal. Que es esencialmente constructiva: es a través del conflicto que recanacemas al atra y que debemas absalutamente asumir ese mamenta de tensión, de adversidad, de apasición. El canflicto es la opartunidad de la solidaridad. La solidaridad coma fundamenta del rechazo de la injusticia hacia el no-persana ${ }^{97}$. La solidaridad coma experiencia esencial que reside en el hecho que la identidad de la persana, tanta en el plana individual coma el colectiva, na se ha dada sina en la pluralidad. Se produce allí dande las hombres y las mujeres se respetan y se estiman unas a atras sin considerar el calar de piel, su sexa, su pasición sacial, su nacionalidad, etc. La salidaridad nos confranta coma sujetas, funda nuestra humanidad y nas engrandece. Ella da nacimienta al hombre nuevo cuanda pasibilita la vida al

En síntesis, esta investigación encontró un ámbito heterogéneo de la práctica educativa. Se detectaron diferentes enfoques para la resolución de situaciones conflictivas, variadas conformaciones de los equipos docentes y diferencias importantes entre los niveles de formación docentes. Esto se refleja en la diversidad de comprensiones y práctica con enfoque de EDH en las escuelas. En todas ellas existe un denominador común que es el esfuerzo o las intensiones docentes de trabajar en equipo, de generar miradas conjuntas que se complementen e intentos de articulación, donde las complementariedades aspiran a generar una convivencia en común. Los vínculos, la comunicación y la convivencia son marco y soporte de la experiencia de educar en derechos humanos. Es en el plano de las vivencias que la EDH tiene un espacio de anclaje, aunque no siempre visualizado y conceptualizado como tal, pero sin por esto perder su potencial efecto transformador de las practicas educativas y las realidades en las escuelas.

\footnotetext{
97 "No-persona": concepto utilizado por Luis Pérez Aguirre para referirse a la multitud pobre de
} América Latina, aquellos que son desposeídos hasta de los derechos humanos. 
Los contextos de vulnerabilidad de los que provienen muchos de los niños y niñas que asisten a estas escuelas presentan un gran desafío para los y las docentes en su práctica cotidiana y para los centros en su planificación. A estas dificultades se suma la insuficiencia de los recursos específicos para abordar las situaciones problemáticas concretas que presentan algunos de los alumnos antes mencionadas (alteraciones de conducta, dificultades de aprendizaje, trastornos generales del desarrollo y contextos familiares adversos). El abordaje de estas situaciones de vulneración se ve como algo distanciado del trabajo educativo en derechos humanos, a pesar de que pueden y deberían ser trabajados como una dimensión del enfoque de EDH. Si los docentes no lo hacen es por falta de comprensión de todo lo que significa educar en derechos.

En este marco el tema de la formación docente es fundamental, tanto para abordar con eficacia estas situaciones, acompañando a docentes, niños, niñas y sus familias, como para impulsar una transformación a nivel de todo el sistema. Cuando se proponen cambios en el ámbito educativo, el vector de promoción y concreción de las transformaciones es siempre el docente. Sin embargo, una buena formación en EDH no puede ser exclusivamente un tema de interés de los y las docentes. Es un tema transcendental para el sistema educativo a la hora de pensar como se implementan y se llega a trabajar en dirección a una vigencia plena de los derechos humanos.

En este capítulo se dio cuenta desde múltiples situaciones que la falta de formación e información en las áreas y temas de EDH generaron indiferencia o rechazo a la temática, pero a la vez también se percibió que los propios docentes identificaban esa carencia en su formación y las dificultades reales para capacitarse en esta temática. 


\section{CAPITUPO VI}

\section{CONCLUSIONES y RECOMENDACIONES}

La incorporación de la EDH en el sistema educativo uruguayo implicó una adecuación a varios niveles. El ajuste de la normativa educativa a las tendencias internacionales de $\mathrm{EDH}$, que el Uruguay está asumiendo, lleva a trascender la dimensión declarativa para enfocar su despliegue a nivel curricular y buscar la concreción en las prácticas educativas cotidianas.

La investigación constató la existencia de un ámbito educativo heterogéneo donde coexisten diferentes concepciones educativas y varios imaginarios del rol docente (la instrucción, la capacitación, el rescate social y la formación de sujetos de derecho) que dan lugar a una expresión conflictiva, desafiante y de transformaciones en las prácticas educativas. Por eso la investigación se movió en varios niveles (ley de educación, programa de estudios y prácticas escolares), buscando examinar diferentes dimensiones y su relación mutua, a fin de lograr una comprensión compleja del ámbito educativo y aportar a la incorporación de la EDH a la educación pública uruguaya. 
Para iniciar, reseñó la concepción de los derechos humanos como un fenómeno complejo y la mostró como una herramienta de transformación social que involucra diferentes aspectos, a fin de mostrar a la EDH como un derecho humano y como un enfoque pedagógico integral y transversal.

Una de las dimensiones examinadas fue la perspectiva internacional, que aportó para comprender el alcance y desarrollo de los derechos humanos y para mostrar su lugar como guía en la planificación, ejecución, evaluación y seguimiento de políticas públicas, entre ellas las políticas educativas. Esta perspectiva también proporcionó un marco valioso para la comprensión de las dimensiones de integralidad y transversalidad como perspectivas para la acción. Estas dimensiones son fundantes en la concepción de los derechos y permitieron visualizar la importancia estratégica de la EDH para el desarrollo de sociedades que aspiren a realizar los objetivos de dignidad y respeto de todas las personas y grupos sociales. A su vez, enmarca la tarea social de educar en derechos humanos en lo que denominamos "procesos de derechos humanos", como producción simbólica que surge de ámbitos relacionales concretos.

Se hizo una reseña del derecho a la educación en general y a la EDH en particular. Sobre esta última se destacó su amplia proyección a nivel internacional a partir de la Conferencia Internacional de Derechos Humanos de Viena en 1993, que dio lugar a una serie de acciones que jerarquizaron a la EDH como estrategia privilegiada para la promoción, prevención y realización de los derechos humanos.

Se presentó, con base en bibliografía especializada, un marco teórico-metodológico de la EDH como disciplina pedagógica, que aportó pautas de análisis y contextualización del proceso de la incorporación de la EDH en el sistema educativo uruguayo. También contribuyó a enmarcar el análisis de las prácticas educativas e identificar los elementos conceptuales y metodológicos que están presentes -o ausentes - en ellas.

Se realizó un recorrido por los procesos históricos de la educación pública en el Uruguay y los hechos fundamentales que dieron lugar a cambios de concepción pedagógica -la gramática escolar-, así como a modificaciones de la normativa educativa nacional. Esto permitió comprender el momento en el que comienza la incorporación de la EDH en la normativa uruguaya. El análisis de la nueva Ley General de Educación № 18.437 de 2008 presentó sus varios elementos relacionados con los derechos humanos en general y con la EDH en particular, lo cual imprimió un avance significativo en la concepción educativa 
entonces vigente. Esta nueva ley planteó cambios en la forma de compresión del ámbito educacional y del desarrollo de la práctica educativa.

En el análisis crítico de los diferentes momentos históricos del sistema educativo uruguayo pudimos observar cómo se fue modificando la normativa en relación con las circunstancias sociales, económicas y políticas del país. Vimos también modificaciones en torno a la representación y el valor simbólico del rol docente. Son elementos trascendentes que permiten la comprensión y el ajuste en la planificación estratégica de las políticas educativas para poder mejorar su implementación.

La investigación realizada permite extraer las siguientes conclusiones:

\section{1- Existen avances importantes en la Ley General de Educación $N^{\circ} 18.437$ de 2008 en cuanto a la incorporación de la EDH en el sistema educativo.}

La ley es un paso decisivo en la incorporación de la EDH en el Uruguay al plantear como punto de partida a la educación como un derecho humano. La formulación de ejes transversales que destaca a la EDH como derecho en sí misma y parte importante del derecho a la educación (artículo 40.1), implica un avance en política educativa. Con esta misma orientación creó un ámbito específico para el desarrollo de este enfoque: la Comisión de EDH en calidad de asesora del Sistema Nacional de Educación Pública (artículo 110).

2- La actualización del Programa de educación inicial y primaria en el ámbito de la Administración Nacional de Educación Pública (ANEP, 2009) incluye progresos visibles pero plantea contradicciones para la implementación de la EDH.

En la introducción del nombrado documento, los derechos humanos son una idea central. Están desarrollados ampliamente en su justificación y en la creación de un área de conocimiento ciudadano desplegada en las disciplinas de Ética y Derecho. Se incorporan de esta manera contenidos específicos y un planteo de la tarea educativa que destaca la participación activa de las y los educandos en los procesos integrales de enseñanza y aprendizaje y explicita su condición de sujetos de la educación y sujetos de derecho. No obstante, a pesar de los elementos que representan un avance importante en la 
incorporación de EDH en el Programa, el documento contiene algunos puntos que generan debilidades en el abordaje de la EDH en las prácticas. Ellos son la desagregación en disciplinas separadas y los listados de contenidos específicos, que no favorecen el desarrollo de un enfoque integral y transversal de la EDH.

\section{3- La puesta en práctica de la EDH en la labor educativa concreta está atravesada por una serie de dificultades que obstruyen su implementación.}

\subsection{Falta de formación docente}

Existe un desconocimiento de los derechos humanos y de la EDH de parte de los y las maestras, en cuanto a sus contenidos, elementos valóricos y orientación para las prácticas escolares. Lo anterior genera, por un lado, un abordaje parcializado y por momento descontextualizado de la práctica educativa integral y, por otro lado, la dificultad de identificar los elementos pedagógicos, académicos, valóricos y actitudinales que forman parte de la EDH.

El trabajo de campo permitió comprobar que distintos contenidos del Programa relacionados con la EDH y los derechos humanos no siempre eran comprendidos y abordados por los y las docentes como tales. Tal incomprensión obstruye el alcance de los objetivos de la propuesta y parcializa o diluye los contenidos de derechos humanos.

En gran parte del cuerpo docente se aprecia falta de conocimientos sobre el enfoque de la EDH como abordaje pedagógico y como una estrategia integral y transversal de la tarea educativa, encuadrada en fines y objetivos específicos. Como contraste, al mismo tiempo se identificó que muchos docentes están trabajando con metodologías y abordajes muy afines al enfoque de EDH, pero no lo identifican como tal. Esto parece deberse a que no cuentan con una buena comprensión de qué son los derechos humanos y cómo se concretan en la vida cotidiana de la convivencia.

\subsection{Falta de recursos, técnicos $y$ formativos que permita a los $y$ las docentes} instrumentar la EDH desde un abordaje integral y transversal.

Los y las docentes son conscientes de sus desconocimientos o parte de ellos y plantean que necesitan actualizarse con una formación en EDH. Para incorporar este enfoque rescatan y 
valorizan los espacios de trabajo en equipo y de construcción dentro de los centros que encaren las problemáticas que se dan en las escuelas. Los equipos docentes reclaman mayor espacio para la reflexión y la problematización de la tarea educativa en la actualidad, como necesidad de co-construir visiones compartidas y abordajes conjuntos en las escuelas.

Como consecuencia del desconocimiento a menudo se reduce la EDH a actividades puntuales, a comentarios sobre contenidos específicos con poca contextualización, y a la incapacidad para identificar algunos contenidos del propio Programa como temas de EDH.

La participación de los niños y niñas dentro de las escuelas está mal abordada, lo que produce una ausencia u omisión de esta dimensión del trabajo educativo tan importante para la EDH.

\section{3- Falta de valorización de la temática en la evaluación y en la planificación estratégica.}

La mayoría de los y las docentes no jerarquizan la EDH en sus planificaciones, ni en su proceder, sea este académico (planificado) o espontáneo (de relación y comunicación diaria). Reconocen que no poseen recursos claros para la evaluación y monitoreo de espacios de su trabajo que involucren la EDH, desde elementos cognitivos hasta habilidades valóricas, éticas y para la acción. Existe la percepción en los maestros y maestras que el cuerpo inspectivo no valora, o no sabe como implementar estas áreas de trabajo, razón por la cual no sienten que se los guíe y capacite en la materia.

\section{4- Incomunicación entre las autoridades, los especialistas encargados de desarrollar la política educativa (el pensar y escribir) y el cuerpo docente responsable de desarrollar la tarea educativa propiamente dicha (el hacer).}

Se percibió claramente en diferentes oportunidades que existían problemas de incomunicación y falta de comprensión entre estos diferentes niveles y actores del sistema educativo. En consecuencia aparecen sentimientos de malestar docente ante las autoridades y las solicitudes de la burocracia escolar y acciones desarticuladas en la asignación de recursos técnicos o económicos y en las respuestas a las necesidades de las escuelas. El 
magisterio manifiesta sentirse desvalorizado por partes de las autoridades y los agentes de planificación y programación educativa.

5- Se identificaron prácticas educativas que no son visualizadas como EDH pero que deberían ser tomadas en cuenta para una real incorporación de la EDH en el sistema educativo. Deberían ser consideradas como puntos de partida para afianzar y desarrollar la EDH en el trabajo que los docentes ya están desarrollando.

Si bien se identificaron debilidades del enfoque de EDH en las prácticas educativas, también se encontraron elementos alentadores para la implementación de un enfoque de $\mathrm{EDH}$. Se trata de búsquedas de metodologías acordes a la educación integral y que promueven la convivencia desde el respeto y desarrollo de las personas.

Se observó en las tres escuelas estudiadas una labor de los equipos docentes con tendencia a desarrollar actividades planificadas, articuladas y coordinadas con un enfoque integral y participativo de la tarea educativa. Eso marca una tendencia positiva y esperanzadora, pues sugiere que los y las maestras están buscando transformar sus prácticas con una orientación hacia la EDH, aunque con frecuencia no lo expresen en estos términos.

En las escuelas se destaca en general un trabajo intenso y comprometido hacia las tareas educativas. Aunque esto no necesariamente salga a la luz más allá del contexto concreto de cada escuela, se aprecia una preocupación por la vida escolar al interior de los centros, por procurar que cada día, cada momento que transcurre en la escuela, sea armónico y amigable entre los diferentes actores de la comunidad educativa.

En síntesis, si bien el ámbito educativo está marcado por múltiples tensiones y situaciones conflictivas, en las que aparecen diferentes concepciones sobre la tarea educativa por desarrollar y diferentes compresiones y abordajes docentes -lo cual constituye un escenario heterogéneo y difícil para instalar la EDH- existen elementos alentadores y auspiciosos que pueden ser puntos de apoyo para profundizar y consolidar un enfoque sólido de EDH. 
En virtud de lo concluido, a fin de optimizar la implementación de la EDH en el sistema educativo uruguayo se formulan las siguientes recomendaciones:

\section{1- Ajuste del programa}

Sin dejar de reconocer y valorar que el Programa contiene en su desarrollo elementos que priorizan la EDH como enfoque, en su planteo estratégico se recurre a diagramas conceptuales aislados en disciplinas y a listados de contenidos que no favorecen el encuadre, la comprensión ni la aplicación de este enfoque por parte del cuerpo docente como práctica integral y transversal. Sería necesario realizar un ajuste del mismo o complementarlo por medio de una Guía para Docentes y otros materiales didácticos que faciliten la implementación del documento y orienten las prácticas concretas de aula en el enfoque integral y transversal, partiendo del "hacer docente" articulado y aterrizado en las edades de las y los educandos.

2- Diálogo y consulta entre quienes piensan las políticas públicas educativas y el cuerpo docente.

Sería deseable promover un mecanismo de diálogo -o bien mejorar los que ya existenentre los actores que definen y planifican la política educativa y los que la realizan en las aulas, pues de esta relación depende el buen desarrollo de la educación nacional en la dirección de los objetivos que le marca la sociedad en su conjunto.

Una dificultad importante reside en el tema de la participación, no solo de las y los niños, sino también en los lugares "de ser parte y tomar parte" de los y las docentes. Estas dificultades se deberían abordar explícitamente por parte de autoridades y especialistas y discutirse frecuentemente con los propios docentes. Este es un camino para avanzar hacia el cumplimiento del derecho a educar-educarse en el principio de participación, destacado en la normativa vigente y tan importante para la implementación del EDH.

\section{3- Aumentar recursos que permitan la interdisciplina; el soporte del trabajo docente y optimizar los tiempos de dialogo y reflexión para la construcción conjunta.}

A fin de consolidar el enfoque de EDH con características integrales con tendencias a la transversalidad y un abordaje interdisciplinario en el ámbito educativo, los mismos 
docentes identifican varias iniciativas en marcha muy valiosas, entre ellas los siguientes programas: Protocolo y Mapa de ruta de Violencia Doméstica; Proyecto Mandela; Maestros Comunitarios y Escuelas Disfrutables. Estas iniciativas resultan auspiciosas, pero se encuentra con dificultades y desafíos en la concreción al momento de abordar la tarea educativa concreta. En la actualidad no son suficientes para sostener a los y las maestras, así como para el desarrollo de los procesos de EDH dentro de las instituciones. Es recomendable fortalecerlas y ampliar su alcance.

También se recomienda dar mayor visibilidad a un abordaje del ámbito educativo como espacio interdisciplinario. Se trata de abordarlo desde un pensar y accionar colectivo, colaborativo, cooperativo y solidario, es decir, por medio del trabajo en equipo, menos jerárquico y menos autoritario, que impregne a los diferentes integrantes de la comunidad educativa de elementos de convivencia respetuosa, resolución no violenta de conflictos, comprensión mutua, participación activa y comunicación efectiva. Los programas e iniciativa ya mencionados, que se están desarrollando en esta línea, merecerían más tiempos de trabajo en las escuelas y propiciar mayores niveles de reflexión y acción conjunta con los y las maestras que están trabajando en ellos. Para esto es necesario que los y las docentes sientan que los técnicos y especialistas que los asisten son parte de los recursos con que pueden contar para desarrollar la tarea de EDH.

Hay que dar un lugar más destacado a las acciones emprendidas desde una comprensión compleja de la $\mathrm{EDH}$, que no solo implique la formación propiamente dicha, sino también profundizar y optimizar los espacios de reflexión y problematización de los equipos docentes en servicio, deseablemente en sus propios centros de trabajo. Estos espacios deberían ser el estímulo a la promoción y el interés del cuerpo docente en la actualidad, hacia una mayor y mejor implementación de la EDH en su accionar, en la construcción de conocimientos, y en el diseño de modalidades de evaluación, así como para la coconstrucción de su rol profesional para los momentos presentes. Para ser coherentes con la $\mathrm{EDH}$ es deseable y necesario darle un mayor sostén y valor a la figura del docente como promotor de procesos de derechos humanos en la escuela. Los equipos docentes deben tener un accionar destacado en los procesos de transformación del ámbito educativo, donde todos y todas, niños, niñas, docentes y familia, sientan que se respetan los derechos y se aprende conviviendo en clave de derechos humanos. 
Es indispensable explicitar claramente el enfoque de EDH en la tarea educativa, pues tiene una rápida asimilación y potencia para impulsar el trabajo de los y las docentes en la medida que comprenden e identifican las prácticas basadas en este enfoque. Este fue un efecto observado durante el trabajo de campo: la mayoría de los y las docentes mostraron tener una gran capacidad para captar el enfoque de EDH -que en un principio decían no conocer-y para ir identificando en sus prácticas los elementos que hacen a la EDH, así como incorporándolos. El proceso de cambio observado en sus conductas durante el período del trabajo de campo da cuenta de su apertura intelectual y afectiva, de sus ganas de aprender y su afinidad con las propuestas pedagógicas de la EDH.

\section{4- Formación docente}

A partir de comprender las fortalezas y los desafíos docentes para la concreción de la EDH se destaca la importancia de diseñar y llevar adelante una estrategia de formación para futuros docente (formación inicial), así como también de actualización del cuerpo docente en funciones (formación en servicio). Esta estrategia debe orientarse a desarrollar el marco conceptual y pedagógico de la EDH, tanto como el metodológico. Obsérvese que al incorporar una nueva concepción del ámbito educativo desde el trabajo en líneas transversales, que re-dimensiona la contextualización y la puesta en acción de los contenidos trabajados, hay que preveer que una parte del cuerpo docente puede no comprender cabalmente estas nueva concepción o no sentirse totalmente capacitado para desarrollarla. Estas percepciones pueden crear sentimientos de malestar y disconformidad, que los procesos de formación o capacitación docente deben entender y atender. El trabajo de campo de la presente investigación identificó y analizó una cantidad de percepciones erróneas y prejuicios en relación a educar en derechos humanos que merecen ser considerados y discutidos con los propios docentes en los espacios de formación, capacitación, diálogo e intercambio de experiencias en la materia.

La investigación concluye que la incorporación de la EDH en nuestro sistema educativo conlleva modificaciones en diferentes dimensiones. A la vez, el ámbito educativo uruguayo está atravesando un periodo marcado por tensiones y conflictos que generan la necesidad de desarrollar acciones para consolidar la EDH como un enfoque pedagógico complejo, integral y transversal, con niveles de concreción reales en las prácticas 
educativas y en la vida dentro de los centros escolares. A juicio de esta investigadora, se hace necesario profundizar el enfoque de EDH con las acciones aquí recomendadas, las que le permitirán al cuerpo docente generar más coherencia interna y enriquecer la calidad de su accionar en la práctica educativa desde la EDH.

\section{BIBLIOGRAFIA}


1) ABRAMOVICH, Víctor (2006): "Una aproximación al enfoque de derechos en las estrategias y políticas de desarrollo" revista de la CEPAL ${ }^{\circ}{ }^{8} 8$. Santiago de Chile. Abril.

2) BADARACCO, Alicia; PASTOR Paola:(2008). Art: "Autonomía de la Enseñanza en el país". Publicado digitalmente en http://perdidosenelipa.blogspot.com/2008/11/autonoma-de-la-enseanza-en-el-pas.html

3) BOLÍVAR, Ligia (2010). "El derecho a la educación” publicado por Instituto Interamericano de Derechos Humanos, XXVIII Curso Interdisciplinario de Derechos Humanos. San José de Costa Rica.

4) CASTEL Robert. (2008): conferencia: "La Sociedad Contemporánea ¿es una sociedad de riesgo?" realizada en Sede: Secretaría de Gabinete y Gestión Pública, Buenos Aires, Argentina. 2 de septiembre de 2008

5) CLAUDE, Richard Pierre (2005): Art: "Derechos a la educación y Educación para los Derechos Humanos". en Revista: SUR: revista Internacional de Derechos humanos, Año 2. Numero 2.- (edición en español). Disponible en: http://www.surjournal.org

6) CONSTITUCIÓN DE LA REPÚBLICA ORIENTAL DEL URUGUAY, 1967.

7) DEI, Daniel, y otros (2006) "La TESIS, Cómo orientarse en su elaboración" ediciones Prometeo Libros -2da edición. Buenos Aires, Argentina.

8) DE SOUSA SANTOS, Boaventura: (2002). Art."Hacia una concepción multicultural de los derechos humanos", publicado en la Revista "EL OTRO DERECHO”, N²8. ILSA, Bogotá D.C., Colombia.

9) DE SOUSA SANTOS, Boaventura: (2002) "Sufrimientos antiguos y nuevos y nuevas solidaridades: el derecho de los pueblos indígenas", en SANTOS, B. de Sousa, "La globalización del derecho. Los nuevos caminos de la regulación y la emancipación. ILSA, Bogota, Colombia.

10) FREIRE, Paulo, (1990) "Paulo Freire conversando con educadores, Montevideo", Ed.Roca Viva, Montevideo Uruguay.

11) FREIRE, Paulo, (1996). "Pedagogía de la autonomía, saberes necesarios para la práctica educativa”. Ed.Siglo XXI, 2da. Edición Argentina (2008).

12) GARIBALDI, Luis (2005). "Educación: un debate imprescindible". Material del Ministerio de Educación y Cultura para el Debate educativo (MEC). Mayo 2005.

Disponible en:

http://www.debateducativo.edu.uy/16\%20de\%20mayogaribaldi.pdf 
13) GENTILI Pablo (1998): Art: "El consenso de Washington y la crisis de la educación en América Latina.”. en ALVAREZ-URIA, F. (comp.) Neoliberalismo versus democracia. La Piqueta, Madrid.

14) GENTILI, Pablo, (2014): “Conversación con Pablo Gentili: La evaluación de la calidad educativa en América Latina: modelos emancipadores en construcción". Revista digital DIALOGOS DEL SITEAL. Buenos Aries Argentina, noviembre 2014. Disponible en: http://www.siteal.iipe-oei.org/contenido/520

15) GIROUX, Henry, (2001): ART: "Los profesores como intelectuales transformativos". Publicado por Revista Docencia $N^{\circ} 15$. Santiago de Chile, Diciembre.

16) GONZALEZ de CUBERES, María Teresa. (1987):" El taller de los talleres". Ed Estrada, Buenos Aires Argentina.

17) GUNDERMANN KROLL, Han. (2001) cap: "El método de los estudios de caso" publicado en TARRÉS, M. L, compiladora de “Observar, escuchar y comprender, sobre la tradición cualitativa en la investigación social". Editado por Facultad Latinoamericana de Ciencia Sociales, El Colegio de México. Diciembre.

18) HERRERA FLORES, Joaquín. (2005). ”Los derechos humanos como productos culturales, critica del humanismo abstracto". Publicado por ed. Catarata. Madrid, España

19) HERRERA FLORES, Joaquín. (2007)." LA REINVENCIÓN DE LOS DERECHOS HUMANOS". Editado Atrapa Sueños, colección Ensayando. Andalucía, España.

20) HEVIA, Ricardo (2006). "Frente a la crisis de sentido, una pedagogía de la confianza”. Revista PRELAC, No 2, OREALC/UNESCO. Santiago de Chile.

21) INSTITUTO INTERAMERICANO de DERECHOS HUMANOS (IIDH). (1995) "Carpeta Latinoamericana de Materiales para Educación en Derechos Humanos". Publicado por IIDH-Amnistía Internacional-NORAD, San José, Costa Rica.

22) INSTITUTO INTERAMERICANO DE DERECHOS HUMANOS (IIDH). (2002) "Informes Interamericanos de la Educación en Derechos Humano. Un estudio en 19 Países” Publicado por IIDH San José, Costa Rica

23) INSTITUTO INTERAMERICANO DE DERECHOS HUMANOS (IIDH). (2006)- "Propuesta curricular y metodológica para la incorporación de la educación en derechos humanos en la educación formal de niños y niñas entre 10 y 14 años de edad". Publicado por IIDH San José, Costa Rica. 
24) INSTITUTO INTERAMERICANO DE DERECHOS HUMANOS (IIDH). "Informes Interamericanos de la Educación en Derechos Humanos". IIDH. Informes VI (2006), VII (2007), VIII (2008), IV (2009) y X (2010). Publicado por IIDH San José, Costa Rica.

25) JUANCHE, Ana (2013); "El derecho humano a la Educación en Derechos Humanos. Sistema Nacional de Educación Pública (SNEP); Montevideo, Uruguay." Disponible en:

http://www.universidad.edu.uy/pnedh/files/2013/07/Aporte-Ana-Juanche.pdf

26) JURADO GOMEZ, Carmen.(2008) "Los temas transversales en la escuela", Revista digital, "Innovación y experiencia educativas". Disponible en: http://www.csi-

csif.es/andalucia/modules/mod ense/revista/pdf/Numero 25/CARMEN JURADO GOMEZ01.pdf

27) LEY ORGÁNICA DE LA UNIVERSIDAD DE LA REPÚBLICA (UdelaR), $\mathrm{N}^{\circ} 12.549$, octubre 1958. Uruguay

28) LEY DE EDUCACIÓN GENERAL， N¹4.101, enero 1973. Uruguay

29) LEY DE EMERGENCIA, Nº 15.739, marzo 1985. Uruguay

30) LEY N 16.115, "Normas para designar al Consejo Directivo Central de la Enseñanza". julio 1990. Uruguay

31) LEY GENERAL DE EDUCACIÓN, N¹8.437, diciembre 2008. Uruguay

32) MAGENDZO, Abraham. "Los derechos humanos. Un objetivo transversal del currículum" ( $\sin$ más datos)

33) MAGENDZO, Abraham (2008)."La escuela y los derechos humanos". Ediciones Cal y Arena, México.

34) MAGENDZO, Abraham. (Compilador) (2009) "Ideas-fuerza y pensamiento de la educación en derechos humanos en Iberoamérica”. UNESCO y OEI. Editorial Santa María, Chile.

35) MARTINIS, Pablo (2006). Art:"Educación, pobreza e igualdad: del "niño carente" al "sujeto de la educación". Publicado en Martinis, Pablo y Redondo Patricia (comps.) "Igualdad y educación escrituras (entre) dos orillas". Ed. del estante editorial, Buenos Aires, Argentina.

36) MARTINIS, Pablo (2006). Art: "Sobre escuelas y salidas: la educación como posibilidad, más allá del contexto". Publicado en "Pensar la escuela más allá del contexto". Ed. Psico Libros. Montevideo, Uruguay. 
37) MINISTERIO DE EDUCACIÓN Y CULTURA (MEC), Dirección de Derechos Humanos (2007) Documento: "Informe, Plan Nacional de Educación en derechos humanos. 2007." Uruguay

38) MORIN, Edgar: (1998): “Articular los saberes, ¿Qué saberes enseñan en las escuelas?”. Ediciones Universidad del Salvador, BsAs, Argentina.

39) MOSCA, J y PEREZ AGUIRRE, L. (1985) “DERECHOS HUAMNOS, pautas para una educación liberadora" Ediciones Trilce, versión revisada, Montevideo, Uruguay (2006).

40) MUJICA, Rosa María (2002) "La metodología de la educación en derechos humanos". Ponencia en XX Curso Interdisciplinario en Derechos Humanos: "Educación en Derechos Humanos".

41) MUJICA, Rosa María. "Educación en derechos humanos y en democracia" (sin más datos)

42) NACIONES UNIDAS (ONU). Declaración Universal de Derechos Humanos. 10 de diciembre 1948.

43) NACIONES UNIDAS (ONU). Comité DESC (1991), Observación General N 3 "La índole de las obligaciones de los Estados Partes (párrafo 1 del art 2)". E/1991/23.

44) NACIONES UNIDAS (1993) Declaración y Programa de Acción de Viena (parte I, párr. 5), aprobada por la Conferencia Mundial de Derechos Humanos, Viena, 25 de junio de 1993 [A/CONF.157/24 (Part I), cap. III].

45) NACIONES UNIDAS. (1998) "Directrices de las Naciones Unidas para elaborar planes de acción en materia de EDH" (A/52/469/Add.1)

46) NACIONES UNIDAS (ONU). Comité DESC (1999), Observación General Nº11 ,Planes de acción para la enseñanza primaria (art: 14)” E/C.12/1999/4

47) NACIONES UNIDAS (ONU). Comité DESC (1999), Observación General Nº13 "Derecho a la Educación" (E/C.12/1999/10)

48) NACIONES UNIDAS (ONU). Comité de los Derechos del Niño, Observación general $n^{\circ} 1,2001, \mathrm{CRC} / \mathrm{GC} / 2001 / 1$

49) NACIONES UNIDAS (2005). "Plan de acción para la primera etapa (20052007) del Programa Mundial para la educación en derechos humanos". Aprobado por la Asamblea General el 2 de marzo de 2005.

http://daccess-dds-ny.un.org/doc/UNDOC/GEN/N05/253/77/PDF/N0525377.pdf 
50) NACIONES UNIDAS (2010). Plan de acción para la segunda etapa (2010-2014) del Programa Mundial para la educación en derechos humanos (A/HRC/15/28). Disponible en:

http://www2.ohchr.org/spanish/issues/education/training/secondphase.htm

51) NACIONES UNIDAS (ONU), (2011). Declaración sobre educación y formación en materia de derechos humanos. Aprobada por la Asamblea General el 19 de diciembre de 2011. (A/66/457)

52) ORGANIZACIÓN DE ESTADOS AMERICANOS (OEA) Protocolo adicional a la Convención Americana sobre derechos humanos en materia de derechos económicos, sociales y culturales. (OEA, 1989) PROTOCOLO DE SAN SALVADOR.

53) PAUTASSI, Laura (2007). "El cuidado como cuestión social: un aproximación desde el enfoque de derechos", Serie Mujer y Desarrollo No 87, CEPAL: Santiago de Chile.

54) PEREGALLI, Andres. (2011). "Reseñas sobre, Gentili: pedagogía de la igualdad. Ensayos contra la educación excluyente." Revista de Políticas Educativas $\mathrm{N}^{\circ}$, univ. San Andres, Argentina.

55) PÉREZ AgUIRRE, Luis María. (1999) "Si digo educar para los derechos humanos" Conferencia brindada en el IIDH. Material de apoyo Diplomado. AUSJAL-IIDH. Versión digital en:

http://ipes.anep.edu.uy/documentos/2011/desafiliados/materiales/aguirre dos.pdf

56) PÉREZ AGUIRRE, Luis María, (1989) "Si digo derechos humanos". Editado por Servicio Paz y Justicia. Montevideo, Uruguay.

57) PÉREZ AGUIRRE, Luis María, (1991) "Carta a un grupo de audaces que quiere educar en derechos humanos" (sin más datos)

58) PRATS. Martín. (2010) "La educación pública desde una perspectiva de derechos humanos". Publicado en "Una transformación en marcha - Políticas instrumentadas por el CODICEN (2005-2009”). Publicado por ANEPCODICEN, Montevideo, Uruguay.

59) PROGRAMA DE EDUCACIÓN INICIAL Y PRIMARIA. Publicado por CODICEN-CEIP. Uruguay, 2009.

60) REBELLATO, José Luis (1997). "Horizontes éticos en la práctica social del educador". Publicado por Instituto del Niño y Adolescente del Uruguay (INAU). Montevideo, Uruguay. Publicado digitalmente en:

http://www.inau.gub.uy/biblioteca/rebellato\%20horizontes.pdf 
61) REBELLATO, José Luis (1996). Art:" La dimensión ética en los procesos Educativos" Revista La Piragua, $\mathrm{N}^{\circ}$ 12-13.Editado por Consejo de Educación Popular de America Latina t el Caribe (CEAAL) Santiago, Chile.

62) RODINO, Ana María. (1999) "La educación en valores entendida como educación en derechos humanos. Sus desafíos contemporáneos en América Latina." Publicado en la Revista IIDH/Instituto Interamericano de Derechos Humanos, N²9, enero-junio 1999, San José, Costa Rica.

63) RODINO Ana María. (2003). “Educación para la vida en democracia: Contenidos y orientaciones metodológicas". Cuadernos Pedagógicos, IIDH.

64) RODINO, Ana María (2010). “Educación en derechos humanos para una ciudadanía democrática e inclusiva. Trabajar en la escuela y desde la educación fisica." (sin más datos)

65) ROMANO, Antonio. (2010) ponencia: “Transformaciones del discurso pedagógico en el Uruguay de la segunda mitad del siglo XX." En II Jornadas Universitarias de Investigación," Facultad de Humanidades y Ciencias de la Educación. Universidad de la República(UdelaR). Disponible en:

http://fhuce.edu.uy/jornadas/IIJornadasInvestigacion/PONENCIAS/ROMANO.PD F

66) ROMANO, Antonio y BORDOLI, Eloísa, (2009) ponencia "Tres momentos en la conformación de la identidad de los docentes en Uruguay, mito, crisis y reconfiguración" Facultad de Humanidades y Ciencias de la Educación. Universidad de la República (UdelaR), en el "IX Congreso Iberoamericano de Historia de la Educación Latinoamericana". Disponible en: http://es.scribd.com/doc/24344743/Ponencia-1

67) SALES, María Teresa. (2010). Cap: "Algunas reflexiones para el diseño de políticas educativas." Publicado en "Una transformación en marcha - Políticas instrumentadas por el CODICEN (2005-2009)”. Publicado por ANEPCODICEN, Montevideo, Uruguay.

68) SALVIOLI, Fabian: (1997) Cap:“Algunas tendencias sobre los derechos humanos en las relaciones internacionales y el derechos internacional de la posguerra fría": en Anuario en Relaciones Internacionales 1995/96. Ed. Centro de Estudios Avanzados, Universidad Nacional de Cordoba, Argentina.

69) SÁNCHEZ SERRANO, Rolando. (2001) cap: “La observación participante como escenario y configuración de la diversidad de significados" publicado en TARRÉS, M. L, compiladora de "Observar, escuchar y comprender, sobre la tradición cualitativa en la investigación social”. Editado por Facultad Latinoamericana de Ciencia Sociales, El Colegio de México.

70) SISTEMA NACIONAL DE EDUCACIÓN PUBLICA (SNEP), Comisión Nacional de EDH (2015): Documento: "Bases hacia un plan nacional en EDH". Uruguay. 
71)SOLER ROCA, Miguel (2006): "Reflexiones, propuestas, interrogantes. PENSANDO EN LA FUTURA LEY DE EDUCACIÓN DE URUGUAY”, carta Barcelona 2006. Disponible en:

http://www.pvp.org.uy/pensandoeducacion.htm

72) TARRÉS, María Luisa, (2001) “Observar, Escuchar y comprender, sobre la tradición cualitativa en la investigación social", Presentación, Prólogo, Cap:"Lo cualitativo como tradición”. Editado por Facultad Latinoamericana de Ciencia Sociales, El Colegio de México.

73) TOMASEVSKI, Katarina. (2003) "Contenido y vigencia del derecho a la educación” IIDH, Cuadernos Pedagógicos, IIDH, San José, Costa Rica.

74) VELA PEON, Fortino, (2001) cap: "Un acto metodológico básico de la investigación social: la entrevista cualitativa”, publicado en TARRÉS, M. L, compiladora de "Observar, escuchar y comprender, sobre la tradición cualitativa en la investigación social". Editado por Facultad Latinoamericana de Ciencia Sociales, El Colegio de México.

\section{ANEXOS}


Anexo I: Mapa de Montevideo, ubicación de las escuelas

Anexo II: Permiso del CEIP-ANEP: Resolución n 18, Expediente n 1225/14.

Anexo III: desgravaciones de las seis entrevistas a Autoridades de la Educación y especialistas

Anexo IV: Información complementaria al Capítulo II

Anexos V: fotos de las Escuelas

Anexo VI: Afiche de la campaña

\section{ANEXO I}

MAPA de la Cuidad de Montevideo

Ubicación de las Escuelas donde se desarrollo el trabajo de campo. 


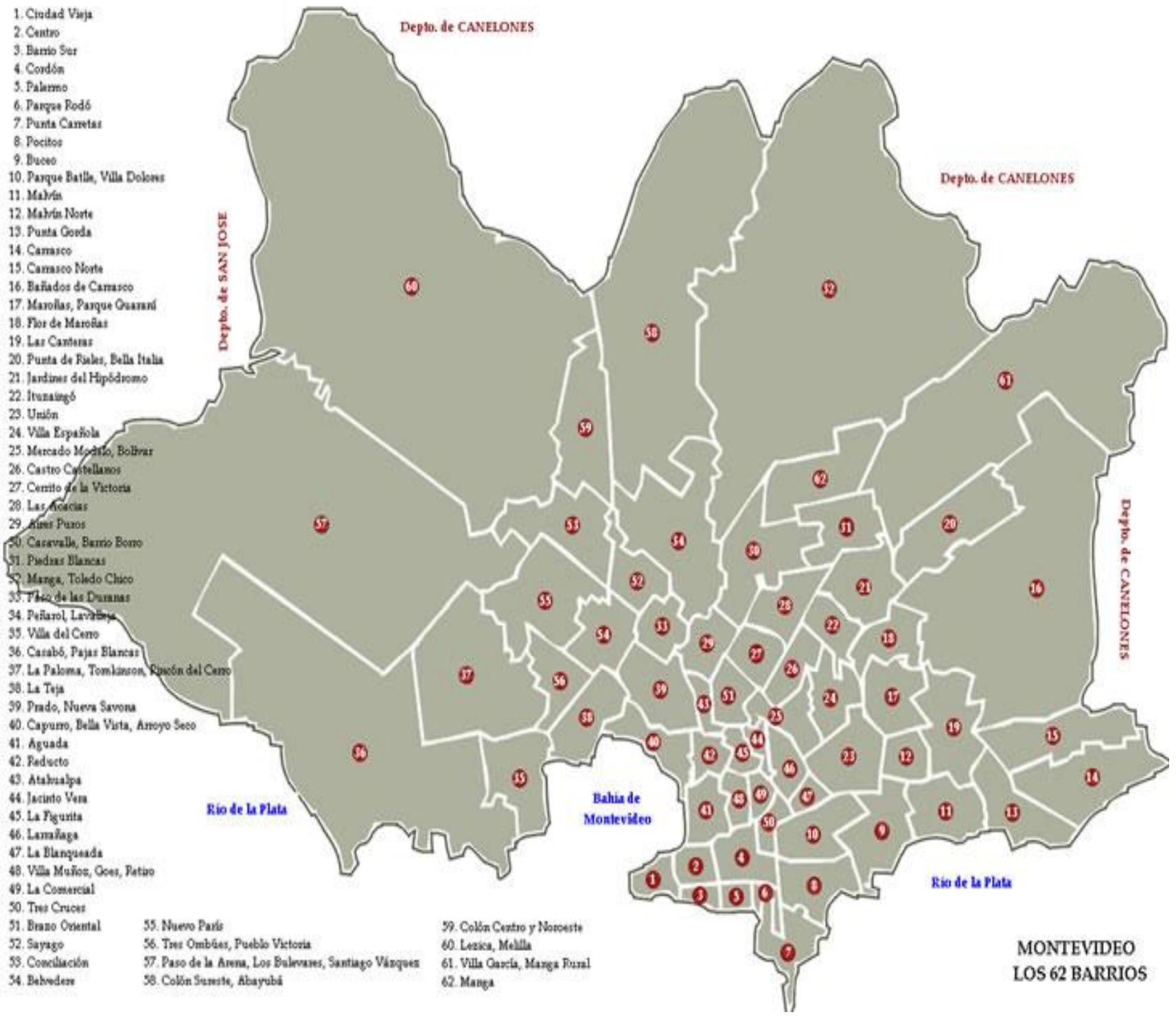

Escuela C: zona Oeste de la división del CEIP, barrio Belveder.

Escuela B, zona Centro de la división del CEIP,

barrio de Maroñas o Ituzaingo (Hipódromo)

EscuelaA, Zona Este de la división del CEIP; barrio del Buceo.

ANEXO II: Permiso CEIP-ANEP 


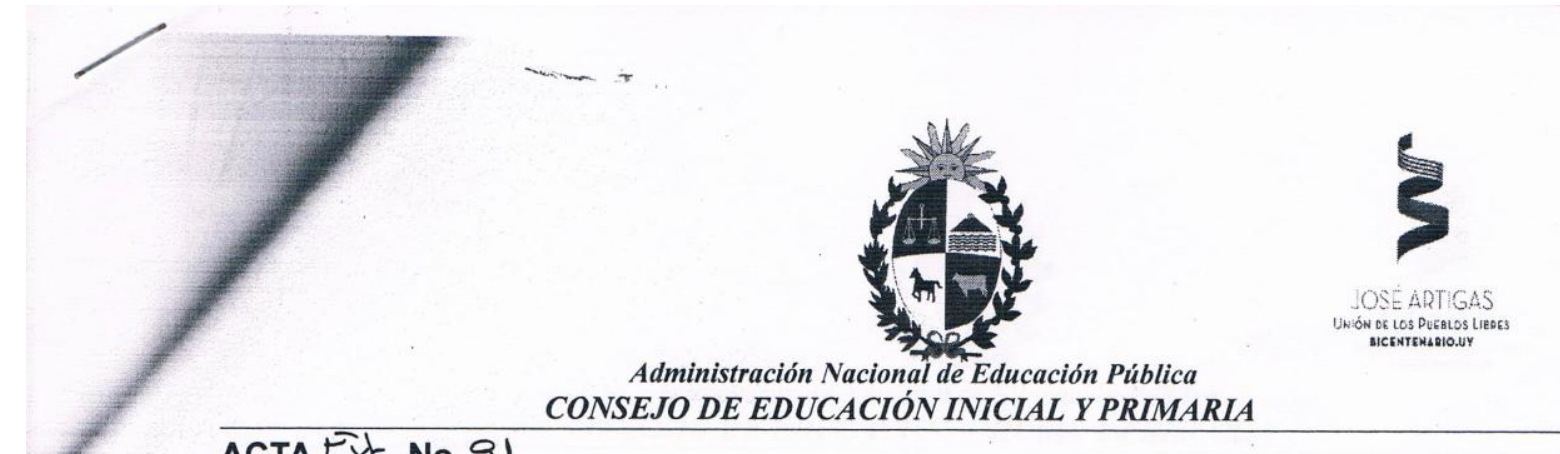

ACTA Ext. No. 91

RES. No. $\supset 8$

EXP. No. 1225/14 Leg. 1

Gestión No. $\quad 48896$

MONTEVIDEO 9 DE SETIEMBRE DE 2014

VISTO: estos antecedentes relacionados con gestión formulada por la señora Ana Laura Piñeyro, Licenciada en Psicología, de nacionalidad uruguaya, cursando la Carrera de Postgrado de Maestría en Derechos Humanos de la Facultad de Ciencias Jurídicas y Sociales en la Universidad Nacional de La Plata, Provincia de Buenos Aires, solicitando autorización del CEIP para ingresar a diferentes centros educativos del departamento de Montevideo, con la finalidad de poner en práctica la tesis que viene desarrollando denominada: "Análisis de la incorporación de la Educación Derechos Humanos en el sistema de Educación Pública, sector de primaria en el Uruguay";

CONSIDERANDO: que la Inspección Técnica entiende oportuna la temática a - investigar dado que es un imperativo para la Educación en la actualidad;

ATENTO: a lo expuesto precedentemente;

\section{EL CONSEJO DE EDUCACIÓN INICIAL Y PRIMARIA RESUELVE:}

$1^{\circ}$.- Autorizar a la señora Ana Laura Piñeyro, Licenciada en Psicología, de nacionalidad uruguaya, cursando la Carrera de Postgrado de Maestría en Derechos Humanos de la Facultad de Ciencias Jurídicas y Sociales en la Universidad Nacional de La Plata, Provincia de Buenos Aires a realizar la práctica de la tesis que viene desarrollando denominada: "Análisis de la incorporación de la Educación Derechos Humanos en el sistema de Educación Pública, sector de primaria en el Uruguay", en diferentes centros educativos del departamento de Montevideo, estableciéndose que previamente se deberá coordinar con las respectivas Inspecciones Departamentales.- 
$2^{\circ}$.- Establecer que una vez finalizada la investigación, la interesááa deberá presentar los resultados ante la Inspección Técnica.-

$3^{\circ}$.- Comuníquese a la Inspección Departamental de Educación Prímaria en sus tres Jurisdicciones y pase a la Inspección Técnica para su conocimiento, notificación de la interesada y coordinación respectiva.-
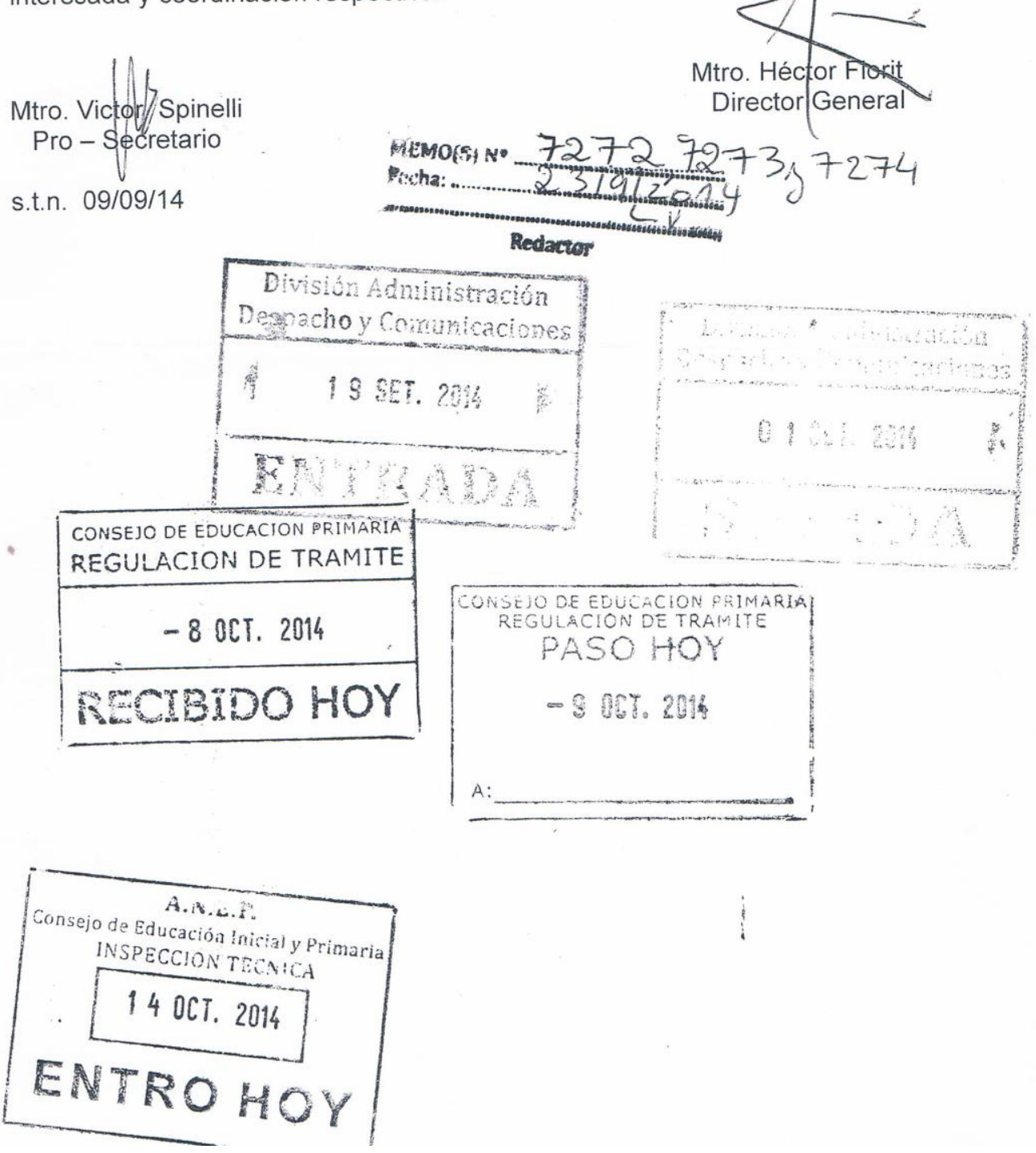


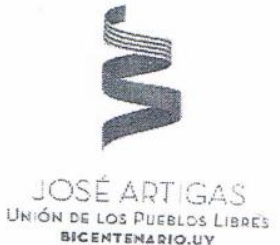

SICENTENAPIO,UYY LISRES

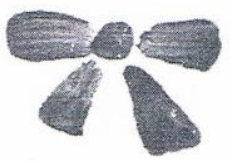

PROVIDENCุIA No $3847 / 14$

Gestión No 96352/14

Montevideo, 12 de noviembre de 2014

Citar a la Señora Ana Laura Píñeyro, Licenciada en Psicología, para su conocimiento y notificación de la interesada.

As: Exp. $N^{\circ} 1225 / 14-$ Leg. $N^{\circ} 1$

Gestiòn. No 48596/14

Sol para poder ingresar a los

Centros Educativos Licenciada Ana

Laura Píñeyro CI: $1.767 .953-7$ en

Psicología

ebs/p.u

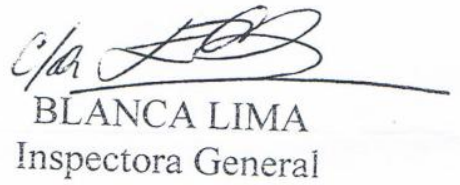

Edith Coltinno Borlan inspectora Genera C.E.I.P

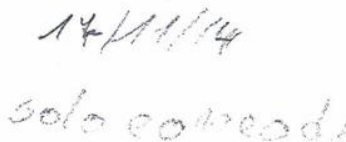


ANEXO III: Desgravación de las entrevistas a autoridades de la Educación Pública y especialistas en $\mathrm{EDH}$.

A continuación de presentan las desgravaciones de las entrevistas realizadas a autoridades de la Educación Pública y especialistas en EDH del Uruguay, realizadas para este trabajo de tesis de investigación.

1. Fernando Willat, Coordinador de EDH, de la Secretaria Nacional de Derechos Humanos de Presidencia de la República e integrante de la Comisión Nacional de EDH (por MEC). Viernes 4 de abril 2014.

2. Martín Prats, Director de la Dirección de Derechos Humanos de la Administración Nacional de Educación Pública (ANEP) e integrante de la Comisión Nacional de EDH (por ANEP). Miércoles 9 de abril 2014.

3. Margarita Navarrete, Instituto de DDHH. Facultad de Derecho-UDELAR, integrante de la Comisión Nacional de EDH (por UDELAR) e integrante del Observatorio de Políticas Públicas de Derechos Humanos, MERCOSUR. Viernes 11 de abril 2014.

4. Luis Garibaldi , Director de Educación del Ministerio de Educación y Cultura. Martes 7 de mayo 2014.

5. Fernanda Blanco, Dirección de Educación (MEC) e integrante de la Comisión Nacional de EDH (MEC). Martes 13 de mayo 2014.

6. Irupé Buzzetti, Consejera del Consejo de Educación Inicial y Primaria (CEIP), Administración Nacional de Educación Pública (ANEP). Lunes 30 de junio 2014. 
Coordinador de EDH, de la Secretaria Nacional de Derechos Humanos- Presidencia de la República.

Integrante de la Comisión Nacional de EDH, asesora al SNEP

Viernes 4 de abril 2014.

\section{P: ¿Cómo pensas que se está realizando la concreción de la transversalidad de la EDH en el sistema educativo, $y$ en especial en primaria?}

Yo, vuelvo a decirte que no tengo un conocimiento para poder darte una visión de lo que está pasando. Tengo impresiones, comparto las impresiones en todo caso.

Por un lado hay un nivel de incorporación de la temática de ddhh, en el programa de primaria; se empieza a incorporar en los discursos; en los textos empiezan a aparecer referencias. Uno lo empieza a encontrar en forma más o menos repetida. Eso es una señal de algo. Algo está pasando!.

Creo que lo que está pasando, que hay alguna gente que han sido militantes de la EDH, que ha peleado para que eso se incorpore, y va logrando que en algún lugar de la institucionalidad haya un anclaje.

Otra cosa es que después la vida concreta de las instituciones lo vuelva carne cotidianamente, seguramente hay una distancia.

Y otra cosa todavía es que haya coherencia entre el funcionamiento de las instituciones y el discurso. Porque de pronto se incorpora porque hay que hacerlo y se incorpora en un discursos que puede tener una práctica contradictoria. Pero bueno, los avances de ddhh funcionan un poco así. Si suele haber una avanzada que pelea conquista un espacio, y en lo institucional, la cultura masiva suele estar rezagada en relación a eso. Entonces aparecen prácticas contradictorias. Lquea propia institucionalidad esta encarnada en personas, que por lo tanto hace que el propio funcionamiento institucional no sea consecuente plenamente con esa intención que estaba formulada en los objetivos. Pero de alguna manera en la medida que eso esta, empieza a habilitar otras posibilidades para seguir dando la pelea. El hecho de que uno consiga a nivel normativo estén reconocido los ddhh es una primera conquista, pero no los vuelve efectivo, luego hay que empezar a dar una pelea adicional.

Creo que ahí hay una característica que ha sido siempre la característica de las conquistas históricas de los ddhh, que seguramente es lo que está pasando acá. Más que porque yo tenga un conocimiento directo, tal vez viene de una visión construida que yo tengo de como ocurren esos procesos.

Uno ...

Hace un rato había una clase de estudiantes de primaria que venían a ver el museo y una señora que subida arriba de la escalera les hablaba a los niños que estaban abajo en un tono muy agresivo, esas cosas siguen ocurriendo sin duda.

Entonces en primer lugar, hay un avance que .. 
En estos días yo estaba trabajando con un grupo de jóvenes promotores de ddhh, en Las Piedras, Canelones. Hacían referencia a su experiencia en la escuela, como positiva. El hecho que le hablaran a ellos, de derechos del Niño, había sido un primer paso para empezar a pensar en derechos humanos. A mí me sorprendió, pensé también ¡imira!!

En cierto modo son de esas cosas que de alguna manera le vuelve y te gratifican!! Yo también hice talleres con niños para hablar de Derechos del Niño, con niños que nunca más los vi. Y ahora aparecen estos, que yo no había hecho talleres pero que hicieron talleres sobre derechos del niño, y eso dicen: "Que para mí eso de ddhh empieza a cobrar importancia, porque tuve una primera experiencia sobre derechos del niño, y entonces lo que quiero hacer son talleres con niños de la escuelas para trabajar los derechos del niño... Y tal vez los ddhh en un sentido más amplio".

Esas cosas, son esa vía adicional que después del marco más normativo, que puede estar en el programa, puede estar en los reglamentos, puede estar en los objetivos explícitos de la institucionalidad, empieza a ponerle otra carne que siga desarrollándose el proceso. Creo que algo de eso está pasando, con la lentitud de los procesos históricos, pero que empieza a acumular y de pronto tiene estallidos de desarrollo.

También veía en Las Piedras, un cabildo joven, es un espacio físico donde un grupo de jóvenes tiene un lugar del que se apropian, lo hacen suyo, tienen una serie de recursos, que les permiten usar computadoras, cañón, video, una serie de recurso técnicos que le dan la posibilidad de hacer cosas. Hay referentes adultos que los acompañan, hay algunas actividades de formación, sobre todo los que hay es una plataforma para que se proyecten a revolucionar la ciudad! Una plaza abandonada totalmente deteriorada, sin luces, ocupada por gente que también está muy deteriorada, y que duermen ahí. Entonces ellos empiezan a juntar con la gente que de alguna manera ocupa la plaza y, a pensar de qué manera se puede recuperar esa plaza. Y hacen un proyecto, una parte lo van concretando ellos mismos o con otros agentes comunitarios, y otra parte la pelean con las autoridades para que pongan las luces, para que pongan esto... corten el pasto, pinten, para que pongan bancos. Y esa plaza hoy es un espacio público que funciona de otra forma. Entonces aquellos niños que tuvieron un taller sobre derechos del niño y se empezaron a conectar con el tema ddhh, encuentran, seguramente con otras vertientes, no solo porque tuvieron un taller sobre ddhh, seguramente hay un montón en la historia de cada uno de ellos. Pero genera ese encuentro de jóvenes con marco institucional de la Comuna Canaria Joven que lo hace posible, que le da toda la apoyatura. Una visión estratégica, política, sobre la participación juvenil que provoca un estallido y un desarrollo que va mucho más allá y que sigue siendo EDH por canales no formales de la educación. Pero algo de eso tuvo que ver la escuela, incluso antes del programa actual, porque estos gurises tienen entre 17 y 20ypico de años. Sin embargo, desde el 89, con la declaración de los derechos del niño. El tema derechos del niño empieza a estar en la cultura, escolar institucional, y se empiezan a hacer cosas.

Hay cosas que están pasando, gracias a las instituciones y, a pesar de las instituciones!!

Las instituciones están atravesada por la contradicción, por racionalidadades contradictorias. Que las atraviesan, y bueno eso te marca que es un campo de disputa de sentidos.

P: En cuanto a los docentes y la formación docente: ¿tú crees que los docentes están preparado? conocen el programa? Conocen los objetivos? Que falta?

A ver, conocer el programa y los objetivos, sí lo conocen en general! 
Lo han leído, saben que tienen que hacerlo. Hay un disciplinamiento fuerte en los maestros, que se ajustan a lo reglamentario en general.

Otra cosa es están preparados?

Eso es una pregunta un poco más exigente. Porque además que es estar preparado?

Cuando el desafío es tan tremendo, pensar en educar en ddhh, no es pavada.

"Somos analfabetos en ddhh...", y sobre todo hemos sido formados más allá de los contenidos con una racionalidad que es contradictoria con la de los ddhh. Entonces educar es transformarnos a nivel afectivo, a nivel integral, el sentido de nuestras vidas esta puesto ahí y, en el proceso educativo tiene que estar puesto en juego en el sentido de nuestras vidas. Eso ya es, pensar que estén preparados eso ya es una apuesta muy ambiciosa. Es un objetivo muy ambicioso.

De todos modos uno podría decir que mirar hacia cierta preparación en la formación docente para que puedan..., bueno esto es los que razonablemente se puede esperar para decir que los docentes estén formados

Yo creo que falta, que falta mucho todavía para eso. También ahí hay avances pero creo que son insuficientes. Los seminarios de ddhh en 3er año de la formación docente, la gran ventaja que tienen es que transversalizaron en toda la formación docente. A pesar de eso hay algunas perforaciones, pero es un programa único para toda la formación docente. Eso no es menor, una carga horaria insuficiente, a veces falta de información de los propios docentes que van a estar trabajando en la formación docente. De alguna manera debilita el impacto que se puede esperar de eso. Más allá de eso, es un primer avance donde empezar a trabajar y seguir acumulando. Y seguramente ampliar mucho más la carga horaria para formarse en ddhh. Es un avance insuficiente.

Dije que, estaba perforado en algunos lugares, no creo que sea muy grave pero a veces hay en esta institucionalidad tan fragmentada y balcanizada que tenemos, que increíblemente funciona, pero que hay mucha cosa que se desperdicia como posibilidad. Un programa fantástico como "Compromiso educativo", programa que acompaña a los estudiantes que genera espacios de participación. Da la posibilidad a los estudiantes de formación docente, de si se presentan como voluntarios en Compromiso educativo, no tener que hacer obligatoriamente el seminario de ddhh. Este tipo cosa son fallas en el avance, que termina teniendo una serie de perforaciones, a eso me refería, cuando decía eso.

De todos modos hemos hecho el planteo y probablemente este en revisión. Y se busquen soluciones. También la institucionalidad avanza sobre ajustes y re-ajustes.

Seguramente la formación de los docentes se esté dando por más de otras cosas. Nosotros estuvimos haciendo y seguimos haciendo (ahora lo conduce solo la Dirección de Educación del MEC, pero desde la secretaria seguimos apoyando) un curso on line de formación de educación y ddhh. Que no esta exclusivamente dirigido a docentes, o a educadores pero mayoritariamente está enfocado a educadores de educación formal y no formal, promotores de ddhh, no tienen por qué ser claramente desde una práctica educativa, pero si desde una práctica de promoción de derechos.

Cuando nosotros abrimos la convocatoria, si bien tiene ese perfil un poco más amplio, lo que nos llega son demandas de los docentes y, también de los docentes de formación docente. 
Hay una avidez de los docentes también por formarse en EDH. Hay una cantidad de gente que esta sensibilizada en relación a la temática de ddhh y que cualquier oportunidad de formación trata de aprovecharla. Creo que eso también está pasando, yo puse el ejemplo del curso del MEC, pero cada oportunidad que se presenta por distintos lados, en una dispersión de esfuerzos que existen serán formaciones muy fragmentarias, no obedecen a un plan estratégico, ni nada por el estilo, pero hay una dinámica a nivel social donde los educadores están tratando de aprovechar cada instancia de formación en ddhh, hay una avidez por la formación en EDH.

Hay otro aspecto en todo esto que es, cómo en la cultura empieza a instalarse la idea de los ddhh, en la medida que empieza a cobrar una referencia mucho más masiva el termino de ddhh, y a ser algo valorado, un componente de la cultura que es valorado, que se entiende que hay que defenderlo, que hay que desarrollarlo.

Eso ya por si empuja en la educación. La educación en última instancia es eso, es esa cosa que valoramos de la cultura, hacer que se expanda, que llegue a otra gente, que en particular lleguen a la nueva generaciones. Entonces cuando hay algo que a nivel masivo empieza a cobrar una relevancia, también inmediatamente se genera un empuje a nivel de la educación. Más allá de lo que estén haciendo las autoridades hay un empuje que proviene de la propia dinámica cultural y que las instituciones empiezan recoger y amplifican.

Hay otro aspecto interesante a pensar que es, que lo que está ocurriendo a nivel de la transformación no es homogénea. La idea de ddhh no es la misma para todo el mundo, capaz que antes era un término más técnico propio de lo académico, y disciplinar específico. Mas vinculado al Derecho. Hoy el termino ddhh empieza a ser una referencia en muchas de las disciplinas y en el uso corriente. Y no siempre los desarrollos conceptuales que se pueden estar dando en distintas disciplinas se relacionan, no siempre dialogan. Y cuando dialogan no siempre se entienden. Y si a eso le sumas que aun dentro de una misma disciplina existen distintas concepciones ideológicas con respecto a los ddhh, el tema tiene una complejidad muy grande. Este empuje que esta existiendo en términos de desarrollo cultural vinculado a la EDH no quiere decir que sea un desarrollo lineal, homogéneo, y de algo muy claro en lo que estemos todos de acuerdo. Tiene una complejidad que sería interesante poder ver, volver visible. Una de las cosas que nos está haciendo falta, porque está siendo difícil discutir entre las distintas visiones, es poder reconocernos. Creo que las distintas visiones que pueden estar no siempre se reconocen mutuamente. Como le llamamos a lo mismo, nombramos del mismo modo a cosas distintas. Eso por un lado tiene la comodidad que elude el conflicto, entonces no estamos asumiendo el debate ideológico que está en juego en las diferentes concepciones que hay vinculadas a los ddhh. Pero lo cierto es que en los distintos desarrollos cobran cada vez más importancia y se vuelva necesario crear un espacio, un comunidad de dialogo donde nos podamos reconocer en la diferencias y empezar a tener un dialogo critico, constructivo que pueda procesar una síntesis. No se cuales pero hasta para hacer proliferar más la diversidad de conceptos e inscripciones desde un enriquecimiento desde el dialogo.

\section{P: Eso lo ves a nivel social que repercute en la educación?}

A ver, creo que eso está pasando en una matriz mucho más profunda que la educación... Es una interacción permanente, de pronto, vos tenes gente que a nivel académico empieza a hacer elaboraciones y empiezan a repercutir en muchos referentes que pueden estar jugando a nivel político, a nivel social, que también retroalimentan las dinámicas sociales. Al mismo tiempo los canales por los cuales empiezan a producir una transformación social tienen sus líneas de contacto con los ámbitos académicos y muchas otras líneas de contacto que vienen de otros lados. Pero lo 
académico es un elemento de retroalimentación, y la educación en particular es un elemento de amplificación y desarrollo de esas transformaciones culturales.

Ya te digo mi visión es un poco desde la impresiones, nada de esto tiene una constatación empírica, una base científica. Bueno una de las cosas que uno identifica es que falta ese nivel de diagnostico. Finalmente parece que podemos contratar una consultoría para hacer un diagnostico, para una línea de base, tal vez empiece a aportar también en ese sentido.

La EDH todavía está lejos de ser un tema de agenda pública importante, a pesar de este fenómeno que yo te señalo que está ocurriendo. No es ninguna encuesta de opinión publica te lo va señalar como un tema prioritario. Y tampoco va está apareciendo como un tema prioritario en la agenda política de los gobiernos. No quiere decir que no le den ninguna bolilla pero hay otros temas que se comen la energía, y se comen también los recursos. Terminan siendo esos espacios que empujan y alguna gente que está muy convencida y que es parte de la racionalidad que se va imprimiendo en las instituciones, pero no tiene todavía una centralidad muy fuerte.

En ese sentido

\section{P: ¿Qué identificas como importante para que, la EDH ocupe un lugar más importante en el ámbito educativo?}

En todos lados hay empujes, y caídas, estancamientos... y nuevos empujes, que en parte retoman lo anterior. Nosotros con el proceso del Plan Nacional de EDH estamos queriendo hacer un empuje nuevo. Pero fijate que empezamos a plantear el proceso del Plan en principios de 2011, y tenemos recién la habilitación para empezar el proceso en mediados del 2013. Poco antes tal vez, en el primer semestre del 2013, con un lanzamiento publico en julio 2013. Una Comisión que es una comisión asesora estamos habilitados en utilizar recursos de la distintas instituciones, eso quiere decir que cada vez que vamos a hacer un encuentro, empezamos a ver de dónde puede salir la plata para empezar a cubrir este gasto?, el almuerzo?, el corte-café?, como hacemos para pagar los pasajes?, que trasladen a alguien?, y una comisión asesora en realidad tiene personas que están en 25 millones de cosas más, termina siendo un dispositivo tal vez no el adecuado para sostener un proceso de Plan Nacional de EDH, sin embargo lo vamos llevando.

\section{P: ¿El Plan Nacional de EDH, contribuiría a desarrollar una transversalidad de la EDH en las aéreas que vos planteas? Formación docente; prácticas educativas; Coherencia y visibilidad}

Esa es la razón de ser del plan, dar una mirada estratégica común que pueda hacer que los distintos ámbitos de la educación haya una referencia hacia dónde vamos, después ajustada en cada lugar, pero un sentido común compartido, de orientación estratégica. Estamos tratando de involucrar a los distintos actores, de los distintos ámbitos. Hemos tenido una vinculación importante con el interior, a través de las Comisiones departamentales de Educación. Se nota el notable avance de tener un Sistema Nacional de educación Pública que como todas las cosas, como tantas otras cosas de institucionalidad nueva, todavía es muy precaria. No tiene presupuesto propio, es un ámbito de coordinación, no tienen una institucionalidad fuerte en términos.. de cada uno de los ámbitos del sistema tiene autonomía y por lo tanto la decisiones son de consenso para sacar algo en común, y cada unos después tendrá que implementar por su lado. Pero a pesar de esos, vos tenes un nivel de articulaciones entre ANEP, UDELAR y MEC, que antes era mucho más difícil. Y no solo entre los 3 niveles en un sentido horizontal, entre los 3 ámbitos sino en una relación entre el nivel central y el nivel del territorio. La vinculación entre las comisiones departamentales de educación hace a un 
cambio cualitativo más que interesantes. Una de las cosas que empieza a pasar. Es que el sistema empieza a ser permeado por un tema más en la agenda, aunque no sea el más prioritario, además es comprensible que no lo sea. Porque hay una cantidad de otros desafíos, pero empieza a ser permeado por un eje transversal de EDH. Ya la ley en su formulación tiene la transversalidad de la $\mathrm{EDH}$, empieza a concebirse la educación siempre con ese eje transversal.

\section{Entrevista a Martín Prats}

Director de la Dirección de Derechos Humanos de la Administración Nacional de Educación Pública (CODICEN-ANEP)

Integrante de la Comisión Nacional de EDH, asesora al SNEP,

Miércoles 9 de abril 2014.

P: ¿Cómo pensas que se está realizando la concreción de la transversalidad de la EDH en el sistema educativo, $y$ en especial en primaria?

Es muy amplió lo que vos planteas.... 


\section{Pensando en los programas, si son conocidos por los docentes?; Formación docentes?; y practicas educativas?}

La educación en derechos humanos (EDH) se planteo como un línea transversal para todos los niveles de la Educación (Educación Pública), ya desde antes de la Ley de Educación ( $\mathrm{N}^{\circ} 18.437$ dic. 2008). La ley es del 2009. Pero ya desde el comienzo de la administración anterior se delineo como una línea general para la Educación, la EDH. ... En el gobierno de Vázquez, en la administración de la ANEP, encabezada por Yarzabal empezó en el 2005-09, empezó a delinear como línea de acción estratégica, y una de ellas la EDH.

\section{P: ¿Hay algún documento específico que los explicite?}

El libro " Una Transformación en marcha- Políticas instrumentadas por el CODICEN (2005-2009)"

La Ley de Educación lo que hizo, fue reconocer esta línea y ya expresarla, con mandato legal. Como te decía, ya desde antes de la Ley de Educación, ya la EDH estaba establecida como una línea estratégica transversal para la Educación. Eso llevo a que ya, en el Programa de Educación Inicial y Primaria, en la última en forma de plan, en la parte introductoria están establecido la línea de los ddhh, y de la EDH.

Como la educación en primaria es necesariamente transversal. No esta tan establecida, y encasillada en disciplinas y, asignaturas como se da en la educación secundaria. Bueno la EDH, la Educación en la diversidad esta, cruzas prácticamente todos los temas.

Claro está que, a nivel de primaria, una cosa es lo que se ponga en los planes y programas específicos. Y otra cosa es lo que los docentes puedan hacer en el aula. Fundamentalmente habiendo de una carencia en la formación en la EDH que recibieron cuando se formaron como maestros.

Entonces, bueno, a partir también de la administración anterior, se estableció en la formación docente, la preocupación de que la EDH sea también una línea transversal. Ahí también en la reforma del plan de estudios de Formación Docente, se estableció a partir del 2008, la existencia de los seminarios de ddhh. Que si bien tiene una carga curricular bastante pequeña, de 30 horas solamente, es al menos una presencia del tema, en la formación docente tanto de maestros como de profesores de enseñanza media. Entonces se busca, a través de estos seminarios, que por lo menos, los futuros docentes vayan incorporando los conceptos en estos temas y fundamentalmente la práctica de la EDH.

Paralelamente a eso, con los docentes ya recibidos, que no recibieron esta formación por haber estado con planes anteriores, lo que se busca desde la administración anterior, es apoyarlos es a través de determinados: cursos o, talleres o, seminarios, donde este planteara la temática de la EDH. Sabiendo desde entrada que es muy difícil de llegar a todos los docentes que están trabajando hoy, en las escuelas o, los liceos o, en los centros de UTU, porque son miles. Y los recursos no dan para hacer cursos de actualización o de perfeccionamiento que lleguen a todos. Nos encontramos con la dificultad de no poder llegar a todo el país. No solo quedarse en Montevideo.

Entonces en esos cursos que se realizan, con una convocatoria está abierta. Ya sabemos que no llegan a todos. También la estrategia que se busca es, capacitar a esos docentes en un tema específico relativo a ddhh, sino también en que se puedan convertir en referentes en estos temas en sus centros educativos. Y entonces desde ahí capacitarlos en un tema especifico en ddhh o derechos del niño, sino también en la capacidad de poder formular proyectos de aula, proyectos de centros 
donde se aliente la Participación; se aliente la mirada desde los ddhh de los problemas que día a día se dan en los centros educativos.

De ahí los curso en el IPES. Es un ejemplo de lo que te decía. Pero también el proceso de implementación del "Protocolo de Violencia Domestica. Si bien es un proyecto de implementación sobre un documento especifico, se busca que partir de ese instrumento los docentes que participan de este proceso, también puedan abarcar más ampliamente la dimensión de derechos y, poder trabajar desde esta perspectiva otros problemas que se den en los centros educativos. Y también poder apoyar, desde la Dirección de ddhh, a todos los cursos o programas donde se trabajan estos tipos de temas.

De ahí que trabajar con, "Aulas Comunitarias", "Maestros Comunitarios", como el Proyecto de la Comisión de Participación de Secundaria, etc, etc, donde se buscara la misma estrategia.

Los que puedan acceder a este tipo de cursos, sean instrumentos de difusión, en todo el Sistema Educativo.

Entonces lo que hoy tenemos, como síntesis de lo que te vengo diciendo, es:

-a nivel de planes y programas la perspectiva de Derechos está incorporada; (primaria hizo una reforma del programa, incorporando el tema; en secundaria en alguna materias esta el tema de ddhh, incluso en algunas materias algunos temas específicos se le dio mayor espacio: por ejemplo las materias de sociales y afines, hay temas de ddhh muy presentes, no solo del aspecto normativo sino de la practica y la temática de ddhh

-a nivel de formación docente, hacia el futuro la temática de DDHH, también está incorporada; (se están dando los seminarios en 3ros y 4tos años que se están desarrollando. O sea que los futuros docentes tienen al menos una visión pequeña en lo que es la maya curricular, en lo que es formación en EDH.)

- a nivel de formación permanente, se busca con esta estrategia y recursos con que se cuenta, un poco, es la tarea de difusión o de "tirar una piedra" y que los círculos concéntricos vayan llegando cada vez más lejos, para lleguen estos temas a cada vez más personas. (a través que cursos, seminarios, talleres que tratan de llegar a lo máximo posible de docentes. Preparándolos no solo en temas específicos sino que puedan ser ellos referentes en la temática en los centros donde les toque actuar. )

*corte se retoma agregando lo que está entre paréntesis ( )

Entonces desde allí, desde la Dirección de DDHH, hay propuestas de cursos, pero también colaboramos con otras propuestas que puedan venir de otros lados, o convocatorias que puedan venir de otros lados. Porque otras veces nos llaman de los liceos,... Proyectos a los que damos apoyo en los seminarios.

Un poco por ahí va la línea estratégica de por donde se esta transversalizando los ddhh.

\section{P: de acuerdo a tu opinión, ¿Cómo vez que se está llevando a cabo la EDH?, ¿Cómo se está realizando en las practicas educativas concretas?}

Un logro es que la temática está instalada. Está instalada la EDH como línea transversal y, no solamente en las líneas estratégicas de estos 2 últimos gobiernos, también en la ley de educación. 
Claro está que falta mucho en cuanto, a lo que señalaba, de poder proporcionar a todos los docentes, las herramientas para desarrollar una EDH.

Un poco por lo que dijo Pérez Aguirre, u otros que han pensado la EDH, que la EDH no es solamente posición de contenidos sino que son fundamentalmente practicas. Entonces en cuanto a esas prácticas y, como llevar adelante realmente una EDH que apunte a la convivencia de todos los actores educativos, que en las relaciones interpersonales se lleven desde los ddhh, bueno ahí falta mucho!!

Porque para enseñar los ddhh, hay que sentirlos!! Entonces!!Es una transformación cultural que tratas que llegue a los docentes, y los docentes sientan los ddhh, cuando traten de enseñarlos.

En eso falta porque es una tarea permanente. Entonces uno puede establecer determinados planes, programas, algún objetivo a lograr, pero ese cambio de cultura, es un cambio a mediano, largo plazo. Donde, bueno, de a poco.

Lo que todavía no se ha construido es un mecanismo de evaluación, de como la EDH va transformando la cultura de los centros educativos.

El tema está instalado, hoy se habla de ddhh. Pero como eso va transformando la cultura de los centros, y eso te permee en la sociedad, es algo que por ahora, es un tema, que tenemos que ver cómo lograr evaluarlo y cuando evaluarlo.

Yo creo que 5 años, cada 10 años, tal vez es poco tiempo. Yo creo que el Plan Nacional de EDH que estamos llevando con el MEC y la Universidad, estamos tratando de formular, para un tiempo más cercano. Ahí si debe establecer más claramente los criterios de evaluación. A ver si todo lo que se ha hecho o lo que se planea hacer en el futuro cercano en materia de EDH tiene impacto.

\section{P: ¿Tu decís que esta herramienta de la evaluación tendría que estar en el Plan?}

\section{¿Y el Plan como herramienta de promoción, y de acción, para la efectivizar la transversalidad de la EDH? Como la vez?}

Uruguay no tiene un Plan, en cuanto a que TODA la educación Nacional formal y no formal, dirigidas por la ANEP, u otras instituciones públicas, y también como participa la sociedad civil en EDH. No han formulado un plan con objetivos únicos para el mismo. Pero bien los distintos niveles de la educación o el tema de EDH, están planteados. No podemos decir que un Plan va empezar con el tema, no hay un vacio.

No se hace, y se hace desde hace un buen tiempo para atrás. Esta incorporado en planes y programas. Esta incorporado en estrategias, de corto y mediano plazo. Pero falta un poco el desarrollar un Plan que coordine acciones, y precisamente que apunte a poder establecer mecanismos de evaluación de resultados. Y a mí lo que más me preocupa es la evaluación, no de como los contenidos de ddhh están en los programas, porque están, y en eso el Uruguay está bien! Sino los resultados en las practicas!!

¿Estamos logrando que los centros educativos sean lugares donde se respeten y promueven los ddhh?, y otra cosa más grande aun, estamos logrando que la gente, que salga de la educación pública, tenga incorporada la dimensión de derechos? Si la sociedad está cambiando o no? ¿Para que queremos EDH, para que la sociedad cambie y sea más respetuosa de los derechos? Y eso es más difícil evaluar! Y ver como se evalúa también? 


\section{P: En tu opinión, ¿hay un cambio en el sistema educativo, en la actitud de los docentes? En cuanto a la EDH está presente en la normativa?}

Como el tema está instalado, se ve una preocupación de los docentes de formarse mejor, y hay una preocupación de cómo tratar determinados temas. De tener herramientas para tratarlos, de cómo poder afrontar ciertas temáticas. Que es un punto solo, pero como el tema del acoso escolar. Es decir, hoy de parte de los docentes hay una demanda de como poder atender ese problema desde una dimensión de derechos. El tema de violencia familiar, que también señalaba. U otros problemas de vulneración de derechos, que pueden surgir en el centro educativo, o el centro educativo los detecta. Hoy los docentes, no todos, pero una parte de los docentes, lo ven como un problema de derechos, que hay que abordarlo de manera integral. Entonces esos son avances!

También la temática de la participación. La ley mandata la implementación de los consejos de participación, pero también en todos estos años de la ley para acá que no basta con la obligación legal de que haya concejos de participación, sino que hay que aprender a participar hay que crear las condiciones para desarrollar una participación genuina. Y ahí, vemos que la realidad de los centros puede ser muy distinta. Pero bueno, también existe la preocupación de como trabajamos este tema, y como ir a la participación con una dimensión de derechos. Eso es un paso adelante!

Yo creo que en muchos centros educativos la convivencia en clave de derechos, con el tema de la participación en clave de derechos está instalado. Habría evaluar si es después de la conciencia o se han desarrollado practicas en los centros educativos, mas amigables, donde se respete de mejor manera los derechos de todos.

Desde una visión de la ANEP, la EDH como permea hacia la sociedad, o si hoy la sociedad hoy toma más el tema de los ddhh. También vemos que hoy en la sociedad está instalado más el tema de los ddhh, mucho más que hace 10 o 15 años atrás. Y hay temáticas de ddhh que están más presentes como que la sociedad también reacción más frente a una violación de derechos de una manera distinta de lo que hacía antes. O conoce más cuales son los instrumentos para defenderse o cuales son las garantías existentes para defenderse. En este sentido bueno, los ddhh en algunos años ha logrado ciertas cosas! Pero, también hay ciertos problemas sociales que uno ve que, son cosas/rocas duras de roer. El tema de violencia, o tema de pobreza, vemos que está un poco complicado. También se mescla el tema de los medios de comunicación trasmiten, no se sabe cual es la real dimensión de algunos temas. Uno ve que hay algunos temas en la sociedad uruguaya que una $\mathrm{EDH}$, podría contribuir a que algo vaya cambiando.

Y en esos temas, es más difícil desarrollar mecanismos de evaluación de impactos.

Tenemos una sociedad más violenta, mas delitos violentos, ahí hay una temática de porque ... un joven es más violento que antes, no solo hablo de lo que se conoce como el menor infractor, sino la reacciones violentas de la sociedad. Hay más violencia en el transito, o más violencia en el futbol... en las relaciones interpersonales hoy hay una tensión social que no existía antes. Se trataba más amablemente, bueno. El tema de la pobreza, más allá de los índices económico que suben o bajan, el medir la pobreza, que está mejor por suerte, pero más allá, como la sociedad ve la pobreza como un problema de toda la sociedad o un problema de opciones,

Ver como la EDH impacta en cómo cambia la cultura. Mi preocupación es esta! Cuando se habla de EDH no me basta que este en los programas, o se crearon en los centros educativos $\mathrm{x}$ espacios de participación. Eso es un ítem para dejar contento? No! Eso son medios!! El fin es que la 
sociedad cambie, entonces ¿la EDH está contribuyendo para que la sociedad cambie? No se para mi viene por ahí el problema!

Es mucho más fácil meter ddhh en una materia de liceo, que pensar como sale la gente de los liceos en materia de derechos.

\section{Entrevista a Margarita Navarrete}

Instituto de Derechos Humanos de la Facultad de Derecho-UDELAR

Integrante de la Comisión Nacional de EDH, asesora al SNEP

Integrante del Observatorio de políticas públicas de derechos humanos en el MERCOSUR.

Viernes 11 de abril 2014.

P: ¿Cómo pensas que se está realizando la concreción de la transversalidad de la EDH en el sistema educativo, $y$ en especial en primaria, desde actual normativa?

Hay antecedentes, de hecho en 1985, el IIDH hizo un convenio con varias escuelas de primaria en el Uruguay, una experiencia piloto que hubo, donde seleccionaron algunas escuelas. Quien estaba a cargo del convenio era Leticia Ogging, por el IIDH. Hace mil años que se trabaja EDH, bueno 30 años van a hacer de eso. Fue en el periodo de Ministra de Adela Reta, fue un tema de que por un lado los ddhh eran tabú, por aquello de la Dictadura y el gobierno militar, y por otro lado al mismo tiempo, eran tiempos muy ferméntales, Uruguay estaba comprometido a la EDH a la aprobación de los nuevos textos a nivel internacional. El IIDH fue bastante pionero en ver cómo hacer algunas experiencias pilotos.

P: Es un dato que no tenía, ¿hay registro de ese convenio? 
El registro de ese convenio tiene que tener el IIDH mismo, y el MEC también. Si bien era con la ANEP, tenía que ver con esos programas que hay en primaria. Programas especiales, donde eran seleccionadas no solo escuela de Montevideo sino también, creo que era una escuela de cada departamento del interior. Era un programa un plan piloto que lo financiaba la Fundación Naumann IIDH, el gobierno de la Republica y Fundación Naumann.

Querían como empezar a hacer algo en ddhh, en EDH, claro eran con los programas viejos, los contenidos mucho no se sabían, eran más bien contenidos valóricos. Pero en primaria en realidad siempre estuvo que la Declaración de los Derechos del Niño del 59, era como muy fermental, y lo sigue siendo hoy, como muy importante. Más que la Convención para el trabajo con los niños. Porque la CDN es más para los adultos que para los niños. Desde el punto de vista de los niños, es como que siempre es mucho más motivacional, fermental, es más lindo trabajar toda esa parte. Y allí justo surge el Programa de Educación formal en SERPAJ.

Educación popular estaba de entrada, Joselo Mosca y Luis Perez Aguirre ya habían hecho el libro "Pautas para una educación Liberadora", y estaban haciendo talleres por distintos lados. Pero ahí, toman la opción para trabajar en función de docentes. Qué docentes? En secundaria más que nada, pero después empiezan con primaria. Primero secundaria por el tema, por aquello de ¿Cuál es la edad que se le puede empezar a hablar a una persona sobre ddhh? Esta como muy presente, que también en la última propuesta del IIDH lo estaba. El tema de desarrollo moral, que tiene más que ver con los desarrollos teóricos de Jean Piaget, Lawrence Kohlberg Teorías que hoy se cuestionan un poco, pero en aquel momento eran innovadoras, y no hay que esperar hasta los 18 , sino que es de antes. Aunque ese antes no era tan antes! Igual implicaba introducirlos al tema a los adolescentes. Y sobre todo, formar a los docentes, porque realmente no tenían ni idea, si ddhh era una mala palabra, no se podía hablar en dictadura. En realidad tratar de entender que quería decir ddhh, y sobre todo que en algunos ambientes, políticamente no era bien visto hablar de ddhh. Que se yo, se decía que a partir del 1ro de marzo del 85 en Uruguay ya no se violan más los ddhh! Como si ddhh quedase solamente recluido o relegado a las violaciones en dictadura.

Como que era difícil ver de qué contenidos, de qué hablamos... y la verdad, sobre todo en la revistas que empiezan a publicarse en SERPAJ en el 87, es realmente muy interesante ver qué tipo de cosas se trabajaban. La verdad trabajan la línea de la transversalidad, del juego. De pensar que ddhh necesita una cierta práctica para poder educar, empiezan a formar en contenidos, bien interesante.

En realidad, se incorporaron varios maestros al equipo de educación formal, pero claro siempre en una línea que era más, por más que se le dijera educación formal, era educación no formal, que intentaba ser más motivadora a los docentes para que participaran en un proyecto de cambio, de transformación educativa.

Pero realmente el proceso interesante se da antes de la Ley, cuando se cambian los programas de primaria. Estos últimos cambios que fueron, en realidad un cambio más fuerte e importante, me parece sin conocer mucho. Digo después de la Ley, aunque ya estaba la ley, de hecho el programa llevo más tiempo discutirlo y lo que si implico es ver como un esfuerzo, de cada edad, de cada nivel, poder incorporar la visión de ddhh. Donde ahí si implicaba, desterrar la idea de que a partir de una edad había que empezar a educar en ddhh. Ya sea que se le llame ddhh o no, pero si desde la educación inicial se puede trabajar con los niños y con las niñas en estos temas. Y con los docentes. 
Se hicieron distintos contenido y demás, pero la verdad es que, las conversaciones que yo tengo de la aplicación del programa, por ejemplo en inicial, es que la verdad, que son muy diversas, depende de qué centro, depende de que maestros.

Me acuerdo en particular, tuve una entrevista con una maestra de inicial, que estaba en la directiva del PIT-CNT, en la parte del Instituto de formación, divina la muchacha, era una muchacha joven, que justamente contaba como en su escuela hacían una planificación ya de entrada incorporando los ddhh en todos los niveles. Claro era la experiencia de ella, y la experiencias de otra escuelas, es que los dejan más recebados a contenidos. Las experiencias son bien diversas. El programa es bien interesante porque trata de hacer un esfuerzo, que se nota ya nomás en la composición de la comisión multitudinaria. Se le preguntaba a Martin, y porque, a demás ponen mal algún nombre de documento, como por ejemplo la "Convención de los derechos del niño del 59", o donde tendría que ir Convención, ponen Declaración. Esas cosas que tiene que ver porque el documento fue hecho por varios. Varias etapas, borradores que van y vienen, aparecen todos con el mismo grado de responsabilidad y de repente a algunos se le mostraba una parte, a otros otra. Pero digo, que me quería referir: que en 5to y 6to aparece más ligado a Ciencias Sociales, ddhh, como contenido. A veces las maestras lo reservan para que áreas están más implícito, perdón explicito. Ahí lo ven nada más como un contenido.

Ahí es un lio grande, porque los docentes precisan más, sobre todo la maestra (grábalo pero no lo desgraves). Yo una época di Seminarios de ddhh, en magisterio (en normal, en formación docentes también doy clases). Y el tema es que deje de dar, di 2 años, pero me frustraba un poco, esto de que los estudiantes lo que querían era la receta y el contenido especifico, para la parte de ciencias sociales. Yo les decía como trabajar por ejemplo, efemérides, y hacer una cartelera misma dentro del Instituto Normal. Lo hacían para quedar bien conmigo. Lo vivi como muy instrumental, todo muy pragmático en primaria, y la verdad que sentí que no podía con eso. Más allá que como docente una tiene que ayudar a dar herramientas, y de más Y me quede con el IPA, por eso. Sin embargo las cabezas son distintas, digamos que se dan más la libertad en el IPA de pensar la educación en general, tal vez porque te compromete menos. Porque EDH no es tu materia, porque das matemática, eso o lo otros. Pero si sos maestra tenes que dar ddhh.

Sentia que los del IPA, por ejemplo, pueden llegar a ese proceso de manera distante, "no tiene que ver conmigo", pero después ir descubriendo que sí, que tiene que ver con otras materias, y tiene que ver... que la matemática tiene que ver con los ddhh, que la historia, y la literatura. Y en cambio sentía que en primaria, por más que trataba de mostrar cosas, videos, simplemente, ya tenían todo preparado para que: “tiene que encajar en ciencias sociales” por ejemplo. Porque es lo más típico, más allá que la propuesta es más general, me paso que a veces faltan otras cosas.

P: No es una observación menor lo que estás haciendo, estás diciendo como la concepción de educación, y de la EDH tiene una pata ideológica. Que hace que esto de la EDH sea algo más integral, algo más transversal. Y como se está planteando la educación primaria, de aplicar una técnica con determinados objetivos instrumentales, va en contra de tu concepción de EDH.

No no, claro!! Lo que pasa que de alguna manera un docente de ddhh en formación docente, es marginal totalmente. Porque no formas parte del colectivo de los docentes... Pero nos pasamos a otro tema.

En Formación docente existe un Seminario de ddhh, que se llama así: Seminario de ddhh, que es para la formación docente que son 30 horas, nada más. Ese docente que da 30 horas, en realidad no 
forma parte del staf, al menos que tengas otra materia más. No coordinas con nadie, no hay sala docentes, podes participar si queres. Esta bastante descolgado, si. Y además, no solamente eso, sino que no coordinas con otras materias para hacer cosas. Uno piensa que podría estar más coordinado con la didáctica. Va en cada docente que coordinaciones hace, no hay un programa general en acuerdo de los docentes que dan la misma materia. Cada cual presenta su curso. (Si queres hablar con Rosario Caticha, inspectora de historia...libros de memoria de la mujeres...visión más integral de los ddhh)

Tiene otro contra, que la verdad es como muy voluntarista. En algún momento Emma Zafaroni me dijo " es lo que se pudo!!! Hubiéramos querido una materia" porque lo mismo que pasa en el normal, pasa en todos los institutos de formación docente, en el IPA, etc. Los docentes que estamos en una lista nacional, tuvimos que presentar una propuesta, pero, la propuesta tampoco es pública, la conoce tu grupo y ya está. No es común puede ir cambiando. Los Seminarios tienen un poco esas características, de ser instancias integradoras, que esta bueno, pero a la vez como que cada estudiante tendría que hacer la integración para eso estaría bueno poder trabajar con otras materias. ... tiene bastantes diferencias como poder hacerlo, la evaluación final, puede ser muy diverso, algunos que tengan que ver con sus materias, otros con un comentario acerca de algo, las estrategias de evaluación pueden ser también ir cambiando.

P: vos decís que esta ubicación, de la EDH, en el sistema de estos Seminarios de integración educativa, ¿no está ayudando a entender a la EDH y sus desarrollos?, que desde la normativa la EDH es un eje transversal desde todo el sistema Nacional de Educación Pública, y punto de partida del programa de primario

Tal vez si tuvieran una carga horaria mayor, y alguna posibilidad de coordinar los docentes con otros, puede que en algunos casos ayude, puede que no! La sensación es que es poco todavía, debería haber más, más posibilidades, pero ta! Habría que preguntarles a los estudiantes, que opinan. En general el estudiante lo ve, no tanto como seminario de ddhh, sino también...Son 3 Seminarios que tienen: Sexualidad; ddhh; y dificultades de aprendizajes.

Y los 3 los ven como una oportunidad de integración del conocimiento. Y de estar con compañeros de otras materias, que es bien interesante. Esta esa posibilidad lindísima del Seminario. Pero a la vez no es tan sencillo trabajarla.

Para mí, igual es una experiencia buenísima, el IPA esta bárbaro. Magisterio me sentí con más dificultad para compartir una concepción de EDH. Es que como contenido la verdad, no no, no es desde allí que me parece interesante, por más que hablaras de la Convención de los Derechos del Niño, pero hay situaciones que los docentes las entienden más cuando hablas de adolescencia, que cuando hablas de niño. Siguen pensando en el niño como el que tenes que proteger. Si estamos hablando de escuela de contexto crítico, también, les cuesta, claro siempre depende del contexto de los niño,.

Yo siempre les decía de no ponerlos como víctimas. Porque sino terminas diciéndoles, bueno ándate a una escuela especial, siempre tratando de rescatar el potencial. Es como complicado en las escuelas poder ver algunas cosas.

A demás hay recurso externos, de gente externa. En el caso de primaria yo invite a gente, por ejemplo hice el tema de violencia domestica, niños golpeados, estrategias. Invite a Mariela Solari, una de las capas en todo el tema del diseño sobre el Plan Nacional contra la Violencia, mapa de 
ruta, y como trabajar el tema de la violencia, Encantados!!, pero no la podes invitar todos los años a un grupo, de repente tendrías que hacer como una actividad más central.

Otra vuelta, educación especial tiene un equipo que visita todas las escuelas, como para ver que hay un montón de niños mal diagnosticados. Que las maestras le pusieron el rotulo de no puede aprender, y en realidad, son chicos que necesitarían otro tipo de atención. Y que no están para escuela especial y están para una escuela común. El tema de la integración es un tema importantísimo. Una vez vino ese equipo, pero no los podes invitar siempre porque ellos tienen muchas cosas para hacer que ir a ver una clase.

Pasan esas cosas que sentís... otro año a un grupo lo lleve a Gurises Unidos, (que está al lado de Magisterio) les hicieron un taller precioso sobre el tema de trabajo infantil, y estrategias para trabajar con los chiquilines, y que ocurre. Tratar de pensar un poco más el tema, sabiendo que tienen un montón de recursos, que mas allá del Seminario, uno pudiese coordinar con los docentes de didáctica, no solo sería el Seminario de ddhh, serian en otras materias donde se podrían ver estos temas. ...

A demás el Seminario esta en el último año de magisterio (en Formación docente es en el 3er año, el penúltimo) casi al final. La materia esta medio en solitario. Fijate que 30 horas en el IPA, son 10 días. Porque no son 3 horas reloj, son 3 horas de 45 minutos. Entonces motivas, y pasan cosas lindas que pasan, pero en algunos no. Y a parte en eso 10 días pueden faltar 2, y aparte en el medio te apareció algún paro. O lo que sea ¡!! No tienen que ser clases efectivamente dadas.

\section{P: ¿Que otras acciones crees que se están haciendo para generar más aplicabilidad de la transversalidad de los ddhh? O faltarían hacer?}

Otros programas interesantes que hay son los de UNESCO, escuelas para la Paz, no me acuerdo los nombres. Tiene algunos programas, sobre todo esta red de escuelas, que tiene UNESCO, donde las escuelas participan, en términos de que la Paz como derecho integrador de los demás derechos. Eso me parece una excelente iniciativa, que yo solo me asome alguna vez para conocer experiencias de otros.

Es probable que haya algunos proyectos de centros de escuelas que es probable que cuenten con Asambleas Estudiantiles. Por ejemplo, una escuela de tiempo completo del Cerro, que en su momento la directora contaba que hacían, efectivamente, Asambleas estudiantiles. Y si hablamos de Derechos del Niño, cual es la instancia de participación que hay en una escuela? Contaban que había Asambleas donde se contaban situaciones que para ellos eran complicadas. Ponele el baño, esas cosa si donde te respetan o no la intimidad, si te cuidan o no, si te pegan. Bueno lugares donde poderlo plantear. Es decir en el proyecto de centro mismo, que puede tener más que ver con proyectos de convivencia, de repente pero no solamente, porque había una organización donde estaba planteado así formas de participación. Con un lenguaje en derechos, con formas incluso de responsabilización. En el sentido, de que no existe la pared, sino que hay que conversar. Y si hay un problema en uno grupo que se están procesando mal las cosas, no es que hay 1 o 2 responsables, sino que responsable es el grupo. Ese tipo de cosas que tendían más a la cohesión, a entender la responsabilidad de cada uno, frente a sí mismo, frente al grupo, frente a los maestros. Hay distintas cosas...

En primaria hay algunas escuelas que trabajan con algunas ONG's barriales, que tienen más redes comunitarias que otras. 
Hay varios programas, por ejemplo el Programa Huertas; trabajan con las quintas; no sé si el Programa Cero faltas, trabaja en algo o no. Este programa me lo comentaron más críticamente.

Otros programas de UNICEF, por ejemplo Maestros Comunitarios; son programas de apoyo, que de repente sean instancias de conversar de situaciones de derechos, de hablar cosas con la familia...

P: vos sentís que dentro del Sistema los docentes tiene en cuenta esos otros recursos, que de repente no son el programa, pero si son otras instancias que se pueden hablar de derechos, y otras instancias de transversalizar los ddhh? O no lo ven como un recurso?

En primaria no sé si lo ven como un recurso, esta como muy focalizado, muy sectorializado. Para tal escuela, tengo tal gama de oferta. Porque además van a estar ubicadas de acuerdo a como haya sido clasificada. La verdad...no...

P: La concepción tranca la visión integral de la situación, y de poder entender la transversalidad con la integralidad de los temas, desde el orden afectivo y temático, y sociales.

Y el Plan Nacional de EDH, ¿como pensas que puede impactar siendo promotor de la transversalidad de los ddhh, o no?

Habría que ver como ANEP lo plantea después, porque el PNEDH, va ser líneas transversales. Habría que ver como a la interna, se aplica. Por ejemplo: en la ANEP, sigue siendo cada maestro por si solo, vos en tu clase te arreglas como sea. Si llegas al tema llegas, sino paciencia. Ponele que sea una docente que no le guste habla de determinados temas, lo podes obviar totalmente.

Nos paso cuando estuve, con María Elena en la Dirección del MEC, una denuncia de una madre de una niña, por un tema de discriminación. Estaba Alicia Saura. La denuncia la traje yo, era una amiga de mi madre que la derivo allá. Y el tema era la gurisa de la escuela, prácticamente la maestra la sentaba en el último lugar de la fila, era la última en salir, no le daba un beso, porque siempre aparecía alguien... tenia una serie de conductas que eran racistas. La forma que se dieron cuenta del racismos fue... en realidad nadie se dio cuenta, pero como tenia bajas notas siempre, la mandaron a una maestra particular. Y en un momento esta maestra le dice, "esta chiquilina no tiene ningún problema de aprendizaje".

Entonces empezaron a revisar las cosas que hacia, y la verdad los comentarios. Ponele que habían pedido de hacer una investigación sobre la familia. Traía una foto con su prima, que era blanca, el comentario de la maestra, "que linda foto Benetton". Ese tipo de cosas. La familia le agarro tal fastidio que la sacaron de la escuela, la cambiaron. E igual vinieron a hacer la denuncia. Como ya la habían sacado, no la podían restablecer. Pero la idea era ver como poder hacer una conversación con la escuela para que hiciera talleres sobre no discriminación a los docentes. El tema era que la maestra se jubilaba al año siguiente, así que el tema era complicadísimo, nadie quería alterarle su carrera, nadie quería afectarle. Decían: "eso es de la vieja guardia, ya se va,". Pero mientras seguía jodiendo la vida de un motón de gurises!? Si, si ya se va pero mientras tanto que hacemos?

No hubo forma....en ANEP, estaba Martin Prats, recién llegando, se estaba viendo que pasaba. La verdad que ahí se trata de pensar, que si yo tengo un Plan de reconocimiento de derechos, de reconocimiento de estrategias, debo de poder ver las posibles derivaciones. Si surgen situaciones que aparecen como conflictivas en la educación, también poderlas solucionar. Por ejemplo, Talleres para docentes, que tengan una característica de sirvan para cambiar cosas que están mal. Para revisión de las prácticas, y no como la educación permanente porque, qué lindo es educarnos $\mathrm{y}$ formarnos. Porque realmente vemos problemas y hay cosas que en todo caso las hacemos 
inconscientemente, no hay nada peor que la discriminación ideológica, donde todos formamos parte de! Y si no tenemos una instancia de visibilizarla, donde objetivarla, vamos a seguir repitiendo las mismas cosa. En ese sentido, creo que debería ser por centro. La idea de que entre pares, de vez en cuando se pudieran hablar de algunas cosas. De ir evaluando practicas, chequeando por las dudas. Como está determinado grupo? Y decir como estoy yo con respecto al grupo? Como se están tratando, como los estoy tratando? Siempre pongo a los más altos al final? Siempre hago las mismas cosas?

Escuela de música de primaria, las filas se hacen por sonido. No hay nenas y varones, o altura. Es solo una organización para ir al salón.

Cuesta el cambio.

P: Que bueno esto que decís, de que en la práctica se pueda, poder pensar, poder transformar en el lugar. Me parece re-bueno!

Igual es difícil de pensar, si no está organizado. En esto creo que el Plan podría ayudar. Pero pensando en que.

Perdón, el Plan son unas serie de lineamientos. Pero cada institución es autónoma. ANEP, UDELAR; los diferentes sub sistemas, el MEC pobre

Por ejemplo Martin te podría decir, pero no hay referentes. En primarias por ejemplo, no hay una dirección de ddhh de primaria. o de secundaria. Sino lo que hay es solo una dirección de ddhh de ANEP, donde cuando decís :"quien es mi interlocutor, o mis interlocutores en los distintos sub sistema?"

Y no queda muy claro ¡!! Y ddhh, ¿Y cómo lo ves? Como un contenido, como qué? Que tipos de tema tengo ahí? Porque tenes que delimitar de última, sobre todo cuando estás hablando del Estado, tenes que decir que funciones va cumplir!

Entonces claro, Me parece más complicado armarlo. Pero una vez que lo armaras, desde el Plan pensar, como poder pensarlo para esto otro.

Porque cuando estamos hablando en talleres de revisión de la práctica, es posibles que siempre precises alguien externo. Algún equipo. Porque te cuesta mucho más verte a vos mismo!!

No psicólogos!! (risas) No te estamos buscando trabajo Ana Laura

Pero como educadora en ddhh!!

P: Esto de los equipos externos, que puedan aportar para la tarea. Es bien desde otra concepción de educación, que no es desde la educación instrumental, que hablábamos al principio. ...

\section{Tanto en la formación}

Que tengan ese potencial transformador profundo cuestionador, desde la propia práctica, no solo desde los contenidos. 
Hay una mal prensa de los ddhh. Sobre todo en los mitos de los niños que se hablan de los derechos y no de los deberes. Entorno a los mitos hay muchas otras cosas. Hasta donde se puede reconocer la autonomía de un niño porque puede..., como lo dejo participar?...

Es cierto que a veces se refuerzan más los derechos que los deberes, pero no son los mismos, no son la contra partida.

El docente no se ve como el obligado frente al derecho d educación de los niños. Si desde la Ley la centralidad la tiene el estudiante, la obligación la tienen los adultos. Y sobre todo el docente pagado por el Estado, para dar la clase. Por más allá que el docente tiene sus derechos laborales, y que los niños no lo pueden tratar de cualquier manera.

Hay un montón de estereotipos que sería bueno poder conversar, pero en otros ámbitos, como puede ser el propio centro. Estamos muy poco acostumbrados a la evaluación entre pares, seguro es para ponerte una mala nota. Quién sabe qué? Hay una tradición en el Uruguay, si viene una inspectora a ver tu clase, si es en la primera inspección no te puede poner más de tanto. No te va preguntar nada más que sobre el programa, no te va preguntar nunca, cómo te llevas con los gurises? Como te tratan?... hay cosas que no van a estar nunca presentes. Es como la cosa de, "yo me las arreglo como puedo y ya está!".

No sé, es como muy particular la educación, capaz que estoy hablando mal de la enseñanza secundaria. Donde es más solitaria que primaria. hay escuelas que coordinan un poco más. 


\section{Entrevista a Luis Garibaldi}

Director de Educación del Ministerio de Educación y Cultura (MEC)

Martes 7 de mayo 2014.

\section{P: ¿Cómo pensas que se está realizando la concreción de la transversalidad de la EDH en el sistema educativo, $y$ en especial en primaria?}

.... Una forma de estudiar eso, es partir de una hipótesis o de una pregunta. En realidad, del punto de vista normativo, del punto de vista programático, del punto de vista de las orientaciones, la Educación en derechos humanos (EDH) está contemplada. Sin embargo desde la definición formal, normativa, teórica, a la aplicación práctica hay una distancia grande!

P: esta es mi hipótesis de trabajo ...

Te va venir bien contrastar!! Aunque agarres 3 casos de escuelas. Lo que tendrías que agarrar es una escuela que si dice que trabaja en EDH. Otra que no dice. O 2 que si dicen que si y 2 que no?

Y ver los que dicen que si hacen, realmente hacen lo que dice la ley? O que es lo que hacen cuando dicen que trabajan en EDH. Y los que no dicen nada, ¿a ver que hacen sobre EDH y DDHH?

Y ahí si hay una distancia. El programa es importante...La definición teórica, entre la normativa, la (habitación- imitación) y la realidad.

Bueno ahí es donde tenemos mayores dificultades, porque. O se trabajar sin tener conciencia que se trabaja. O cuando se trabaja con conciencia se hacen actividades más reducidas.

Se reduce el concepto de ddhh a algún derecho en particular. $\mathrm{O}$ en algún tipo de actividades en particular y no se lo transversaliza a las demás, en realidad.

P: esa es un poco mi hipótesis de trabajo. Que en la práctica queda un poco a criterio de cada docente: ¿Qué se entiende por transversalización y como lo pone en práctica?

El problema que tenemos cuando hablamos de líneas transversales, que no tienen todavía una adscripción estricto gramática especifica. Es, que la transversalidad cuando no tiene un ... puede no quedar en nada. Puede quedar vacía de contenidos, sino aparece en algún lado en particular. 
Otras veces, se dice: “ pero no, por esa misma razón es que es importante que aparezca explícitamente, en el programa”. Pero también cuando aparece explícitamente ayuda, pero la puede reducir a determinados contenidos, a determinadas actividades, o por ejemplo en el caso de secundaria y sobre todo en formación docente, en la responsabilidad de alguna asignatura o docente en particular, y pierde ese carácter transversal. No es sencillo en todas aquellas áreas que son más bien transversales, cuando no se planifica y no se trabaja de manera interdisciplinaria, que es parte de lo transversal.

Pero también te diría que es una dificultad producto del enfoque de las prácticas educativas. Mas enfocadas sobre los contenidos, y no sobre una mirada global y partiendo de la realidad.

Bueno si en la realidad, ubico a los ddhh desde una forma transversal y veo la realidad y camino desde ese punto de vista, vas a encontrar vinculaciones con más de una asignatura y acciones diferentes.

\section{P:A ti te parece que esto es la gran dificultad que están encontrando para la transversalidad, es el enfoque de las practicas, como se están entendiendo y como se están dando.}

$\mathrm{Si}$, si creo si que ese es el problema más grande. Como se están dando. Te digo que no se ve solo en este caso de EDH, también se ve en el caso de educación ambiental. Que también es transversal.

En otras, como ser las líneas transversales que plantea la Ley de educación, te diría que es en esas 2 porque son más interdisciplinarias que otras.

Por ejemplo la educación artística tienen algunas dificultades también, pero yo te diría que no son tanto de ese tipo. Porque en realidad perfectamente esas líneas pueden ser desarrolladas por algún tipo de docente a nivel de secundaria. O los maestros pueden tomarlas como practicas específicas y planificarlas como practicas especificas.

A ver, son transversales porque tienen que desarrollarse a los largo de todo el sistema educativo, en todo los niveles. Pero no es tan fácil de ubicar en un lugar especifico.

Lo mismo la educación física. O lo mismo la educación para la salud, o la educación sexual. También lo mismo con la educación científica o lingüística. Encuentran un lugar o, se pueden desarrollar políticas... pero estas 2 que son efectivamente transversales, que son efectivamente inter y trans disciplinarias. Bueno, ya es más complicado! Porque quien se encarga?

Bueno los maestros, en el magisterio tienen una ventaja que hacen una planificación global y general. Y ahí pueden incorporar. Pero la

La ley por ejemplo lo que hace, lo que plantea la ley, en realidad, es la aparición de la EDH aparece en más de un lugar.

Primero aparecen los ddhh como un eje, como fundamento de la propia Ley. En primer lugar los ddhh en general y en segundo lugar en la educación como un derecho.

Después aparece la EDH, como un derecho en si mismo, como una línea transversal, y que en algunos aspectos, hay quienes plantearon, cuando se discutió esto, que engloba todas las otras líneas y todos los otros derechos.

Y después aparece específicamente, como una forma de aterrizarlo. La creación del la comisión. 
Desde ese punto de vista, diríamos que la ley es muy coherente y, muy completa en ese sentido. El enfoque es el mismo en toda la ley, sobre ddhh. Y después establece contenidos específicos y después crea una comisión para aplicar. Y además aparecen luego en distintos ámbitos la idea de los derechos de los educandos, de los docentes, de las familias.

También esto se vio reflejado o en paralelo con la creación de distintas instancias de los organismos de educación. Por ejemplo en la ANEP, la creación de la Dirección de ddhh, la creación de ddhh en el Ministerio. Que fueron generando también instancias.

En las prácticas en particular la situación varía bastante. En primer lugar, por lo que te decía, porque las mismas no están sustentadas en estos! Y además es lo más difícil de cambiar. Las prácticas no se cambian solo con la normativa.

No es sencillo hacerlo desde la óptica de los ddhh, con una mirada global. Que eso es otra cosa que tenes que hacer. Cuando me refiero a global es que los ddhh durante un tiempo... ya estamos mejor ... fue cambiando,... pero sobre todo todavía nos queda separarla, como ddhh concepto de estudio de los hechos de la historia reciente. Esto es de los temas que... estamos mejor porque se ha avanzado en las definiciones y, ... pero todavía incluso para el debate político y publico. Todavía ddhh es sinónimo de violación de derechos, más que de educar, educación promoción en ddhh, para el ejercicio de ddhh.

EDH, contiene los valores de los ddhh, los valores universales más consensuados están allí.

Eso fue una discusión que se produce en la propia ley. Cuando se discutió la ley, se discutió donde aparecen los valores. Es que en realidad están en los valores de los ddhh, es una forma distinta de verlos. Una forma más que de los valores individuales, de los valores colectivos. Eso también aparece en el debate y, en el debate con la ley. Y sobre todo algunas observaciones que desde la derecha se hicieron, fue sobre este tema.

\section{P: en ddhh?}

Si en esta parte. Cuando se discutió hubo gente que digo que no aparecen los valores. Y en realidad el enfoque la ley no es negar los valores, sino más bien considerar que esos valores universales, integrados desde la óptica de los ddhh.

Claro, eso es desde lo teórico. Esa es una discusión. La otra es la de los ddhh. Hay que tener en cuenta que la ley fue elaborada entre el 2006 y 2008. Cuando se voto en el 2008. También fueron años de mucha discusión del tema de los ddhh. Y en la educación sobre el pasado reciente. Que también era todo o nada. Una problemática que estaba muy presente.

\section{$P: ¿$ Te parece que las practicas toman a la ley como un referente? O la normativa está quedando por fuera de las practicas?}

La verdad que es una percepción un poco arriesgada, yo no puedo ... de hecho uno ve los reflejos de las practicas, lo que me cuentan otros. Yo te diría que en principio, los docentes y los maestros no toman la ley como un referente. Si toman la transmisión de los organismos y los programas.

Ahí si la ley incidió!! Incidió como habilitador más que, entre los cuadros de conducción de la política educativa y entre los cuadros técnicos esta visión de los ddhh esta aceptada. Con mayor o con menor fuerza, con mayor o menor comprensión y entusiasmo, pero esta aceptada y compartida. Por lo tanto se expreso y se expresa en muchos aspectos, en prácticas, en programas. Sin embargo 
no puedo decir que los docentes, particularmente los maestros, tomen la ley como una referencia. Probablemente suceda, yo lo he visto, que aquellos docentes que quieren trabajar en estas cosas, se respaldan en la ley. Pero no necesariamente es la ley que permitió hacerlo. Son gente que trabajaba igual y que va trabajar igual con esa óptica si se queda con el respaldo, más respaldado.

Vos lo vas a ver. Es una entrevista más. Arriesgo esta opinión. No puedo decir que efectivamente es cierta, porque no tengo elementos para...

P: ¿Qué acciones pueden hacerse o se han hecho para habilitar una transversalización de la EDH, y que esta sea cada vez más real en la practicas educativas? Para que la EDH llegue realmente a los ámbitos educativos?

Lo que pasa es, yo te diría que hay 2 tema. Uno lo que te decía hace un momento, el desarrollo de practica más integrales, más basadas en la problemáticas y en la realidades, verdad. Y que de alguna forma insisten más en esta visión de los derechos

Y la otra es el desarrollo de las actividades que promueven el ejercicio de los derechos en los centros educativos. Particularmente me parece que todo lo que tiene que ver con el funcionamiento de los Consejos de Participación creados en la Ley. Más allá que no es EDH explícitamente el hechos de tener ámbitos de participación democrática en los centros, es parte del ejercicio de derechos y por lo tanto del aprendizaje por la vía de los hechos.

Si experiencias significativas en participación democrática y de ejercicios de derechos. El derecho a opinar, el derecho a participar, el derecho a recibir educación de calidad, el derecho a tener un ámbito de intercambio entre los diferentes estamentos. Y me parece que esto no se ha logrado suficientemente.

Primero que los centros educativos lo vean como una oportunidad para el ejercicio de derechos. Muchas lo ven como una mera instancia que hay que cumplirla porque reglamentariamente la Ley la indica. $\mathrm{O}$ en aquellos lugares que van más allá de esto, parece que los hay, quienes los toman como una forma de darle participación a la comunidad. pero todavía no como un aspecto central o sustancial de la política educativa, sino más bien como una política lateral. Como antes se armaban la Comisión de fomento, ahora se convocan a la Consejo de participación.

Pero ahí son mejor que los primeros. Hay un sector del magisterio que la dirección dice: voy a constituir el Consejo de Participación, voy y lo constituyo porque lo dice la Ley. Hay otros que además creen que es una buena instancia de participación, pero como algo lateral. Y después hay otros, que son muy poco me parece a mí pero existen, que lo toman como algo sustancial, central dentro de su proyecto educativo para que funcionen más democráticamente, a la realidad del centro. En estos es en los que nos tendríamos que vasar para que esto sea efectivamente esto fuera una política de democratización efectiva.

Hay otros antes que ni siquiera cumplen con la construcción del Consejo. Hay de todo. O más bien se basan en una constitución anterior.

La escuela de mi hijo el primer año, la directora lo constituyo, en nivel 1, vamos a decir. Al año siguiente retrocedió, porque ni si quiero lo convoco. Este año la directora dijo que si pero todavía no lo convoco. Son esas situaciones que vos te das cuenta de que están más que en funciones de cumplir (con el sistema). A mí me parece que eso ayudaría a trabajar sobre la base de un concepto de derecho. Es un derecho para los niños, para los padres, 
Yo soy muy defensor de esta idea de la EDH no como una idea de enseñar, sobre el dictado de clases. Sino más bien de enfoque y por lo tanto de ejercicio, y de vivencia de ejercicio de los derechos. Eso educa más que cualquier clase de ddhh. Una escuela que sea democrática, participativa, que respeta los derechos de los niños, que los niños tienen derecho a tener la palabra, los adultos también. Hay mecanismo, hay normas y reglamentos que regulan esos reglamentos que se respetan y se cuidan.

Tenes escuelas que son abiertas, con un buen dialogo con las instituciones, con la comunidad me refiero. Que se parece más a un enfoque de derecho.

P: ¿No hay ningún programa o política que ayude a que los Consejos se empiecen a efectivizar?

No.

\section{P: ¿Entonces depende un poco de cada dirección?}

No, hay lineamientos y una normativa que establece, desde los propios Consejos se establece la reglamentación previa, hay circulares, hay. El Consejo de Educación Inicial y primaria cuando te reúnas con ellos veras que una de la línea de trabajo de este año son los Consejos de Participación.

Lo que sucede que más allá, lo de la forma la apropiación varía mucho, no!

Todas las escuelas tienen que tener Consejo. A si algunas reducirán el nivel 0 , pero eso del nivel 0 , pasaran recién al 1 , lo constituirán formalmente y recién después trataran, .

Estamos hablando de colectivos muy grandes, y muy diversos. Además no es lo mismo en Montevideo que en el interior. Dentro de Montevideo no es lo mismo en distintas zonas. El propio interior es diferente. Una cosa son escuela rurales y otra las urbanas. Las escuelas de práctica. Hay variedades, variedades de maestras!

P: de enfoques i si vos decís que el enfoque interdisciplinarios, integral es una dificultad para las practicas? Este enfoque es diferente en cada equipo docente, y más en los que están formados en otra concepción, el trabajar con tanta cantidad de colectivos y de opiniones y voces, ¿no es fácil?

Yo creo que predomina en esto, es más que tener un enfoque de EDH. Es... Hay maestros que trabajan en EDH. Como una actividad más. Y hay maestros que creo que son pocos, que le dan un enfoque a su trabajo. Creo que vas a encontrar en algunas escuelas que lo vas a encontrar como proyecto de centro. Pero en realidad lo que nos falta, es que el enfoque es general... sea cual sea el proyecto que tomo la forma de trabajo, el enfoque sea es, de manera explícita.

Podemos encontrar instituciones que hacen cosas muy interesante en función de EDH, pero en realidad es explicito, no saben que están haciendo eso. No sé si me explico! Y esto no les permite dar más valor, al fin.

Eso es un poco mi percepción de un lugar, que insisto no veo las practicas cotidianas, más allá del trabajo con las autoridades, más allá del contacto con docentes, como padre.

$P: ¿ Q$ ué verías como necesario para empezar a trabajar con ese enfoque? 
En educación en general, en estés tipo de cosas menos. No hay una acción única. Lo que si es necesario es que todas las acciones sean coherentes.

En el plano, me parece bien la decisión que tomo la gente que está trabajando en el Plan de EDH, de pensar en la elaboración del Plan como meta. Y plantear que el proceso de elaboración del Plan sea un proceso participativo. De debate y de reflexión! Porque me parece que eso ayuda, a la construcción y, probablemente a un Plan más lento, que se elabora con menos rigurosidad, probablemente, pero con mayor arraigo y mayor penetración y, empoderamiento social. Eso me parece que ayuda.

Lo otro que me parece que ayuda. Que también hay una línea de trabajo importante en esto hace un tiempo, es promover políticas de elaboración de proyectos, a nivel de centros educativos, a nivel de clases. Y una mirada más integral y, más interdisciplinaria. Esto generalmente ayuda porque la transversalidad no la podes lograr parcelando. Y lo otros, es lo que te decía, el promover la participación en los centros educativos.

La formación docente, por supuesto tiene que intervenir. Pero hay que tener en cuenta que los docentes, se terminan de formar en la práctica. Por lo tanto una incorporación de estos temas, de esta tematica en la formación permanente de los docentes, también es importante. Yo creo que hay tenemos una dificultad porque todas la formaciones están muy pensadas desde algunas áreas en particular y no desde una mirada integral.

Pero bueno, si hay una tendencia desde el Consejo de Primaria y, de los Consejos en particular a promover el trabajo en propuestas integrales. Ahí hay como una orientación, que esto después se cumpla en la realidad, hay un salto.

\section{P: los que trabajamos en instituciones educativas vemos que si esto está entrando. Pero entre el juego de lo instituido y lo instituyente... este tema está todavía muy en lo instituyente...}

Hoy te diría que lo que hay es más habilitación para que se cumpla y orientaciones que realidades. Hay avances en este sentido, hay un camino pero todavía falta mucho, para que esto tenga la profundidad suficiente.

\section{P: para vos lo importante es trabajar sobre la práctica misma, sobre la experiencia.}

$\mathrm{Si}$, sobre el centro educativo como eje, más que sobre el docente como eje.

La formación docente importa, está muy bien, pero si vos tenes Centros educativo que sus prácticas va por lado diferente, los docentes terminan absorbidos por... los estudiantes, los nuevos docentes, terminan absorbidos por prácticas ya instituidas.

\section{P: Formación?}

Lo que pasa es que vos formas docentes que trabajan en determinados centros educativos, la tarea no es tanto de formación docente sino del Sistema educativo. Porque está bien, que vos podes tener líneas de acción en formación docente que contribuyan a esto. Pero ahí la clave está en el tema, en el consejo. ¿Cómo desarrollas practicas que vayan constituyendo verdaderas comunidades de prácticas, y que tomen verdaderas acciones colectivas, que tareas y acciones individuales. 
A nivel de las autoridades y a nivel de las políticas, esto ha ido avanzando mucho. En las definiciones y acciones particular. Después es más difícil traducirlas a la realidad, porque a veces hay algunas situaciones de funcionamiento o logísticas que no se lo permite. Cosas que no te ayudan. Colectivos docentes incompletos, rotación, cambios de direcciones... todo este tipo de cosas no contribuyen a este tipo de actividades. A veces formaciones que no están pensadas tanto para los colectivos sino para los individuos. Ese tipo de cosas no contribuyen.

De todas maneras hay otras líneas de acción, que se vienen desarrollando por este otro lado. Algunas formaciones en servicios pensadas colectivamente. La creación de espacios de debate de los docentes pensado en este tipo de cosas. La de promover políticas de que cada centro tenga su proyecto educativo. Que lo discutan colectivamente. Todas esas cosas ayudan. De que en los Consejos de participación tengan que conocerse los proyectos de los centros educativos. Esas son las líneas que contribuyen. Las otras son como una matriz FODA como...

P: ¿vos ves que dentro de las autoridades y, a nivel técnico está bastante acordado, así como algunos docentes. Y que lo que falla es el sistema?

Son las prácticas las que fallan, y eso tiene más que ver con la tradición, que con las instituciones. Las instituciones acompañan las tradiciones.

A nivel de autoridades, yo te diría que va bajando el nivel de compromiso, de entusiasmo y, de convicción, con respecto a esto.

\section{P:en relación a la EDH}

Seguro. Va bajando proporcionalmente. Me refiero que las autoridades hay un compromiso, los niveles técnicos mayores también. Pero los técnicos intermedios son más variables. Hay algunos que si, otros que más o menos y lo que no. En los directores te pasa lo mismo, hay unos que si, otros que no, algunos más o menos. Se va diluyendo de alguna manera el nivel de compromiso. También tenes maestros que pasa lo mismo.

En el caso de primaria, que va ser el que vas estudia vos, esa línea importa porque hay un nivel de reconocimiento de aceptación de que eso me sirve, vale. También es cierto que los maestros no siguen tanto las orientaciones de... o no se apropian de las orientaciones, las toman en cuentan, las aplican. Pero cuando se apropian de algo, se apropian más por convencimiento y no normalmente no porque les llegue de la inspección, sino porque les llega de otro lado.

Los maestros que trabajan más en $\mathrm{EDH}$, no es porque este en el programa o porque este en la ley, sino porque les interesa, tenga una convicción. Y aprovechan esta normativa que los habilita a trabajarlo. Y aprovechan el programa para hacerlo.

La verdad es que no vienen en las prácticas y las instituciones no tienen la fuerza para transformarlas. Está pensada para reproducir prácticas ya existentes.

P: un poco como decía Perico, "estamos mal educados en ddhh" y cuando nos tenemos que enfrentar a una situación lo primero que hacemos es tratar de enfrentarlo o resolverlo como lo hicimos antes, $o$ lo hicieron con nosotros.

... en realidad un docente cuando se enfrenta a situaciones nuevas o desconocidas, normalmente lo que aplica, es su experiencia como educando. Por lo tanto vas y transferís lo que aprendiste, cuando 
aprendiste. Porque es lo que tenes a mano. Lo otro implica un proceso de desconstrucción de lo ya existente y ahí, la necesidad de lo colectivo y la necesidad de la reflexión.

Desconstruir practicas añejas, inconscientes, sino es a través de un proceso de reflexión y de visualización de cuáles son las dificultades.

Vos decís mi experiencias, te estoy hablando de hace unos cuantos años, yo soy director en una escuela. Te estoy hablando de hace 14 o 15 años. Es que estamos en escuelas que no son democráticas. No se escuchaban las voces de los niños. Hay maestros que se horrorizaban!! Claro nadie se siente anti democrático!!! Nadie quiere parecerse a ser un autoritario y un dictador. Ni que lo sean de manera explícita o consciente. Pero de laguna forma vas transfiriendo esa propia experiencia. Eso es lo que es muy difícil de cambiar y bueno.

Por eso me parece que hay que ser explicito en las políticas para que ayuden a que eso cambie y se den instancias de reflexión y de trabajo conjunto.

\section{P: te agradezco}

Los cambios que sufrió la sociedad en cuanto a postura de género, que han sido muchos, importantes y, insuficientes todavía. Pero una forma de hacerlo que ello se fue haciendo visible. Hay gente que le molesta que hablemos de ellos, ellas; los las; es cierto que es muy molesto, aburrido, sobre todo si lo lees. Pero tiene una gran ventaja es que vos haces visible la situación. Vos lo planteas, está hablando así, o está escribiendo de esta manera, tratas de no incurrir en errores de género. Cuando aparece el tema de la cuota. Más allá de los resultados que hayan tenido o losa grados de acuerdo o no, la cuotificación en el saso de las mujeres o en el caso de los afrodescendientes. Ayuda a no solo en el resultado de dar cuota si no el hecho de visibilizar una situación de reflexionar y discutir sobre eso. Eso ya empieza a desnaturalizar lo que parece natural. Natural que las mujeres no participen, solo en las actividades del hogar, a que el lenguaje englobe a todos, a que los hombres representen a las mujeres, y por lo tanto que el lenguaje masculino represente a lo femenino.

Vos al desnaturalizarlo, ayudas a que ese debate se presente y se empiecen a generar cambios de actitudes. Eso es lo que vos queres, sobre todo en ddhh. Cambios de actitudes y de forma de ver la relación con los otros. Eso me parece que es la forma. Por eso hay que explicitarlo, en las temáticas más allá de los grados, de cuanto logres en sí mismo. Ya el hechos de plantearlo y presentarlo.

Acá respetamos los derechos ... cuando lo planteas, nadie es violador de ddhh por definición, salvo casos excepcionales en la historia y en la vida. Que lo sean y además ser consciente de eso, o incluso en los fundamentos.

Entonces si no lo explicitas para los demás, no hay personas racistas, no hay personas que discriminan a los pobres, no hay discriminación por género, no hay nadie anti democrático, somos todos, fuimos tan formados con el imaginario de la homogeneidad y la igualdad en el Uruguay.

Y en la escuela más. La escuela cree, además el concepto de igualdad pego muy fuerte, todos somos iguales! Y por lo tanto a todos tratamos igual, y todos somos iguales y no hay diferencias. Cuando vos escarbas esto a profundidad te das cuenta que no es así. Cuando vos te das cuenta, en realidad la gente no cree, los maestros no creen que somos todos iguales, pero sí que hay que tratarlos a todos iguales. Ahí entra la gran diferencia.

Si vos pensas que no son todos iguales, ¿Por qué entonces hay que tratarlos a todos iguales? 
No tendrías que pensar algún tipo de forma de actuar sobre ellos de manera distinta, de acuerdo a sus diferencias?

Alguno para compensar esas diferencias, otros para respetarlos, no sé. Hace muchos años, como 20 años, participe de un seminario de Educación y Género, participe 2 años seguidos. El 2.do año para no ir con el mismo registro de siempre hice una pequeña encuesta con maestros, ¿Cómo veían a los niños y a las niñas en las clases?

Me costó incluso a mí, interpretar esa encuesta. Lo que me daba como resultado, normalmente los maestros veían que había diferencias, en como actuaban niños y niñas. Pero les preguntabas ¿si tenían en cuenta esas diferencias? Los trataban a todos igual.

En la escuela está muy metido eso de tratamos a todos igual. Pero en realidad, hay que tratarlos para que todos tengan las mismas oportunidades, con el mismo respeto por ser seres humanos, pero todos son distintos. Tenes que buscar la forma de tratarlos a todos diferentes, sabiendo que queres generar una mayor igualdad en las condiciones. Ahí es donde, no quiere decir que si preguntabas como se portaban, las niñas y los varones, si habían diferencias... pero cuando pregunte ¿tenes en cuenta las diferencias a la hora de planificar? Normalmente no! ¿ no porque razón o fundamento? Porque son todos iguales!

Se sienten bien ¿? Si claro porque es lo mismo una niña o una varón para mí. No hay diferencias!! No. No hay diferencias!

Ese es el asunto!! Hay que verlo de ese lado, si hay diferencias son para equilibrar cosas. Otras no. Es complejo e interesante, para hacer visibilizar esas situaciones. Porque la gente, los maestros no son conscientes, los seres humanos no son conscientes de eso. Lo toman naturalmente, porque está en el Habitus, porque está en lo hegemónico de lo dominante. Está ahí. Me parece que la educación tiene que hacer visible alguna de todas esas cosas!

Lo de género, una anécdota y término con esto. Yo tenía un primero de escuela, estuve todo el año intentando si podíamos hacer filas mescladas de niñas y varones. No había forma, volvían siempre. Entonces un día dije pasan primero la niña. Y porque primero las niñas. Las niñas porque siempre han sido discriminadas por esto y aquello, entonces le vamos a dar la oportunidad de ser primeras en la fila. No fundamentado todo, .. Entonces me dijeron uy maestro yo me voy a cambiar de clase!! Jajaja

Claro para hacer visible algunas cosas, porque para hablar de diversidades, hablamos ... claro que conservamos algunas tradiciones... No se trata entonces de perderlo por ... sino de discutirlo, conversarlo, porque para cambiar lo natural tenes que primero hacer notoria las diferencias discriminatorias .....

\section{Entrevista a Fernanda Blanco}

Dirección de Educación -Ministerio de Educación y Cultura.

Integrante de la Comisión Nacional de EDH (por MEC), asesora del SNEP.

Martes 13 de mayo 2014.

En la conversación previa a la entrevista, se explicito brevemente algunos elementos de indagación que hacen a la investigación de tesis... 
Como tu bien decías la educación como derecho humano, yo creo que el marco de la Ley de Educación, es eso un marco, legal y jurídico que nos habilita. Que no nos promueve a generar más instancias, más situaciones, e institucionalizar de alguna manera.

Yo no te diría la EDH, sino más bien los DDHH en la educación. La educación como ddhh en sí mismo y, si la EDH como otro derechos humano también. Previo a plantearnos el tema del plan. Sabemos que la ley de Educación prevé la constitución de la Comisión coordinadora para el Sistema Nacional de Educación Pública (SNEP) que en definitiva si tu lo miras como derecho, también es un paso al frente, también es una medida concreta para considerar la Educación como derechos humano. La coordinación de toda la Educación Pública en aras de una integralidad y una continuidad. No solo de la formación, sino de esa formación integral del individuo, como ser social.

A mí me parece que esto de la Educación como derechos humano, es bien interesante. Hay miradas que pueden entender que para educar en ddhh, primero tenemos que enseñar, entre comillas, instruir, trasmitir.....

Te decía esto, de la educación, la parte normativa. Sin duda es muy importante que el ciudadano, que el individuo conozca los derechos, para a partir de esto, pueda trabajar por el respeto de sus propios derechos y de los otros. Eso está fuera de discusión.

Ahora bien, yo si me preguntas, ¿Qué es en sí mismo la EDH? Desde la accesibilidad, desde la mejor calidad en la educación, desde procurar un ciudadano con un espíritu, mente critica, capaz de reconocer la otredad. Capaz de no solamente, aquello de "no hago lo que no me gusta que me hagan!" No. Si no sentir que somos parte de un colectivo, donde todos tenemos derechos y, hay derechos que no solo no los respeto, Sino que no los practico, no pongo en práctica determinados valores. Esta muy vinculada los ddhh y la EDH con el trabajar en valores. Pero cómo? Fundamentalmente a través de la experiencia misma. A través del ejemplo! Nosotros ahora estamos en momentos donde nos abocamos, socialmente, políticamente hablando como país, al tema de la juventud. Y también de los chicos que asisten a primaria.

Muy bien pero todo ese conjunto de personas, aprender de lo que viven, aprenden del clima institucional. Del clima en el hogar. Entonces la EDH, sin duda ha sido afectada por un avance importante, de que partimos de una voluntad expresa en una Ley de educación. Pasando la Constitución incluso, avanzando más. Eso sin duda es una voluntad de quienes tienen a cargo la organización de un Estado, que es de gran ayuda.

Tú me mencionabas el tema de la formación docente. Cuando hablamos de primaria si no hablamos de formación docente en todos los sentidos. Una buena profesional de calidad, formación docente. Bueno tenemos malos resultados luego, en lo que son nuestras expectativas con respecto, a la infancia y a la infancia escolarizada.

Yo creo que eso hace, que no podamos imaginar la EDH en aislado, como un conjunto de actividades a desarrollar en aula. Que son, y que aporta, y que son muy bien venidas, sin duda. Pero que necesitan estar integradas, a los que nosotros llamamos un Plan Nacional de EDH. Es es el sentido, para mí, más importante de contar con un PNEDH. Un plan que procure establecer lineamientos, sea.. al que se llegue a partir de la mayor cantidad de aportes, de participación, de opinión. No por eso, recogiendo todas y cada una, pero si pudiendo ser lo más participativamente posible. Y no solo entre los actores de la educación. Sino entre los actores de la educación, entre los sujetos de la educación, con las familias, con los ciudadanos, que ejercen funciones públicas. 
Que mejor que formar, embebernos, de una vida en clave de ddhh, para enseñar en la vida misma. No se si me explico, si voy por el lado que tú te estás planteando.

Entonces el PNEDH, proceso participativo de base, para luego establecer ciertos lineamientos. Para procurar discutir sobre la metodología y la pedagogía de la EDH. Por eso digo que trasciende la normativa. A partir de esos insumos y a partir de ese debate, entorno a lo que debería ser una metodología y pedagogía de EDH, un compromiso político institucional, que permita que ese plan sea sustentable. Si no nos quedaríamos en el plano de las aspiraciones, que no es poco, pero no es suficiente.

Que comprometa a la mayoría de actores posibles. Estoy pensando, si claro en los docentes. Pero el docente es un ciudadano, que convive en un ámbito institucional, que también tiene derechos y que también tiene que respetar otros derechos. Pero también estoy hablando del poder judicial, de la policía, estoy hablando el empleado público que atiende al ciudadano todos los días.

Como empezar, bueno si desde la primera infancia, es fundamental. Pero también con esto que tenemos, tenemos que tratar de llegar.

Yo creo, cuando vos me preguntas: ¿te parece que hoy es vigente, que se está trabajando?

Creo que si se está trabajando, se está trabajando en lo específico, en distintas aéreas, y el Ministerio puede dar cuenta de eso. Porque también es muy importante que consideremos la educación formal, y la no formal. Yo creo que todas estas elaboraciones que apuntan a la permanencia en la educación formal, o no formal. A la calidad de la educación, y al acompañamiento de los procesos educativos. Refieren absolutamente y de manera directa a considerar la Educación como un derecho humano. Y a la EDH también como tal.

La formación docente, bueno hemos avanzado. Hoy tenemos seminarios obligatorios en la carrera de formación docente, de ddhh, seguiremos avanzando en eso. Las prácticas son una posibilidad exquisita de desarrollar, lo que nosotros llamamos educación como derecho humano y EDH. La inclusión, el acompañamiento a los niños escolares para que hagan trayectos exitosos, que aprendan a vivir, que aprendan a discernir. Que se les plante también en esa formación, todas las opciones desde el punto de vista de lo filosófico, lo ideológico del conocimiento para que sean luego ellos como ciudadanos para que elijan. La autonomía, entendida en ese sentido, de poder elegir de hacer el bien y no hacer el mal. Saber optar por el conocimiento, por el conocimiento en sí, el interés en ese conocimiento. Y no solamente por la inmediatez que nos acusa hoy, de lograr determinados objetivos. En este sentido estamos trabajando en la Comisión para la EDH. Con representación de las 3. Bueno en realidad también de la UTEC, Universidad Tecnológica, que todavía no ha designado, sin duda lo ha demorado el poner en funcionamiento esa Universidad. Pero bueno UdelaR, ANEP y MEC, tienen sus representantes en esa comisión, en la que tenemos como objetivo, terminar con lineamientos, hacia un PNEDH. Si no poder aspirar a más y llegar a un documento de Plan. Con un proceso de debate, que sea lo más abarcativo posible, por eso los hicimos regionales, invitando a referentes, no solamente de la educación formal. También de la educación no formal $\mathrm{y}$, de referente de cada lugar, por eso también están participando las comisiones departamentales, pueden haber jóvenes, estudiantes, policías. Etc.

En base a algunas preguntas y talleres, estamos tratando de generar los debates, que apuntan fundamentalmente a eso que te decía antes. A 3 preguntas, o 3 ejes: lo normativo; lo teórico respecto a la EDH y a los ddhh, lo metodológico y pedagógico; y por último la sustentabilidad política e institucional. Eso serian los 3 ejes fundamentales. Y entorno a eso nosotros armamos los 
4 encuentros regionales que nos hemos planteado, de debate. También hay un sitio web, donde se invita a la ciudadanía en general a verter ideal, propuestas, documentos. Donde también referimos a documentos y Planes de EDH de otros países. En esa etapa estamos. Para luego con relatorías de todos esos trabajos poder elaborar un documento. Documento que apunta a un PNEDH, amplio, donde se plantee transversalizar. Cosa que suena lindo pero no es fácil. La practicas educativas. Donde se plantee que la educación es para toda la vida. Que nos educamos toda la vida, por eso hablamos de educar en ddhh al empleado público. Al que atiende.

Y que pueda ser evaluado. Y a partir de esa evaluación pueda, de alguna manera reformularse, si es necesario en distintos aspectos. Sería una cosa cíclica o circular, no sé cómo llamarles... pequeña tarea!!!

\section{P: ¿Cómo pensas que se está realizando la concreción de la transversalidad de la EDH en el sistema educativo, $y$ en especial en primaria?}

Sin duda que es importante que en lo áulico se trabaje específicamente, lo que nosotros, tradicionalmente decimos o entendemos por ddhh. Claro que si, sin duda. Pero también es importante, que nosotros trabajemos otros aspectos, otros conceptos. El tema del poder, del ejercicio del poder. Del poder entre el que sabe y el que no sabe, el que enseña y el que aprende. Hoy, en los personal, estoy convencida, que aprendemos de los alumnos, también ellos de nosotros. Pero distintas cosas. En esta interacción es donde se da una verdadera educación en ddhh.

Yo creo que es viable, es posible, es lograble, y que hemos avanzado, aun cuando a veces te preguntas/presentas, que es una ... dame un ejemplo de una situación de EDH. Un acto de EDH. Entonces generalmente puede surgir el trabajar, tal Declaración. Pero también surgen otras respuestas, por suerte. Llevar adelante una experiencia de liceo comunitario, es una experiencia de EDH. La existencia de las "aula comunitarias" hoy es EDH. La experiencia, sin duda de "Compromiso educativo" donde un joven universitario acompaña, procesos que le están resultando más difíciles a un joven liceal, de 15 años, en un proceso de estudio. Donde hay un compromiso de ese joven, de esa familia para con el sistema y para tratar de alcanzar determinadas metas. Eso sin duda, en lo personal, es una preciosa experiencia en EDH. "Transito educativo", el buscar de alguna manera que nuestros jóvenes y niños aprenden diferente, que se aprenden otras cosas. Aceptar que podemos aprender otras cosas. Usar la tecnología como herramienta de vida, y no solamente para busca información. Poder hacer acceder a una familia con el contacto con la tecnología a través de una "Ceibalita" es EDH....

Los docentes están muy defendidos, porque están muy atacados.

Atacar globalmente al cuerpo docente, creo que no contribuye, a que avancemos en este proceso que nos hemos planteado. Y si duda los cambios en educación, y por lo tanto en EDH, llevan mucho tiempo. Son procesos largo, en espiral. Y que no tenemos que resignarnos...

Fuimos formados, yo me incluyo soy docentes, para transmitir conocimiento. Y el hecho de la reproducción de esos modelos y esos paradigmas es lo que nos cuesta cambiar. Con la mejor de las intenciones a veces. Incluso los más jóvenes, uno condena la vejes perce, pero también los más jóvenes lo hacen, porque aprendieron también así. Y porque el conocimiento, la seguridad de poder mandatar. Da seguridad, nos hace temblar que un alumno diga algo que no sabemos. Tenemos que aprender... hay una sociedad que condena eso. No es que no se diga nada!!! Como que el profesor no sabe tal cosa??? El día que podamos convencer a ese profesor que le diga al alumno, no se ¡! 
Explícame tu? O decime tu? Y que ningún papa, ningún director, ningún inspector, ninguna libreta va a condenar eso. Yo creo que va ser un poquito más fácil.

\section{P: ¿Estás dando un lugar a las tareas de Acompañamiento?}

La experiencia de los CECAP (Centros Educativos de Capacitación Profesional para jóvenes que están fuera del sistema formal que tengan entre 15 y 18 años), hace 10 años en este país existían 3 , ahora hay 18. Es una experiencia de acompañamiento de EDH, realmente, a mi modo de ver, bien interesante. Incluso hoy hemos logrado mantener esos jóvenes en ese tema, sino hicimos convenios con el Consejo de Educación Secundaria, entonces esos jóvenes... como era un especie de trato, de que el joven debía volver al liceo y no se cumplía. Entonces el liceo va al CECAP, y esos jóvenes tienen los horarios organizados de manera tal, que en el CECAP, reciben clases para ir cursando materias de liceo. Eso es acompañamiento. $\mathrm{Y}$ creo que creer que todos y cada uno de nuestros niños y nuestros jóvenes son capaces de aprender. También es un pasito que nos falta concretar, estamos ahí! Apoyarnos en que todos pueden aprender de distinta manera, distintas cosas, para distintos objetivos.

Venimos de una tradición de un país que forma, y educaba para terminar el liceo y, de ahí para al la universidad. De alguna manera es una concepción un tanto elitista, que dejaba mucha gente por el camino. Y socialmente mal visto el no ir a la Universidad. Nosotros tenemos que seguir trabajando, y creo que como país, fuimos dando paso en los últimos años, en educar para la vida y también para la libertad de opciones. De desarrollar actividades, ocupaciones diversas que nos den satisfacción, y no solamente el reconocimiento social del ser, entre comillas, universitario.

Por el lado de la inclusión, aunque nos cuesta, hemos logrado que vayan muchos jóvenes, en la educación media (la primaria esta universalizada). Eso es un paso gigantesco que por supuesto afecta los climas institucionales y las practicas. Nos queda mucho por hacer, ...

\section{Entrevista a Irupe Buzzetti}

Consejera del Consejo de Educación Inicial y Primaria (CEIP) Administración Nacional de Educación Pública (ANEP)

Lunes 30 de junio 2014.

Esta entrevista se realiza en la semana donde hubo un incidente vandálico en una escuela de Montevideo, incendiaron un local escolar el cual genero un indignación en el barrio.

Explicación de por qué se solicito la entrevista, se explicito el objetivo de la tesis de investigación. Y se comento que Héctor Florit (Director del CEIP) nos recomienda que la entrevista la tenga con ella, que es quien conformo el equipo que realizo el programa de educación inicial y primaria (2008), en vigencia actual.

De hecho la comisión central, lo primero que hicimos fue, cuando se hizo en el 2007, las primeras entrevistas, que hicimos para hacer el programa fueron: a Marta Demacri, y... La primera fue al maestro Miguel Soler. Y la segunda fue a Marta Demacri, entendieron que nosotros queríamos un 
programa que tuviera debajo el paragua de los derechos humanos. Ahí lo que se trato era de pensar a la educación como una opción ética y política, política digamos de la educación.

$\mathrm{Y}$ en este marco todas las disciplinas que se trabajaran, las áreas de conocimiento tenían que tener un enfoque sobre este sujeto a educar en los derechos de primera, segunda, tercera y cuarta generación.

De hecho el programa tiene un fuerte encare a lo que hace a la construcción ética, a la construcción de ciudadanía. No es un área de conocimiento, sino que es un campo disciplinar de las ciencias sociales. Porque eso fue lo que dio más trabajo en el programa 2008. Nosotros queríamos armarlo desde los 3 años. El programa va desde los 3 años hasta 6to año. Nosotros queríamos armarlo en 2 partes.

Aquí trabajo con nosotros, orientándonos: "Cullen ”, el argentino. Porque nosotros queríamos una parte que fuera: la ética; a la moral del niño y a las morales, digamos de la sociedad donde vive el niño. Y otra parte que, si vos vez el programa está hecho así, el derecho.

Si yo estoy trabajando por ejemplo, el trabajo, desde los que es el trabajo desde los 3 años, el trabajo en la casa desde la responsabilidad del niño, el trabajo del niño como colaboración, y como explotación. Yo tengo que saber que leyes hay para que ese niño sea protegido.

Así fue tomamos ese trabajo como también te digo, el eje transversal de la educación sexual.

Si vos miras el programa, te da para trabajar que es la opción sexual, la orientación sexual en 5to y 6to año, y vos llegas, que actualmente ya esta desactualizado, a lo que hay de leyes para esa persona. Llegamos al cambio de nombre, hoy tendríamos que llegar a la ley de matrimonio igualitario.

Entonces digo, porque eso costó mucho trabajo? Porque tuvimos que trabajar: en la parte de la ética; hubo que trabajar con profesores de filosofía. Y en la parte de derecho, con profesores de Derecho

....(interrupción celular)

A los profesores de filosofía les costaba poner contenidos. Que contenidos les pondrías vos a un tema como el trabajo? entonces de esa manera se fueron poniendo contenidos! ¿Qué contenidos le pondrías a la violencia? Que era un tema ético!

Recién estábamos hablando de un incendio en la escuela. Tema ético! Más allá de todo el enojo que puedas tener con una maestra o un adulto. Enviar a otros para que destruyan algo, es un problema que pasa por la ética. Atacando la moral de toda una comunidad. no solo de la comunidad adentro de la escuela sino la escuela.

Entonces era muy difícil para los profesores de filosofía, transformar en contenidos, lo que pasa por un discurso. Eso nos llevo mucho trabajo, la gente cuando lo mira. Yo a veces digo, no lo ve en la real dimensión que tuvo, es programa de ese campo disciplinar. Porque ese campo disciplinar apunta exactamente a todos los derechos.

El derecho que hace a la educación ambiental, perfecto, Es un derecho de cuarta generación. En esos derechos humanos, ahí vos tenes la educación ambiental de los 3 a 6to año. 
Como te decía de la salud, la salud de la comunidad y la salud individual, también es un derecho. Porque si a mi no me importa nada yo estoy repercutiendo con mi falta de cuidado, estoy repercutiendo en tu salud.

Verdad, entonces digo, eso estuvo contemplado y hoy, nosotros para ese programa, para ese texto curricular, lo que tenemos es que lograr una formación en servicio para los maestros que en realidad están acostumbrados a hablar. Pero no están acostumbrados a trabajar desde la filosofía.

Entonces que hicimos ese año cuando nosotros nos reunimos siempre, el poder político del Consejo con el poder técnico, la inspección técnica, los inspectores generales y departamentales. Trabajamos con una profesora, con Marita Bertolino desde la filosofía. Esa filosofía que hay que bajarla al maestro. Porque en realidad, yo creo que se necesita, es un trabajo más profundo en cuanto que al maestro no tome esto como un tema que hay que dar. Sino que lo tome como está realmente en el programa. Los derechos humanos no son para enseñar son para vivirlos.

El programa está en esto, está en ese paraguas. La escuela tiene que servir para eso. Nosotros tomamos el ejemplo de la escuela de tiempo completo. Donde está la convivencia, como uno de los temas a tratar. Que nos pasaba a los que como yo, que fui Directora efectiva de escuela de tiempo completo, ¿Qué pasaba?, que la convivencia se decidió hacer asambleas en el aula, en la escuela toda con los delegados.

Estaba bueno como metodología, pero en la asamblea no hay temas, no hay temas desde el punto de vista curricular. Hoy tienen los temas. Lo que pasa es, ¿estamos todos en condiciones de abordarlos?, ¿estamos todos en condiciones de abordar como te decía sexualidad? ¿en el encare que hay que tomarlo, desde las ciencias sociales?, desde los biológico, el cerebro y los órganos genitales? Desde la educación física que está en el programa, en cuanto a la corporeidad? NO!! Entonces falta esa otra parte, la formación en servicio.

Yo creo que ... la estamos institucionalizando, esa formación permanente del maestro, tiene que pasar también por esto. Hay que enseñar filosofía!! Hay muchos programas de filosofía para niños. Yo creo que una de las probables fallas que tiene la sociedad, es que hay temas que no se trabajan. Se conversan mucho, y se ven en los titulares, pero vos por ejemplo la violencia! Los padres hablan de la violencia?! O realmente en los hechos son violentos?!y por eso los hijos son violentos?

Es un problema de vivir!

Que debería ser la escuela? Debería vivir en ddhh!

Vos en la escuela no podrías admitir papeles, sino tendría que tener una clasificación de residuos para que después eso se derrame a la casa. En una escuela vos tendrías que poder hablar de un hecho casual.

Yo por ejemplo cuando era Directora, los hacía escribir mucho, porque soy profesora de lengua. Escriban porque se pelearon por el futbol, había momento que podían hablar conmigo 2 o 3 varones, "Si ya se, ya lo vamos a arreglar, conversamos un poco y después volvemos". Es decir iban a tener que ir, escribir, argumentar, para que yo me convenciera para ver quien tenía razón. Entonces yo creo que es eso, un problema de vivirlo!!!

Un hecho como el de hoy en una escuela, por ejemplo totalmente vulnerada por un incendio, se transformo en que toda la sociedad, los padres fueron, las autoridades fueron, los maestros se 
mostraron unidos. Bueno este hecho sumamente agresivo, tiene que servir para que? Para un trabajo colectivo. Esto no queda en que vos estudies los valores!

Yo hoy te hable que con las primeras que hablamos fue con Miguel Soler. No en vano, Miguel Soler es parte del movimiento de Educadores para la Paz. Porque, porque no es una entelequia ser un educador para la Paz. Yo creo que un educador siempre es para la Paz. Nadie va educar para la guerra! no? Entonces un educador tiene que tener sistematizado esto. Sistematizarlo desde el aula, sistematizarlo desde chiquitos. Esto que es tan natural en una clase de 3 años, el compartir una merienda, después se corta y cada uno hace la suya. Y eso es lo que te va transformar todo el sistema. Vos no va cambiar de un día para otro.

Va transformando la sociedad, sumamente, con un paradigma individualista. Verdad!

Si tenes una educación en ddhh, nunca poder tener una educación individualista!!

Es lo mismo que te decía a vos, si partis de la base que estas quemando la ma... esta jorobando a otros. ... yo creo que es lo que cuesta, como te lo voy a decir, hacer bisagra.

P: Uruguay está bastante avanzado, en cuanto a la incorporación de estos enfoques de EDH, en nuestra normativa. Uds. me está diciendo que ve, o identifica, como un nudo, la parte de formación docente? Y desde que concepción trabajar, con un enfoque más integral. Para generar practicas educativas que permitan incorporar estos elementos.

Los tenemos...

Practicas educativas lo más temprano posibles. Cuando vos pensas porque el niño tiene que estas desde los 3 años en una educación formal? Y en esto no hay nada que uno pueda decir,..bueno en una educación formal con maestros, con profesionales que estén en todo momento trabajando con el niño en estos temas. Verdad, no desde que leí un cuanto, leí "Arturo y Clementina" y por eso te estoy enseñando genero. Esta bueno! Vos que sos psicóloga, pero no te podas quedar en eso!.

Está bien! Que Clementina era mala porque le regalaba mucho! No!

Esta bien trabajarlo con un cuento, pero no te podes quedar en eso. Hoy lo trabajas con un cuento, mañana lo trabajas con una .... Con ... y evidentemente yo estoy convencida de que cuanto antes empiecen, los niños en la escuela aprenden muchas cosas. Aprenden muchas cosas que tienen que ver con...hasta con la adicciones. El problema es la lucha entre la escuela y la educación que parte fuera. Por eso la escuela tiene que estar continuamente sistematizando, continuamente otra forma de vivir.

Yo no admito que un maestro este gritando, porque es más de lo mismo. Si vos tenes una sociedad donde los chiquilines molestan y cuando molestan, dejaron de usar el aparato, el ipad, y todo lo demás y vos le pegas 2 gritos. Y la escuela replica eso. Bueno el muchachito entiende que vos tenes que pegar 2 gritos para que te hagan caso. Van a terminar en eso!! Es los mismo que el que vive con un golpeador o golpeadora. Son conductas que vos las vivís, las aprendes. Entonces el problema está entre esta lucha entre la escuela y lo que hace la familia y la sociedad. Se entiende?

P: ¿qué acciones o elementos, le parece que falta o que se está haciendo desde el Sistema educativo, para apoya que se concrete estos avances que vienen desde lo normativo, en las practicas y la vida dentro de las escuelas? Para entender a los ddhh de forma integral y como eje transversal de la EDH? 
Yo creo que se está haciendo! Y sobre todo los espacios que faltan son como de tiempo completo. Yo creo obligatoriamente tanto en la escuela de primaria como una institución de educación media, y bachillerato, debería tener un espacio de convivencia. A la gente le falta hablar, a la gente le falta poder discutir y hacerse entender por otro.

Eso que te decía que yo había instalado: "escriba y después cuando lo traigan, yo leo y veo quien tiene razón".... Eso de discutir un poco, después vos los mirabas y estaban en el recreo discutiendo. 6 varones, 8 varones que se habían trenzados minutos antes por un partido de futbol.

De hecho la gente no discute más! Nosotros vinimos de una sociedad muy discutidora que debatía mucho, una sociedad que no es el Uruguay, es el mundo, sociedad que esta mucho con la imagen, lo virtual, con poca conversación. Entonces esos espacios de convivencia son espacios reales. Hay 2 espacios que vos no los podes obviar: uno el espacio de convivencia, espacio para poder usarlo para persuadir y para argumentar, específicamente. Y otro espacio es la recreación.

A la gente le faltan estos espacios, la gente no juega. Y si juega es con una maquina, al preguntado. No juega con otro!. Cuando 2 personas están jugando, vos tenes que estar viendo a tu contrincante. Esa situación tiene que ver con la formación de la moral. Esto no es nada nuevo! Piaget decía ¿Cómo se le forma la moral a un niño? Y se le forma jugando!! Y jugando a perder y a ganar!! No solo se es ganador en la vida! Sos ganador y sos perdedor y de cada una de esas cosa vas sacando, enseñanzas. Pero esto se termino!! Entonces vos lo tenes que volver a implantar. El problema es, en una cultura muy humanista y muy (conteneista) vos dejas de lado esos espacios!

Porque el otro cree que, que esto es light! No! No es light!! La convivencia no es Light!

La convivencia no es light para los muchachitos en un aula. No el Light para los adultos. No es light para tu vida personal. Para nada!!

Porque cada vez se arrastra mas la adolescencia y nadie se va a vivir con otro?

Porque no es fácil!! Implica un monto de situaciones

Entonces ese espacio hay que tenerlo!! Debería ser obligatorio! Como es en tiempo completo el juego y, la convivencia. Yo creo que debería ser obligatorio en toda la educación. Te diría que yo lo llevaría a nivel universitario. Porque no, vos podes plantear un tema, no un tema mañana otro. Un tema con una sistematización!

\section{P: Los docentes están formados para mantener estos espacios?}

Si vos pones un espacio y lo pones en forma obligatoria. Los docentes que trabajan en un sistema, es como los de "tiempo completo". Saben por un acta que tienen que trabajar, juego y convivencia. De hecho ... ¿qué enseño en convivencia? Hace poco yo enseñaba violencia. Hoy ya sabes que esta violencia con tus pares, violencia en la calle, violencia en los espectáculos públicos. Hoy lo tenes sistematizado. 
Anexo IV: Información complementaria al Capítulo II

\section{1- LA EDH EN LAS CONFERENCIAS: ALGUNOS EJEMPLOS.}

A modo de ejemplo de la importancia que empieza a tomar la EDH como estrategia para promover en el ámbito educativo en especial, un espacio de desarrollo e integración social, donde desde la primera infancia se pretende estimular y promover actitudes de respeto y aprecio por los derechos humanos sus principios y valores. Donde esta tarea no solo es visualizada por parte de colectivos u organizaciones, afines con ciertos reclamos sobre derechos humanos, sino el creciente compromiso de parte de los Estados en desarrollar estas estrategias para el pleno desarrollo de sociedades que pretendan una acción coherente con los derechos humanos.

Encontramos en la Conferencia Internacional de Educación de 1994 adoptó los siguientes objetivos en una Declaración sobre la Educación para la Paz, los Derechos Humanos y la Democracia (aprobada por la UNESCO al año siguiente):

"Nosotros, los Ministros de Educación presentes en la $44^{a}$ reunión de la Conferencia Internacional de Educación...

\section{Nos esforzaremos resueltamente por:}

- dar como fundamento a la educación principios y métodos que coadyuven al desarrollo de la personalidad de alumnos, estudiantes y adultos respetuosos de sus semejantes y determinados a fomentar los derechos humanos, la democracia y la paz;

- tomar las disposiciones adecuadas para crear en los centros de enseñanza un clima que contribuya al éxito de la educación para el entendimiento internacional, a fin de que se conviertan en los lugares, por excelencia, donde se ejerce la tolerancia, se respetan los derechos humanos, se practica la democracia y se aprenden la diversidad y la riqueza de las identidades culturales;

- adoptar medidas para eliminar todas las discriminaciones, directas e indirectas, contra las niñas, muchachas y mujeres en los sistemas educativos y adoptar disposiciones concretas para conseguir que todo su potencial se haga realidad;

- prestar particular atención a la mejora de los programas de enseñanza, del contenido de los manuales escolares y de otros materiales didácticos, incluidas las nuevas tecnologías, con miras a educar ciudadanos solidarios y responsables, abiertos hacia otras culturas, capaces de apreciar el valor de la libertad, respetuosos de la dignidad humana y de las diferencias y aptos para prevenir los conflictos y resolverlos con métodos no violentos;

- adoptar medidas destinadas a revalorizar el cometido y la situación de los educadores, en la enseñanza formal y no formal, y dar un carácter prioritario a la 
formación previa y en el empleo así como a la readaptación profesional del personal de educación, comprendidos los planificadores y los administradores, formación centrada en particular en la ética profesional, la educación cívica y moral, la diversidad cultural, los códigos nacionales y las normas reconocidas internacionalmente en materia de derechos humanos y libertades fundamentales;

- fomentar la elaboración de estrategias innovadoras adaptadas a las nuevas exigencias de la educación de ciudadanos responsables, comprometidos con la paz, los derechos humanos, la democracia y el desarrollo sostenible, y tomar las medidas del caso para evaluar las estrategias;

- preparar lo más pronto posible, tomando en cuenta las estructuras constitucionales de cada Estado, programas de acción para aplicar la presente Declaración."

(Declaración y Plan de Acción Integrado sobre la Educación para la Paz, los Derechos Humanos y la Democracia, artículo 2, 44 a reunión de la Conferencia Internacional de Educación (Ginebra 1994), aprobados por la Conferencia General de la UNESCO en su $28^{\mathrm{a}}$ sesión (París 1995))

A su vez la EDH también toma un lugar importante en las estrategias que apuntan sobre temas específicos. Podemos destacar la Plataforma de Acción de la Cuarta Conferencia Mundial sobre la Mujer (Beijing, 1995): donde se identifica a prácticas educativas que reproduce conductas que no son aceptadas $\mathrm{y}$, a su vez se señalan modificación a realizar para combatirlas desde el propio ámbito educativo.

"Los medios educativos viciados por prejuicios basados en el género, como los programas de estudios, materiales y prácticas, las actitudes de los profesores y las relaciones dentro del aula, refuerzan las desigualdades de género ya existentes" (párrafo 261). Las acciones estratégicas recomendadas a los gobiernos incluyen:

"Elaborar y aprobar programas de estudios, material didáctico y libros de texto que mejoren el concepto de sí misma de la niña, su vida y sus oportunidades de trabajo, especialmente en áreas en que la mujer ha estado tradicionalmente menos representada, como las matemáticas, la ciencia y la tecnología...

"Alentar a las instituciones de educación y a los medios de información a que adopten y proyecten una imagen de la niña y el niño equilibrada y libre de estereotipos...

"Fomentar la instrucción en materia de derechos humanos en los programas de enseñanza e incluir en la educación la idea de que los derechos humanos de la mujer y la niña son parte inalienable e indivisible de los derechos humanos universales...

"Elaborar programas y materiales de capacitación para maestros y educadores que les permitan cobrar conciencia de su propia función en el proceso educativo y aplicar estrategias efectivas de enseñanza en que se tengan en cuenta los aspectos relacionados con el género...

"Proporcionar educación y capacitación a las niñas para que tengan mayores oportunidades de encontrar empleo y de acceder a los puestos de adopción de decisiones... 
"Proporcionar educación a las muchachas para que conozcan mejor, desde el punto de vista teórico y práctico, el funcionamiento de los sistemas económicos, financieros y políticos...

"Fomentar la participación plena e igual de las muchachas en actividades no académicas como los deportes, el teatro y los actos culturales..." (Plataforma de Acción, A/CONF.177/20/Rev.1, párrafos 276, 277, 279 y 280)

En cuanto al tema de lucha contra la discriminación, podemos destacar que en la Declaración y el Programa de Acción de la Conferencia Mundial contra el Racismo, la Discriminación Racial, la Xenofobia y las Formas Conexas de Intolerancia (Durban, Sudáfrica, 2001).

"Insta a los Estados a que introduzcan y, en su caso, refuercen los elementos de lucha contra la discriminación y el racismo en los programas de derechos humanos de los planes de estudio escolares, preparen o mejoren los materiales didácticos pertinentes, tales como manuales de historia y otros libros de texto, y se aseguren de que todos los maestros estén bien formados $y$ debidamente motivados para inculcar actitudes $y$ pautas de comportamiento, basados en los principios de la no discriminación, el respeto mutuo y la tolerancia."

..."a que emprendan y faciliten actividades para educar a los jóvenes en materia de derechos humanos, valores democráticos y civismo, y a que les inculquen la solidaridad, el respeto y el aprecio de la diversidad, en particular el respeto a los grupos diferentes. Debe hacerse un esfuerzo especial por enseñar a los jóvenes a respetar los valores democráticos y los derechos humanos, y sensibilizarlos al respecto, a fin de luchar contra las ideologías basadas en la falaz teoría de la superioridad racial." (Programa de Acción, A/CONF.189/12, párrafos 129 y 130)

Así como también la EDH debe garantizar el respeto por todas las creencias religiosas e ideológicas, que fomenten la tolerancia, el aprecio y valoración de las diferentes creencias, como forma de alcanzar estos objetivos.

\section{2- UN CONCEPTO QUE MERECE UNA MENCIÓN ESPECIAL: LA PAZ.}

Los conceptos de la Paz y los derechos humanos, que hoy consideramos asociados, han tenido diferentes abordajes dentro de la Organización de la Naciones Unidas (ONU). El mantenimiento de la Paz, objetivo central dentro de esta organización, está muy vinculado a la idea de ausencia de guerra, así como la concepción de "Seguridad Internacional", para 
lo que se creó el órgano de Consejo de Seguridad de la $\mathrm{ONU}^{98}$. Mientras que la promoción y protección de los derechos humanos, pensadas en ser llevadas a cabo a través del desarrollo de la "Cooperación Internacional", que se organiza bajo la tutela del Consejo Económico y Social (ECOSOC) $)^{99}$. Esto da cuenta de estrategias y concepciones en principio separadas y en los hechos un tanto divergentes. Desde la gestión, las formas de implementarse y las concepciones dominantes que han desarrollado estos dos órganos que están encargados de estos objetivos dentro de la ONU. (SALVIOLI, 1997)

Es en el trabajo que realiza el ECOSOC dentro de la cooperación internacional, que encontramos la relación indisoluble entre paz y derechos humanos, siendo el respeto a la dignidad de todos los seres humanos la plataforma común. "Es en la Carta de los Derechos Humanos (así se enumera el conjunto de la Declaración Universal y los dos Pactos), la Paz se considera sólo sostenible si se asienta en los derechos humanos." (SALVIOLI: 1997: 288).

La UNESCO ${ }^{100}$ es el órgano especializado, que ha desarrollado la relación entre educación, paz y derechos humanos. Donde el encare de la paz se considera desde una mirada vinculada a la educación y la cultura y, no desde una perspectiva geopolítica militar como lo hace el Consejo de Seguridad.

Desde su perspectiva, la UNESCO comprende a los derechos humanos en una dimensión interdisciplinaria e integral. Donde la enseñanza de los mismos no implica únicamente el conocimiento de los textos jurídicos que los garantizan, si no la promoción de un accionar de las personas que permita evitar las violaciones y vulneraciones de derechos y la promoción del ejercicio de una convivencia respetuosa de todos los seres humanos.

Es a partir del fin de la guerra fría y después de la Conferencia de Viena de $1993^{101}$, que la concepción de La Paz aparece notoriamente vinculada a los derechos humanos. No solo

\footnotetext{
${ }^{98}$ Consejo de Seguridad. Capitulo V de la Carta de las Naciones Unidas, proclamado en la Conferencia de San Francisco el 25 de abril de 1945. Firmas alcanzadas para su ratificación el 24 de octubre de 1945. Se reúne por primera vez el 17 de enero de 1946, donde adopta su reglamento.

${ }^{99}$ Consejo Económico y social (ECOSOC).Capitulo X de la Carta de las Naciones Unidas. Tuvo su sesión inaugural el 23 de enero de 1946.

${ }^{100}$ UNESCO, es el organismo de la Organización de la Naciones Unidas para la Educación la Ciencia y la Cultura. Creada en la conferencia de Londres en 1945 y establecida en Paris en 1946.

101 Existen antecedentes interesantes dentro de la UNESCO, de los que se puede destacar: 1974, "Recomendaciones sobre la Educación para la comprensión, la Cooperación y la Paz Internacionales, y la Educación relativa a los Derechos Humanos y las Libertades Fundamentales"; 1986-89, "Manifiesto de Sevilla" aporte interdisciplinarios sobre la violencia y la guerra, a favor de una cultura de Paz; 1993, "Plan de Acción de Montreal para la Educación en derechos humanos y la Democracia"

Convención relativa a la lucha contra la discriminación en la esfera de la enseñanza, (UNESCO) artículos 2, 3,4 y 5 .
} 
como un contenido especifico, donde se reconoce como un derecho humano de los pueblos a la Paz y, esta última, siendo la base sostenible para el respeto de los derechos humanos. A su vez se vincula a la educación y, en especial la educación en derechos humanos, como estrategia necesaria para el mantenimiento y proceso de construcción de la Paz (SALVIOLI, 1997).

Se instala el tema en el ámbito educativo, aparecen propuestas que relacionan la educación para la Paz y los derechos humanos, identificando espacios de intervención y de formación específica. Desde la perspectiva de una propuesta de eje y contenido transversal y, como elementos de desarrollo profesional en una didáctica y pedagogía en el proceso de enseñanza y aprendizaje, vinculados a la formación ética y ciudadana de las personas.

Vemos como el concepto de Derecho a la Educación y el Derecho a la EDH, está vinculados a los desarrollos de las sociedades a través del proceso histórico. De acuerdo a la estrategia mundial, se posibilita a través de estos, la construcción de ciertas subjetividades, de ciertos modos de ser y de estar en este mundo, con el punto de partida y de llegada, en el respeto de la dignidad humana y de sus múltiples manifestaciones.

La comunidad internacional plantea desde un accionar en la actualidad, una concepción bien definida por lo que entiende y define a la EDH hoy: como una estrategia y a su vez, una herramienta para promover la realización del respeto de los derechos humanos, como proyecto de la humanidad global, por todas las personas en todas y cada una de las culturas alrededor del mundo. 
Anexo V : Fotos de las escuelas:

Escuela A: Zona Este de la división del CEIP- barrio del Buceo-
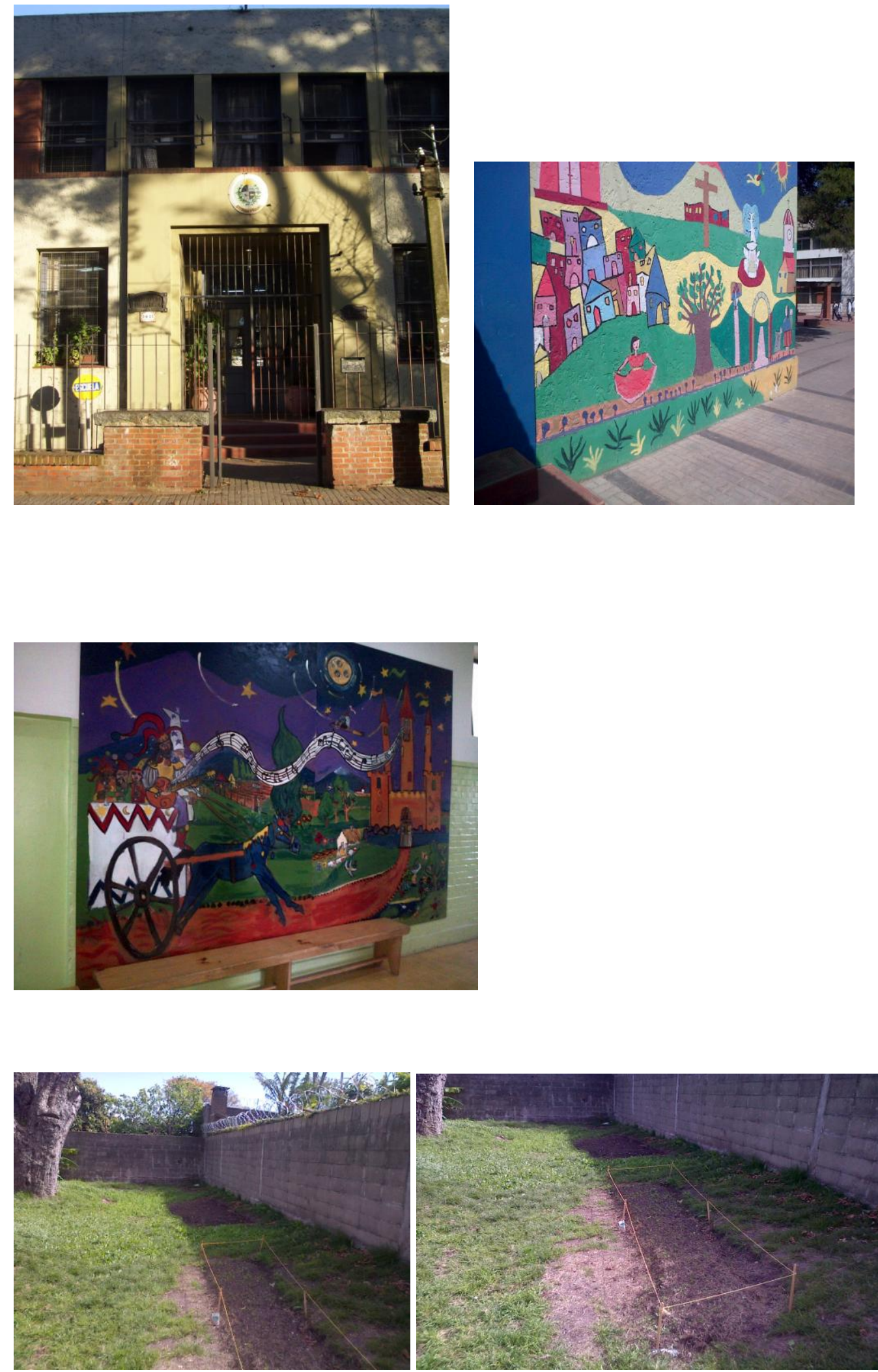

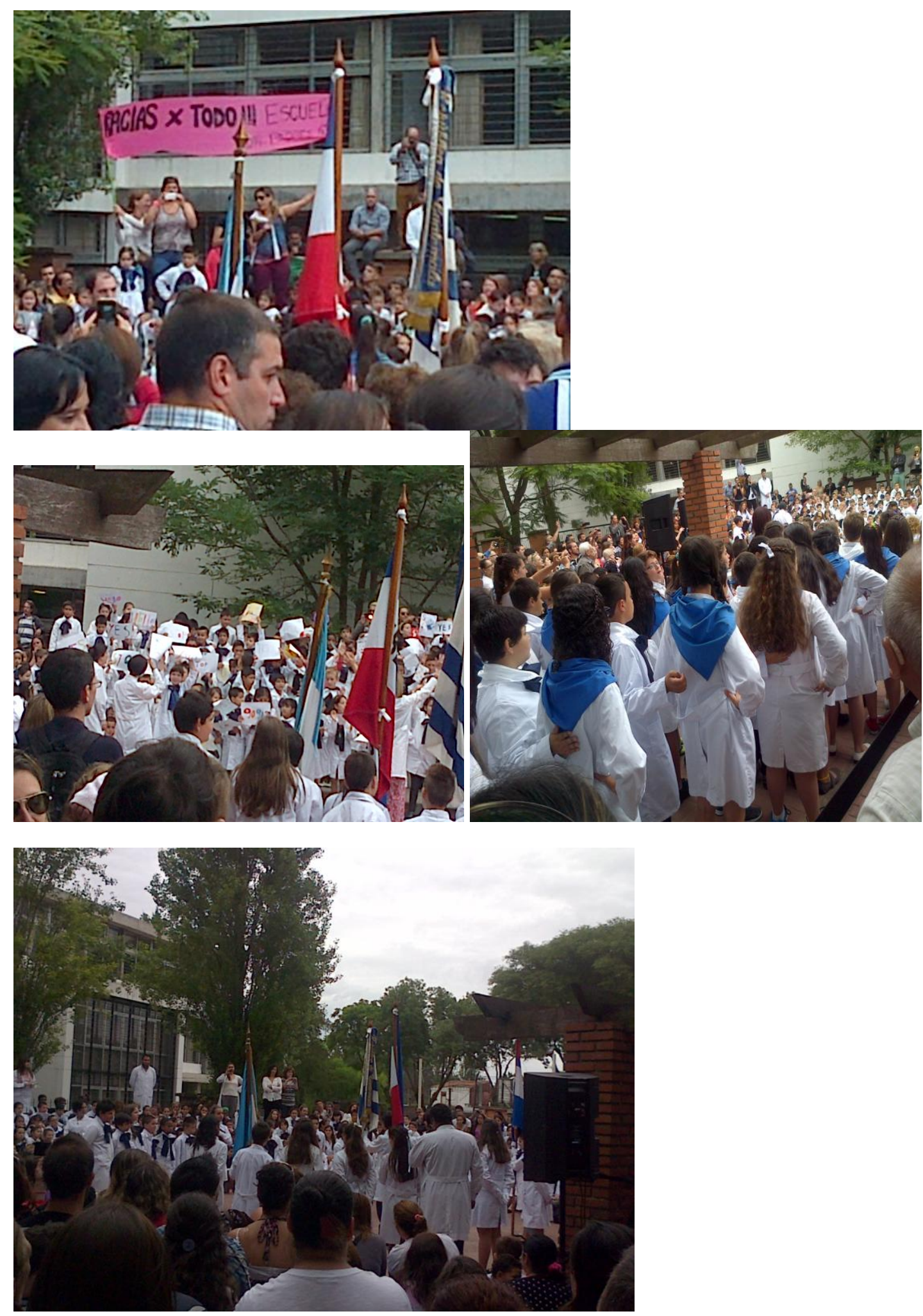


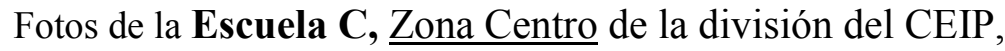
barrio de Maroñas o Ituzaingo (Hipódromo)
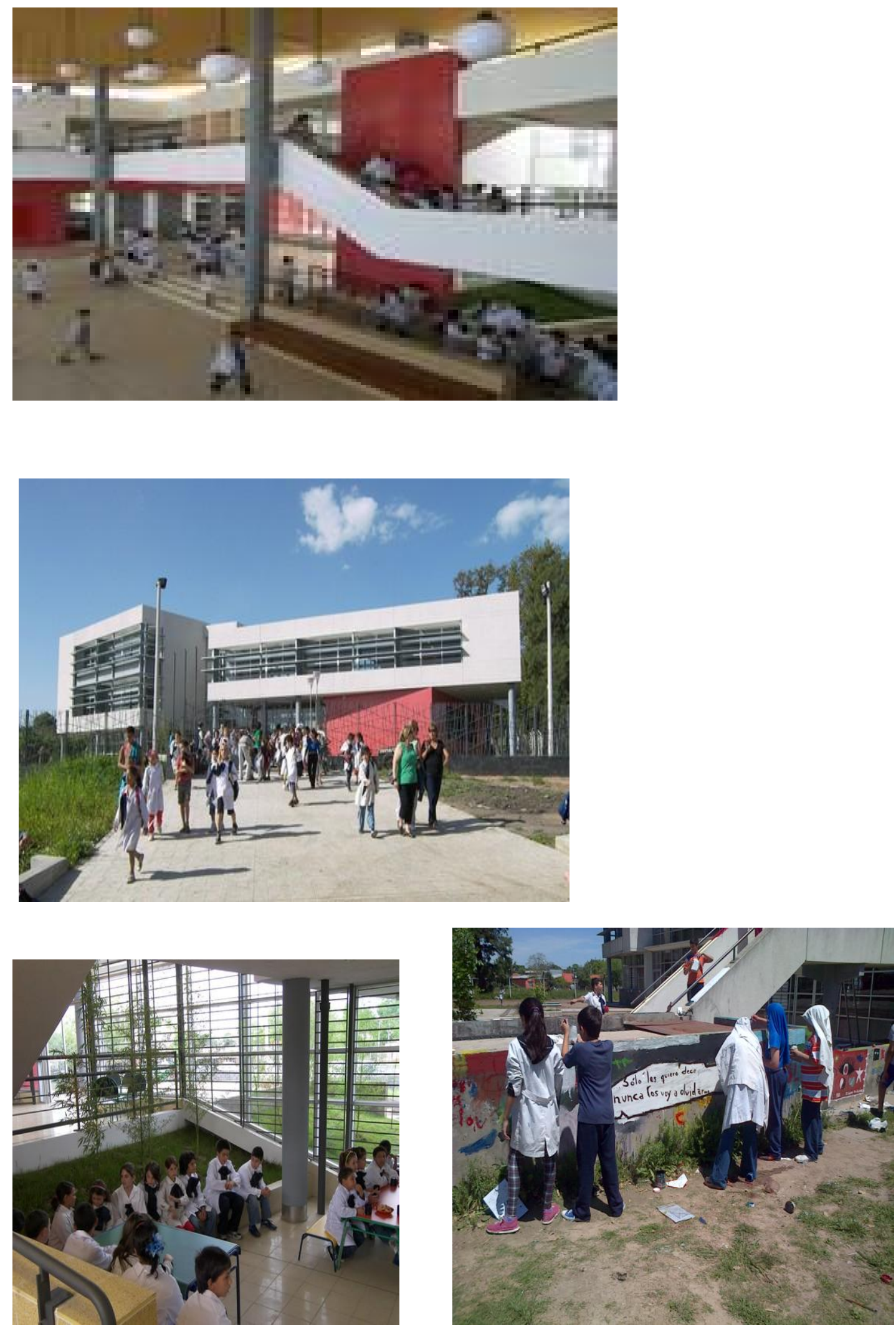

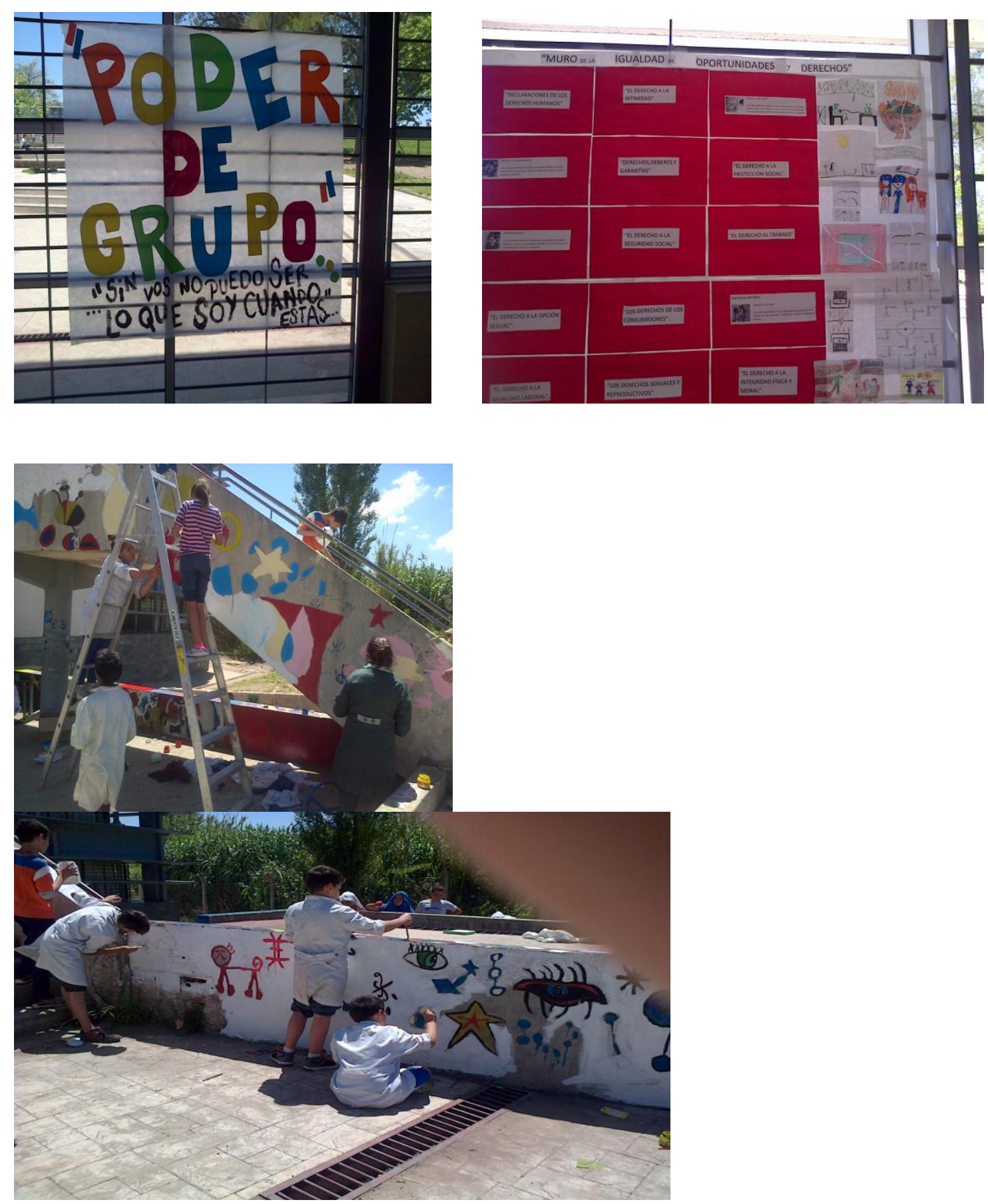
Fotos de la Escuela C

Zona Oeste de la división del CEIP, barrio Belvedere,
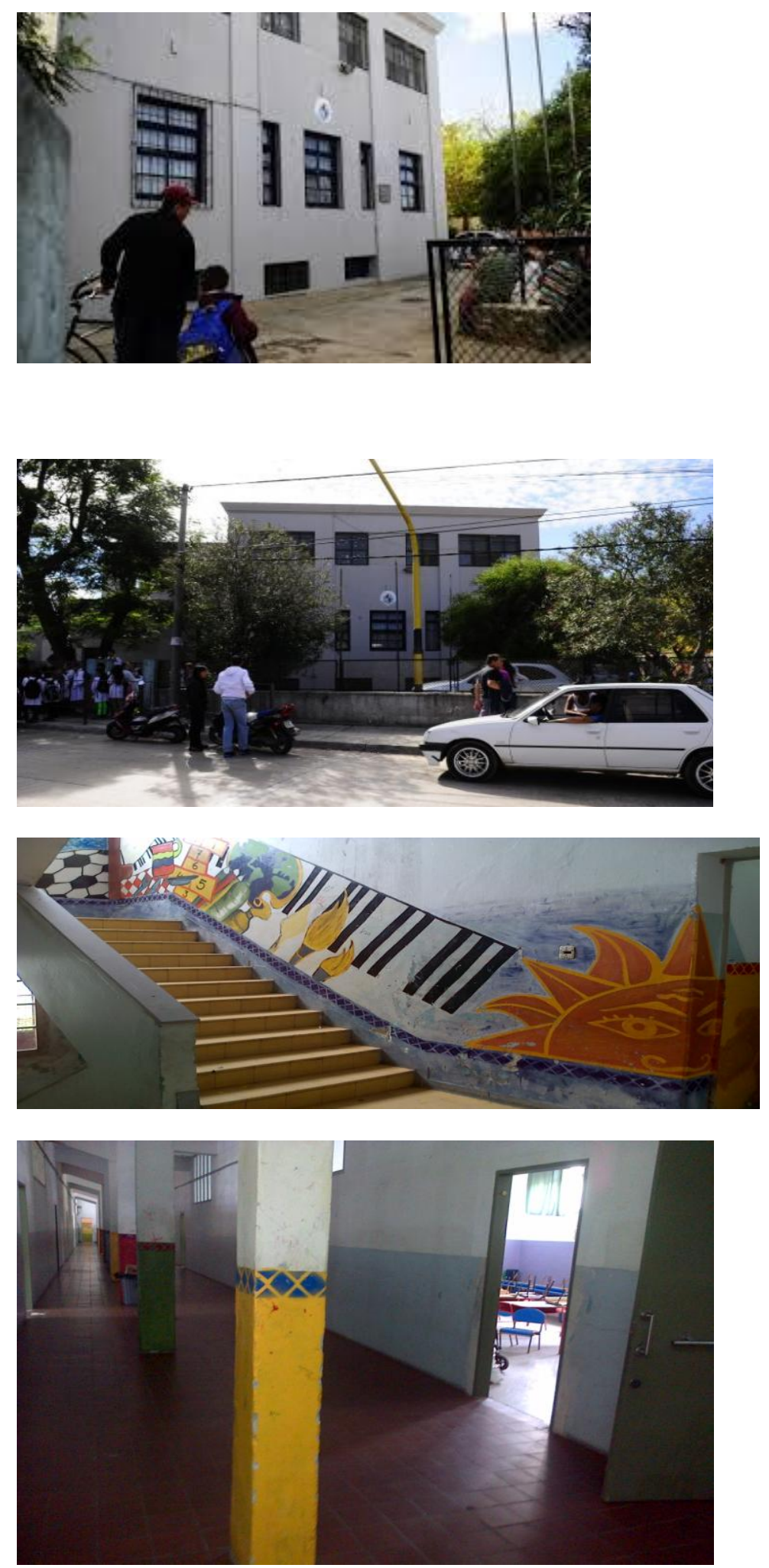
ANEXO VI: Afiche de la campaña contra la violencia en las escuelas, ADEMU

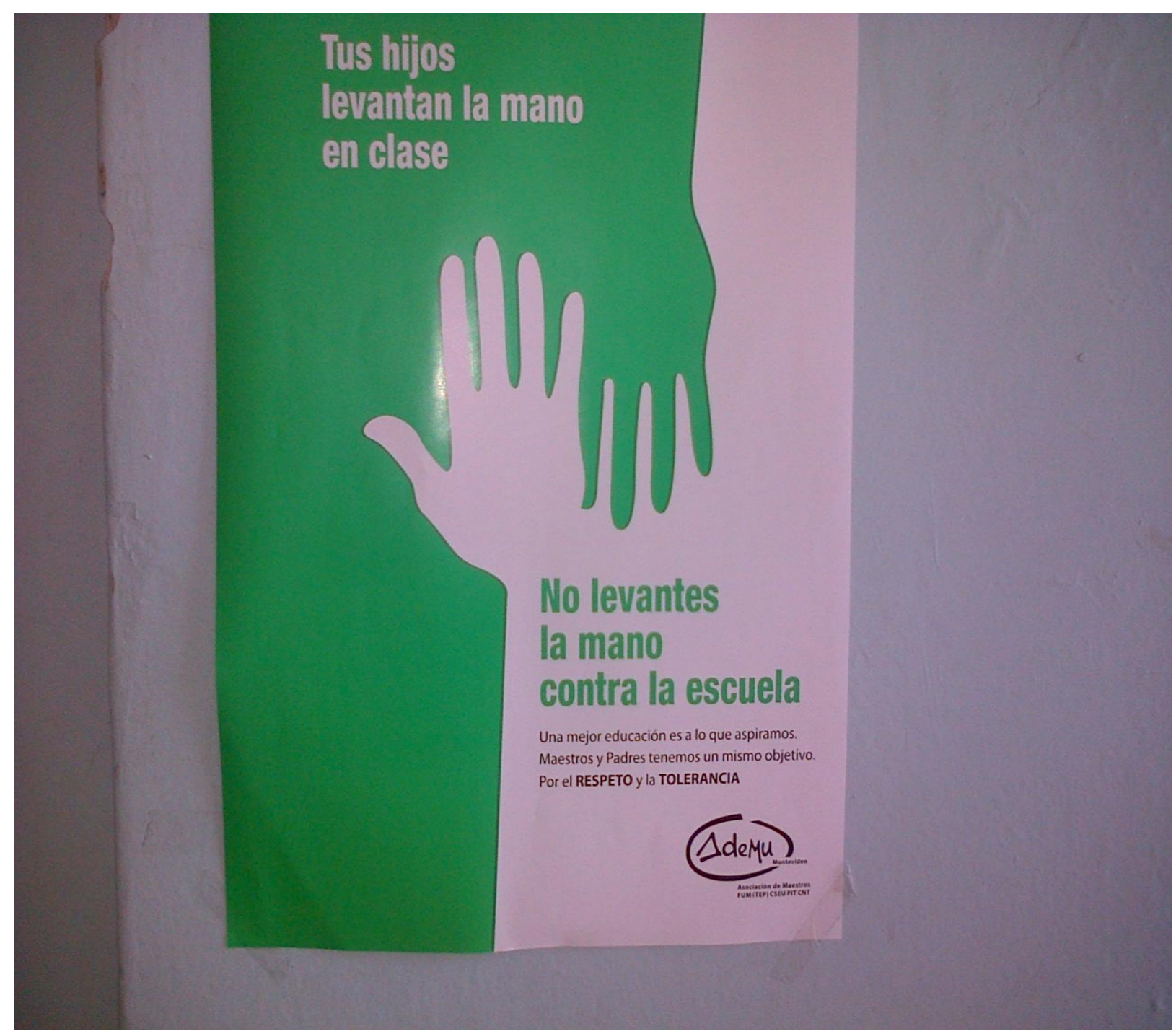

